\title{
Atmospheric Release Advisory Capability Year 2000 Documentation
}

Hoyt Walker

ARAC Y2K Project Team Leader

June 1999

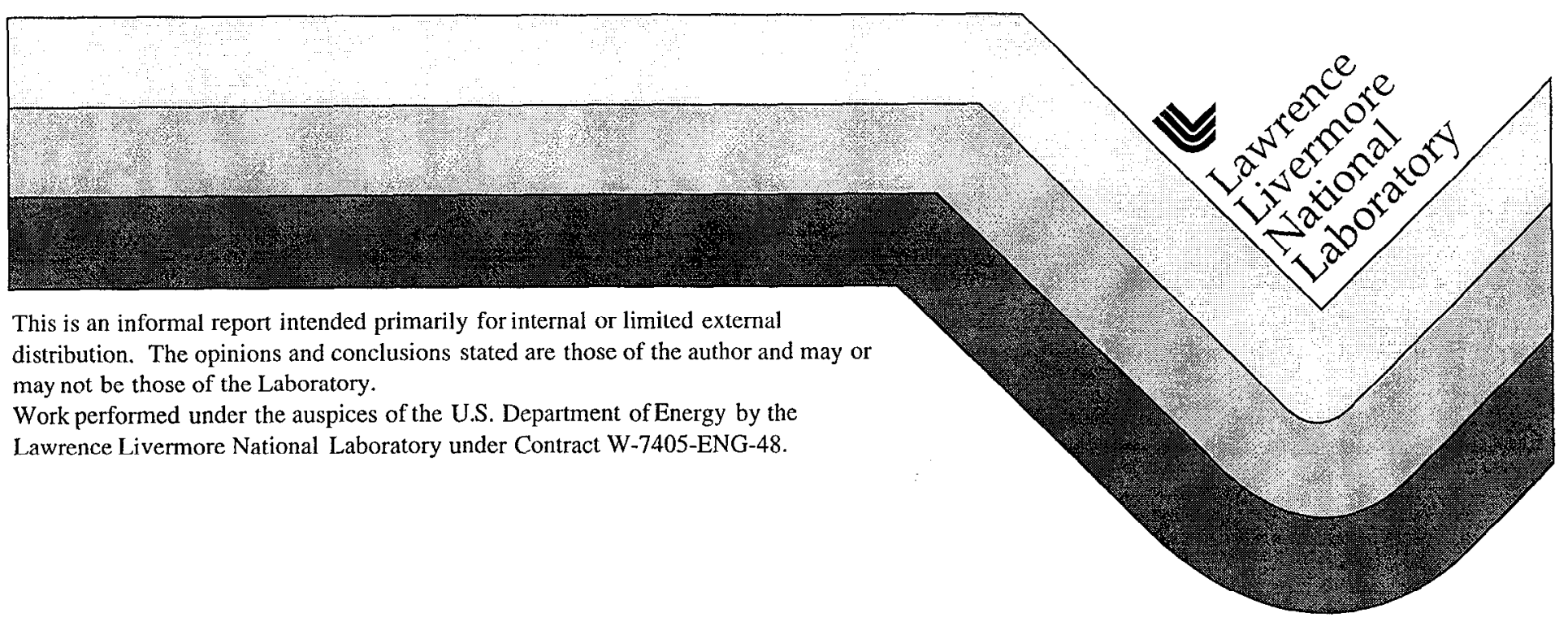




\section{DISCLAIMER}

This document was prepared as an account of work sponsored by an agency of the United States Government. Neither the United States Government nor the University of California nor any of their employees, makes any warranty, express or implied, or assumes any legal liability or responsibility for the accuracy, completeness, or usefulness of any information, apparatus, product, or process disclosed, or represents that its use would not infringe privately owned rights. Reference herein to any specific commercial products, process, or service by trade name, trademark, manufacturer, or otherwise, does not necessarily constitute or imply its endorsement, recommendation, or favoring by the United States Government or the University of California. The views and opinions of authors expressed herein do not necessarily state or reflect those of the United States Government or the University of California, and shall not be used for advertising or product endorsement purposes.

This report has been reproduced

directly from the best available copy.

Available to DOE and DOE contractors from the Office of Scientific and Technical Information

P.O. Box 62, Oak Ridge, TN 37831

Prices available from (615) 576-8401, FTS 626-8401

Available to the public from the

National Technical Information Service

U.S. Department of Commerce

5285 Port Royal Rd.

Springfield, VA 22161 


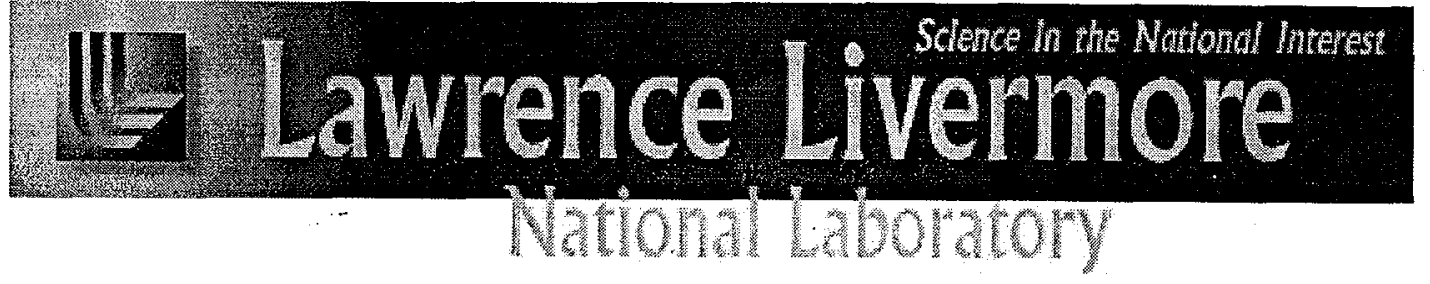

\title{
ATMOSPHERIC RELEASE ADVISORY CAPABILITY
}

\section{YEAR 2000 DOCUMENTATION}

\author{
Hoyt Walker \\ ARAC Y2K ProJeCt Team LEAder
}





\section{ARAC YEAR 2000 DOCUMENTATION}

\section{Foreword}

The ARAC has made a significant effort in detecting y ear 2000 (Y2K) problems, correcting these problems and verify ing $\mathrm{Y} 2 \mathrm{~K}$ compliance. The following documents provide a complete overvicw of the Y2K effort and document the successful testing of the renovated sy stem. To answer questions or for more detailed information from the supporting documentation, please contact:

Hoyt Walker

Year2000 Project TeamLead

Phone: (925) 422-1840

Internet: walker7@ @Inl.gov or

\author{
Kevin Foster \\ Systems Operations TeamLead \\ Phone: (925) 422-1864 \\ Internet: kfoster@IInl.gov
}

\section{Acknowledgments}

Numerous people made significant contributions to the ARAC Year 2000 Project who deserve recognition for their hard work.

- Gordon Duckworth - completed the renovation of the core of the ARAC-2 Central System. Hc also performed csscntially all of the associated unit testing and much of the integration testing.

- $E d$ Bush - reviewed the Y2K status of the hardware, operating system and all thirdparty packages used in ARAC-2. Coordinated the acquisition and installation of all the necessary upgrades.

- Vicky Weseloh - coordinated the software updates of the Central System as well as the ARAC Classified Sy stems, which were used for the final tests. She successfully worked with a vendor of a user interface package to resolve a number of problems introduced by the necessary Y2K upgrade.

- Kevin Foster - performed all testing and upgrades of the observed meteorological data receiving and decoding software. He also extended the decoding software to allow receipt of a new format from the Air Force Weather Agency that decoupled ARAC from an archaic sy stem there, in addition to reducing ARAC's dependence on some difficult-totest software components.

- Jon Welch - performed all Site Workstation Sy stem integration testing and was actively involved in the final tests that involved this system. He also performed all tests of the metcorological observing equipment.

- Leon Richardson - performed operating sy stem and third-party package upgrades on the ARAC Classified Systems. He moved data and software to the classified systems to sup port the final tests.

- Todd Biske - completed the Site Workstation Sy stem renovation along with unit testing and some integration testing of this sy stem. 

- Richard Yamauchi - corrected the Site Workstation System date display problems and generated the Site Workstation Sy stem Y2K update package.

- Fernando Aluzzi - performed acceptance testing for the ARAC-2 Central System. In addition, he moved data to the Classified Systems in support of the final tests and helped in the evaluation of these simulations.

- Phil Vogt-performed acceptance testing for the Site Workstation Sy stem. He performed and evaluated a number of the integration and final tests. He also coordinated Y $2 \mathrm{~K}$ communications with ARAC customers.

- Ernie Arnold - performed early Y2K testing of the ARAC-2 models for an external group.

- Robert Addis - from Savannah River Site, performed the required Independent Validation and Verification review of the ARAC system and contributed significantly to this documentation, both in completing the required IV\&V templates and providing useful supplemental information about the IV\&V process.

In addition, Tom Sullivan, who was the ARAC Program Leader for most of the Y2K project, and Jim Ellis, the Deputy Program leader during the project (now acting-Program Leader), deserve acknowledgment for their support and guidance on completing the $\mathrm{Y} 2 \mathrm{~K}$ project while allowing ARAC to meet its other op erational and development commitments. 



\section{ARAC YEAR 2000 DOCUMENTATION}

\section{TABLE OF CONTENTS}

1. Assurance of compliance completion of Y2K IV\&V activities

2. Y2K compliance IV\&V checklist

3. Supplemental information to the external and independent validation and verification of year $\mathbf{2 0 0 0}$ compliance for ARAC

4. ARAC system structure and connectivity (April 10, 1998)

5. ARAC Y2K plan (May 18, 1998)

6. ARAC Y2K plan (August 10, 1998)

7. Memorandum from AFWA: Year 2000 transition

8. Memorandum from FNMOC: Y2K status of distributed data products

9. Memorandum from Alden Electronics: Y2K status

10. ARAC Year 2000 guidelines and test plan

11. DOE LLNL Year 2000 Compliance Review (September, 1998 including ARAC-specific comments)

12. Y2K end-to-end test strategy and resource plan (March 2, 1999)

13. Memorandum to ARAC supported sites: Systems and Software Year 2000 (Y2K) Issues (March 5, 1999)

14. ARAC Year 2000 Documentation: plan, renovation and test results

15. ARAC Year 2000 Documentation: contingency plan 



\title{
ASSURANCE OF COMPLIANCE COMPLETION OF Y2K IV\&V ACTIVITIES
}

\author{
System Name: Atmospheric Release Advisory Capability (ARAC) \\ System Owner: Hoyt Walker, ARAC Systems Operations Team Leader
}

The System Owner has documented completion of the following:

$\mathrm{X}$ All data exchanges for this system have been identified and tested to the extent possible.

$\mathrm{X}$ The system is implemented and ready to process Year 2000 related data.

$\mathrm{X} \quad$ The system has been subject to the Independent Validation and Verification (IV\&V) of Y2K compliance by an external, independent organization.

$\mathrm{X}$ Recommendations from the IV\&V effort have been reviewed, and appropriate follow-up actions have been taken.

Based on the information and documentation presented, the undersigned acknowledge that due diligence was conducted to assure that the system under review is $\mathrm{Y} 2 \mathrm{~K}$ compliant, in accordance with Federal and Departmental policy and direction.
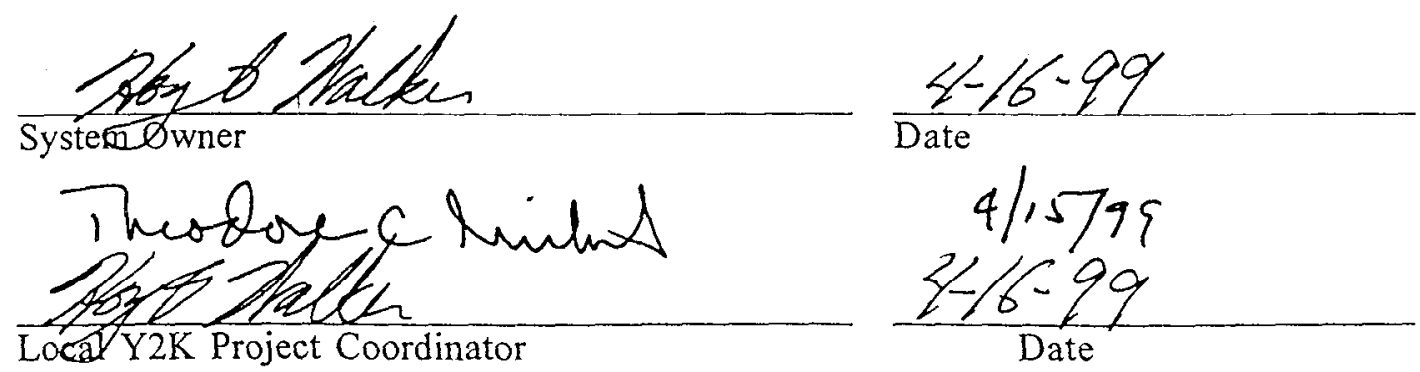

HQ/Field Office or Site Manager

Date 



\section{ATTACHMENT 2 Y2K COMPLIANCE IV\&V CHECKLIST}

\section{PURPOSE}

This clıecklist provides the minimum requirements to be met for the IV\&V of Y2K compliance for each mission-critical system. However, please note that other important items specific to your Program, Field or Site Offices, or Laboratory may not be adequately addressed by this checklist. Consequently, it is the responsibility of each Local Y2K Project Coordinator to ensure that due diligence has been conducted, whereby every reasonable effort has been made to assure Y2K compliance, and these efforts have been documented.

Additional requirements should be jointly reviewed and agreed to by the System Owner and the IV\&V agent prior to its execution. The IV\&V agent should undertake the activities necessary to address all items as thoroughly as possible. The System Owner should identify and be ready to provide access to any documents that will help in the IV\&V process, such as requirement definition documents, test plans, test results, etc.

\section{INSTRUCTIONS}

The remaining sections of the checklist are to be completed by the IV\&V organization and provided to the System Owner along with the IV\&V organization's findings, conclusions, and recommendations. Specific instructions are provided within each section. Any questions about the checklist should be addressed to the System Owner or the Local Y2K Project Coordinator, as appropriate.

\section{IV\&V TEMPLATES}

Two templates have been developed to facilitate the IV\&V of Y $2 \mathrm{~K}$ compliance for mission-critical systems. The first template, presented in Table 1 , focuses on the completion of key activities within each phase of the "Year 2000 Conversion Model," which is OMB's approach to assure Y2K compliance. The information and documentation to be reviewed by the IV\&V agent, including implementation plans and schedules (and possibly the resources allocated toward the achievement of specific milestones and activities) will be used to gain confidence in the approach employed by the System Owner to address existing or potential $\mathrm{Y} 2 \mathrm{~K}$ problems.

The second template is designed to assist the IV\&V agent with the review of specific test activities performed during the Validation phase of the Conversion Model. The Test Template for Y2K IV\&V of the Validation Phase (provided in Table 2) identifies selected items (such as test results and other information) to be reviewed by the IV\&V agent to help determine whether the system is $Y 2 \mathrm{~K}$ compliant. Please note, however, that the IV\&V review is not limited to the tests listed in the template. The IV\&V agent may ask to witness or review the results of other tests, or gain access to other information, as necessary to adequately determine Y2K compliance.

The completed templates must be signed by the IV\&V leader. Additionally, the IV\&V leader should attach other documentation, including other findings, conclusions, and recommendations to the System Owner. 


\section{SYSTEM IDENTIFICATION}

System Name: Atmospheric Release Advisory Capability (ARAC)

System Owner: Hoyt Walker

Sponsoring Organization of the System: Lawrence Livermore National Laboratory (LLNL)

Y2K Renovation Team Leader: Hoyt Walker

Is the System in Operation? Yes or No [please circle one]

Additional Comments:

\section{THE IV\&V AGENT}

IV\&V Agent Leader: [provide the name and contact information for the individual leading the IV\&V effort]

Robert Addis Savannah River Site

(803) $725-3325$

robert.addis@srs.gov

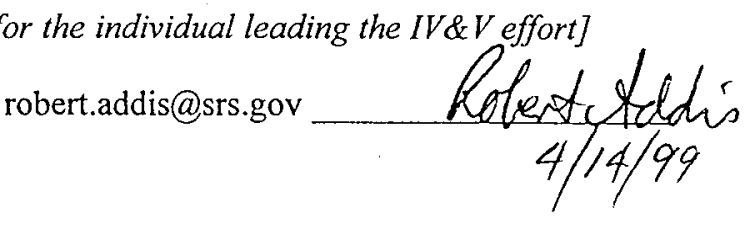

4/14/99

IV\&V Agent Organization: Savannah River Technology Center

Period of Review: [provide IV\&V start and completion dates] March 30, 1999-April 9, 1999

Description of IV\&V Methodology: [provide or attach a summary of the IV\&V approach, not to exceed one page]: see attachment

see attachment 
Table 1. Template for IV\&V of Year 2000 Conversion Model Activities

\begin{tabular}{|c|c|c|c|}
\hline $\begin{array}{l}\text { IV\&V } \\
\text { Element }\end{array}$ & Description & $\begin{array}{l}\text { Completed } \\
\text { by the } \\
\text { IV\&V } \\
\text { Agent } \\
\text { (Y/N) }\end{array}$ & Comments \\
\hline 1.0 & Assessment Phase & & \\
\hline 1.1 & $\begin{array}{l}\text { Verify the linkage of the system to core } \\
\text { business areas and procedures. }\end{array}$ & $\mathrm{Y}$ & $\begin{array}{l}\text { ARAC's use as a decision assistance } \\
\text { tool for atmospheric releases of } \\
\text { hazardous materials are essential } \\
\text { element of DOE's programs. }\end{array}$ \\
\hline 1.2 & $\begin{array}{l}\text { Confirm the development and } \\
\text { documentation of an asscssment plan } \\
\text { and schedule. }\end{array}$ & $\bar{Y}$ & $\begin{array}{l}\text { Rolled up "ARAC Year } 2000 \\
\text { Guidelines and Test Plan" See also } \\
\text { draft "ARAC Y2K Plan" documentation } \\
\text { from May } 18 \text { and August 10, } 1998 .\end{array}$ \\
\hline 1.3 & $\begin{array}{l}\text { Confirm the performance of risk } \\
\text { assessments. }\end{array}$ & $\bar{Y}$ & $\begin{array}{l}\text { Rolled up "ARAC Year } 2000 \\
\text { Guidelines and Test Plan" }\end{array}$ \\
\hline 1.4 & $\begin{array}{l}\text { Confirm the identification of related } \\
\text { systems and information technology } \\
\text { components. }\end{array}$ & $\bar{Y}$ & $\begin{array}{l}\text { Rolled up "ARAC Year } 2000 \\
\text { Guidelines and Test Plan" }\end{array}$ \\
\hline 1.5 & $\begin{array}{l}\text { Developed validation strategies and } \\
\text { testing plans. }\end{array}$ & $\bar{Y}$ & $\begin{array}{l}\text { Rolled up "ARAC Year } 2000 \\
\text { Guidelines and Test Plan" }\end{array}$ \\
\hline 2.0 & Renovation Phase & & \\
\hline 2.1 & $\begin{array}{l}\text { Confirm the development and } \\
\text { documentation of a renovation plan and } \\
\text { schedule. }\end{array}$ & $Y$ & $\begin{array}{l}\text { See "ARAC Year } 2000 \text { Guidelines and } \\
\text { Test Plan" p. } 34\end{array}$ \\
\hline 2.2 & $\begin{array}{l}\text { Confirm that budget and schedule are } \\
\text { being met for the following: } \\
\text { Conversion of targeted applications, } \\
\text { platforms, databases, archives, and/or } \\
\text { interfaces. } \\
\text { Bridges and filters can handle non- } \\
\text { conforming data. } \\
\text { Targeted applications and system } \\
\text { components are repaired/replaced. } \\
\text { Targeted applications and system } \\
\text { components are eliminated. }\end{array}$ & $\bar{Y}$ & $\begin{array}{l}\text { IV\&V occurred following } \\
\text { implementation phase: early } \\
\text { documentation had budgets and } \\
\text { schedules. Slippage from original } \\
\text { schedule of about two months was due } \\
\text { to unforeseen renovations issues } \\
\text { related to a required third-party } \\
\text { package upgrade. }\end{array}$ \\
\hline 2.3 & $\begin{array}{l}\text { Confirm documentation of all code and } \\
\text { system modifications. }\end{array}$ & $Y$ & $\begin{array}{l}\text { Reviewed ARAC Production Software } \\
\text { Update Memos }(11 / 19 / 98 \text { and } 3 / 22 / 99)\end{array}$ \\
\hline 2.4 & $\begin{array}{l}\text { Verify that internal and external users are } \\
\text { aware of changes to information systems. }\end{array}$ & $\bar{Y}$ & $\begin{array}{l}\text { Reviewed ARAC Production Software } \\
\text { Update Memos ( } 11 / 19 / 98 \text { and } 3 / 22 / 99) \\
\text { to ARAC's internal users and Memo } \\
\text { ARAC } 99-06(3 / 5 / 99) \text { and ARAC Site- } \\
\text { Workstation software } 2.5 \text { upgrade } \\
\text { Memo }(3 / 15 / 99) \text { to ARAC supported } \\
\text { sites. }\end{array}$ \\
\hline 2.5 & $\begin{array}{l}\text { Confirm tracking of repairs/replacements } \\
\text { as well as usage of project metrics, as } \\
\text { available, appropriate, or required. }\end{array}$ & $\bar{Y}$ & $\begin{array}{l}\text { Reviewed ARAC Production Software } \\
\text { Update Memos ( } 11 / 19 / 98 \text { and } \\
3 / 22 / 99) \text {. Other supporting } \\
\text { documentation is available but was } \\
\text { new reviewed. }\end{array}$ \\
\hline 3.0 & Validation Phase & & \\
\hline 3.1 & $\begin{array}{l}\text { Confirm the development, } \\
\text { documentation, validity, and adequacy } \\
\text { of test and validation plans, and } \\
\text { associated schedules. }\end{array}$ & $\mathrm{Y}$ & $\begin{array}{l}\text { See ARAC Year } 2000 \text { Documentation: } \\
\text { Plan, Renovation and Test Results }\end{array}$ \\
\hline 3.2 & $\begin{array}{l}\text { Verify the design, development, validity, } \\
\text { and adequacy of test scripts. }\end{array}$ & $\bar{Y}$ & $\begin{array}{l}\text { Testing procedures were verified } \\
\text { although test scripts were not } \\
\text { applicable. }\end{array}$ \\
\hline 3.3 & Confirm the execution of tests and the & $Y$ & Secondary reviews conducted $w$ \\
\hline
\end{tabular}




\begin{tabular}{|c|c|c|c|}
\hline $\begin{array}{l}\text { IV\&V } \\
\text { Element }\end{array}$ & Description & $\begin{array}{l}\text { Completed } \\
\text { by the } \\
\text { IV\&V } \\
\text { Agent } \\
\text { (Y / N) }\end{array}$ & Comments \\
\hline & documentation of test results. & & $\begin{array}{l}\text { random spot checks as well as } \\
\text { reviewed system end-to-end test results. }\end{array}$ \\
\hline 3.4 & $\begin{array}{l}\text { If applicable, confirm that the system has } \\
\text { been tested on an infrastructure that is } \\
\text { Y2K compliant. }\end{array}$ & $\bar{Y}$ & $\begin{array}{l}\text { ARAC tested on Y2K-compliant with } \\
\text { system clock set to rollover } 12: 31 / 99 \text { to } \\
1 / 1 / 2000 \text {. }\end{array}$ \\
\hline 4.0 & Implementation Phase & & \\
\hline 4.1 & $\begin{array}{l}\text { Confirm the development and adequacy } \\
\text { of a detailed implementation plan and } \\
\text { schedule. }\end{array}$ & $\bar{Y}$ & $\begin{array}{l}\text { See ARAC Year } 2000 \text { Documentation: } \\
\text { Plan, Renovation and Test Results }\end{array}$ \\
\hline 4.2 & $\begin{array}{l}\text { Confirm the identification of trading } \\
\text { partners and the existing of trading } \\
\text { partner exchange agreements. }\end{array}$ & $\bar{Y}$ & $\begin{array}{l}\text { See "ARAC System Structure and } \\
\text { Connectivity" by Walker, Bush and } \\
\text { Lawver; See memoranda from } \\
\text { Department of the Navy ( } 5230 \text { Ser } \\
\text { 006TK/333 } 15 \text { Sep 98) and } \\
\text { Department of the Air Force (From } \\
\text { AFWAVC } 3 \text { Sep 98) and } \\
\text { communications with Alden } \\
\text { Electronics from Web page. }\end{array}$ \\
\hline
\end{tabular}

\begin{tabular}{|c|c|c|c|}
\hline $\begin{array}{l}\text { IV\&V } \\
\text { Element }\end{array}$ & Description & $\begin{array}{l}\text { Completed } \\
\text { by the } \\
\text { IV\&V } \\
\text { Agent } \\
\text { (Y/N) }\end{array}$ & Comments \\
\hline 4.3 & $\begin{array}{l}\text { Confirm the conversion of databases and } \\
\text { archives. }\end{array}$ & $\bar{Y}$ & $\begin{array}{l}\text { Use of moving window (from } 1 / 1 / 1950 \\
\text { to } 12 / 31 / 2049 \text { ) avoided the need for } \\
\text { database modification. }\end{array}$ \\
\hline 4.4 & $\begin{array}{l}\text { Confirm the completion of acceptance } \\
\text { testing. }\end{array}$ & $\bar{Y}$ & $\begin{array}{l}\text { Reviewed ARAC Production Software } \\
\text { Update Memos (11/19/98 and } 3 / 22 / 99) \\
\text { and related procedures. }\end{array}$ \\
\hline 4.5 & $\begin{array}{l}\text { Verify the availability of a contingency } \\
\text { plan and/or updated disaster recovery } \\
\text { plan. }\end{array}$ & $\bar{Y}$ & $\begin{array}{l}\text { A preliminary contingency plan is } \\
\text { provided in ARAC Year } 2000 \\
\text { Documentation: Plan, Renovation and } \\
\text { Test Results. A more complete version } \\
\text { is being developed. }\end{array}$ \\
\hline 4.6 & $\begin{array}{l}\text { Confirm the reintroduction/reintegration } \\
\text { of the repaired/replaced system and } \\
\text { related components into the production } \\
\text { computing environment. }\end{array}$ & $\bar{Y}$ & $\begin{array}{l}\text { The ARAC Central Production System } \\
\text { has been updated to be Y2K- } \\
\text { compliant (see ARAC Production } \\
\text { Software Update Memo - 3/22/99). The } \\
\text { changes to the Site Workstation } \\
\text { System are expected to be complete } \\
\text { by April } 15,1999 \text {. }\end{array}$ \\
\hline
\end{tabular}

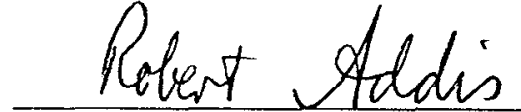

Leader, IV\&V Agent

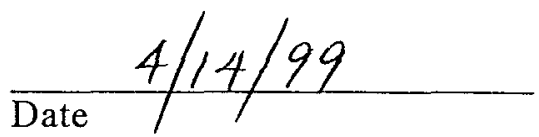


Table 2. Test Template for Y2K IV\&V of the Validation Phase

\begin{tabular}{|c|c|c|c|c|c|}
\hline $\begin{array}{l}\text { IV\&V Test } \\
\text { Element }\end{array}$ & Test Date/Type & Description & $\begin{array}{l}\text { Completed } \\
\text { By the } \\
\text { IV\&V Agent } \\
(Y / N)\end{array}$ & $\begin{array}{l}\text { Primary or } \\
\text { Secondary } \\
\text { Review }\end{array}$ & Comments/Recommendations \\
\hline 1.0 & Y2K DATES & & & & \\
\hline 1.1 & 1998 & $\begin{array}{l}\text { Confirm the application still works with current dates. This is } \\
\text { sometimes called a regression test. }\end{array}$ & $\bar{Y}$ & P\&S & \\
\hline 12 & $\begin{array}{l}12 / 31 / 1999 \\
9 / 9 / 99\end{array}$ & $\begin{array}{l}\text { Some applications were designed to store specific dates to } \\
\text { represent an invalid or special value. After renovation, the system } \\
\text { must be able to recognize and handle these dates correctly. }\end{array}$ & $\bar{Y}$ & $\bar{s}$ & \\
\hline 1.3 & $1 / 1 / 2000$ & $\begin{array}{l}\text { The application must work with the first day of the next decade. } \\
\text { Verify that the system continues to operate correclly during } \\
\text { system clock cycle from } 12 / 31 / 99 \text { into } 1 / 1 / 2000 \text {. }\end{array}$ & $\bar{Y}$ & $\mathrm{~s}$ & $\begin{array}{l}\text { ARAC run Classified (Green Room) System with clocks set to rollover } \\
\text { to 1/1/2000. }\end{array}$ \\
\hline 1.4 & $2 / 29 / 2000$ & $\begin{array}{l}\text { The application must be able to recognize this day since year } 2000 \\
\text { is a leap year. Verify that the system continues to operate } \\
\text { correctly during system clock cycle from } 2 / 28 / 2000 \text { into } 3 / 1 / 2000 \text {. }\end{array}$ & $\bar{Y}$ & $\bar{s}$ & $\begin{array}{l}\text { ARAC run Classified (Green Room) Systern with clocks sel to rollover } \\
\text { to 2/29/2000. }\end{array}$ \\
\hline 1.5 & $3 / 1 / 2000$ & $\begin{array}{l}\text { This serves to verify if } 2 / 29 / 2000 \text { was indeed recognized. An } \\
\text { important thing to watch for is the day-of-week for this date. } \\
\text { March } 1.2000 \text { is a Wednesday. }\end{array}$ & $\bar{Y}$ & 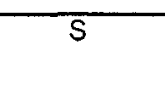 & $\begin{array}{l}\text { ARAC run Classified (Green Room) System with clocks set to rollover } \\
\text { to } 3 / 1 / 2000 .\end{array}$ \\
\hline 1.6 & $10 / 1 / 99-9 / 30 / 2000$ & $\begin{array}{l}\text { f relevant, the application must recognize } 10 / 1 / 1999 \text { and } 9 / 30 / 2000 \\
\text { as the beginning and ending, respectively, of the fiscal year } 2000 \text {. }\end{array}$ & $\bar{Y}$ & $\bar{s}$ & $\begin{array}{l}\text { Fiscal year boundaries are not relevant to the functioning of the ARAC } \\
\text { system. Software licenses were checked to ensure they elapse on fiscal } \\
\text { year boundaries. }\end{array}$ \\
\hline 1.7 & $\begin{array}{l}12 / 31 / 1999 \\
3 / 31 / 2000\end{array}$ & $\begin{array}{l}\text { Confirm date calculations for elapsed time are performed } \\
\text { correctly when one date is pre-2000 and other is post-2000. }\end{array}$ & $\bar{Y}$ & $\bar{s}$ & \\
\hline 1.8 & 1999,2001 & Confirm that non leap years are handled correctly. & $\bar{Y}$ & $\bar{s}$ & $\begin{array}{l}\text { ARAC-2, the current operational system will go out of service in mid- } \\
2000 \text {. }\end{array}$ \\
\hline 1.9 & $4 / 31 / 1999$ & Confirm the handling of invalid dates. & $\bar{Y}$ & P\&S & \\
\hline 1.10 & 2001 & Check if the application accepts other $21^{\text {st }}$ century dates. & $\bar{Y}$ & 5 & $\begin{array}{l}\text { ARAC-2, the current operational system will go out of service in mid- } \\
2000 .\end{array}$ \\
\hline 20 & $\begin{array}{l}\text { EXTERNAL } \\
\text { INTERFACES }\end{array}$ & $\begin{array}{l}\text { Extemal interfaces are identified and validated to correctly function } \\
\text { for all dates passed from the system. }\end{array}$ & & & \\
\hline 2.2 & & $\begin{array}{l}\text { Verify that the interfacing system functions the same when the data } \\
\text { passed to that interface is generated from the system (for } \\
\text { example, an interface is two-dlgglt year and another is four-digit } \\
\text { year). }\end{array}$ & $\bar{Y}$ & $\mathrm{~s}$ & $\begin{array}{l}\text { An extensive test and renovation effort was performed to ensure that } \\
\text { both observed and gridded meteorological data received from extemal } \\
\text { sources is processed correctly. }\end{array}$ \\
\hline 2.3 & & $\begin{array}{l}\text { For each interface that exchanges date data, confim that the } \\
\text { responsible organizations have discussed and verified that } \\
\text { consistent } Y 2 K \text { correctlons have been Implemented that will } \\
\text { correctly process date data passed between the systems. }\end{array}$ & $\bar{Y}$ & $\bar{s}$ & $\begin{array}{l}\text { See memoranda from Department of the Navy (5230 Ser 006TK/333 } 15 \\
\text { Sep 98) and Department of the Air Force (From AFWACC } 3 \text { Sep 98) } \\
\text { and communications with Alden Electronics from Web page. }\end{array}$ \\
\hline 3.0 & DATE FIELD TYPE & $\begin{array}{l}\text { Describe the type of date fields used by the system, in either } \\
\text { application software or data bases. }\end{array}$ & & & \\
\hline $3.1 \mathrm{a}$ & & Confirm whether the system uses two-digit year data fieids. & $\bar{Y}$ & $\overline{P \& S}$ & $\begin{array}{l}\text { ARAC-2 uses two- and four-digit years, The subsystems that use two- } \\
\text { digit years are handled implicitly with a moving window strategy } \\
\text { (from } 1 / 1 / 1950 \text { to } 12 / 31 / 2049 \text { ) }\end{array}$ \\
\hline
\end{tabular}




\begin{tabular}{|c|c|c|c|c|c|}
\hline $\begin{array}{l}\text { IV\&V Test } \\
\text { Element }\end{array}$ & Test Date/Type & Description & $\begin{array}{l}\text { Completed } \\
\text { By the } \\
\text { IV\&V Agent } \\
(Y / N)\end{array}$ & $\begin{array}{l}\text { Primary or } \\
\text { Secondary } \\
\text { Review }\end{array}$ & Comments/Recommendations \\
\hline $3.1 \mathrm{~b}$ & & $\begin{array}{l}\text { If two-digit, verify if the system uses a windowing logic technique } \\
\text { to correctly infer the century? }\end{array}$ & $\bar{Y}$ & P\&S & $\begin{array}{l}\text { ARAC-2 uses two-and four-digit years, The subsystems that use two- } \\
\text { digit years are handled implicitly with a moving window strategy } \\
\text { (from } 1 / 1 / 1950 \text { to } 12 / 31 / 2049 \text { ) }\end{array}$ \\
\hline 3.10 & & $\begin{array}{l}\text { If yes, identify the windowing date ranges that are used? } \\
\text { [Please provide "From" and "To" range in the Comments column] }\end{array}$ & $\bar{Y}$ & $\overline{P \& S}$ & $\begin{array}{l}\text { ARAC-2 uses two- and four-digit years, The subsystems that use two- } \\
\text { digit years are handled implicitly with a moving window strategy } \\
\text { (from } 1 / 1 / 1950 \text { to } 12 / 31 / 2049 \text { ) }\end{array}$ \\
\hline 3.2 & & Confirm whether the system uses four-digit year data fields. & $\bar{Y}$ & P\&S & \\
\hline 3.3 & & Identify when the windowing logic fix will fail. & $\bar{Y}$ & P\&S & The windowing logic will fail on $1 / 1 / 2050$. \\
\hline $3.4 a$ & & $\begin{array}{l}\text { Determine whether there are any internal data types for date, such } \\
\text { as character or variable character. }\end{array}$ & $\bar{Y}$ & P\&S & $\begin{array}{l}\text { The internal types for representing dates are character strings and } \\
\text { numbers of various standard formats that all represent dates in the } \\
\text { range from } 1 / 1 / 1950 \text { to } 12 / 31 / 2049 \text {. }\end{array}$ \\
\hline $3.4 b$ & & $\begin{array}{l}\text { If yes, identify the range of dates that the date field can represent } \\
\text { [Please provide "Minimum Date" and "Maximum Date" values in } \\
\text { the Comments column; and If character type date, please describe } \\
\text { the process the system uses to convert the date data] }\end{array}$ & $\bar{Y}$ & P\&S & $1 / 1 / 1950$ to $12 / 31 / 2049$ \\
\hline 4.0 & $\begin{array}{l}\text { VENDOR } \\
\text { PROVIDED } \\
\text { SOFTWARE }\end{array}$ & $\begin{array}{l}\text { The Department does not accept vendor-provided certifications of } \\
\text { Y2K compliance. }\end{array}$ & $\therefore$ & & \\
\hline 4.1 & & $\begin{array}{l}\text { Confirm whether the system uses vendor-provided software } \\
\text { packages or infrastructure components. [lf yes, please provide the } \\
\text { software name in the Comments column] }\end{array}$ & $\bar{Y}$ & $\bar{S}$ & $\begin{array}{l}\text { See ARAC Year } 2000 \text { Documentation: Plan, Renovation and Test } \\
\text { Results p. } 15 \text { and p. } 17 .\end{array}$ \\
\hline 4.2 & & $\begin{array}{l}\text { Confirm whether the vendor-provided software has been verified } \\
\text { to be } \mathrm{Y} 2 \mathrm{~K} \text { compliant. }\end{array}$ & $\bar{Y}$ & $\mathrm{~S}$ & \\
\hline 4.3 & & $\begin{array}{l}\text { Describe how Y2K compliance was determined, such as vendor } \\
\text { certification, in-house testing, etc. [Please provide the response in } \\
\text { the Comments column] }\end{array}$ & $\bar{Y}$ & P\&S & Both vendor documentation and in-house testing were used. \\
\hline 4.4 & & $\begin{array}{l}\text { If spare parts were provided by vendor(s), confirm whether they } \\
\text { have been verified to be Y } 2 K \text { compliant, and how the compliance } \\
\text { was determined. }\end{array}$ & $\bar{Y}$ & $\bar{S}$ & $\begin{array}{l}\text { All hardware components of the ARAC-2 system have been checked for } \\
\text { Y2K-compliance against vendor compliance. }\end{array}$ \\
\hline 5.0 & $\begin{array}{l}\text { EMBEDDED } \\
\text { SYSTEMS }\end{array}$ & & & & \\
\hline 5.1 & $\begin{array}{l}\text { Date Setting and } \\
\text { Representation }\end{array}$ & $\begin{array}{l}\text { Verify the following: } \\
\text { System can be set to any date in a range, e.g., between } 1995 \\
\text { and } 2005 \text {. } \\
\text { System can be set to dates both in Julian and Gregorian } \\
\text { formats where applicable. } \\
\text { System can be set to high risk dates. } \\
\text { System can be re-initialized from cold start using high risk } \\
\text { dates. }\end{array}$ & $\bar{Y}$ & P\&S & Both vendor documentation and in-house testing were used. \\
\hline 5.2 & Date Rollover & $\begin{array}{l}\text { Verify the following: } \\
\text { System rolls over correctly on high risk dates. } \\
\text { System rolls over correctly both in powered up and powcred } \\
\text { down states. } \\
\text { Systert rolls uver correcily both in Gregorian and Julian } \\
\text { formats where applicable. }\end{array}$ & $\bar{Y}$ & $\bar{s}$ & \\
\hline
\end{tabular}




\begin{tabular}{|c|c|c|c|c|c|}
\hline $\begin{array}{l}\text { IV\&V Test } \\
\text { Element }\end{array}$ & Test Date/Type & Description & $\begin{array}{l}\text { Completed } \\
\text { By the } \\
\text { IV\&V Agent } \\
(Y / N)\end{array}$ & $\begin{array}{c}\text { Primary or } \\
\text { Secondary } \\
\text { Review }\end{array}$ & Comments/Recommendations \\
\hline 5.3 & Date Arithmetic & $\begin{array}{l}\text { Verify the following: } \\
\text { System correctly calculates elapsed dates on either side of } \\
\text { century rollover. } \\
\text { System correctly calculates days of the week, based on } \\
\text { dates. } \\
\text { System correctly computes leap year dates. } \\
\text { System correctly converts between Julian and Gregorian } \\
\text { representations. }\end{array}$ & $\bar{Y}$ & $\bar{s}$ & \\
\hline 5.4 & Date Comparison & $\begin{array}{l}\text { Verify the following: } \\
\text { System is able to make correct date comparison, e.g., } \\
<00 \text {. } 99 \\
\text { System is able to correctly sort date fields on bcth sides of } \\
\text { century. }\end{array}$ & $\bar{Y}$ & $\bar{s}$ & \\
\hline 5.5 & Date Interface & $\begin{array}{l}\text { Verify the following: } \\
\text { System is correctly able to pass date values to external } \\
\text { devices and systems. } \\
\text { System is correctly able to maintain date information in the } \\
\text { upstream/downstream chain. }\end{array}$ & $\bar{Y}$ & $\bar{s}$ & \\
\hline
\end{tabular}

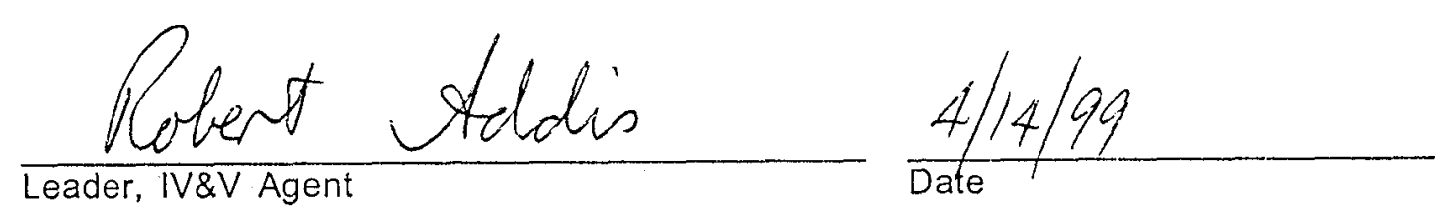




\section{Description of I V\&V Methodology \\ ARAC, LLNL \\ Robert P. Addis \\ 3/30-4/1/99}

Extensive and detailed discussions were conducted to enable me to become familiar with the current status of ARAC and LLNL management's plan for ARAC development and implementation for the next 12 months. Although I have been familiar with ARAC's capabilities for about 15 years, these discussions with the various leads in each major functional area, provided a strong background from which to conduct a meaningful independent V\&V. The ARAC personnel provided me unlimited access to their files and facilities, and gave frank and open answers to all of my questions.

I conducted primary and secondary reviews of test results, inspected documentation and validated the system capabilities. I investigated the strategy and evidence that it had been employed to ensure compliance. The strategy for implementing ARAC-3 and continued use of ARAC-2 as a backup were also discussed indepth. I inspected and reviewed test plans and results for each stage of the system:

- meteorological measurement and signal conditioning,

- observed and gridded meteorological data acquisition,

- forecast gridded data and ARAC model results,

- data archival and retrieval,

- computer, communications and áncillary equipment,

- infrastructure system support

- $\quad \&$ products from third party vendors or other government agencies.

I inspected test results for critical dates both on paper records and on-line electronic records (secondary or after-the-fact reviews). I suggested ad-hoc tests for critical dates and verified that these tests worked satisfactorily as they were run (primary or "over-the-shoulder" reviews).

In addition to the required test cases, I suggested a specific test case involving a hypothetical nuclear accident at Chernobyl's sister reactor unit at midnight on December 31, 1999. This tested the effects of three midnights: local midnight at Chernobyl, midnight at Greenwich Mean Time (Universal Coordinated Time), the time on which ARAC runs, and local west coast midnight (PST). This was run on a completely independent workstation with its local computer clock changed to December 31, 1999. A case like this tests most of ARAC's integrated functions. 


\section{Attachment 1}

Description of credentials supporting my suitability to conduct an external Y2K IV\&V on ARAC 
Robert P. Addis

Savannah River Technology Center

Building 773-A, SRS,

Aiken, South Carolina 29808

(803) 725-3325

robert.addis@srs.gov

\section{Summary}

Environmental research manager with eleven years of technical leadership in research and problem solving at SRTC. Strong technical background with proven team building and leadership skills.

\section{Professional Achievements}

1988-present Manager, Atmospheric Technologies Group,

Savannah River Technology Center, Aiken, South Carolina

Manage team of 13 senior scientists and engineers for Savannah River Technology Center.

- Initiated \& directed 3 - dimensional atmospheric modeling program, emphasizing regional prognostic modeling for emergency response, nonproliferation studies \& simulation of flows in complex terrain.

- Provided leadership for developing technologies and technical support for responding to unplanned releases of radionuclides and chemicals to the atmosphere and streams. Maintained SRS consequence assessment capability (WNND System) in excess of $99 \%$ availability for 11 years.

- Directed operation and development of the Savannah River Site meteorological monitoring program (This program was reviewed independently in a DOE Comprehensive Compliance Audit Review.)

- Directed one of three United States real-time atmospheric modeling contributions to the European Tracer EXperiment (EIEX), an international atmospheric tracer experiment. Represents the United States on the ETEX executive steering committee.

- Directed writing of calibration \& quality assurance/control procedures for meteorol. instruments.

- Initiated redesign of site emergency response consequence assessment system to a PC/NT base.

- Initiated cooperative agreement with the local counties to provide technology transfer.

1984-88

Research Meteorologist Savannah River Technology Center, Aiken, South Carolina

Conducted applied research on measurement and modeling of transport and diffusion of radionuclides in the atmospheric boundary layer.

- Directed a $\$ 1$ million project to modernize a network of meteorological towers, instrumentation and communications equipment.

- Conducted atmospheric tracer studies and evaluated operational atmospheric models.

- Conducted consequence assessment modeling for emergency response at a large nuclear facility.

- Managed and operated National Weather Service automated computer system.

1982-84 Post Doctoral Research Fellow, Department of Meteorology, University of Hawaii, Honolulu, Hawaii

Conducted research into the climatology of the tropical Pacific, investigating the structure and dynamics of the inter-tropical convcrgence zone.

1975-76

Meteorologist, Darwin Regional Meteorological Centre, Australian Bureau of Meteorology

Forecast aviation and public weather at a regional weather center. Analyzed contour and streamline charts. 


\section{Education}

1983

1977

1974

1973

International

\section{American \\ Meteorological \\ Society}

American
Nuclear
Society

U.S Committees Ph.D. (Environmental Sciences), University of Virginia, Charlottesville, Virginia
Major: Atmospheric Sciences Minor: Hydrology

M.Sc. (Meteorology), University of Reading, Reading, England, United Kingdom Specialty: Agricultural Meteorology

Diploma of Meteorology, Australian Bureau of Meteorology Training School, Melbourne, Victoria, Australia

B.Sc. (Honours) (Physics), Monash University, Clayton, Victoria, Australia

\section{Affiliations}

- Represents the U.S. on the RTMOD Executive Committee (1998-present) RTMOD is sponsored by the European Commission

- Represented the U.S. on the ETEX Executive Committee (1992-1998) ETEX is sponsored by the European Commission, the World Meteorological Organization and International Atomic Energy Agency

- Represented the U.S. on the Organizing Committee for the 4th International Workshop on Real-Time Computing of the Environmental Consequences of an Accidental Release from a Nuclear Installation: Decision-Making Support for Offsite Emergency Management", Aronsborg, Sweden, October 6-11, 1996.

- Chaired Committee on Boundary Layers and Turbulence 1991-1993 (member 1985-1993)

- Organized 10th Symposium on Turbulence \& Diffusion, Portland, Oregon 10/92

- Assisted organizing 7th, 8th, \& 9th Symposia on Turbulence \& Diffusion.

- Member of the American Meteorological Society since 1981.

- Organizing ANS/AMS Global Warming Special Symposium for Nov 1999.

- Chair ANS/Environmental Sciences Division 1997-1998 (Vice Chair 1996-1997)

- Technical Program Chair of ANS/Environmental Sciences Division 1994-95

- Member Executive Committee of ANS/Environmental Sciences Div 1991-94

- Technical Program Chair ANS Topical Meeting on Environmental Transport \& Dosimetry, Charleston, SC 10/93

- Member Executive Committee and Technical Program Committee 5th Topical Meeting on Emergency Preparedness and Response 1995 (Helped organize 2nd and 4th)

- Member of the American Nuclear Society since 1985.

- Member DOE Meteorological Coordinating Council Executive Committee (1996-)

- Member ANS/ANSI 2.5 Meteorological Standard rewrite committee (1996-) (initiated cooperation between the DMCC and the Nuclear Utilities Meteorological Users' Group to provide a coordinated approach to update meteorological monitoring standards at nuclear facilities)

- Member DOE Subcommittee on Dose Assessment and Protective Actions (1987-) 


\title{
Attachment 2
}

\author{
Agenda for External \\ Y2K IV\&V
}

March 30 - April 1, 1999 
s most of you should know, Rob Addis will be visiting ARAC on Tuesday, Jednesday and Thursday to review our $\mathrm{Y} 2 \mathrm{~K}$ testing and general $\mathrm{Y} 2 \mathrm{~K}$ status as sart of completing the required external review for mission-critical systems. $\because d$ like to propose the following schedule for meeting with Rob in order to sover the overall situation. Please let me know if you see any problems with this schedule or any important omissions.

Thanks,

Hoyt

$\begin{array}{ll}\text {.uesday } & 8: 30-9: 00 \\ \text { Puesday } & 9: 00-9: 30 \\ \text { Iuesday } & 9: 30-12: 00\end{array}$

Puesday

ruesday

$12: 00-1: 15$

$1: 15-2: 30$

ruesday $2: 30-3: 30$

Tuesday

$3: 30-5: 00$

Vednesday 9:00-10:00*

vednesday 10:00-11:00*

Nednesday $11: 00-12: 00$ *

Nednesday 12:00- 1:15

Nednesday 1:00- 2:00

Nednesday $2: 45-4: 15$ *

Nednesday $4: 15-5: 00$

Thursday 9:00-10:00

Thursday 10:00-12:00 arrival

Jim Ellis - ARAC overview

Hoyt Walker - Overview of Y $2 \mathrm{~K}$

strategy, system

architecture, $\mathrm{Y} 2 \mathrm{~K}$

status

Hoyt Walker - lunch

Ed Bush - Y2K status of ARAC-2

packages, $Y 2 \mathrm{~K}$

compliance statements

Jon Welch - SWS clock tests/

Handar tests

Hoyt Walker - Introduction of

final tests

Hoyt Walker - Model performance

Hoyt Walker - NOGAPS Degribbing, Model use of yridaed data

Hoyt Walker, Jon Welch TAHOE tests

Hoyt Walker - lunch

Eric Davis - status of local, LLNL, external networks

Phil Vogt - review of Chernobyl tests

Hoyt Walker - discussion

Hoyt Walker - discussion

Kevin Foster - review of observed metdata testing

Hoyt walker - lunch

Hoyt Walker - discussion/wrapup

Phursday $\begin{aligned} 12: 00-1: 15-5: 00\end{aligned}$

* - meeting in Green room (other sessions will be in the ARAC center or $\mathrm{Rm} 1010$ as appropriate)

(note that I will be scheduling a half-hour mecting for Rob with Don Ermak on Thursday morning so things may nove around a bit Thursday).

anyone is welcome to join us for any of the discussions or for lunch on any of the days. I'm planning on going out to dinner with Rob on Tuesday night (again, anyone is welcome to join us). I have a previous committment on Wednesday night so if anyone would like to join Rob for dinner, let me know.

Thanks, 


\section{Attachment 3}

Schematic Diagram of ARAC-2 and ARAC-3

Central Systems 



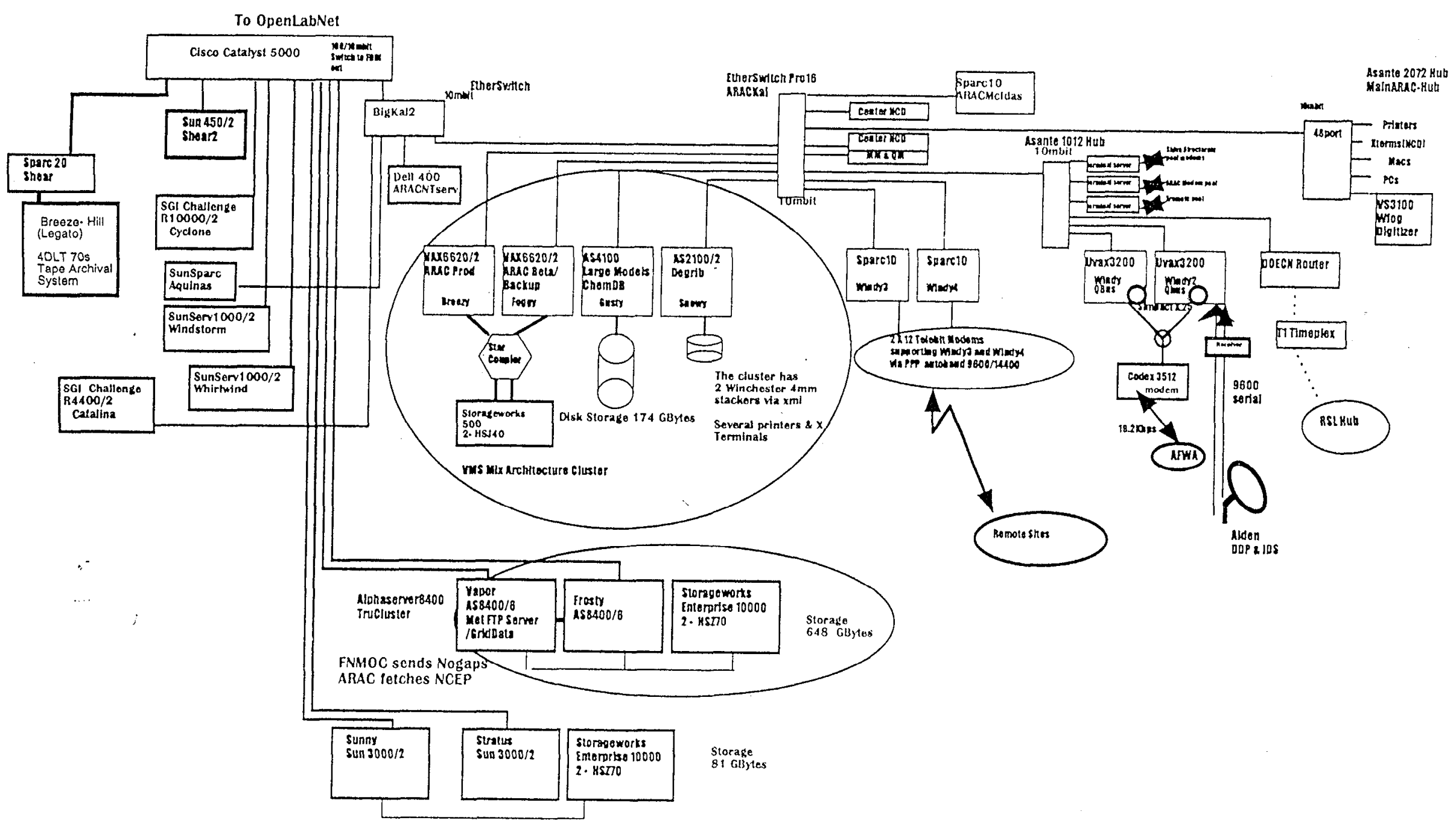




\title{
Attachment 4
}

\author{
Memorandum ARAC 97-51 \\ July 28, 1997 \\ "Organizational Restructure
}

(sce section 4.1) 

July 28, 1997

ARAC $97-51$

\section{MEMORANDUM}

To:

From:

ARAC Program Staff and Distribution homas J. Sulkvan

Subject:

Organizational Restructure

The attached organization (chart) has been developed to provide the perceived structure needed to successfully plan and manage the various tasks associated with building our ARAC-3 operational environment while maintaining a reliable ARAC-2 capability. Hoyt Walker will lead the Systems Operations and Support Team in this challenging transition. A second chart is attached, reflecting the clear need for many of you to be extended resources to this team on an "as needed" basis. Jim Ellis will continue to lead the ARAC-3 Implementation Team, whose primary tasks are to make/negotiate key decisions, set priorities and target dates, specify hardwarc, and assure successful completion of this major programmatic transition by 30 September 1999 . The explicit "Special Projects". task area reporting to program management is eliminated; Kevin Foster will continue to work on a variety of assignments including $A R A C$ models validation, chem/bio technical resources, VTR and classified systems support, etc. for Jim Ellis, Bryan Lawver will contribute systems, architecture, multiprocessor optimization, etc. support to Hoyt's team.

TJS:pmd 


\section{Attachment 5}

Screen Dump Showing the Results from a Primary Review of ARAC in an End-to-End Test of the Remote Site System

(see section 4.3) 



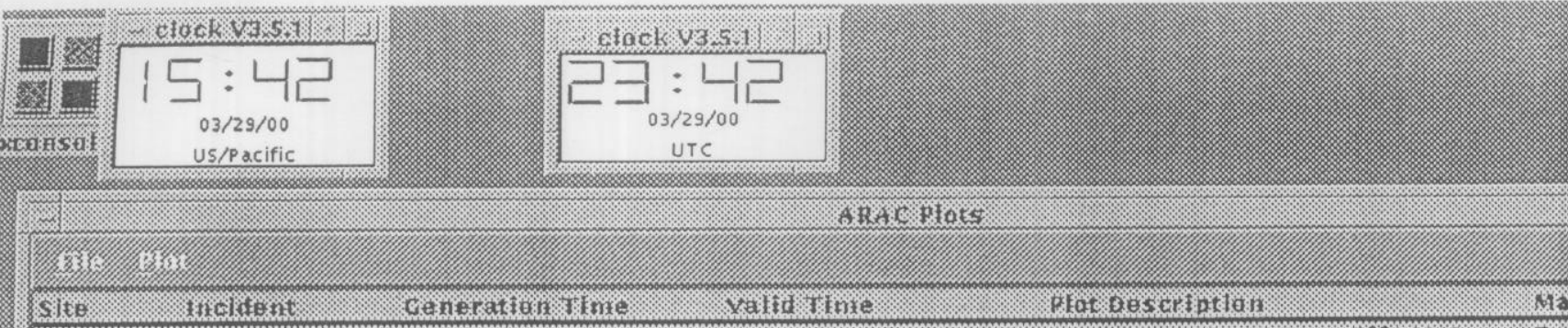

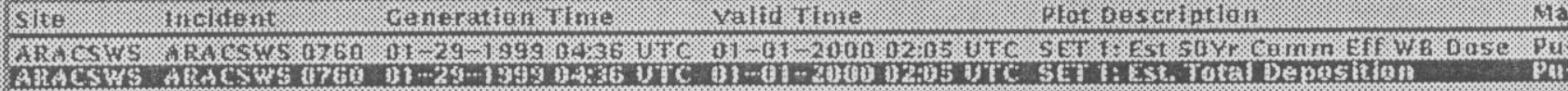

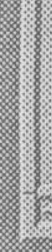

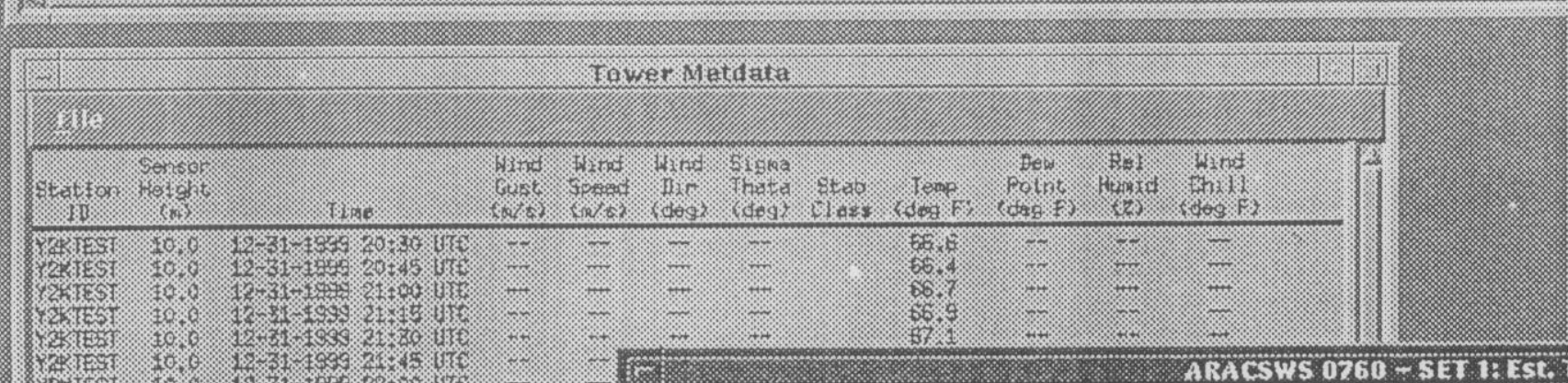

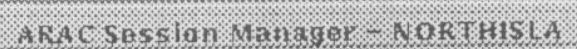

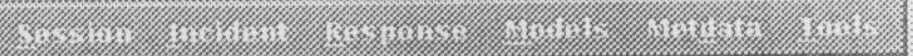

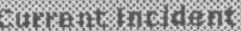

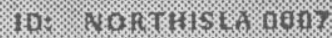

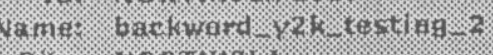

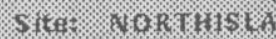

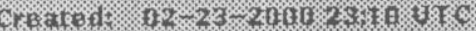

\section{Notil. ARAC}

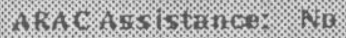

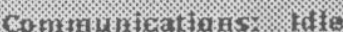

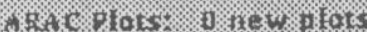

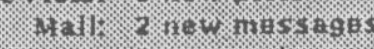

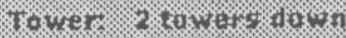

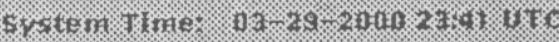

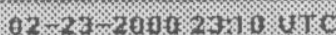

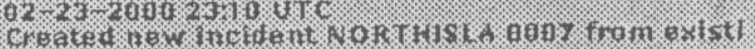

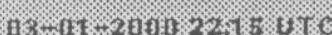

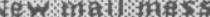

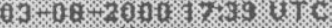

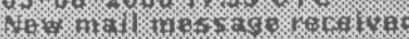

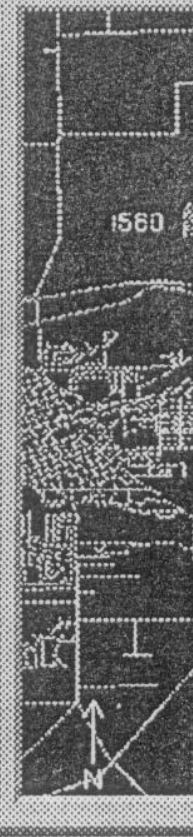

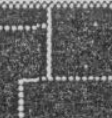<smiles>C1=[As]C1</smiles>

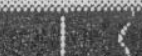<smiles>C1CC[SiH2]C1</smiles>
, 34

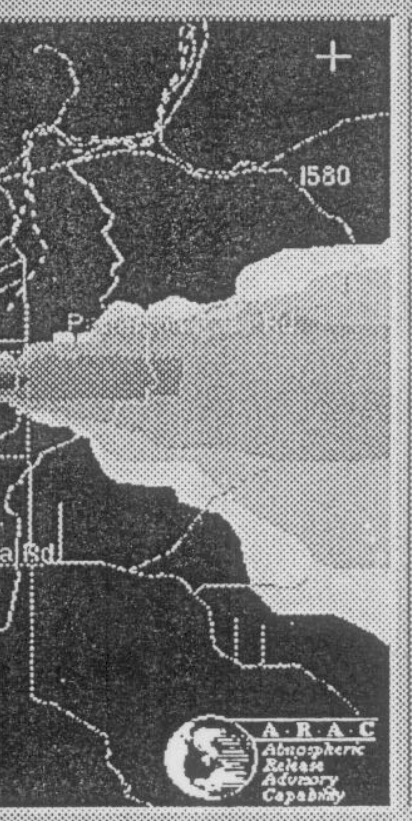

Conto urs: (Level and Area Covered)

$>1.000 \mathrm{E}+02 \mathrm{uCi} / \mathrm{m} 2$

$0.19 \mathrm{sq} \mathrm{km}$

$>1.000 \mathrm{E}+01 \mathrm{uCl} / \mathrm{m} 2$

$1.765 \mathrm{sm}$

$>1.000 \mathrm{E}+00 \mathrm{u} \mathrm{CV} / \mathrm{m} 2$

$13.46 \mathrm{sq} \mathrm{km}$

$>1.000 \mathrm{E}-01 \mathrm{uCi} / \mathrm{m} 2$

$62.26 \mathrm{sq} \mathrm{km}$

$>1.000 \mathrm{E}-02 \mathrm{uCV} / \mathrm{m} 2$

$105.17 \mathrm{sq} \mathrm{km}$

ARAC Computer Simulation Noles

Gerteration time:

Cont tour type:

Vahid from:

Yatid to:
Material:

Source

Location (Lat, Lang):

Location $(X, Y)$ :

Remarks

NITIAL PLOT - WEAPON A CCIDENT D
01-29-1999 04:36 UTC Total Deposition at $0.0 \mathrm{~m}$ above terrain 12-31-1999 23:05 UTC Pu-239

$37^{\circ} 41^{\prime} 23^{\prime \prime} \mathrm{N}, 121^{\circ} 42^{\prime} 27^{\prime \prime} \mathrm{W}$ $613957,4172.174$ 


\title{
Attachment 6
}

\section{Three Key Secondary Reviews}

\author{
$12 / 31 / 99$ to $1 / 1 / 2000$ \\ $2 / 28 / 2000$ to $2 / 29 / 2000$ \\ $2 / 29 / 2000$ to $3 / 1 / 2000$
}

(see section 4.4) 


\section{WWLASSAPIET}

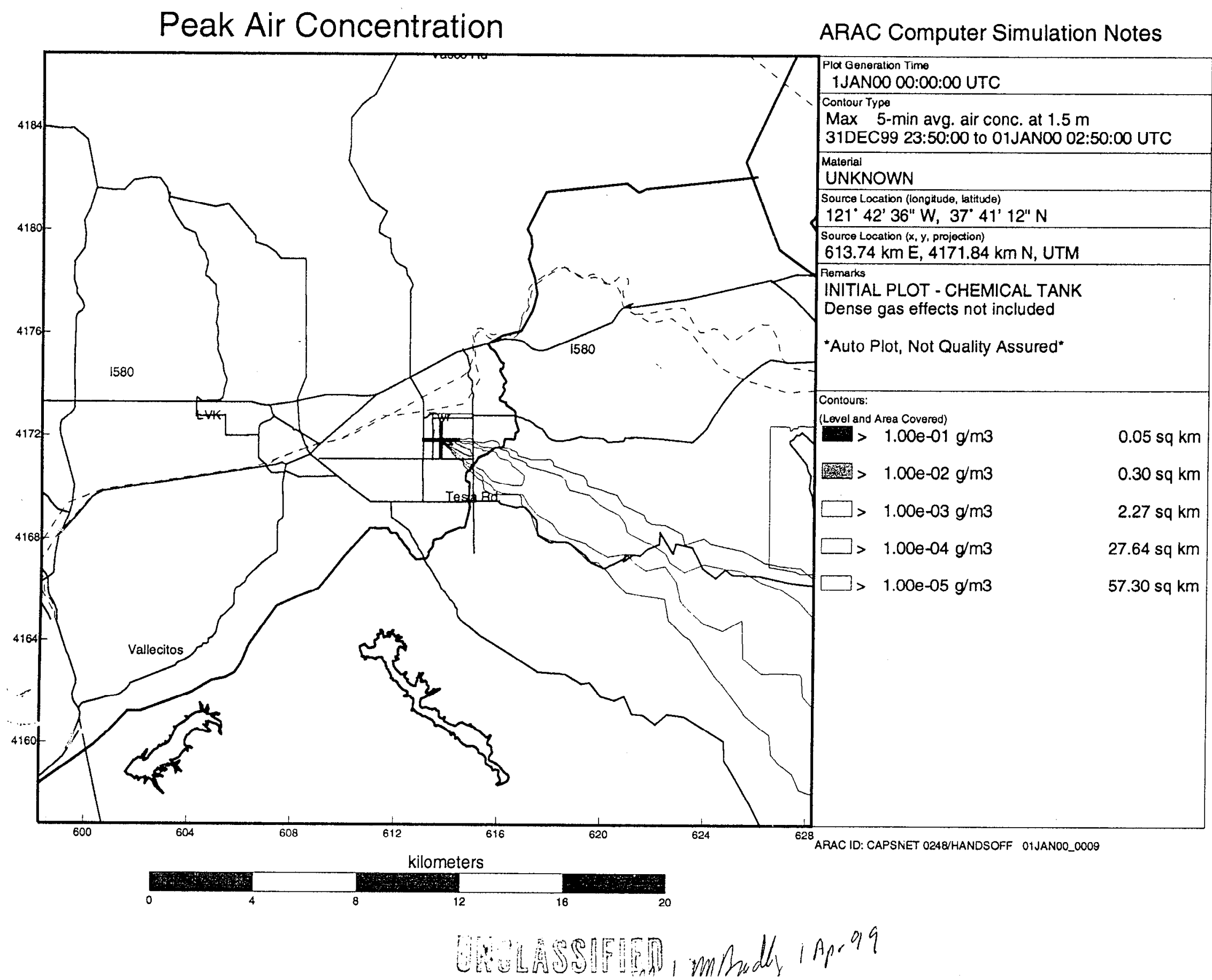




\section{UACLASSIFIEO}

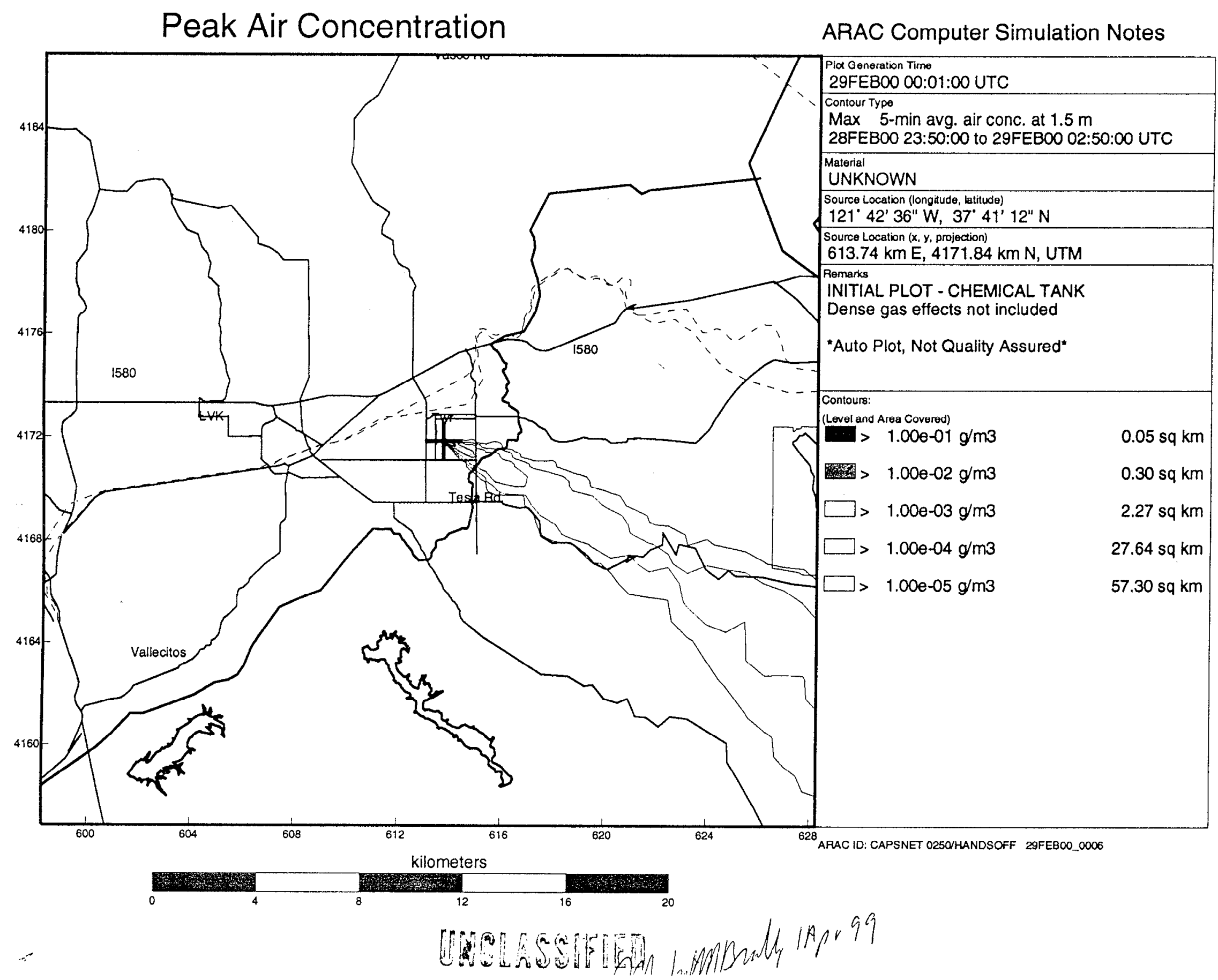




\section{WWLASSEPUE}

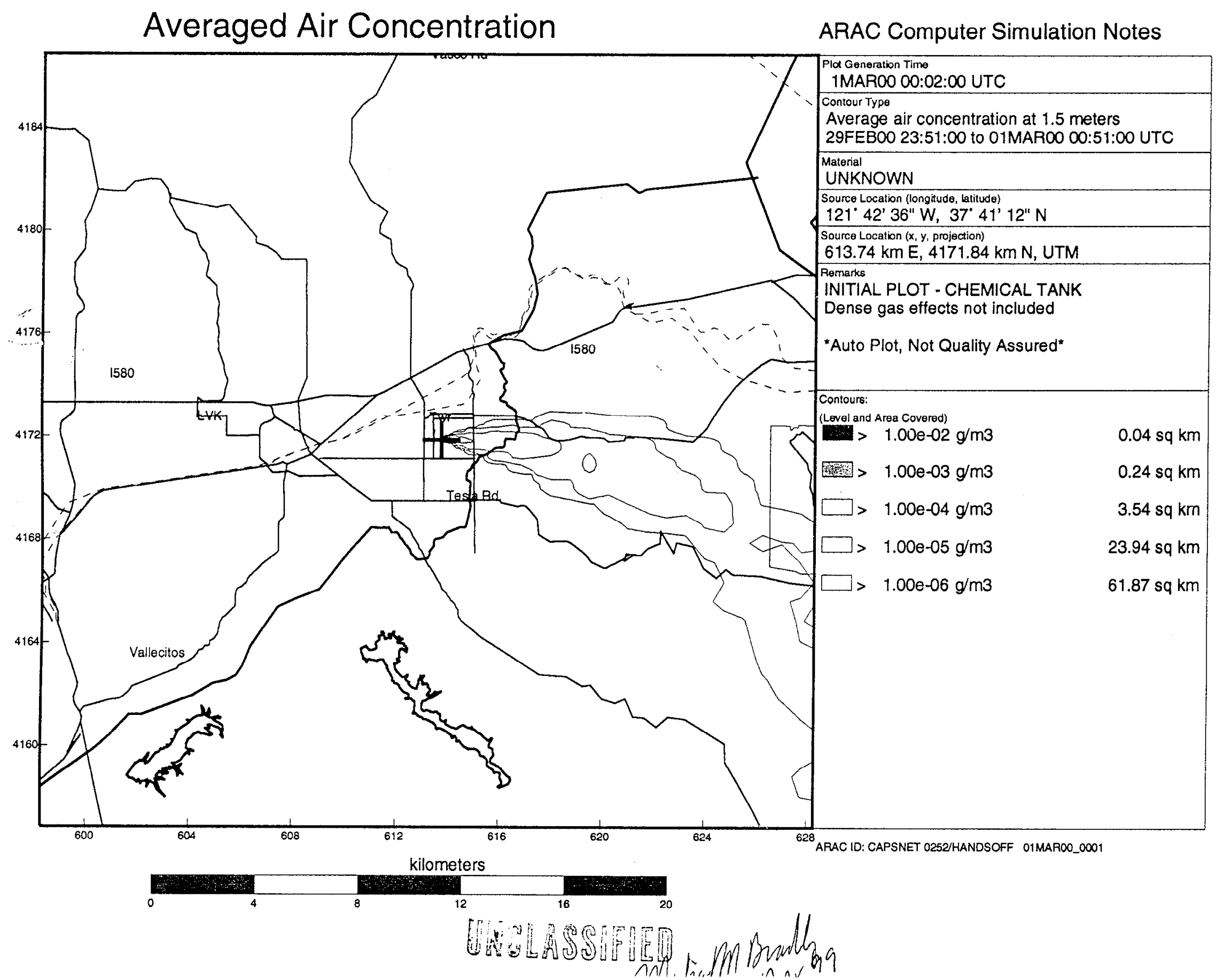




\section{Attachment 7 \\ Chernobyl Revisited}

Test Personally Designed and Requested

by

External IV\&V Investigator

(see section 4.5) 
Set 1: 4-Day TEDE Y2K TEST - CHERNOBYL OBS METDATA

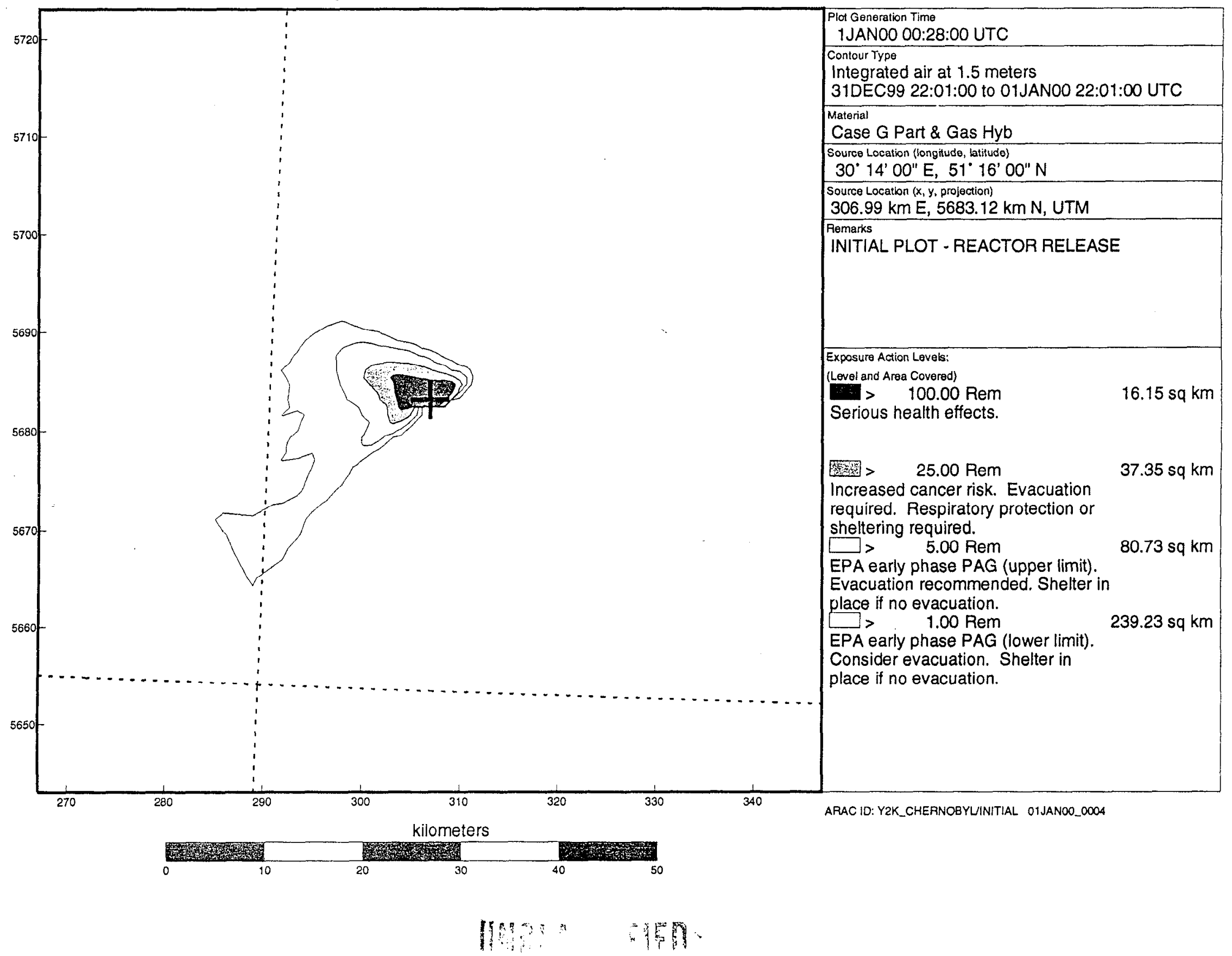




\section{WHOASSHED}

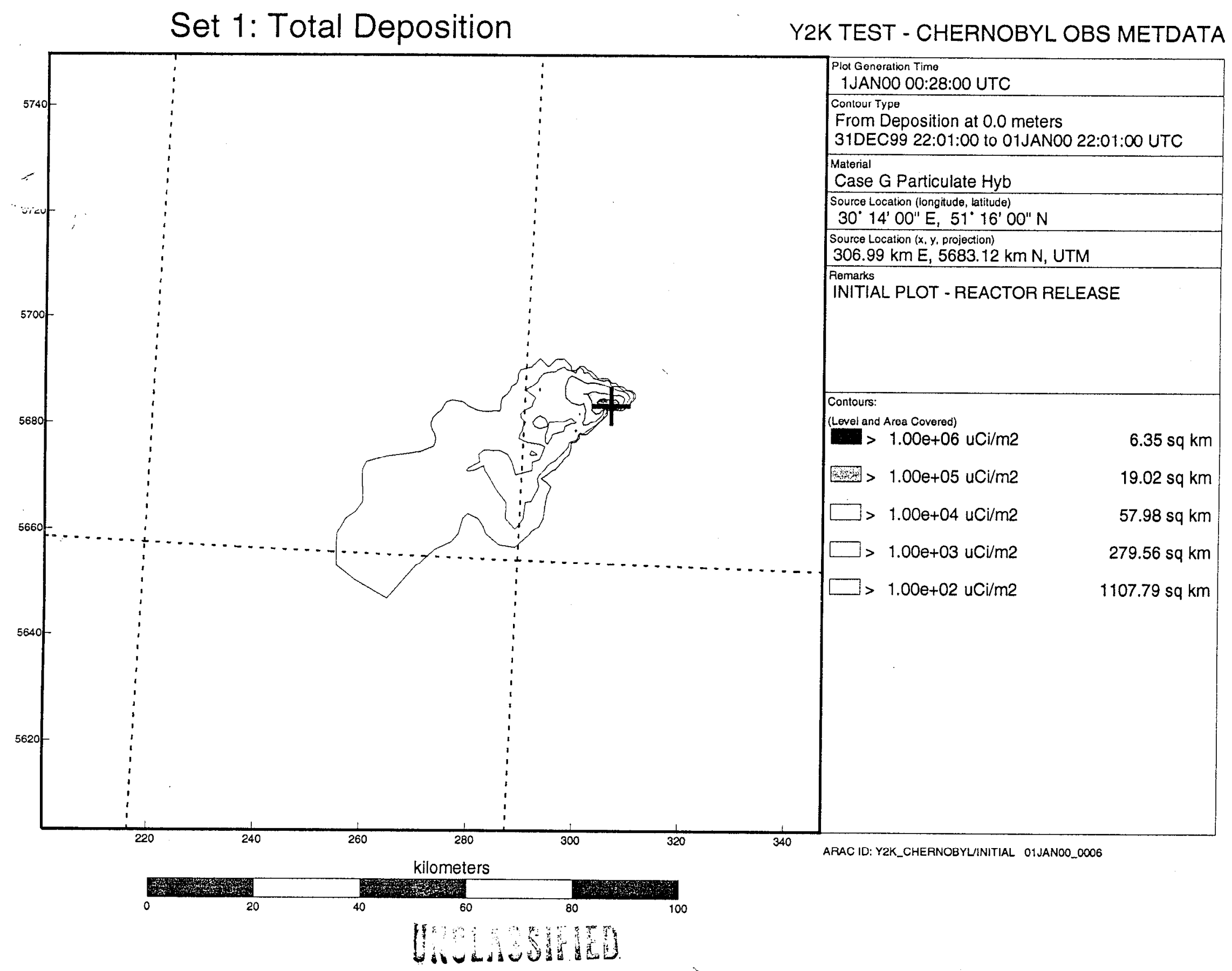


Set 1: 4-Day TEDE Y2K TEST - CHERNOBYL GRIDDED DATA

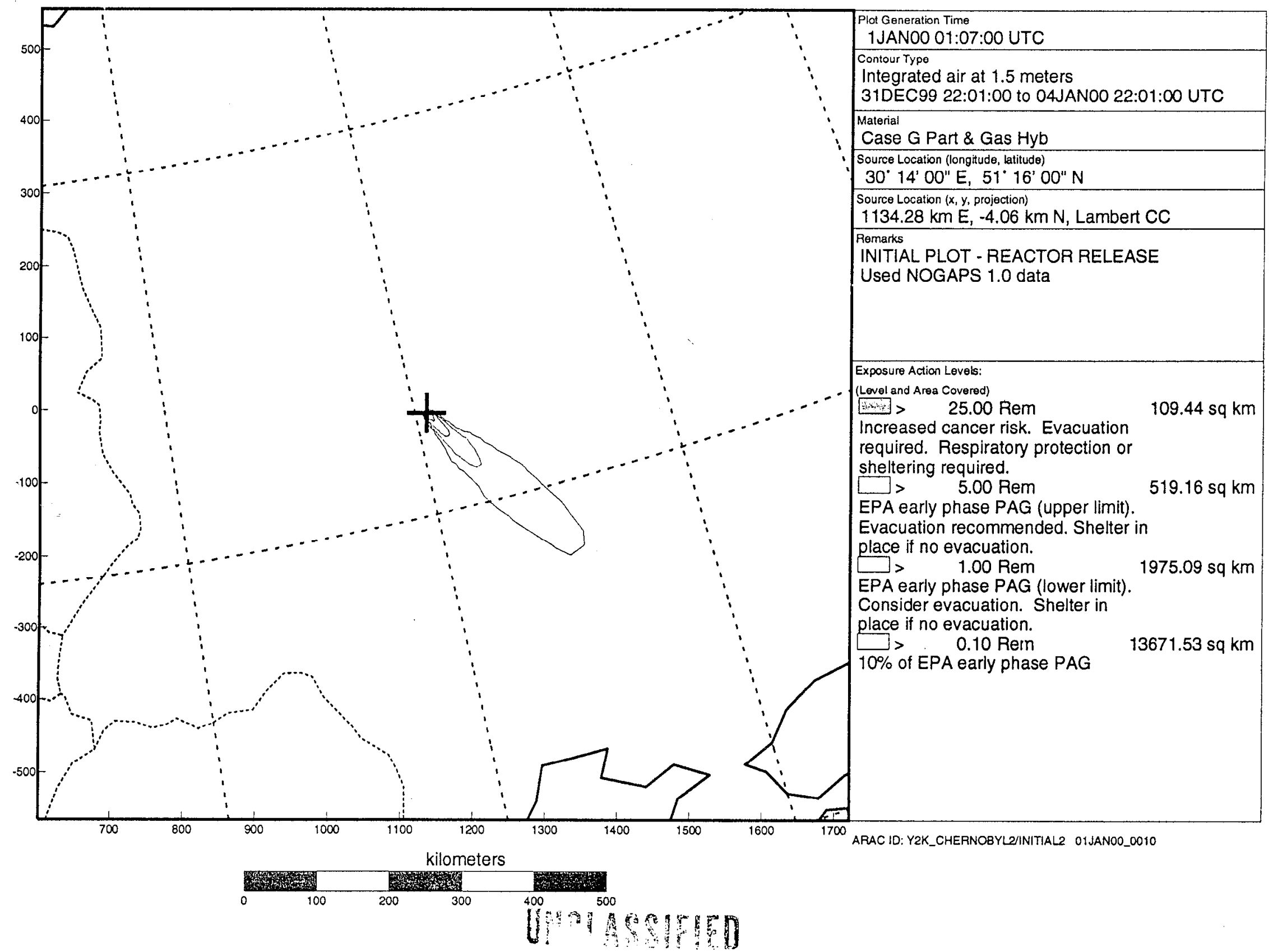




\section{UWABSHED}

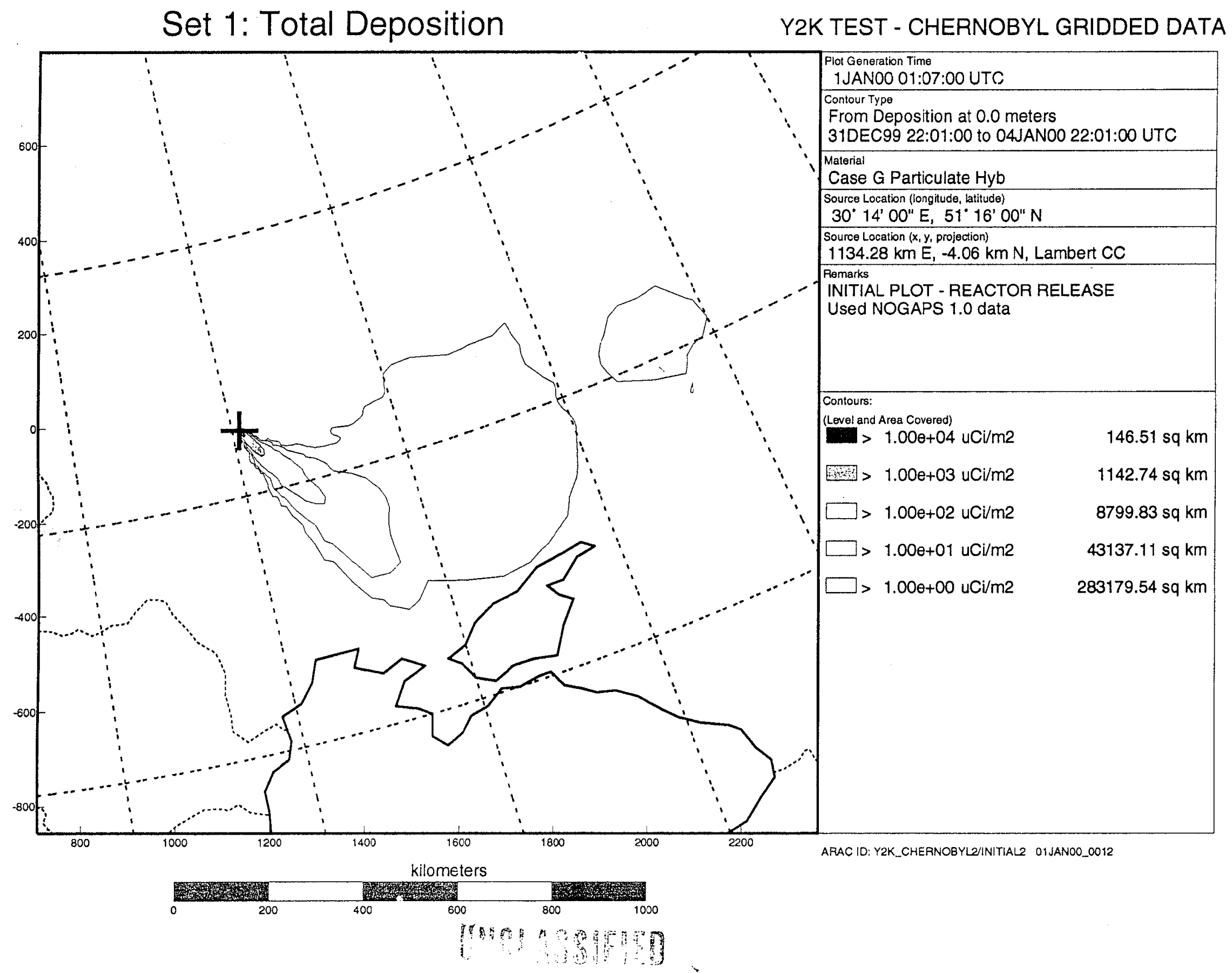




\title{
Supplemental Information to the External and Independent Validation and Verificitic of Year 2000 Compliance for
}

\author{
ARAC \\ Dr. Robert P. Addis \\ Atmospheric Technologies \\ Savannah River Technology Center \\ Building 773-A, SRS \\ Aiken, SC 29808 \\ (803) $725-3325$ \\ (803) $725-4233 \mathrm{fax}$ \\ robcrt.addis@srs.gov
}

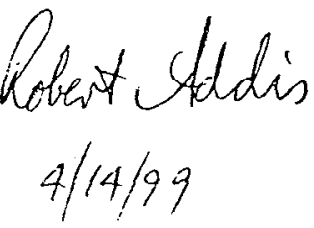

Summary:

The ARAC mission critical subsystems were subjected to an external and independent validation and verification for Year 2000 compliance on March 30 April 1, 1999. The result of this I V\&V indicate that the ARAC Y2K vulnerability evaluation, testing and corrective actions conducted and planned appear complete and sufficient to assure that ARAC will be in complete compliance for Y2K issues by April 30, 1999. Remote ARAC field stations (SWS - site workstations) are currently undergoing software upgrades to complete the ARAC Y $2 \mathrm{~K}$ compliance. At the time of this audit, these were over $50 \%$ complete, and are, scheduled to be $100 \%$ complete by April 30, 1999. All other aspects of ARAC as it currently is configured, are Y2K compliant.

The ARAC strategy of providing and testing all redundant capabilities within each component of ARAC, provides supporting assurances that ARAC's consequence assessment capabilities will not be diminished due to $\mathrm{Y} 2 \mathrm{~K}$ issues. In addition, indepth discussions with ARAC support staff members and management during the Y2K IV\&V revealed extensive in-house experience, expertise and dedication, providing ample evidence that they are capable of acting creatively to overcome any unforeseen $\mathrm{Y} 2 \mathrm{~K}$ difficulties, should they occur, and provide the necessary support and guidance expected of ARAC.

Recommendation: 1. The LLNL needs to follow through on the finding by the Year 2000 Compliance Review Team in their September 23, 1998 audit, viz. to verify that the infrastructure dependent mission critical items, such as ARAC, are tested within a Year 2000 compliant infrastructure.

Recommendation 2: The ARAC contingency plan needs greater detail.

Recommendation 3: ARAC-3 needs to be shown to be Y2K compliant prior to implementation as the primary ARAC system. 


\section{ARAC Mission Critical Core Subsystems:}

The ARAC Mission Critical Core Subsystems investigated during the Y2K IV\&V were:

modeling system

gridded met data receiving system

gridded met data processing system

observed meteorological data extraction system

geographic data system

model parameter generation system

visualization system

product generation system

communications system

In addition, infrastructure support for these systems was investigated.

\section{ARAC System Owner:}

Hoyt Walker

Lawrence Livermore National Laboratory

\section{Y2K IV\&V Investigator:}

Robert P. Addis

Savannah River Technology Center

I was asked to conduct this Y2K IV\&V due to my 15 year experience with a similar type of emergency response consequence assessment system at DOE's Savannah River Site, as well as my independent familiarity with ARAC's capabilities. A brief description of my credentials to conduct the Y2K IV\&V is attachment 1.

\section{Description of IV\&V:}

Each of ARAC's mission critical subsystems was investigated in as much depth as a three-day visit would allow. The IV\&V in general followed the plan proposed by the system owner Hoyt Walker, deviating from it as needed (see attachment 2). The ARAC system diagram was used extensively in discussions of each component (see attachment 3). A complete summary of the results of the IV\&V are included in the attachment 8 (the Templates of the IV\&V Tables 1 and 2). Some highlights are included below to provide some detailed descriptions.

\subsection{ARAC Management Strategy:}

A key management move described in an Interdepartmental Memorandum (ARAC 97-51) (attachment 4) issued by Thomas Sullivan, ARAC Manager, on July 28, 1997, placed all ARAC system operations and support under one person, Hoyt Walker. The expressed purpose was to ensure a coordinated approach to the transition from ARAC-2 to ARAC-3 scheduled for September 30, 1999. Although 
Y2K was not explicitly addressed in the memo, this management more provided the organizational structure to ensure that $\mathrm{Y} 2 \mathrm{~K}$ issues affecting the intes rity of the entire ARAC system could be cocrdinated by a single line management point of contact.

Originally the system upgrade of ARAC-2 to ARAC-3 was planned for AprilMay 1999. However, budget cuts delayed implementation of this upgrade.

Additional customer requirements resulted in the planned implementation of ARAC3 being scheduled for 1/1/2000, with ARAC-2 running as a back up. The tests for Y2K compliance in this IV\&V were conducted on $\Lambda \mathrm{R} \Lambda \mathrm{C}-2$.

ARAC-3 is still under development. However, the software for the new system uses 4 digit years. Plans for Y2K compliance for ARAC-3 appear similar to those for ARAC-2. Clearly, prior to implementing ARAC-3 as the primary system, it will need to undergo a similarly rigorous $\mathrm{Y} 2 \mathrm{~K}$ compliance test program. Although administrative constraints to implementation of ARAC-3 as the primary system may seem to preclude the 12/31/99 - 1/1/2000 transition, nevertheless it should be tested for this, as well as the numerous other dates identified with the "millennial bug" or Year 2000.

\subsection{ARAC Y2K Planning:}

There was evidence that ARAC personnel were alerted to $\mathrm{Y} 2 \mathrm{~K}$ issues prior to 1997. However, the earliest version of an ARAC Y2K Plan was one issued on April 15,1998 . This plan underwent several modifications as an understanding of $Y 2 \mathrm{~K}$ issues matured $(4 / 28 / 98,5 / 12 / 98,8 / 10 / 98)$ becoming the following document which was reviewed by the local DOE office:

"ARAC Year 2000 Guidelines and Test Plan" (September 8, 1998)

The DOE Oakland Operations Office reviewed LLNL's mission critical systems, including $\Lambda \mathrm{R} \Lambda \mathrm{C}$, for $\mathrm{Y} 2 \mathrm{~K}$ compliance on September 23, 1998. It found ARAC's plan deficient in some areas and made several recommendations:

1. the plan was incomplete and required additional narratives and scheduling information

2. information on data vulnerability was insufficient and information on specific interface exchanges of data and status of contacts with sending/receiving organizations

3. the test plans were deemed incomplete and required specific modules to be tested and schedules etc.

4. they recommended that all LLNL mission critical infrastructure dependent systems should be tested within a Y2000 compliant infrastructure.

In response to items 1, 2 and 3, the ARAC system manager, Hoyt Walker, issued a more complete Y2K plan addressing these issues: "ARAC Year 2000 Documentation: Plan, Renovation and Test Results" (still being revised). In addition, a "Y2K End-to-End Test Strategy and Resource Plan" was issued March 2, 1999. I reviewed both documents and believe that these three issues have been addressed. The fourth item, does not appear to have been conducted as yet. I believe that this 

fourth item should be tested by LLNL as part of an infrastructure Y2K compliance test.

A completely non Y2K recommendation to ARAC management is to enforce a more structured document management system with issue dates and version/revision numbers etc.

A Primary Review of the ARAC system in an end-to-end test was conducted with Jon Welch, the ARAC lead on remote meteorological towers and ARAC field stations (site workstations). I observed meteorological data acquisition, display and dispersion model runs on a stand-alone workstation operating in a computer clock time for Year 2000. The results were all displayed simultaneously on the computer screen showing the meteorological data, ARAC Session Manager, ARAC system plot manager, and ARAC dispersion model display utilizing this meteorological data, all operating successfully in year 2000 time. This provided an end-to-end test of the remote site systems. (See attachment 5)

\subsection{Some Key Date Tests of ARAC}

Numerous Secondary Reviews were conducted for the key dates listed in the Y2K Compliance IV\&V Checklists (Tables 1 and 2) (attached). However, the visual impact of these tests is often lost when condensed in summary form in the tables of IV\&V Templates 1 and 2. Attachment 6 provides three examples displaying ARAC dispersion model runs for releases overlapping the following dates:

1. $12 / 31 / 99$ to $1 / 1 / 2000$,

2. $2 / 28 / 2000$ to $2 / 29 / 2000$

3. $2 / 29 / 2000$ to $3 / 1 / 2000$.

These examples cover the New Year's eve 2000 problem, as well as the leap year problem for 2000 . These were conducted on the completely independent security classified system in the ARAC "Green Room". The clock on this system, which has identical software as the non-classified ARAC, was set to operate in synch with the model runs, simulating the above date changes. This was similar to the example given in 4.3 above, except in these cases, met data was input in data base format rather than from the instrument.

To verify that this could occur on demand. I requested a Primary Review of this capability for 12/31/99 to 1/1/2000. Similar results were produced.

\subsection{Requested Critical Function Test}

Prior to arriving for the IV\&V, I requested that the operators set up and run a test of the ARAC system to accommodate a realistic, but hopefully unrealized, critical test of ARAC. I wanted to see how ARAC would respond to a nuclear accident occurring in the ex-Soviet Union to see ARAC accommodate three separate midnights (i.e. Chernobyl midnight, Greenwich Mean Time (UTC) midnight, and local Livermore midnight) for $1 / 1 / 2000$. We assumed that the nuclear reactor at Chernobyl (sister to the previous unit that experienced a catastrophic failure) 
became unstable at local midnight and resulted in a massive release to the atmosphere. The ARAC model runs were conducted on the classified computer system, with its clock set to accommodate local midnight. A data file for observed met data was used for 24 hours, and gridded met data for 5 days. The ARAC results for these runs are in attachment 7. Integrated dose and deposition are shown. The system handled this test well.

\subsection{Tests of the National Meteorological Data File}

The plan to modify data base management and ensuring Y2K date compliance was discussed at length with the ARAC lead on this issue, Kevin Foster. The implementation and test plans for the meteorological data from both suppliers appears to be thorough and complete.

\subsection{Third Party Vendor Supplied Capabilities}

Documentation of $\mathrm{Y} 2 \mathrm{~K}$ compliance by third party vendors and government suppliers was reviewed and discussed with the ARAC lead on this issue, Ed Bush. Computer operating systems had been installed with various patches provided by the computer manufacturer to ensure operating system compliance, while other operating systems were compliant in and of themselves. The site work stations are scheduled to be upgraded to compliance by $4 / 15 / 99$.

Documentation by the LLNL network supplier declaring their capabilities as Y2K compliant was reviewed.

\subsection{Contingency Plans}

The ARAC contingency plans required more details. Although one cannot provide a detailed plan for every conceivable failure, some key items should be identified and alternatives spelled out in a contingency table. For example, if all world-wide met data completely fails, then how does one get met data? This issue has been addressed by ARAC staff, but was not documented. A contingency plan with key strategies identified in a simple table of no more than several pages would suffice. 


\title{
ARAC System Structure and Connectivity
}

\author{
Hoyt Walker, Ed Bush, Bryan Lawver \\ Systems Operations \\ Atmospheric Release Advisory Capability
}

The following is a description of the salient features of the ARAC-2 central system and its key connections with the outside world. There are currently two versions of the operational ARAC system, the main unclassified system (the Central System) and the classified system maintained in the VTR in B-170. The Classified System is a clone of most of the Central System running on less powerful hardware. A few comments about the Classified System will be made below. In addition, negotiations are on-going to install a clone at the Air Force Weather Agency (AFWA, Offutt AFB) to serve as a backup to the ARAC system. Note that the entire ARAC system is being reengineered to produce a replacement system (ARAC-3) with the intention that the ARAC-2 system be largely out of service before January, 2000. The primary connections between the ARAC system and the external world will be quite similar between the two systems although the particulars of any data transfer are likely to change.

\section{ARAC-2}

\section{System summary}

The key elements of the ARAC-2 system include:

- the primary VAX systems

- the VMS Alpha systems

- the AFWA observational metdata front end

- the Alden metdata feed

- the SWS front ends

- the FCN router

- the Internet connection

- the Digital-Unix Alpha systems

- the McIDAS metdata system

- the NORAPS Web page

- user terminals

- supporting equipment (printers, FAXes, digitizer)

The elements are discussed in more detail below and are represented in the attached system diagram.

Primary VAX systems

The majority of ARAC-2 capabilities are implemented on the primary VAX system. The ARAC-2 central system uses a 2-processor 6620 with $256 \mathrm{Mb}$ of memory (breezy) and a copy of this system (foggy) is used as a backup as well as for development and beta testing. The Classified System utilizes two VAXstations as the primary VAX components.

VMS Alpha systems

The ARAC-2 system makes use of an Alpha system for a few applications such as gridded metdata degribbing, TAHOE (handsoff exercise) model executions, large model executions 
and maintenance of the chemical database. The Central System Alphas are server-class machines while the Classified System has a Alpha workstation that fills this role. On both the Central and Classified Systems, the VAX and Alpha components are integrated as VMSClusters.

\section{AFWA obscrvational metdata front end}

Observational meteorological data is a critical component of the ARAC system and AFWA has been the primary source of this data for over 20 years. ARAC-2 relies on a VMS MicroVAX 3200 that serves as a front end for AFWA communications and preliminary routing of messages to/from the Central System processes that ultimately handle them. Note that a backup machine is available although switchover is manual process. The communications are based on the X.25 protocol running over a $56 \mathrm{~Kb}$ leased line between ARAC and AFWA. The X.25 protocol on the front end is mostly handled by a board produced by the Simpact company that is installed on the Q-bus and runs at $19.2 \mathrm{~Kb}$ through Motorola Codex 3512 digital modems. The remainder of the protocol is managed by custom software that runs on the MicroV $\Lambda$, which also handles the TPTP (Trivial Product Transfer Protocol, an AFWA communications protocol) and then routes messages appropriately.

\section{Alden metdata front end}

Observational metdata, along with meteorological charts, are received from Alden, a commercial distributor of meteorological information, via a satellite link. The satellite dish is conncetcd to onc of the microVAX 3200s that can scrve as the AFWA metdata front ends and most of the decoding process is similar to that for the AFWA data. U.S. metdata (Domestic Data Plus, DDP) and international metdata (International Data Service, IDS) are both received.

\section{$S W S$ communications front end}

ARAC has about 40 sites that receive committed support from the project. This support includes a dedicated Sun workstation installed at the site that allows the sitcs to initiate an exercise or a response on the basis of information provided via a questionnaire interface and to receive the products generated by ARAC, along with various other processing and maintenance capabilities. In most cases installation of the operating system and all of the SWS software is handled by ARAC, as much as possible by logging into these systems remotely. Many of these SWS are installed with meteorological towers and metdata is collected and archived by the SWS as well as being available to ARAC directly over telephone lines. These systems are referred to as Site Workstation Systems (SWS). ARAC has a Site Support Team dedicated to dealing with these systems and their users. The majority of the SWS communicate with ARAC via dial-up modems that are part of the installed SWS using PPP as the basic protocol. ARAC receives these communications on one of two dedicated front ends. These front ends are Sun 1040 workstations, each with a bank of 12 Telebit $14.4 \mathrm{~Kb}$ modems. ARAC maintains two of these systems as part of the Central System. Switching to the backup system is a manual process.

$S W S$ communications via $E C N$

DOE NN has developed an Emergency Communications Network (ECN) for use by DOE 
emergency response resources of which ARAC is one. ARAC SWS communications with DOE SWS, as well as to SWS at other DOE facilities, are handled using the ECN. This network has two hubs, one in Washington, D.C. and the other at the Bechtel Nevada Remote Sensing Laboratory (RSL), that are connected with a T3 line and the various nodes are connected to one of the hubs using a T1 line. A router connects the ECN into the ARAC LAN. This intranet is connected to the Internet in Washington.

\section{Internet connection for receipt of FNMOC and NCEP grids}

ARAC receives NOGAPS grids at both 1.0 and 2.5 degree resolution from FNMOC via the Internet. FNMOC pushes the files to ARAC using $\mathrm{ftp}$ in GRIB format. The files initially arrive on a Digital-UNIX Alpha and scripts transfer the files to a cross-mounted disk that the VMS Alpha can see (the Digital-UNIX Alpha is part of the ARAC-3 system, the prognostic modeling component of which requires a much larger number of fields than are needed for ARAC-2 and so the data are brought into the ARAC-3 system and then transferred to ARAC-2). A process wakes up on a regular basis and checks the directory and when complete sets of files are available initiates the degribbing process, producing files that can be read by the ARAC-2 models. ARAC can call FNMOC to redeliver all or part of the data set for a watch if data was missed for any reason. Grids from models at the National Center for Environmental Prediction (NCEP) are pulled via ftp over the Internet although these grids are not normally used by ARAC-2.

\section{McIDAS meldata system}

ARAC receives various meteorological data from Unidata (part of the University Consortium for Atmospheric Research focused on providing access to atmospheric data, primarily for research purposes) in a specialized format over the Internet using specialized protocols. These are used by the McIDAS (Man computer Interactive Data Access System) program primarily to support the ARAC weather briefings and general atmospheric analysis, particularly in the area of satellite images. These data are also used by the GEMPAK atmospheric data visualization program (also from Unidata) for model development use. The capabilities are not directly linked to the operational ARAC environment at this time. In cooperation with Unidata, ARAC has been designated as a backup data distribution node for the McIDAS data to a small number of universities in the area.

\section{NORAPS Web data}

ARAC contributes to the Laboratory's Weather Page (http://www-erd.llnl.gov/metdat/) both with information about ARAC and it's models as well as by presenting the results of the twice daily weather forecast from ARAC's NORAPS model (NORAPS is a weather prediction model developed by the Navy and run operationally at FNMOC). Displays of the model results are converted to gif files and written to a disk that is cross-mounted to croce.llnl.gov where they can be reached from the Web page. The html files for the textual information are maintained in the same place.

\section{User terminals}

ARAC assessment meteorologists and software developers generally access the system using NCD X-terminals. These terminals can boot off of most of the main machines in the system, although performance considerations have caused most users to rely on the VMS 
Alphas as a boot hosts. Assessors also have NCDs at home and have ISDN lines installed so they can logon to the system to initiate responses off-hours. These lines enter the system via Open LabNet pool and passed to the ARAC subnet and are viewed as trusted communications. There is an analog modem pool (Shiva Directorate - LANRover) available modem access. An " $800 "$ number is also available for modem connections. Other remote terminals can access the system via the Internet. ARAC is taking advantage of the recently implemented E\&ES OPIE server (on the 57 subnet) to provide one-time password support for users logging in from insecure environments. ssh is being installed for trusted users (e.g., system administrators) logging in over the network from home over insecure lines. System administrators use Timbuktu to monitoring system status from remote clients.

\section{FAXes}

FAXes often play a role in ARAC's responses, occasionally for distributing products, but more commonly for other ancillary communication with customers and headquarters associated with a response. ARAC also has a VAX-to-FAX where products are sent directly from the primary VAX to the FAX.

\section{ARAC-3}

To provide a basis for longer term evaluation of ARAC connectivity a brief description of ARAC-3 is provided.

In 18-24 months, the ARAC-2 system will be retired and replaced with a completely new system, ARAC-3. Key components of the new modeling capabilities include new diagnostic and dispersion models utilizing a continuous terrain representation and variable vertical and horizontal gridding. The new models are written in Fortran-90. A prognostic modeling capability is being added by importing the Navy's NORAPS and COAMPS models. The new system is a distributed, client/server architecture with $\mathrm{C}++$ servers and Java user interface clients. The CORBA standard is being used as the basis for integrating this distributed system. An object-oriented database is being used to implement object persistence in most cases.

ARAC-3 is designed to be platform independent, however a variety of issues have motivated the development of an architecture that is likely to remain stable for at least the next 2-3 years. The models are being run on Digital Unix Alphas (2 6-processor $625 \mathrm{MHz}$ systems) with a shared StorageWorks network file system that form a TruCluster. The majority of the AR.AC-3 services currently run on one of two UltraSparc servers, which will be connected with another network file system in a cluster arrangement soon. Desktop platforms for user interface clients have not bcen finalized, however, PCs running Windows NT and enhanced with OpenGL graphics boards are being evaluated for this role.

Regarding observational metdata delivery from AFWA, ARAC-3 will move away from the X.25 basis for data exchange and rely on Internet-style communications instead. For example, delivery of metdata as one or more files using $\mathrm{ftp}$ is an attractive possibility. AFWA is currently servicing some of their customers using this mechanism and appear to be enthusiastic about proceeding in this direction. The primary issue in this area is network connectivity between AFWA and ARAC. Five possibilities have been considered at this point: 
- the Internet, which is attractive because of its convenience but is vulnerable to gateway failures and, more significantly, to saturation during periods of crisis.

- the ECN, which is needed for the future AFWA ARAC backup system.

- continued use of the leased line with ftp/ppp rather than X.25.

- the NIPRNet (the military's Non-secure Internet Protocol Routing Network) is an intranet used by the military. It is connected to the Internet.

- the ATM network that connects AFWA, FNMOC and NCEP. This network is attractive because it would provide connections with three organizations that are of critical interest to ARAC. This network is being upgraded to $\mathrm{OC}-3(155 \mathrm{Mb} / \mathrm{sec})$ soon.

A satellite connection to NOAA observational and gridded metdata (NOAAPort) is being considered for ARAC-3. Future ARAC clients are expected to be supported via Webtechnology interface with initial development to begin shortly. 

ARAC is in the process of rebuilding its entire system including the models and all aspects of the system that supports the models. Development of the new system (referred to as ARAC-3 to distinguish it from the current operational system, ARAC-2) began in 1995 and was planned to be ready to supercede ARAC-2 during 1999. A variety of issues (funding deficits, loss of key personnel, etc.) have contributed to some extension of the expected delivery dates. ARAC-3 is being developed to avoid the $\mathrm{Y} 2 \mathrm{~K}$ problem (4-digit years are used in all situations), however, the likely delay in delivery of a stable, sufficiently complete, operational system until somewhat after Jarl. 1, 2000 suggests consideration of updating $A R A C-2$ to handle the $Y 2 \mathrm{~K}$ problem. As with many legacy systems, full update of the ARAC-2 system lo verifiably handle lhe Y2K problem in all situations can be expected to be reasonably expensive. However, a careful evaluation of the siluation suggests thal a relatively modest expenditure can sufficiently verify the system to the point that ARAC can respond in a timely and creaible way (though nol necessarily optimal way in the most extreme situations) independent of the status of ARAC-3. Note that an appropriate level of preparation of ARAC-2 does not significantly lessen the need to develop ARAC-3 as quickly as possible. A stable ARAC-3 system should also be a component of ARAC's overall response posture during this period of potentially enormous instability. Both of these systems should be viewed as backing each other up and ensuring that ARAC will be able to produce the best response possible to whatever situations develop at the time.

\section{Overal1 Strategy}

Given the transitional nature of the ARAC system during the next two years, planning at all levels must always be cognizant of the status of both ARAC-2 and ARAC-3. The current estimate for the replacement of the ARAC-2 sYstem by ARAC-3 is May 1, 2000. Development for this phase of the systém is expected to be complete on January 1, 2000. Thus, ARAC-3 is a moving target from now through the critical period. To minimize overall expense, such as repeatedly certifying ARAC-3 as it evolves, and to meet the March 1, 1999 deadline defined by the Laboratory's Year 2000 Task Force for mission critical systems, Y2K efforts through the end of calendar year 1998 will focus on preparing ARAC-2 so that all primary ARAC requirements can be met with this systcm. Early 1999 will focus on verifying that the ARAC-3 infrastructure (e.g., third-party software) and the ARAC 3 software to that point works properly. A final round of testing will be associated with the last production update before January 1, 2000 for each system (expected to occur in August October, 1999) to ensure that no problems have crept into either system as they have evolved (note that changes to ARAC-2 during 1999 should be extremely minimal).

The following discussion first presents a roview of ARAC-2 with respcct to the Y2K issues and the plan for updating and testing this system. Similar, though less detailed information for $\mathrm{AR} \lambda \mathrm{C}-3$ follows.

ARAC-2 Y2K Status

Operating systems

VMS 6.2, VMS 5.5, Solaris

Appropriate os patches to these systems are available so no actual upgrades are required, but the patches do need to be installed.

Third-party software

Some work on third party software has started. Upgrades to MultiNet to make it Y2K-compliant are in progress. 
Core Models (TOPOG, MEDIC, MATHEW, ADPIC, PLCNT, TIMEHIS)

The main ARAC-2 models have been previously certified for AFTAC project. A sliding window mechanism has been used to control the problem, as presently coded the models will break on January 1, 2050. While the processing of observational metdata has been verified, the handling of gridded metdata has not and so additional testing is needed.

Model Parameters

This portion of the system was implemented with four digit years. Problems are expected to be minimal. This part of the system can be considered to include most of the small, relatively static databases as well as the questionnaire, which are also expected to introduce minimal problems.

Geodala system

No date dependencies exist other than time-stamping files. Once the os patches are installed no problems are expected.

Metdata systems

The primary issues are likely to be in the metdata system where numerous time calculations occur. In addition to the necessity of frequent time calculation, most of this software was written in 1983-1986 and millenial issues were not on the top of the developer's lists of problems. While this area would require effort, most of making the necessary changes could be completed at manageable costs if appropriate strategies are taken (see below). The primary difficulty is associated with testing. Programs that interact with data that is contained within the system, i.e., the majority of the programs, should be testable in a straightforward manner so that any problems missed by basic search strategies can be discovered and corrected. The main problem area at this point appears to be REQUESTGWC, which manages the asynchronous requesting of metdata from $\Lambda F W A$. It is unclear how this program could be testcd in any compelling way (again more on this later).

Note that the handling of gridded metdata is a much simpler problem, both to detect and correct as well as to test.

other models

KDFOC3 and PREDICT should be evaluated and corrected as necessary. This should not be too difficult as these are relatively simple codes and their time computations are relatively straightforward.

\section{SWS}

The SWS has had $\mathrm{Y} 2 \mathrm{~K}$ changes made and some unit testing has occurred. This testing includes setting the clocks forward as part of exercising the upgrade to Solaris 2.5.1, which is on-going. Running the sws through the date boundary appeared to cause no difficulties.

ARAC Y2K plan

The following is a list of suggested tasks and testing strategies and the associated motivations that should position ARAC-2 to function in essentially all normal circumstances during the Y2K period without a major investment in the process.

1. Install Y2K patches for all relevant operating systems. In the case of the solaris systems (the sws communication front ends), this could coincide with an upgrade to 2.5.1 to minimize the number of os versions being maintained on the project. Version $7 . x$ of OpenvMs is Y2K-compliant, however, patches exist for 5.5 and 6.2 and to avoid the possible instability of a 
major operating upgrade, the cost-effective strategy appears to be to simply install the appropriate patches. Estimated effort: 1-2 days

2. Collect a list of all software packages used on the system. The list should prioritized to separate packages that are critical to the functioning of operations and those that are essential for development to proceed rapidly from packages whose failure would be less important. Check with the associated vendors for all the important third-party software packages regarding $\mathrm{Y} 2 \mathrm{~K}$ status and make upgrades as suggested. Estimated effort: 2-3 weeks

3. Work with AFWA to develop an appropriate test data set that straddles the $Y 2 \mathrm{~K}$ boundary. This may be easier for AFWA if the format discussed in the next section can be used. This data set would shipped at an agreed upon time as part of testing.

4. Upgrade the receipt of subscription data to handle the newer form of metdata that AFWA would like to distribute (and which they did for a day in February causing major problems with the metdata system here) and then extend the data coverage to as much of the world as the existing X.25/READGWC link can manage. This accomplishes several things but most important is that, to the extent that the world's observational data can be received on subscription, this changes insulates ARAC-2 from any failings of portions of the REQUESTGWC program, which appears to be difficult/expensive/impossible to test in a meaningful way. Kevin points that some testing of ARQs is possible by depositing time in the message and passing back into the system but that SDM cannot be exercised this way. Note that the decoders can be effectively tested using existing methods. While much testing can be done, it is important to note that, since this program manages the requested metdata to/from AFWA, it is potentially sensitive to any problems with time handling at AFWA and in the communications protocols. Full testing of this component would require changing clocks at ARAC and AFWA for a combined test with repeats after any failures were tracked down and corrected. Since both are operational systems this would be difficult to manage. Trying to either clone some portion of the AFWA system for testing or simulating the AFWA-end of the data exchange would require the development of difficult, throw-away software that would be as hard to verify as the software in use. Thus, anything that can be done to minimize the requirement for requesting data lessens the relevance of possible failure of this component. Other merits to completing this project include:

1. it insulates ARAC from the status of AFWA's System 1 thus avoiding a possible high-priority distraction from ARAC-3 and other business at an awkward time if in fact System 1 does go out of service on during the next 18-20 months as expected.

2. provides a full set observational data for use in testing and sizing ARAC-3 before the ARAC-3 AFWA connection is developed.

3. when the ARAC-3 AFWA connection is developed, a pre-existing ARAC-2 capability can be used to validate the new ARAC-3 capability.

4. will develop experience with AFWA on the procedures necessary for timely delivery of the observational data in this mode since some issues raised here, such as the handling of special obs, will need to be addressed in ARAC-3 obs data delivery.

Estimated effort: $4-6$ weeks

5) Upgrade the receipt of SWS (VALFORSIT), DDP, IDS and AFWA metdata to handle future metdata. This is likely to involve removing or commenting out an IF test (reasoning by analogy with VALFORSUP which was updated to support handling future met for Cassini) in these programs. Once future metdata can be received and moved into the metdata archive, then testing of key areas such as Create_Problem_Metdata can begin conveniently. 
Estimated effort: 1-2 days (assuming Kevin has reviewed the software that handles the incoming AFWA, DDP and IDS software)

j) Correct obvious problems in ARAC-2 system software. Searching for problems should proceed on two paths, 1) brute force searches and 2) moving through key programs (e.g., VALFORSIT, Create_Problem_Metdata, REQUESTGWC) looking for date computations and rclated proccssing. Thcsc processes should interact. For example, a brute force search through the system for '19' uncovers 18 places where changes obviously need to be made. Examination of Create_Problem_Metdata quickly identifies a time conversion utility that uses individual characters such as ' 1 ' and ' 9 ' to specify a year. A subsequent brute force search through the system for ' 9 ' identifies 6 places where such changes need to be made. While it is not completely obvious that such a strategy can capture essentially all problems, it appears that most of the software was written to use the VMS utilities for time handling which are not (at least with the $\mathrm{Y} 2 \mathrm{~K}$ patches) vulnerable to the $\mathrm{Y} 2 \mathrm{~K}$ problem. Many of the problems indicated above are in the routines that convert various times to and from the standard DEC times and that the actual time arithmetic is done with the DEC utilities. Thus, once the conversion utilities are fixed much of the software is likely to work. Note that searches and changes should be made throughout the system, including REQUESTGWC, obviously to increase the chance that the whole system will work as well try and identify new coding patterns that are associated with failure points that could be the basis for additional search strategies.

Corrections should be made using the sliding window approach. As currently implemented in the ARAC-2 models, this means interpreting years from 50-99 as $19 x \mathrm{x}$ and years from 00-49 as $20 \mathrm{xx}$. Each of the problems mentioned above requires and IF-THEN-ELSE statement to handle this logic. Thus, the system would break on January 1, 2050 (note that should the software actually survives that long, the various if tests could be updated to push the break point out into the future, e.g., 2060, and so sensible sliding of the window can keep things working indefinitely with the limitation that time is restricted to one century). While limiting in some ways, this approach avoids reengineering ARAC-2 to handle 4-digit dates which would be very expensive with software changes and testing probably running to several FTEs.

Given the ability to get future metdata into the metdata archive, many of these updates can be exercised conveniently. That is, the testing goal, once the obvious changes are made, should be to step through all processes necessary to run the models on this future data set, iterating through the tests until all the main processes beyond the receipt and decoding of the metdata are demonstrably working across the $\mathrm{Y} 2 \mathrm{~K}$ boundary (and February 29 , 2000 for good measure). Estimated cost: 4-8 weeks

7) Verify gridded metdata paths into the system. These present no signiticant testing difficulties as files are simply pushed to ARAC or pulled from outside organizations with no ARAC communications software involved. Future dates could be faked reasonably easily and reliably and processed into the system and run through the models for testing.

Estimated cost: $2-4$ weeks

8) Check Center PCs for BIOS problem (some type of internal clock that will reset to January 1, 1980 on January 1, 2000; this is found on older PCs and off-brand machines of more recent vintage). Home computers and $\mathrm{X}$-terminals need to checked. Estimated cost: 2-3 day to check, 1-2 weeks to move software off any systems affected and replace with more appropriate systems.

A reasonable goal would be to complete these tasks near the start of FY 99. 
3) After coordination with CAPS and any other possible Green Room users, set the clocks on the Green Room system and the CAPS SWS to a time shortly before the $\mathrm{Y} 2 \mathrm{~K}$ boundary and run TAHOES across the boundary using future metdata imported from the Central System. Repeat until the systems really work. Note that this will fully verify the SWS against the $\mathrm{Y} 2 \mathrm{~K}$ problem, which needs to be done in any case. Estimated cost: $4-6$ weeks

The goal for this effort would be to complete it before January, 1999. At this point, ARAC-2 will have been verified to work, given the receipt of metdata. In addition, the receipt of subscription and gridded metdata will have been verified. The vulnerability of REQUESTGWC is finessed by placing it in a backup role. The greater the number of primary data paths, the less critical this weakness is. Thus, backup subscription metdata such as IDS, DDP are important. Also, note that all metdata paths into ARAC-3 can be viewed as providing backup to ARAC-2 since OBSERV.MET files that could be used by MATHIEW/ADPIC could be easily generated and automated if this appeared to be an important data path (note that ARAC-2 is a backup to ARAC-3 in the same sense, since all ARAC-2 metdata can be transferred to ARAC-3 automatically). This date is $2-3$ months ahead of the Lab's target date of March, 1999 for completion of all critical changes.

Jther issues include extending the coverage of NOGAPS data as far into the future as possible, at least on the ARAC 3 side, to provide ARAC with the ability to respond using gridded data only in the event of total collapse of the various communications and electrical nctworks (assuming the generators have enough fuel for a few days continuous running). Transferring this data to ARAC-2 is a low cost effort that can be done whencver it is convenient.

Thus, for an estimated effort of 4-6 fte-months a reasonably verified $\lambda R A C-2$ system can be generated. An advantage of beginning these tasks soon is due to the possibility that the estimates are wildly in error. This is not expected, but if it is in fact the case, it is far better for that to come clear sooner rather than later. Also if this effort is started soon; then it is appropriate for the current ARAC-2 maintenance team to handle most of the effort, with the exception of Kevin's work on the new AFWA format. Thus, while any effort not directly spent on ARAC-3 is to some degree a dilution of that project, the dilution is minimized by beginning soon. If the effort is postponed until it is obvious there is no possibility that ARAC-3 can be completed or stabilized soon enough to turn-off ARAC-2, then this effort will require 2-3 ARAC-3 developers to drop their efforts and focus on ARAC-2 to ensure the tasks are completed and verified before the boundary.

ARAC-3 Status

Operating systems

Solaris 2.5.1, Digital-UNIX 4.0d, IRIX 6.2

Digital-UNIX $4.0 \mathrm{~d}$ is Y2K-compliant and is installed on the two compute servers. The Solaris 2.5.1. patches will be installed shortly. IRIX 6.2 needs to be evaluated.

Third-party software

All the key software packages need to evaluated.

Core Models (GridGen, ADAPT, LODI, NORAPS, COAMPS)

4-digit dates are used in all cases. Unit testing the Fortran-90 time package used by the models developed in-house (GridGen, ADAPT, LODI) through the critical period has already been completed. NORAPS and COAMPS are developed by the Naval Research Laboratory and so testing and changes to these models will need to coordinated with the Navy and their own $\mathrm{Y} 2 \mathrm{~K}$ plans. 


\section{ARAC-3 Software}

The new software should have no inherent problems with the Y2K problem since 4-digit years are being used throughout.

Other models

KDFOC3 and PREDICT will likely be available more or less as they are in ARAC-2 and so ARAC-2 Y $2 \mathrm{~K}$ upgrades should apply to these codes.

SWS

Since the interface to the SWS through the turn-off of ARAC-2 will be essentially same as the ARAC-2 interface, the ARAC-2 Y2K procedures should validate the SWS for ARAC-3 use, although some exercising of the system from ARAC-3 will be needed.

ARAC-3 Plan

1. Collect a list of all software packages used on the system. The list should prioritized to separate packages that are critical to the functioning of operations and those that are essential for development to proceed rapialy from packages whose failure would be less important. Check with the associated vendors for all the important third-party software packages regarding $Y 2 \mathrm{~K}$ status and make upgrades as suggested. The software evaluation should occur in parallel with the ARAC-2 evaluation and be completed by early June, 1998. Upgrades will be scheduled over the remainder of CY 1998. Estimated effort: $2-3$ weeks

2. After ARAC-2 is appropriately verified on or about January 1, 1999, testing should begin on a stable version of ARAC-3. The details of the timing will depend on the production update schedule, which has not been set a this point. This testing should focus on setting the clocks on the system and using fake data sets that span the critical period. Details of the testing will depend on the state of the various ARAC-3 software at the time and so will have to developed late in CY 1998 when that picture is relatively clear. Estimated effort: 1-2 months

\section{Final testing}

During the beta test period for the last production update before the critical period, a heavy emphasis should be placed on final Y2K testing to uncover any problems that might have crept in during development on either system.

Estimated effort: 1-2 months

Summary

These estimates suggest that for a total effort of about 1 FTE, both ARAC-2 and ARAC-3 can be appropriately verified to handle the Y2K problem. While it is impossible to guess what the difficulties associated with Y2K may be, the possibility of major system failures needs to be taken seriously. This is an opportunity for ARAC to shine assuming it is up and operational in what may be a highly unstable situation, both with respect to technology and regarding those who attach apocalyptic significance to the millenium (and not sensitive to the designation of January 1, 2001 as the real date) and could induce some self-fulfilling prophesy into the mix. This preparedness is maximized by taking reasonable efforts to ensure that all of ARAC's tools, both old and new, are ready to function in this time period. 


\section{ARAC Y2K Plan \\ Systems Operations Team Atmospheric Release Advisory Capability}

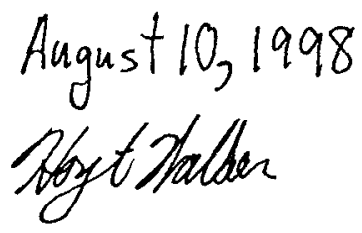

\section{Background}

ARAC is in the process of rebuilding its entire system including the models and all aspects of the system that supports the models. Development of the new system (referred to as ARAC-3 to distinguish it from the current operational system, ARAC-2) began in 1995 and was planned to be ready to supercede ARAC-2 during 1999. A variety of issues (funding deficits, loss of key personnel, etc.) have contributed to some extension of the expected delivery dates. ARAC-3 is being developed to avoid the $\mathrm{Y} 2 \mathrm{~K}$ problem (4-digit years are used in all situations), however, the likcly delay in delivery of a stable, sufficiently complete, operational system until somewhat after Jan. 1, 2000 implies that ARAC-2 must be updated to handle the Y2K problem. As with many legacy systems, full update of the ARAC-2 system to verifiably handle the Y2K problem in all situations would likely be reasonably expensive. However, a careful evaluation of the situation has suggested that a relatively modest expenditure will be able to sufficiently verify the system to the point that ARAC can respond in a timely and credible way (though not necessarily optimal way in the most extreme situations) independent of the status of ARAC-3. Note that an appropriate level of preparation of ARAC-2 does not significantly lessen the need to develop ARAC-3 as quickly as possible. A stable ARAC-3 system is also an important component of ARAC's overall response posture during this period of potentially great instability. Both of these systems should be viewed as backing each other up and ensuring that ARAC will be able to produce the best response possible to whatever situations develop at the time.

\section{Overall Strategy}

Given the transitional nature of the ARAC system during the next two years, planning at all levels must always be cognizant of the status of both ARAC-2 and ARAC-3. The current estimate for the replacement of the ARAC-2 system by ARAC-3 is May 1,2000. Development for this phase of the system is expected to be complete on January 1,2000. Thus, ARAC-3 is a moving target from now through the critical period. To minimize overall expense, such as repeatedly certifying ARAC-3 as it evolves, and to meet the March 1, 1999 deadline defined by the Laboratory's Year 2000 Task Force for mission critical systems, Y2K efforts through the end of calendar year 1998 will focus on preparing $\mathrm{AR} \Lambda \mathrm{C}-2$ so that all primary $\Lambda \mathrm{R} \Lambda \mathrm{C}$ requirements can be met with this system. Early 1999 will focus on verifying that the ARAC-3 infrastructure (e.g., third-party software) and the ARAC-3 software to that point works properly. A final round of testing will be associated with the last production update before January 1, 2000 for each system (expected to occur in August-October, 1999) to ensure that no problems have crept into either system as they have evolved (note that changes to ARAC-2 during 1999 should be very minor).

The following discussion first presents a review of ARAC-2 with respect to the Y2K issues and the plan for updating and testing this system. Similar, though less detailed information for ARAC-3 follows. 


\section{ARAC-2 Y2K Overview}

Operating systems

Appropriate OS patches need to be installed, however it appears that no version upgrades are necessary.

Third-party software

Third party software $\mathrm{Y} 2 \mathrm{~K}$ compliance will require version upgrades in some instances while in other cases patches will be sufficient. Onc kcy package (SmartStar) needs a major plus several minor upgrades and, while the vendor does advertise backward compatibility, some work may be required to update ARAC-2 software as a result of such a change.

\section{Core Models}

The main ARAC-2 models have been previously certified for the AFTAC project. A sliding window mechanism has been used to control the problem, as presently coded the models will break on January 1, 2050. While the processing of observational metdata has been verified, the handling of gridded metdata has not and so additional testing is necded.

Other models

KDFOC3 and PREDICT should be evaluated and corrected as necessary. This is not expected to be particularly difficult.

\section{Model Parameters}

This portion of the system was implemented with four digit years. Problems are expected to be minimal. This part of the system can be considered to include most of the small, relatively static databases as wcll as the questionnaire, which are also expected to suffer from few problems.

\section{Map Projection/GeoData system}

No date dependencies exist other than time-stamping files. No problems are expected.

\section{Metdata systems}

The primary issues are likely to be in the metdata system where numerous time calculations occur. In addition to the necessity of frequent time calculation, most of this software was written in 19831986 and millenial issues were not always considered. Most of the software in this area requires some changes but.the primary difficulty is associated with testing a few specific fucntions. In particular, the asynchronous requesting of metdata from AFWA is would be hard to be tested in a compelling way.

$S W S$

The SWS has had Y2K changes made and unit testing has occurred including setting clocks forward.

\section{ARAC-2 Y2K plan}

The following is a list of suggested tasks and testing strategies and the associated motivations that should position $\mathrm{ARAC}-2$ to function in essentially all normal circumstances during the Y2K period without a major investment in the process.

1. Install $\mathrm{Y} 2 \mathrm{~K}$ patches for all relevant operating systems. In the case of the Solaris systems (the SWS communication front ends), this could coincide with an upgrade to 2.5.1 to minimize the number of OS versions being maintained on the project. Version 7.x of OpenVMS is Y2Kcompliant, however, patches exist for 5.5 and 6.2 and to avoid the possible instability of a major operating upgrade, the cost-effective strategy appears to be to simply install the appropriate patches. Estimated effort: 1-2 days 
2. Collect a list of all software packages used on the system. The list should prioritized to separate packages that are critical to the functioning of operations and those that are essential for development to proceed rapidly from packages whose failure would be less important. Check with the associated vendors for all the important third-party software packages regarding Y2K status and make upgrades as suggested. Estimated effort: 2-3 weeks

3. Work with AFWA to develop an appropriate test data set that straddles the Y2K boundary. This may be easier for AFWA if the format discussed in the next section can be used. This data set would shipped at an agreed upon time as part of testing.

4. Upgrade the receipt of subscription data to handle the newer form of metdata that AFWA would like to distribute (and which they did for a day in February causing major problems with the metdata system here) and then extend the data coverage to as much of the world as the existing X.25/READGWC link can manage. This accomplishes several things but most important is that, to the extent that the world's observational data can be received on subscription, this changes insulates ARAC-2 from any failings of portions of the REQUESTGWC program, which appears to be difficult/expensive/impossible to test in a meaningful way. Kevin points that some testing of ARQs is possible by depositing time in the message and passing back into the system but that SDM cannot be exercised this way. Note that the decoders can be effectively tested using existing methods. While much testing can be done, it is important to note that, since this program manages the requested metdata to/from AFWA, it is potentially sensitive to any problems with time handling at AFWA and in the communications protocols. Full testing of this component would require changing clocks at ARAC and AFWA for a combined test with repeats after any failures were tracked down and corrected. Since both are operational systems this would be difficult to manage. Trying to either clone some portion of the AFWA system for testing or simulating the AFWA-end of the data exchange would require the development of difficult, throw-away software that would be as hard to verify as the software in use. Thus, anything that can be done to minimize the requirement for requesting data lessens the relevance of possible failure of this component. Other merits to completing this project include:

$\ddot{i}$ it insulates ARAC from the status of AFWA's System 1 thus avoiding a possible highpriority distraction from ARAC-3 and other business at an awkward time if in fact System 1 does go out of service on during the next 18-20 months as expected.

$\ddot{i} \quad$ provides a full set observational data for use in testing and sizing ARAC- 3 before the ARAC-3 AFWA connection is developed.

$\ddot{i}$ when the ARAC-3 AFWA connection is developed, a pre-existing ARAC-2 capability can be used to validate the new ARAC-3 capability.

i will develop experience with AFWA on the procedures necessary for timely delivery of the observational data in this mode since some issues raised here, such as the handling of special obs, will need to be addressed in ARAC-3 obs dala delivery. Estimated effort: 4-6 weeks

5. Upgrade the receipt of SWS (VALFORSIT), DDP, IDS and AFWA metdata to handle future metdata. This is likely to involve removing or commenting out an IF-THEN-ELSE test (reasoning by analogy with VALFORSUP which was updated to support handling future met for Cassini) in these programs. Once future metdata can be received and moved into the metdata archive, then testing of key areas such as Create_Problem_Metdata can begin conveniently. Estimated effort: 1-2 days (assuming Kevin has reviewed the software that handles the incoming AFWA, DDP and IDS software) 
6. Correct obvious problems in ARAC-2 system software. Searching for problems should proceed on two paths, 1) brute force searches and 2) moving through key programs (e.g., VALFORSIT, Create_Problem_Metdata, REQUESTGWC) looking for date computations and related processing. These processes should interact. For example, a brute force search through the system for '19' uncovers 18 places where changes obviously need to be made. Examination of Create_Problem_Metdata quickly identifies a time conversion utility that uses individual characters such as ' 1 ' and ' 9 ' to specify a year. A subsequent brute force search through the system for ' 9 ' identifies 6 places where such changes need to be made. While it is not completely obvious that such a strategy can capture essentially all problems, it appears that most of the software was written to use the VMS utilities for time handling which are not (at least with the $\mathrm{Y} 2 \mathrm{~K}$ patches) vulnerable to the $\mathrm{Y} 2 \mathrm{~K}$ problem. Many of the problems indicated above are in the routines that convert various times to and from the standard DEC times and that the actual time arithmetic is done with the DEC utilities. Thus, once the conversion utilities are fixed much of the software is likely to work. Note that searches and changes should be made throughout the system, including REQUESTGWC, obviously to increase the chance that the whole system will work as well try and identify new coding patterns that are associated with failure points that could be the basis for additional search strategies.

Corrections should be made using the sliding window approach. As currently implemented in the ARAC-2 models, this means interpreting years from 50-99 as $19 \mathrm{xx}$ and years from 00- 49 as $20 \mathrm{xx}$. Each of the problems mentioned above requires and IF-THEN-ELSE statement to handle this logic. Thus, the system would break on January 1, 2050 (note that should the software actually survives that long, the various if tests could be updated to push the break point out into the future, e.g., 2060, and so sensible sliding of the window can keep things working indefinitely with the limitation that time is restricted to one century). While limiting in some ways, this approach avoids reengineering ARAC-2 to handle 4-digit dates which would be very expensive with software changes and testing probably running to several FTEs.

Given the ability to get future metdata into the metdata archive, many of these updates can be exercised conveniently. That is, the testing goal, once the obvious changes are made, should be to step through all processes necessary to run the models on this future data set, iterating through the tests until all the main processes beyond the receipt and decoding of the metdata are demonstrably working across the Y2K boundary (and February 29, 2000 for good measure). Estimated cost: 4-8 weeks

1. Verify gridded metdata paths into the system. These present no significant testing difficulties as files are simply pushed to ARAC or pulled from outside organizations with no ARAC communications software involved. Future dates could be faked reasonably easily and reliably and processed into the system and run through the models for testing. Estimated cost: $2-4$ weeks

2. Check Center PCs for BIOS problem (some type of internal clock that will reset to January 1 , 1980 on January 1, 2000; this is found on older PCs and off-brand machines of more recent vintage). Home computers and X-terminals need to checked. Estimated cost: 2-3 day to check, 1-2 weeks to move software off any systems affected and replace with more appropriate systems.

A reasonable goal would be to complete these tasks near the start of FY 99.

1. After coordination with CAPS and any other possible Green Room users, set the clocks on the Green Room system and the CAPS SWS to a time shortly before the Y2K boundary and run 
TAHOES across the boundary using future metdata imported from the Central System. Repeat until the systems really work. Note that this will fully verify the SWS against the Y2K problem, which needs to be done in any case. Estimated cost: 4-6 weeks

The goal for this effort would be to complete it before January, 1999. At this point, ARAC-2 will have been verified to work, given the receipt of metdata. In addition, the receipt of subscription and gridded metdata will have been verified. The vulnerability of REQUESTGWC is finessed by placing it in a backup role. The greater the number of primary data paths, the less critical this weakness is. Thus, backup subscription metdata such as IDS, DDP are important. Also, note that all metdata paths into ARAC-3 can be viewed as providing backup to ARAC-2 since OBSERV.MET files that could be used by MATHEW/ADPIC could be easily generated and automated if this appeared to be an important data path (note that ARAC-2 is a backup to ARAC-3 in the same sense, since all ARAC-2 metdata can be transferred to ARAC-3 automatically). This date is 2-3 months ahead of the Lab's target datc of March, 1999 for completion of all critical changes.

Other issues include extending the coverage of NOGAPS data as far into the future as possible, at least on the ARAC-3 side, to provide ARAC with the ability to respond using gridded data only in the event of total collapse of the various communications and electrical networks (assuming the generators have enough fuel for a few days continuous running). Transferring this data to ARAC-2 is a low cost effort that can be done whenever it is convenient.

Thus, for an estimated effort of 4-6 fte-months a reasonably verified ARAC-2 system can be generated. An advantage of beginning these tasks soon is due to the possibility that the estimates are wildly in error. This is not expected, but if it is in fact the case, it is far better for that to come clear sooner rather than later. Also if this effort is started soon, then it is appropriate for the current ARAC-2 maintenance team to handle most of the effort, with the exception of Kevin's work on the new AFWA format. Thus, while any effort not directly spent on ARAC-3 is to some degree a dilution of that project, the dilution is minimized by beginning soon. If the effort is postponed until it is obvious there is no possibility that ARAC-3 can be completed or stabilized soon enough to turn-off ARAC-2, then this effort will require 2-3 ARAC-3 developers to drop their efforts and focus on ARAC- 2 to ensure the tasks are completed and verified before the boundary.

\section{ARAC-3 Status}

\section{Operating systems}

Solaris 2.5.1, Digital-UNIX 4.0d, IRIX 6.2 Digital-UNIX 4.0d is Y2K-compliant and is installed on the two compute servers. The Solaris 2.5.1. patches will be installed shortly. IRIX 6.2 needs to be evaluated.

\section{Third-party software}

All the key software packages need to evaluated.

Core Models (GridGen, ADAPT, LODI, NORAPS, COAMPS)

4-digit dates are used in all cases. Unit testing the Fortran-90 time package used by the models developed in-house (GridGen, ADAPT, LODI) through the critical period has already been completed. NORAPS and COAMPS are developed by the Naval Research Laboratory and so testing and changes to these models will need to coordinated with the Navy and their own Y2K plans.

ARAC-3 Software 
The new software should have no inherent problems with the $\mathrm{Y} 2 \mathrm{~K}$ problem since 4-digit years are being used throughout.

Other models

KDFOC3 and PREDICT will likely be available more or less as they are in ARAC-2 and so ARAC-2 Y2K upgrades should apply to these codes.

$S W S$

Since the interface to the SWS through the turn-off of ARAC-2 will be essentially same as the ARAC-2 interface, the ARAC-2 Y2K procedures should validate the SWS for ARAC-3 use, although some exercising of the system from ARAC-3 will be needed.

\section{ARAC-3 Plan}

1. Collect a list of all software packages used on the system. The list should prioritized to separate packages that are critical to the functioning of operations and those that are essential for development to proceed rapidly from packages whose failure would be less important. Check with the associated vendors for all the important third-party software packages regarding Y2K status and make upgrades as suggested. The software evaluation should occur in parallel with the ARAC-2 evaluation and be completed by early June, 1998. Upgrades will be scheduled over the remainder of CY 1998. Estimated effort: 2-3 weeks

2. After ARAC-2 is appropriately verified on or about January 1, 1999, testing should begin on a stable version of ARAC-3. The details of the timing will depend on the production update schedule, which has not been set a this point. This testing should focus on setting the clocks on the system and using fake data sets that span the critical period. Details of the testin will depend on the state of the various ARAC-3 software at the time and so will have to developed late in CY 1998 when that picture is relatively clear. Estimated effort: 1-2 months

\section{Final testing}

During the beta test period for the last production update before the critical period, a heavy emphasis should be placed on final $\mathrm{Y} 2 \mathrm{~K}$ testing to uncover any problems that might have crept in during development on either system. The proportion of time spent in final testing between ARAC2 and ARAC-3 should match the expected use in operations for the critical period. Estimated effort: 1-2 months

\section{Summary}

These estimates suggest that for a total effort of about 1 FTE, both ARAC-2 and ARAC-3 can be appropriately verified to handle the $\mathrm{Y} 2 \mathrm{~K}$ problem. While it is impossible to guess what the difficulties associated with Y2K may be, the possibility of major system failures needs to be taken seriously. This is an opportunity for ARAC to shine assuming it is up and operational in what may be a highly unstable situation, both with respect to technology and regarding those who attach apocalyptic significance to the millenium (and not sensitive to the designation of January 1, 2001 as the real date) and could induce some self-fulfilling prophesy into the mix. This preparedness is maximized by taking reasonable efforts to ensure that all of ARAC's tools, both old and new, are ready to function in this time period. 


\section{Appendix 1}

\section{ARAC System Structure and Connectivity}

The following is a description of the salient features of the ARAC-2 central system and its key connections with the outside world. There are currently two versions of the operational ARAC system, the main unclassified system (the Central System) and the classified system maintained in the VTR in B-170. The Classified System is a clone of most of the Central System running on less powerful hardware. A few comments about the Classified System will be made below. In addition, negotiations are on-going to install a clone at the Air Force Weather Agency (AFWA, Offutt AFB) to serve as a backup to the ARAC system. Note that the entire ARAC system is being reengineered to produce a replacement system (ARAC-3) with the intention that the ARAC-2 system be largely out of service before January, 2000. The primary connections between the ARAC system and the external world will be quite similar between the two systems although the particulars of any data transfer are likely to change.

\section{ARAC-2}

\section{System summary}

The key elements of the ARAC-2 system include:

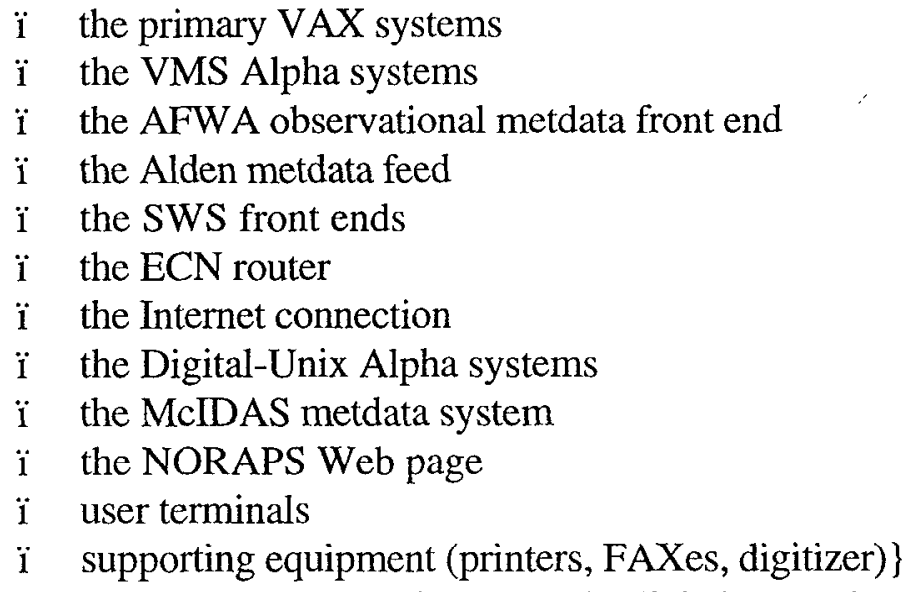

The elements are discussed in more detail below and are represented in the attached system diagram. 


\section{Primary VAX systems}

The majority of ARAC-2 capabilities are implemented on the primary VAX system. The ARAC- 2 central system uses a 2-processor 6620 with $256 \mathrm{Mb}$ of memory (breezy) and a copy of this system (foggy) is used as a backup as well as for development and beta testing. The Classified System utilizes two VAXstations as the primary VAX components.

\section{VMS Alpha systems}

The ARAC-2 system makes use of an Alpha system for a few applications such as gridded metdata degribbing, TAHOE (handsoff exercise) model executions, large model executions and maintenance of the chemical database. The Central System Alphas are server-class machines while the Classified System has a Alpha workstation that fills this role. On both the Central and Classified Systems, the VAX and Alpha components are integrated as VMSClusters.

\section{AFWA observational metdata front end}

Observational meteorological data is a critical component of the ARAC system and AFWA has been the primary source of this data for over 20 years. ARAC-2 relies on a VMS MicroVAX 3200 that serves as a front end for AFWA communications and preliminary routing of messages to/from the Central System processes that ultimately handle them. Note that a backup machine is available although switchover is manual process. The communications are based on the X.25 protocol running over a $56 \mathrm{~Kb}$ leased line between ARAC and AFWA. The X.25 protocol on the front end is mostly handled by a board produced by the Simpact company that is installed on the Q-bus and runs at $19.2 \mathrm{~Kb}$ through Motorola Codex 3512 digital modems. The remainder of the protocol is managed by custom software that runs on the MicroVAX, which also handles the TPTP (Trivial Product Transfer Protocol, an AFWA communications protocol) and then routes messages appropriately.

\section{Alden metdata front end}

Observational metdata, along with meteorological charts, are received from Alden, a commercial distributor of meteorological information, via a satellite link. The satellite dish is connected to one of the microVAX 3200s that can serve as the AFWA metdata front ends and most of the decoding process is similar to that for the AFWA data. U.S. metdata (Domestic Data Plus, DDP) and international metdata (International Data Service, IDS) are both received.

\section{SWS communications front end}

ARAC has about 40 sites that receive committed support from the project. This support includes a dedicated Sun workstation installed at the site that allows the sites to initiate an exercise or a response on the basis of information provided via a questionnaire interface and to receive the products generated by ARAC, along with various other processing and maintenance capabilities. In most cases installation of the operating system and all of the SWS software is handled by ARAC, as much as possible by logging into these systems remotely. Many of these SWS are installed with meteorological towers and metdata is collected and archived by the SWS as well as being available to ARAC directly over telephone lines. These systems are referred to as Site Workstation Systems (SWS). ARAC has a Site Support Team dedicated to dealing with these systems and their users. The majority of the SWS communicate with ARAC via dial-up modems that are part of the installed SWS using PPP as the basic protocol. ARAC receives these communications on one of two 
dedicated front ends. These front ends are Sun 1040 workstations, each with a bank of 12 Telebit 14.4 Kb modems. ARAC maintains two of these systems as part of the Central System. Switching to the backup system is a manual process.

\section{SWS communications via ECN}

DOE NN has developed an Emergency Communications Network (ECN) for use by DOE emergency response resources of which ARAC is one. ARAC SWS communications with DOE SWS, as well as to SWS at other DOE facilities, are handled using the ECN. This network has two hubs, one in Washington, D.C. and the other at the Bechtel Nevada Remote Sensing Laboratory (RSL), that are connected with a T3 line and the various nodes are connected to one of the hubs using a T1 line. A router connects the ECN into the ARAC LAN. This intranet is connected to the Internet in Washington.

\section{Internet connection for receipt of FNMOC and NCEP grids}

ARAC receives NOGAPS grids at both 1.0 and 2.5 degree resolution from FNMOC via the Internet. FNMOC pushes the files to ARAC using ftp in GRIB format. The files initially arrive on a Digital-UNIX Alpha and scripts transfer the files to a cross-mounted disk that the VMS Alpha can see (the Digital-UNIX Alpha is part of the ARAC-3 system, the prognostic modeling component of which requires a much larger number of fields than are needed for ARAC-2 and so the data are brought into the ARAC-3 system and then transferred to ARAC-2). A process wakes up on a regular basis and checks the directory and when complete sets of files are available initiates the degribbing process, producing files that can be read by the ARAC-2 models. ARAC can call FNMOC to redeliver all or part of the data set for a watch if data was missed for any reason. The current connectivity between FNMOC and ARAC is via DREN and ESNET bridging at Moffett. Grids from models at the National Center for Environmental Prediction (NCEP) are pulled via ftp over the Internet although these grids are not normally used by ARAC- 2 .

\section{McIDAS metdata system}

ARAC receives various meteorological data from Unidata (part of the University Consortium for Atmospheric Research focused on providing access to atmospheric data, primarily for research purposes) in a specialized format over the Internet using specialized protocols. These are used by the McIDAS (Man computer Interactive Data Access System) program primarily to support the ARAC weather briefings and general atmospheric analysis, particularly in the area of satellite images. These data are also used by the GEMPAK atmospheric data visualization program (also from Unidata) for model development use. The capabilities are not directly linked to the operational ARAC environment at this time. In cooperation with Unidata, ARAC has been designated as a backup data distribution node for the McIDAS data to a small number of universities in the area.

\section{ARAC Prognostic Model Web data}

$\Lambda \mathrm{R} \Lambda \mathrm{C}$ contributes to the Laboratory's Weather Page (http://www-erd.llnl.gov/metdat/) both with information about ARAC and it's models as well as by presenting the results of the twice daily weather forecast from ARAC's prognostic model (currently NORAPS with a transition to COAMPS in progress; these models are weather prediction models developed by the Navy and run operationally at FNMOC). Displays of the model results are converted to gif files and written to a disk that is cross-mounted to croce.llnl.gov where they can be reached from the Web page. The $\mathrm{html}$ files for the textual information are maintained in the same place. 


\section{User terminals}

ARAC assessment meteorologists and software developers generally access the system using NCD $\mathrm{X}$-terminals. These terminals can boot off of most of the main machines in the system, although performance considerations have caused most users to rely on the VMS Alphas as a boot hosts. Assessors also have NCDs at home and have ISDN lines installed so they can logon to the system to initiate responses off-hours. These lines enter the system via Open LabNet pool and passed to the ARAC subnet and are viewed as trusted communications. There is an analog modem pool (Shiva Directorate - LANRover) available modem access. An "800" number is also available for modem connections. Other remote terminals can access the system via the Internet. ARAC is taking advantage of the recently implemented El\&ES OPIE server (on the 57 subnet) to provide one-time password support for users logging in from insecure environments. ssh is being installed for trusted users (e.g., system administrators) logging in over the network from home over insecure lines. System administrators use Timbuktu to monitoring system status from remote clients.

\section{FAXes}

FAXes often play a role in ARAC's responses, occasionally for distributing products, but more commonly for other ancillary communication with customers and headquarters associated with a response. ARAC also has a VAX-to-FAX where products are sent directly from the primary VAX to the FAX.

\section{ARAC-3}

To provide a basis for longer term evaluation of ARAC connectivity a brief description of ARAC-3 is provided.

In 18-24 months, the ARAC-2 system will be retired and replaced with a completely new system, ARAC-3. Key components of the new modeling capabilities include new diagnostic and dispersion models utilizing a continuous terrain representation and variable vertical and horizontal gridding. The new models are written in Fortran-90. A prognostic modeling capability is being added by importing the Navy's NORAPS and COAMPS models. The new system is a distributed, client/server architecture with $\mathrm{C}++$ servers and Java user interface clients. The CORBA standard is being used as the basis for integrating this distributed system. An object- oriented database is being used to implement object persistence in most cases.

ARAC-3 is designed to be platform independent, however a variety of issues have motivated the development of an architecture that is likely to remain stable for at least the next 2-3 years. The models are being run on Digital Unix Alphas (2 6-processor $625 \mathrm{MHz}$ systems) with a shared StorageWorks network file system that form a TruCluster. The majority of the ARAC-3 services currently run on one of two UltraSparc servers, which will be connected with another network file system in a cluster arrangement soon. Desktop platforms for user interface clients have not been finalized, however, PCs running Windows NT and enhanced with OpenGL graphics boards are being evaluated for this role.

Regarding observational metdata delivery from AFWA, ARAC-3 will move away from the X.25 basis for data exchange and rely on Internet-style communications instead. For example, delivery of metdata as one or more files using ftp is an attractive possibility. AFWA is currently servicing some 
of their customers using this mechanism and appear to be enthusiastic about proceeding in this direction. The primary issue in this area is network connectivity between AFWA and ARAC. Five possibilities have been considered at this point:

$\ddot{i}$ the Internet, which is attractive because of its convenience but is vulnerable to gateway failures and, perhaps more significantly, to saturation during periods of crisis.

i the ECN, which is needed for the future AFWA ARAC backup system.

i continued use of the leased line with ftp/ppp rather than X.25. litemm

i the NIPRNet (the military's Non-secure Internet Protocol Routing Network) is an intranet used by the military. It has a controlled connection to the Internet.

i the ATM network that connects AFWA, FNMOC and NCEP. This network is attractive because it would provide connections with three organizations that are of critical interest to ARAC. The current network (HAWCNET) This network is expected to be replaced by a higher speed network (DISANET) in mid-1999. It is unclear when political issues will be sorted out allowing ARAC onto this network but it would be very convenient to gain access.

A satellite connection to NOAA observational and gridded metdata (NOAAPort) is being considered for ARAC-3. Future ARAC clients are expected to be supported via Web-technology interface with initial development to begin shortly. lend 


\section{Appendix 2}

\section{ARAC Support Software Y2K Status}

ARAC-3 software (preliminary list; note that some of these packages and operating system versions should be out of service well before $1 / 1 / 2000$ )

Table 1: ARAC-2 Central System

\begin{tabular}{|l|l|l|l}
\hline \multicolumn{1}{|c|}{ Software } & Version(s) & Y2K status & ARAC status \\
\hline \hline VMS & 5.5 & updates required & \\
& 6.2 & & \\
\hline Solaris & 2.3 & updates required & \\
\hline Unidata NetCDF & 2.4 .3 & & \\
\hline B2 Systems SmartStar/Ideo & & updates required & \\
\hline PV-Wave & & & \\
\hline BuilderXcessary & & & \\
\hline Motif & 2.4 .3 & & \\
\hline Process Software MultiNet & 2.5 .1 & & updates installed \\
\hline Hierarchical Storage Operating & 3.5 & updates required & \\
Firmware & & & \\
\hline GrayMatter Script Server & 5.0 .2 & & \\
\hline Raxco RaxMaster & 5.1 & & \\
\hline
\end{tabular}

Table 1: SWS

\begin{tabular}{|l|l|l|l}
\hline \multicolumn{1}{|c|}{ Software } & Version(s) & Y2K status & ARAC status \\
\hline \hline Solaris & 2.3 & updates required & updates in progress \\
& 2.5 .1 & & \\
\hline Motif & 2.4 .3 & & \\
& 2.5 .1 & & \\
\hline ppp & 2.0 & & \\
\hline Handar Meteorological Firmware & & & \\
\hline GhostScript/GhostView & & & \\
\hline
\end{tabular}

Table 1: ARAC-3

\begin{tabular}{|l|l|l|l}
\hline \multicolumn{1}{|c|}{ Software } & \multicolumn{1}{c|}{ Version(s) } & \multicolumn{1}{c}{ Y2K status } & \multicolumn{1}{c}{ ARAC status } \\
\hline \hline Solaris & 2.5 .1 & updates required & \\
\hline Digital Unix 4.0d & $4.0 \mathrm{~d}$ & complient & complient \\
\hline
\end{tabular}




\begin{tabular}{|l|l|l|l}
\hline irix & 2.6 & & \\
\hline IONA Orbix & 2.2 & & \\
\hline IONA OrbixOTM & 2.3 & & \\
\hline IONA OrbixWeb & & & \\
\hline ObjectDesign ObjectStore & & & \\
\hline Rational ClearCase & & & \\
\hline IDK & 1.1 .6 & & \\
\hline Swing & 1.0 .1 & & \\
\hline BONGO & 1.1 & & \\
\hline Edinburgh Portable Compilers & 2.5 .1 .3 -sgi & & \\
\hline Fortran 90 & $2.5 .1 .3-D U$ & & \\
\hline USGS proj package & $2.5 .1 .3-$ Sol & & \\
\hline ObjectSpace & 4.3 .2 & & \\
\hline RogueWave Tools.h & 4.2 & & \\
\hline Unidata NetCDF & & & \\
\hline NRL/FNMOC COAMPS/ & 2.4 .2 & & \\
\hline NORAPS & 3.4 & & \\
\hline IDL & 4.0 & & \\
\hline PV-Wave & 5.0 & & \\
\hline Unidata McIDAS & & & \\
\hline Unidata GEMPAK & & & \\
\hline VIS5D & & & \\
\hline ssh & & & \\
\hline tcp wrappers & & & \\
\hline ftp wrappers (wu_ftp) & & & \\
\hline Hierarchical Storage Operating & 7.0 & & \\
Firmware & & & \\
\hline gzip/gunzip & & & \\
\hline GhostScript/GhostVicw & & & \\
\hline PhaserPrint & & & \\
\hline NewsPrint & & & \\
\hline JetAdmin & & & \\
\hline Networker 4.2 & & & \\
\hline SunNet Manager & & \\
\hline Niles ACC router & & \\
\hline
\end{tabular}




\section{MEMORANDUM FOR SEE DISTRIBUTION LIST}

FROM: ÄFWA/CC

106 Peacekeeper Dr STE 2N3

Offut AFB NE $68113-4039$

SUBJECT: Year 2000 Transition

1. Many US government agencies need documentation for their Year 2000 efforts. In order to help the users of AFWA data transmitted from Offutt AFB and Tinker AFB, I am providing this memo in lieu of Memoranda of Agreement. You may use this memo in your documentation of Year 2000 preparations.

2. AFWA's intention is to continue with already agreed-upon formats. Where we currently exchange a two-digit year, we intend to transmit 99 meaning 1999, and transmil 00 meaning 2000. We intend to follow the WMO agreement briefed to us by Mr. Diamond of NWS: the Year 2000 will be encoded in GRIB and BUFR as century 20 and year 100; while the 'Year 2001 will be encoded as century 21 and year 1 . We acknowledge that the Year 2000 is a leap year.

3. My action officer for this program is Capt Charles E. Kaiser, AFWAJSCS-Y2K, DSN 271-1390. Please contact him if you have any questions.

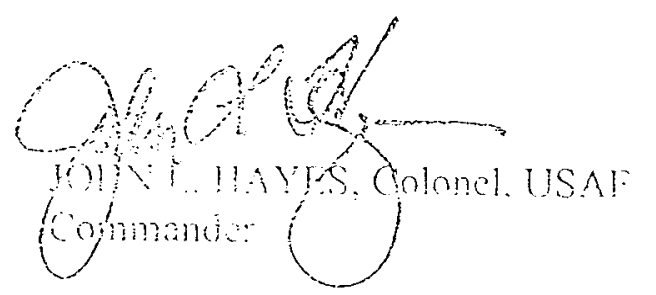





\section{DEPARTMENT OF THE NAVY}

FLEET NUMERICAL METEOROLOGY AND OCEANOGRAPHY CENTER

7 GHACE HOPPER AVE

MONTEREY. CA 93943.5501
IN REPLY REFER TO:

5230

Sex $006 \mathrm{TK} / 333$

15 Sep 98

From: Commanding Officer, Fleet Numerical Meteorology and Oceanography Center $\because \cdots$

Subj: Y2K STATUS OF DISTRIBUTED GRIB DATA PRODUCTS

1. Fleet Numerical Meteorology and Oceanography Center has performed a thorough $\mathrm{Y} 2 \mathrm{~K}$ assessment on the GRIB products for internal and external interfaces. You have been identified as an external recipient of GRIB products scnt from Flcet Numerical.

2. GRIB is compliant for the ycar 2000 criteria following the WMO standards for GRIB data format exchange. This is defined as containing a four (4) digit year whereas octet 13 contains the year 100 and octet 20 contains the century 20.

3. We will continue correspondence and personal contacts as necessary to coordinate actions or verify status for any fleet Numerical GRIB output/input interfaces. Please provide any comments/concerns you may have in regard to $Y 2 \mathrm{~K}$ issues.

4. Our point of contact is Tom Knopp, Comm (831) 656-4367, DSN 878-4367, email knoppt@fnmoc.navy.mil.

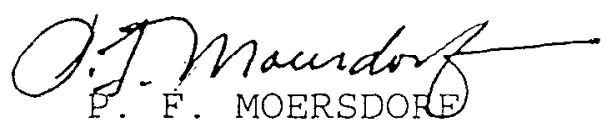

l'echnical Director

Distribution:

SRA

USCG-Martinsburg WV

NWS-Monterey

NRI Monterey-MEL

AFWA

NCEP - OSO

NWS Salt lake City IQ's

Lawrence Livermore National iaboratory

National Hurricane Center

DSWA/WELE 
From: SMTP\%"whiealden.com" 13-APR-1999 18:26:17.05

TO: HWALKER

$\mathrm{CC}:$

Subj: Re: Requesting a copy of the $\mathrm{y}^{2 \mathrm{k}}$ letter you sent me back in Jan.

Message-Id: <199904131826. OAA18882@alden. com>

From: "William H. Highlands" <whhealden. Com>

To: "Ed Bush" <edbushellnl.gov>

Cc: <hwalker@chinook.1lnl.gov>, <walker7@llnl.gov>, <whh@alden.com>

Subject: Re: Requesting a copy of the $\mathrm{y} 2 \mathrm{k}$ letter you sent me back in Jan. Date: Tue, 13 Apr 1999 14:25:37 -0400

X-MSMail-Priority: Normal

$\mathrm{X}$-Priority: 3

X-Mailer: Microsoft Internet Mail 4.70.1161

MIME-Version: 1.0

Content-Type: text/plain; charset=ISO-8859-1

Content-Transfer-Encoding: $7 \mathrm{bit}$

$\mathrm{Hi} \mathrm{Ed}$,

In response to your inquiry, the $\mathrm{M} 2000 \mathrm{~A}$ and $\mathrm{M} 2000 \mathrm{X}$ are year 2000 compliant.

The data streams of Dt, IDS and DiFax are produced by the NWS and they have not certified them as being Year 2000 compliant. When they do certify these data streams, we will display this information on our homepage.

William H. Highlands

Alden Electronics, Inc.

Vice President Operations

5083668851 ext2408 phone

5083663898 Fax

40 Washington St. Westborough, MA 01581

email:highlandswalden.com 



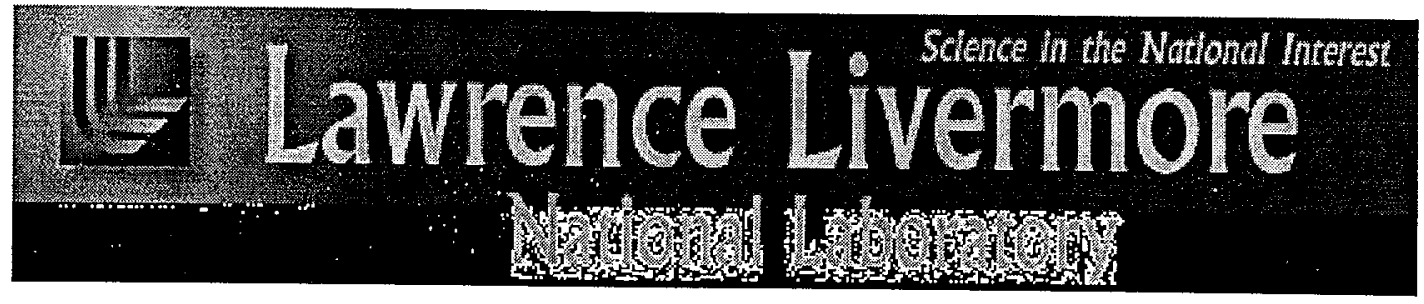

\title{
ATMOSPHERIC RELEASE ADVISORY CAPABILITY
}

\author{
YEAR 2000 \\ Guidelines AND TeSt Plan
}




\section{ARAC YEAR 2000 PLAN}

\section{Foreword}

It is recognized that some testing for detecting y ear $2000(\mathrm{Y} 2 \mathrm{~K})$ problems or for verify ing $\mathrm{Y} 2 \mathrm{~K}$ compliance is necessary. The ARAC Y2K Test Plan has been integrated with guidelines based on a template from the Savannah River Office and received from Ted Michels to provide an appropriate context and terminology for the Test Plan. The guidelines assist in developing test plans by identify ing significant issues to be considered in the test plan.

In general, compliance methods used for determining Year 2000 compliance will vary becausc of sy stem or facility constraints. These constraints include varying levels of funding, resources, priority, system availability, and management prerogative. In addition, a variety of system specific constraints will also influence the testing process. While the following guidelines provide some indication of good practice concerning testing and test plaming, the full range of formal tests may not be appropriate because of the constraints defined above. As a consequence, other methods will be used to determine compliance.

Because full certification testing of the current operational ARAC (ARAC-2) system and the next generation sy stem (ARAC-3) would be cost prohibitive, a measured response to the problem is necessary. This measured response includes making changes to ARAC-2 in light of the experience base that exists with that system, substantial but focused testing of this sy stem along with comparable testing of ARAC-3. Since a critical portions of both systems are vendor provided, reliance on vendor compliance certification (or vendor compliance confirmation) is important but must be sup plemented by in-house testing. 



\section{TABLE OF CONTENTS}

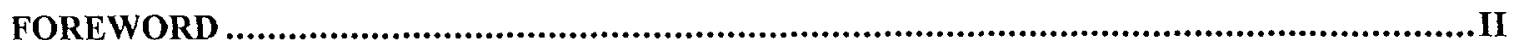

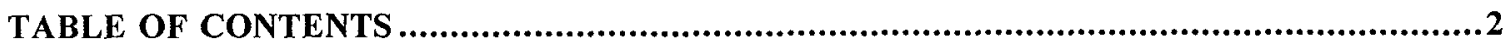

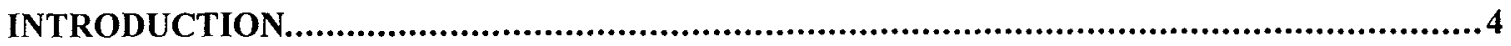

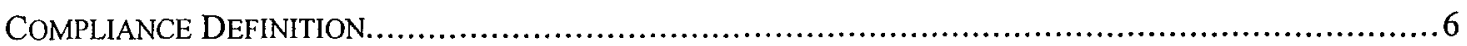

COMPLIANCE RULES

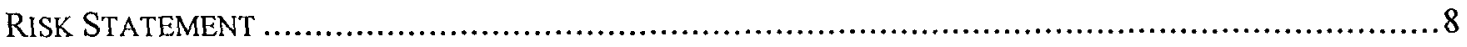

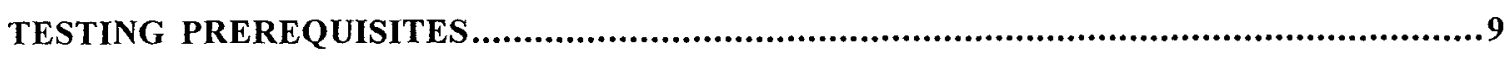

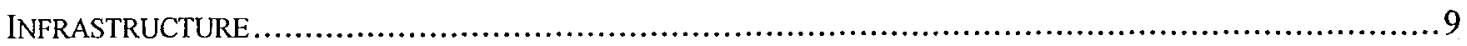

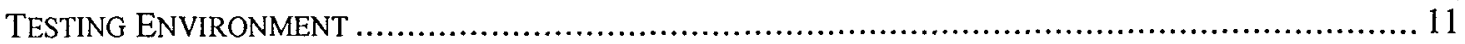

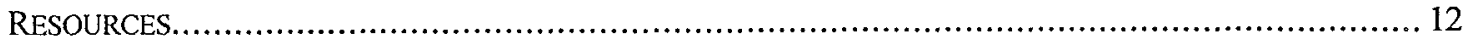

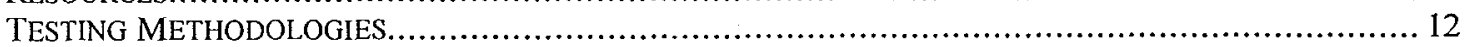

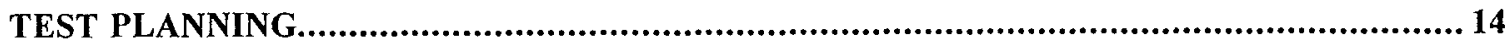

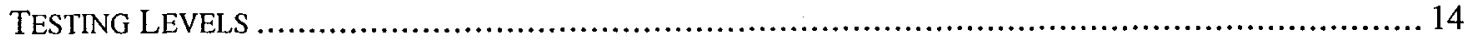

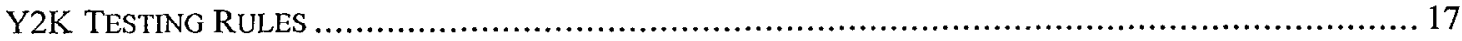

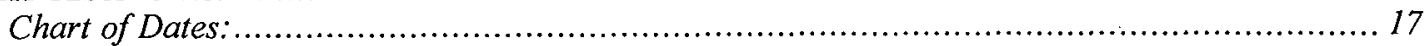

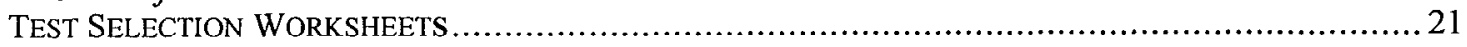

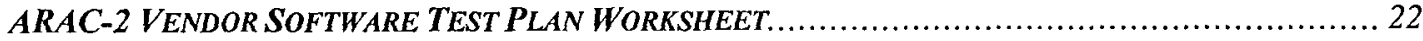

ARAC-SWS VENDOR SOFTWARE TEST PLAN WORKSHEETT ......................................... 24

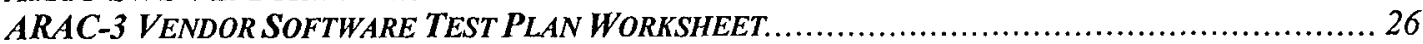

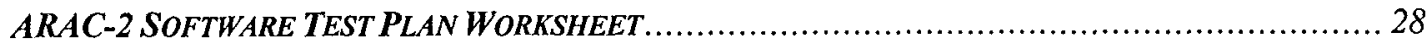

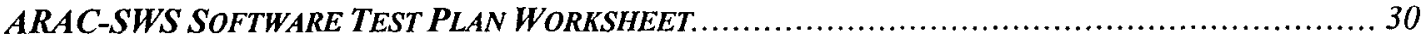

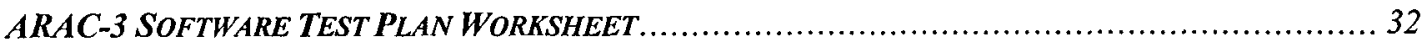

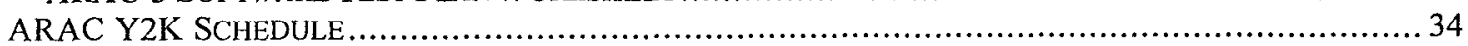

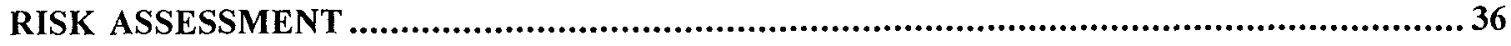

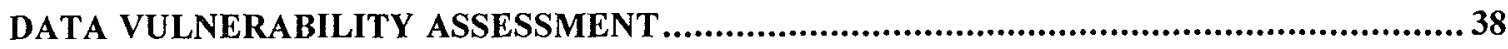

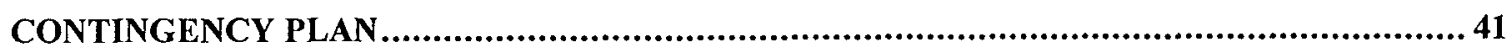

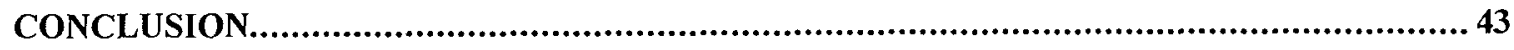

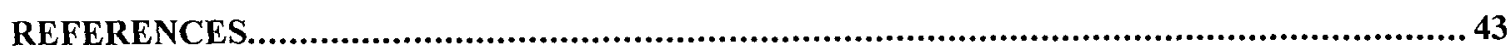

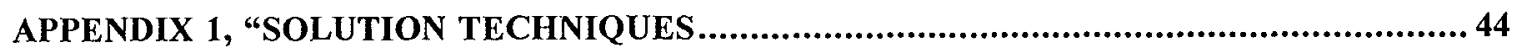

APPENDIX 2, “ADDITIONAL TESTING CONSIDERATIONS .......................................... 45 


\section{ARAC YEAR 2000 PLAN}

\section{Introduction}

The Atmospheric Release Advisory Capability (ARAC) at Lawrence Livermore National Laboratory (LLNL) provides timely and credible estimates of the transport of hazardous material in the atmosphere as an emergency response resource to the Department of Energy and others. ARAC uses computer models, data acquisition, archiving and analysis systems along with highly trained personnel to provide this service. Given the reliance on computer technology inherent in the ARAC system, the $\mathrm{Y} 2 \mathrm{~K}$ issue is of significant concern to the program. This concern is highlighted by ARAC's designation as one of LLNL's mission critical systems. To interpret the following test plan appropriately, some background regarding ARAC's current status is necessary and is provided in the next few paragraphs.

ARAC is in the process of rebuilding its entire system including the atmospheric models and all aspects of the system that supports the models. Development of the new system (referred to as ARAC-3 to distinguish it from the current opcrational system, ARAC-2) began in 1995 and was planned to be ready to supersede ARAC-2 during 1999. A variety of issues (funding deficits, loss of key personnel, etc.) have contributed to some extension of the expected delivery dates. ARAC-3 is being developed to avoid the Y2K problem (4-digit years are used in all situations), however, the likely delay in delivery of a stable, sufficiently complete, operational system until somewhat after Jan. 1, 2000 implies that ARAC-2 must be updated to handle the Y2K problem. As with many legacy systems, full update of the ARAC-2 system to verifiably handle the Y2K problem in all situations would likely be reasonably expensive. However, a careful evaluation of the situation has suggested that a relatively modest expenditure will be able to sufficiently verify the system to the point that ARAC can respond in a timely and credible way (though not necessarily optimal way in certain very unusual situations) independent of the status of the ARAC-3 development effort. However, a stable ARAC-3 system is also an important component of ARAC's overall response posture during this period of potential instability. Both of these systems should be viewed as backing each other up and ensuring that $\triangle R A C$ will be able to produce the best response possible to whatever situations develop at the time.

Given the transitional nature of the ARAC system during the next two years, planning at all levels must always be cognizant of the status of both ARAC-2 and ARAC-3. The current estimate for the replacement of the ARAC-2 system by ARAC-3 is May 1, 2000. Development for this phase of the system is expected to be complete on January 1, 2000. Thus, ARAC-3 is a moving target from now through the critical period. To minimize overall expense, such as repeatedly certifying ARAC-3 as it evolves, and to meet the March 1, 1999 deadline defined by the Laboratory's Year 2000 Task Force for mission critical systems, Y2K efforts through the end of calendar year 1998 will focus on preparing ARAC-2 so that all primary ARAC requirements can be met with this system. Early 1999 will focus on verifying that the ARAC-3 infrastructure 


\section{ARAC YEAR 2000 PLAN}

(e.g., third-party software) and the ARAC-3 software to that point works properly. A final round of testing will be associated with the last production update before January 1, 2000 for each system (expected to occur in August-October, 1999) to ensure that no problems have crept into either system as they have evolved (note that changes to ARAC-2 during 1999 should be very minor).

The following sections include guidelines for testing the various elements associated with year 2000 compliance (also sometimes known as century or millennium conformity). They provide a definition of Year 2000 (Y2K) compliance, a risk statement associated to Y2K testing, testing prerequisites, test planning, and the requirements that must be satisfied for equipment and products using dates and times. The guidelines are supplemented with comments that are specifically relevant to the ARAC test plan.

Problems can arise from some means of representing dates in computer equipment, products and date-logic embedded goods or services, as the year 2000 approaches, during, and even after that year. As a result, equipment or products, including embedded control logic, may completely fail, malfunction or cause data to be corrupted or misinterpreted. Since there are a substantial number of packages that are part of the ARAC system along with the embedded systems in ARACrelated meteorological measurement systems, ARAC is potentially vulnerable in these areas. To avoid such problems, organizations must check, and modify if necessary, internally produced equipment and products and similarly check externally supplied equipment and products with their suppliers. A significant portion of ARAC's Y2K effort will be in this area. Where checks are made with external suppliers, care should be taken to distinguish between claims of compliance and the ability to demonstrate compliance. The guidelines that are introduced below can be used to communicate the compliance definitions and rules with the suppliers.

After the various guidelines are introduced and discussed in the context of the ARAC program, various details the ARAC Y2K Test Plan will be presented, largely in tabular form. 


\section{ARAC YEAR 2000 PLAN}

\section{Compliance Definition}

The following compliance definition is based on DISC PD2000-1, A Definition of Year 2000 Conformity Requirements, a document produced by the British Standards Institution.

Simply stated, Year 2000 compliance shall mean that neither performance nor functionality is affected by dates prior to, during, and after the year 2000. In particular the following rules must be satisfied:

- Rule 1 No value for current date will cause any interruption in operation. (General Integrity)

- $\quad$ Rule 2 Date-based functionality must behave consistently for dates prior to, during and after year 2000. (Date Integrity and Leap Year Integrity)

- $\quad$ Rule 3 In all interfaces and data storage, the century in any date must be specificd either explicitly or by unambiguous algorithms or inference rules. (Century Integrity)

\section{Compliance Rules}

This section describes the compliance definition rules further to provide the reader and test planner a better understanding of each rule.

Rule 1: No value for current date will cause any interruption in operation.

1.1: This rule is known as general integrity (see $\mathbf{R} 1.1$ - Chart of Dates).

1.2: If this requirement is satisfied, roll-over between all significant time demarcations (e.g. days, months, years, and centuries) will be performed correctly.

1.3: Current date means today's date as known to the equipment or product.

- $\quad$ Rule 2: Date-based functionality must behave consistently for dates prior to, during and after year 2000 .

2.1: This rule is sometimes known as date integrity.

2.2: This rule means that all equipment and products must calculate, manipulate and represent dates correctly for the purposes for which they were intended. For ARAC purposes, rule 2.2 will include Leap Year Integrity testing.

2.3: The meaning of functionality includes both processes and the results of 


\section{ARAC YEAR 2000 PLAN}

those processes.

2.4: If desired, a reference point for date values and calculations may be added by organizations; e.g. as defined by the Gregorian calendar.

2.5: No equipment or product shall use particular date values for special meanings; e.g. "99" to signify "no end value" or "end of file" or "00" to mean "not applicable" or "beginning of file".

Rule 3:In all interfaces and data storage, the century in any date must be specified either explicitly or by unambiguous algorithms or inference rules.

3.1: This rule is sometimes known as explicit/implicit century.

3.2: It covers two general approaches:

(a) Explicit representation of the year in dates: e.g. by using four digits or by including a century indicator. In this case, a reference may be inserted (e.g. 4-digit years as allowed by ISO standard 8601:1988) and it may be necessary to allow for exceptions where domain-specific standards (e.g. standards relating to Electronic Data Interchange) should have precedence.

(b) The use of inference rules: e.g. two-digit years with a value greater than 50 imply $19 \mathrm{xx}$, those with a value equal to or less than 50 imply 20xx. Rules for century inference as a whole must apply to all contexts in which the date is used, although different inference rules may apply to different date sets.

For Rules 1 and 2 in particular, organizations may wish to specify allowable ranges for values of current date and dates to be manipulated (i.e. "windowing"). The ranges may relate to one or more of the feasible life-span of equipment or products or the span of dates required to be represented by the organization's business processes. Tests for critical dates may also be added (e.g. for leap years, end of year, etc.). Organizations may wish to append additional tests in support of system specific requirements. Where the term century is used, clear distinction should be made between the "value" denoting the century (e.g. 20th) and its representation in dates (e.g. 19xx); similarly, 21st and 20xx. 


\section{ARAC YEAR 2000 PLAN}

\section{Risk Statement}

Risk and risk management is an integral part of $\mathrm{Y} 2 \mathrm{~K}$ testing. If testing is conducted and documented, it will provide proof of the correct handling of $\mathrm{Y} 2 \mathrm{~K}$ problems or provide an avenue to correct or minimize potential failures required for due diligence. While every effort should be made to accomplish this, resources and funding availability may influence the level of risk a program is willing to assume. In the case of personnel or funding resource restrictions (which may imply lessened priority) testing will likely become less critical. As a direct result, risks associated with system failure must be accepted and do not guarantee that minimization of risk will be achieved.

One or more of the following can minimize some level of risk:

Written or verbal compliance statement from the vendor

Documented code review

Documented risk impact statements

Stated "workarounds"

Vendor certification

Informal system level test

Formal testing

$A R A C$ risk statement: The level of funding being provided to the ARAC Program has fallen short of the plan that was in place with DOE with the initiation of the $\triangle R A C-3$ development effort. As a consequence, the ARAC-3 effort will not be sufficiently complete to turn off ARAC-2 before the turn of the millennium and the division of ARAC's efforts between the two systems will continue into the first two quarters of CY 2000. This division of effort is reflected in the ARAC Y2K Plan. Some risk is inevitable due to the cost of a complcte ccrtification of ARAC-2, particularly regarding certain datagathering functions. However, these risks are minimized both by informed strategies regarding ARAC-2 capabilities and the fact that ARAC-3 will be a reasonably complete, nearly operational system that can serve as important backup to ARAC-2. For example, the ARAC-3 system will include a number of additional data paths that are distinct from those in ARAC-2 with at least partly independent failure modes. Given the cross-links implemented between these systems in the course of the development of ARAC-3, these system will back each other up in a variety of ways. Thus the program will accept something less than an ideal testing plan (e.g., foregoing a fully independent testing program) due to limitations in funding and the need to continue to progress as rapidly as possible with the completion of ARAC-3 while maintaining the operational readiness of the ARAC-2 system. Note that the ARAC Y2K strategy will use aspects of all seven points listed above. 


\section{ARAC YEAR 2000 PLAN}

\section{Testing Prerequisites}

This section provides considerations to be made prior to conducting any testing. These are based on "good practices" that have been used industry wide and provide at a minimum some of the groundwork necessary to ensure good results. In addition, this section provides the minimum resource requirements and various testing methodologies.

Before an application's year 2000 conversion starts, two tasks (verification of the infrastructure and establishment of a test environment, further described below) are performed to set the stage for a successful conversion. These same two tasks are performed many times throughout the entire $\mathrm{Y} 2 \mathrm{~K}$ conversion effort, but performed only once for each application.

\section{Infrastructure}

- Task one: Verify that the infrastructure for the year 2000 conversion of the system in question is $\mathrm{Y} 2 \mathrm{~K}$ compliant. These infrastructure categories include:

- Host systems: Desktop computers, mainframes, machines, equipment, networks, etc.

- Development and productivity tools: Language compilers, language pre-compilers, language interpreters, integrated development environments (IDE), CASE tools, form generators, report writers, job schedulers, etc.

- Database engines: These involve any SQL data servers (relational database management systems) or object servers (object-oriented database management systems).

- Vendor software: This involves software components that are only a part of the application, but are vendor supplied, and will not be subject to year 2000 conversion (e.g., class libraries, frameworks, tool kits, etc.)

Should any part of the infrastructure for a system not be Y2K compliant, it is highly recommended that the impacted portion of the testing be put on hold until such time as it can be made compliant. In practice, this contingency can be revisited, and different plans can be developed on a case-by-case basis. 


\section{ARAC YEAR 2000 PLAN}

ARAC-specific comments: It is the responsibility of the Lead Administrator for Production Systems (Ed Bush) to verify the ARAC-2 infrastructure by contacting the vendors for the components listed above regarding their $\mathrm{Y} 2 \mathrm{~K}$ status and arranging the necessary upgrades. It is the responsibility of the Lead Administrator for Development Systems (Gary Berry) to verify the ARAC-3 infrastructure by contacting the vendors for the components listed above regarding their $\mathrm{Y} 2 \mathrm{~K}$ status and arranging the necessary upgrades. 


\section{ARAC YEAR 2000 PLAN}

\section{Testing Environment}

- Task two: Minimize the amount of assumed risk for Y2K compliance and establish some form of testing environment for the given system. Establishment of a testing environment should appropriately address the following concerns:

- Data contamination (e.g., the intermingling of production data vs. test data)

- System failure (e.g., the system becomes inoperable)

- Licensing (e.g., expiration and additional procurements and maintenance of licenses)

- Production interruption (e.g., scheduling of operational testing, etc.)

- System and/or data back up (e.g., loss of data and system recovery)

ARAC-specific comments: The ARAC Program will utilize its current resources to provide the test environments for the $\mathrm{Y} 2 \mathrm{~K}$ effort. In addition, standard ARAC software quality assurance procedures will be followed as part of the testing infrastructure. Due to the details of how much of the time-dependent data is handled in the ARAC system, significant portions of the testing can be completed in the Central System Beta environment without risk of compromising either the Beta or the Production environments. For example, much of the ARAC system software devoted to handling meteorological data is a function of reported measurement time of the data, but not of the current time. Since the ARAC system handles future meteorological data as an operational capability, synthetic datasets that span the critical time demarcations can be generated and entered into the Beta metdata archive. The software that extracts and utilizes this data can be exercised and when the testing is complete the synthetic files can be removed thereby safely returning the system to a normal state. For testing requiring the setting of the system clocks, the ARAC green room systems will be used since these have carefully managed external connections, standard procedures for purging the data disks and a less formal requirement for $24 \mathrm{hr} /$ day availability. The ARAC Multi-User System will be used for general testing of the system and the CAPSNET Multi-User System will then be used to exercise the Central System interactions with the CAPSNET Site Workstation System (SWS). Testing involving the CAPSNET systems will be coordinated with the CAPS program. The network connection between the CAPSNET SWS and the rest of the CAPS systems will be disconnected to avoid the possibility of contaminating their system with any test data. 


\section{ARAC YEAR 2000 PLAN}

\section{Resources}

ARAC is devoting a significant portion of one computer scientist along with lesser contributions by five other computer scientists, along with a significant portion of a senior system administrator and lesser contributions by another system administrator to the $\Lambda \mathrm{R} \Lambda \mathrm{C}-2$ testing plan. Fewer resources are expected to needed for ARAC- 3 tosting. ARAC assessors, in particular the designated Beta testers will play key roles in the more complete system tests in addition to their normal role in acceptance testing. These various individuals are responsible for developing the Project Plan, Project Schedule, Test Plan Guidelines, Detailed Test Plans, and coordinating the testing.

The following roles have been assigned for the ARAC-2 effort:

- Project Lead - Hoyt Walker (Systems Operations Team Leader)

- ARAC-2 software conversion - Gordon Duckworth, Richard Yamauchi, Vicky Weseloh

- Metdata decoding conversion and testing - Kevin Foster

- General ARAC-2 consulting - Diane Bonner

- External software - Ed Bush

- General system administration - Leon Richardson

- Beta Testers - Fernando Aluzzi, Phil Vogt

The following roles have been tentatively been assigned for the ARAC-3 effort:

- Project Lead - Hoyt Walker

- Metdata test strategy - Bob Shectman

- External software and system administration - Gary Berry

- Beta Testers - Connee Foster, Brenda Pobanz

\section{Testing Methodologies}

Testing can be accomplished by using one or a combination of the following methods:

- Have the developers run thorough tests, manually saving the results (before and after images). A team of end users and independent personnel then reviews the results. This is a very people-intensive option and requires the developers to have a deep understanding of the functional behavior of the application.

- Put together an independent team to test and evaluate all results. This is also a very people-intensive option.

- Develop test scripts using the development tools' macro or script writing capabilities. This is an expensive programming effort and requires modifications by the developer every time the application is changed.

- Perform a sample test. Experimentation is on a limited number of test cases. This is a less rigorous approach, but should contain some form of documentation to show the 


\section{ARAC YEAR 2000 PLAN}

results.

- Have an external independent organization perform testing.

The purpose of testing is to address risk as described in section 1, "Risk Statement". The process, measurable and repeatable techniques, tools, and sequences of tests are designed to minimize risks. An important testing principle is that testing should be staged (different types of testing) and layered (different levels of complexity at each stage). Testing at each stage addresses different concerns. Testing in each layer builds on the confidence gained in previous layers.

ARAC-specific comments: Testing of the ARAC system with respect to the $\mathrm{Y} 2 \mathrm{~K}$ problem will use elements of the first four methods listed above. Reliance on an external, independent group to perform testing is too costly given ARAC's foreseeable funding. In addition, learning the current operational system with any degree of completeness, as either a software developer or a user (i.e., an ARAC assessor), is a 1-2 year process and consequently is not realistic in the time frames involved. 


\section{Test Planning}

This section will assist in the identification of areas to test. There are two considerations to determine these areas. First, standard test plans incorporate testing levels such as system testing, acceptance testing, interface testing, etc. Second, the rules for Y2K compliance require varying degrees of testing. Each of these areas will be discussed in the sections below. At the end of this section, a sample worksheet is provided to assist in identifying the areas and kinds of tests that should be performed. The worksheet can not identify all areas, but gives direction as the testing process begins.

This section does not address test plan platform configuration, infrastructure configuration, nor the Y2K compliance of these configurations. Please see the previous section, "Testing Prerequisites" to ensure your test plan covers these topics.

This section does not address archived data. If archived data must be addressed, see Appendix 2, "Additional Testing Considerations".

\section{Testing Levels}

System owners may determine different levels of testing and the degree of rigor in which to conduct their tests. The following are the classic testing levels employed in a commercial environment and are recommendations for inclusion in a test plan.

Unit testing: Unit testing applies to a single module, or, at a more conceptual level, it applies to a single implemented business function. The developer performs it. Unit testing verifies that the unit works correctly based on some predefined minimal set of requirements. This level of testing is usually performed during code modification and is not part of the formal test plan.

Integration testing: As more modules are integrated into a system, all added functionality is tested in an orderly progression. Moreover, previously tested functionality needs to be tested again to assure that the ncw modules have not corrupted the system. A team of developers performs integration testing. This level of testing is usually performed during code modification and is not part of the formal test plan. 


\section{ARAC YEAR 2000 PLAN}

System testing: System testing verifies that the whole system performs the business functions while meeting the specified performance requirements. A team of individuals who are better equipped to verify and validate the system's functionality performs system testing. The team consists of application technicians, business analysts, and users.

Acceptance testing: Once the system is stabilized and is beyond system testing, acceptance testing can begin. Acceptance testing assures that the system is ready for production and that all the defects and performance issues discovered in previous testing stages are rcsolved. Acceptance tests are run by the users for final approval and is usually performed in a controlled production, or productionlike, environment using live data. This requires constant supervision by the development team.

Interface testing: (Added for the benefit of $\mathrm{Y} 2 \mathrm{~K}$ conversion) After successful system testing, the system is tested with respect to its relative position among other systems that it interfaces with. This is to measure the level of correctness of the system's interfaces. A team of developers in a test environment using test data performs these tests.

ARAC-specific comments: These levels of testing will all be utilized in ARAC's testing efforts.

Unit testing: Individual routines that perform time calculations, particularly those that are changed as part of the ARAC- 2 conversion effort will be subjected to testing to verify the basic functioning of the routine. This testing will be done by the responsible developer.

Integration testing: Major sub-systems of the ARAC system, such as problem metdata extraction, will be tested against synthesized data sets. This testing will be done by the responsible developer.

System testing: The full ARAC system will be exercised, primarily by the designated Beta testers, supplemented with testing by other experienced users as appropriate. A first round of testing will be against synthesized data sets. A second round of testing will involve setting system clocks as well as providing synthesized inputs to the system that are consistent with the system clock settings. This round will include tests of the SWS including full responses, TAHOEs and world site exercises, as well as testing the Handar meteorological instrumentation. Tests will include full system exercises that span the date demarcation, that are started after the 


\section{ARAC YEAR 2000 PLAN}

demarcation but use data from before the demarcation and other cases intended to stress the system. The tests will include both large and small time and space domains and consequently will use both observational and gridded meteorological data. While any feasible set of tests cannot exercise all the code in the ARAC system, the tests will be chosen to span the range of normal system usage experienced over that past several years. Where scripts exists to automate this process, they will be used as is or slightly extended to facilitate the testing.

Acceptance testing: Once the system level testing is complete, a standard Production Update will be performed with the requisite Beta freeze and acceptance testing procedures.

Interface testing: As resources permit, ARAC will work with its primary external providers of meteorological data to arrange and perform tests with these various systems to verify as much as possible the functioning of both systems. The key organizations involved here include the Air Force Weather Agency (AFWA), Fleet Numerical Meteorology and Oceanography Center (FNMOC), National Weather Service (NWS) and Alden Electronics. In addition efforts will be made to organize tests of DOE's Emergency Communications Network (ECN). The completeness of these tests will be function of resource availability both in ARAC and in ARAC's collaborating organizations. 


\section{ARAC YEAR 2000 PLAN}

\section{Y2K Testing Rules}

The following is a list of testing scenarios that will enable the year 2000 conversion team (as well as the users) to evaluate the level of the compliance of the converted application. These test scenarios apply to the "Compliance Definition" and "Compliance Rules" section.

The situations listed below are not an exhaustive list of situations to be checked or test cases to be used. They have been included in this document to further document the types of tests that LLNL expects to complete during the Validation Phase of the project.

\section{Rule 1: General Integrity}

If the programming language (s) used for this application provides a function (s) to obtain the system date on the host or through a time service, then:

$R$ 1.1 The date function must return the correct values for system date for high-risk dates. The following dates have been identified as dates requiring testing. The following chart summarizes the dates that will be tested throughout the following rules:

Chart of Dates:

\begin{tabular}{|l|l|}
\hline \multicolumn{1}{|c|}{ Date(S) } & \multicolumn{1}{|c|}{ Testing Requirements } \\
\hline 1999 dates & $\begin{array}{l}\text { Test once to ensure that 1999 dates are recognized when processing in } \\
2000\end{array}$ \\
\hline $9 / 9 / 99$ & $\begin{array}{l}\text { - Test date behavior; many programmers have used } 9999 \text { as end of file } \\
\text { indicator }\end{array}$ \\
\hline $12 / 31 / 99$ to $1 / 1 / 00$ & $\begin{array}{l}\text { - Transition to year } 2000 \\
\text { - Full test of all components }\end{array}$ \\
\hline $2 / 29 / 00$ & $\begin{array}{l}\text { - Leap Year - ensure } 2 / 29 \text { is recognized as a date } \\
\text { Ensure calculations of number of days is correct }\end{array}$ \\
\hline $12 / 31 / 00$ to $1 / 1 / 01$ & $\begin{array}{l}\text { Transition to year 2001 (not needed for ARAC-2, which should be out } \\
\text { of service by } 5 / 00)\end{array}$ \\
\hline
\end{tabular}

$R$ 1.2 The date function(s) must return the correct values for system dates after the system date rolls over on high-risk dates listed in the R1.1 chart.

The following set of tests will be conducted for all tools and applications two times. First, perform tests on a running system during 1999 with the year 2000 date renovations completed. Second, after setting the system clock appropriately, check that the system behaves properly after the demarcation. Note that if there 


\section{ARAC YEAR 2000 PLAN}

are third-party products embedded in the application or system being tested, they must all be century compliant.

\section{Rule 2: Date Integrity}

$R 2.1$ The values in the date fields must be within the expected ranges for dates tested.

$R 2.2$ Leap-year calculations must treat 2000 as a leap year.

$R$ 2.3 The date arithmetic correctly calculates periods (differences) between dates, adds dates and periods, and computes day of week. Dates to be tested are referenced in R 1.1 Chart of Dates.

$R$ 2.4 Applications that convert date values to and from various specific formats must be correct. Dates to be tested are referenced in R 1.1 Chart of Dates.

$R$ 2.5 Where applications compare dates in any of its branching logic or calculation of Boolean values, then all these comparisons must produce correct results for all combinations of values within the expected ranges for dates. Dates to be tested are referenced in R 1.1 Chart of Dates.

$R$ 2.6 Where applications include searching or indexing on date variables or date indexes or any other data structures based on date variables, then these operations must perform correctly for all possible values for dates in the key variables. Dates to be tested are referenced in $\mathrm{R} 1.1$ Chart of Dates.

$R$ 2.7 If an application includes sorting or merging date variables or date indexes or any other data structures based on date variables, then a key index that includes a date field must produce correct sequences across date demarcations. Dates to be tested are referenced in $\mathrm{R} 1.1$ Chart of Dates. 


\section{ARAC YEAR 2000 PLAN}

\section{Rule 3: Century Integrity}

Explicit century: This applies to the expansion and encoding solutions (or any other solution that uses the century explicitly). See Appendix 1, "Solution Techniques" for details.

$R$ 3.1 Values for century in variables of these types must be supplied as input and not logically derived.

$R$ 3.2 Such products must support explicit values for century in every date variable stored and retrieved.

$R$ 3.3 Appropriate bridging needs to be developed to supply the century value where the application has external interfaces (I/O, APIs, external subprogram calls, library routines) which contain a date variable without explicit century.

$R$ 3.4 All representations of date with explicit century, both internal to the application and in all of its interfaces, must satisfy the criteria for century compliance.

Implicit century: This applies to the "windowing" solution (or any other solution that uses the century implicitly). See Appendix 1, "Solution Techniques" for details.

$R$ 3.5 The century value derived for any manipulations, for passing across any interface, or for permanent storage must always be correct when the application uses a language(s), tool $\mathrm{kit}(\mathrm{s})$, and/or a code generator(s) which permit date representation without an explicit century in the date data types.

$R$ 3.6 Any application program interface (API), which passes date variables must handle them correctly. Test for any date value supplied across this interface, that the receiving application provides a default or derived value of century that is consistent with respect to each other.

$R$ 3.7 Where any application supports a user interface containing date fields without explicit century, then the century must be unambiguous to the users.

$R$ 3.8 All representations of date, both internal to the application and in all of its interfaces, must satisfy the criteria for century compliance. 


\section{$\checkmark$ ARAC YEAR 2000 PLAN}

ARAC-specific comments: The ARAC-2 system relies primarily on the implicit century approach (with the exception of the model parameter system, which uses a 4-digit year and so is explicit) with 2-digit years less than 50 being interpreted as $20 \mathrm{xx}$ and years greater than or equal to 50 being interpreted as $19 \mathrm{xx}$. This covers the earliest field experiment data in ARAC's model evaluation database (1956) while extended 49+ years beyond the expected lifetime of the system.

ARAC-3 uses 4-digit years throughout and so it is explicit. 
$\checkmark$ ARAC YEAR 2000 PLAN

\section{Test Selection Worksheets}

The following worksheets will be used for determining the scope of testing associated to each testing level (based on the size, complexity and functionality of the system) and to help coordinate the preliminary information needed for successful testing to begin as discussed in the section, "Testing Prerequisites". For clarification of each referenced testing criteria, refer to the section, "Testing Rules" for scenarios. "Testing Levels" gives definitions for each of the testing levels. 


\section{ARAC YeAR 2000 PLAN}

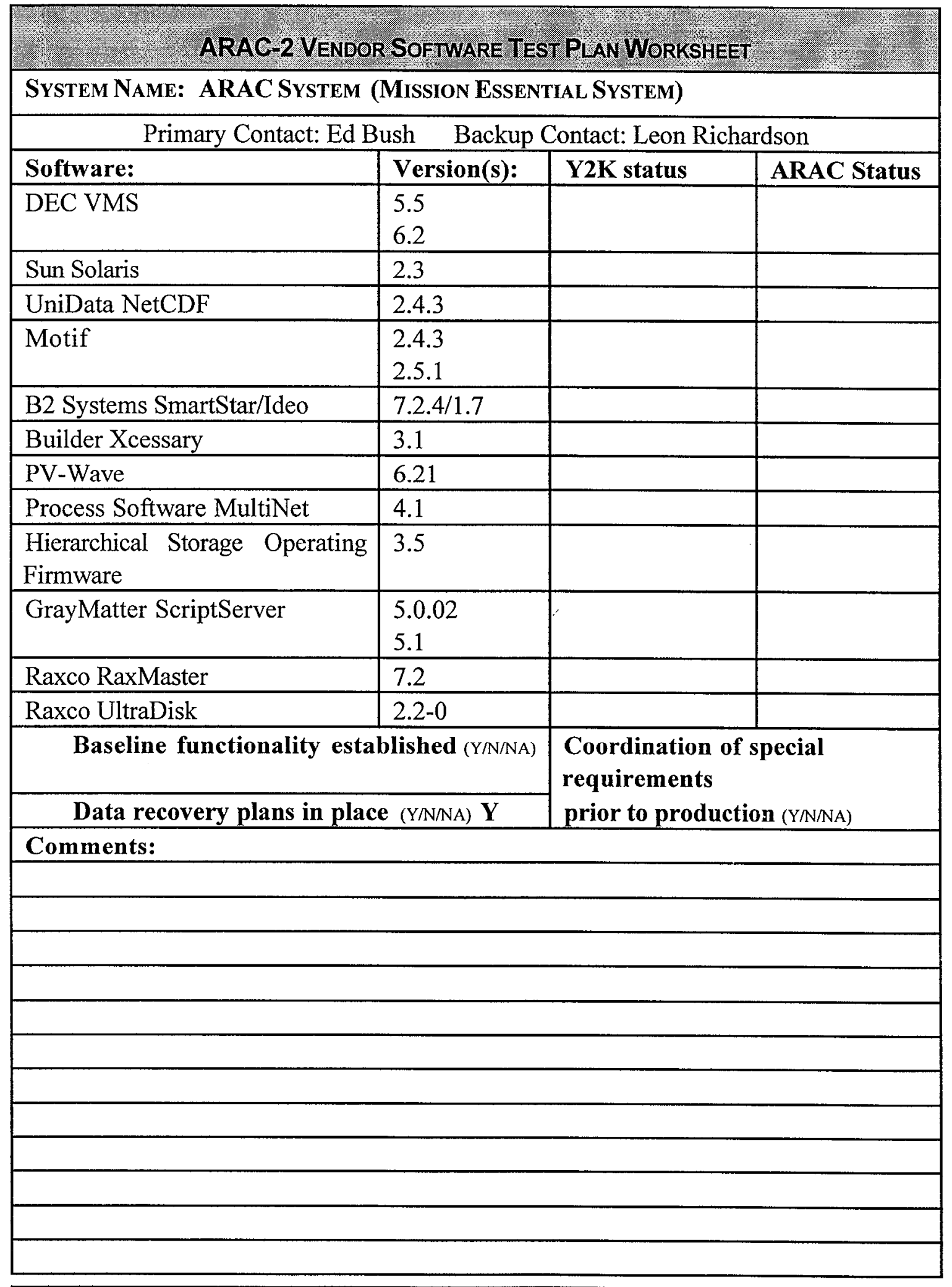




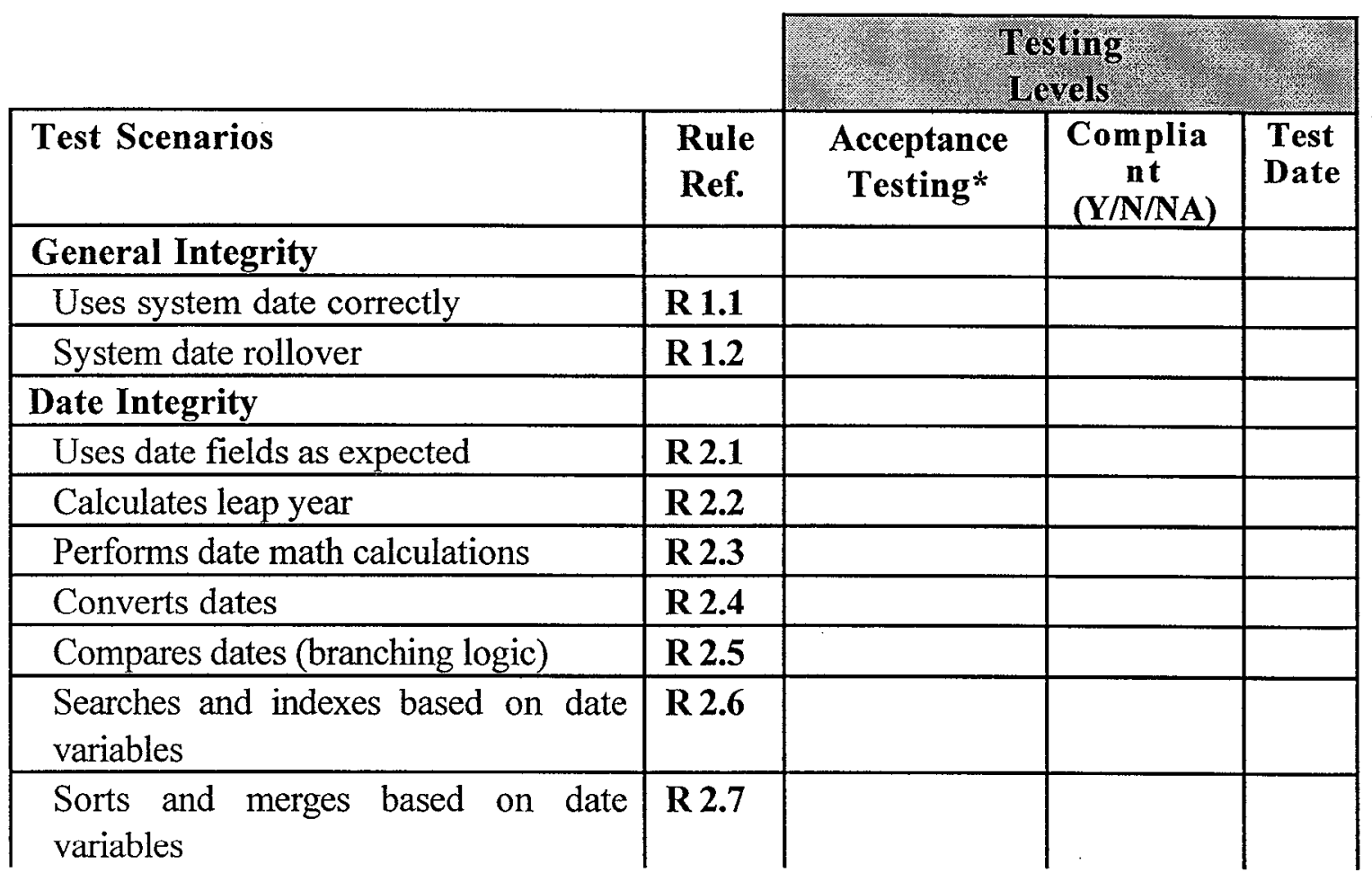

\begin{tabular}{|l|l|l|l|l|}
\hline Century Integrity (Explicit) & & & & \\
\hline $\begin{array}{l}\text { Correct use of tool kits or code } \\
\text { generators }\end{array}$ & $\mathbf{R 3 . 1}$ & & & \\
\hline Uses DBMS or layered product & R 3.2 & & & \\
\hline External interfaces & R 3.3 & & & \\
\hline Satisfies century compliance & R3.4 & & & \\
\hline Century Integrity (Implicit) & & & & \\
\hline $\begin{array}{l}\text { Correct use of tool kits or code } \\
\text { generators }\end{array}$ & R 3.5 & & & \\
\hline Uses API interfaces correctly & R3.6 & & & \\
\hline Correct use of user interface & R3.7 & & & \\
\hline Satisfies century compliance & R3.8 & & & \\
\hline
\end{tabular}

ARAC-2 Vendor Software Worksheet Page 2 of 2 


\begin{tabular}{|l|l|l|l|}
\hline \multicolumn{5}{|c|}{ ARAC-SWS VENDOR SOFTWARE TEST PLAN WORKSHEET } \\
\hline \multicolumn{3}{|c|}{ Primary Contact: Jon Welch } \\
\hline SYSTEM NAME: ARAC SYSTEM (MISSION ESSENTIAL SYSTEM) \\
\hline Software: & Version(s): & Y2K status & ARAC Status \\
\hline Sun Solaris & 2.3 & & \\
\hline Motif & 2.5 .1 & & \\
\hline ppp & 2.4 .3 & & \\
\hline GhostScript/GhostView & 2.5 .1 & & \\
\hline Handar Meteorological Firmware & 2.0 & & \\
\hline Baseline functionality established (YNNNA) & $\begin{array}{l}\text { Coordination of special } \\
\text { requirements } \\
\text { prior to production (YN/NA) }\end{array}$ \\
\hline Data recovery plans in place (YNNA) Y & \\
\hline Comments: & \\
\hline & \\
\hline & \\
\hline & \\
\hline
\end{tabular}




\begin{tabular}{|c|c|c|c|c|}
\hline \multirow[b]{2}{*}{ Test Scenarios } & \multirow[b]{2}{*}{$\begin{array}{l}\text { Rule } \\
\text { Ref. }\end{array}$} & \multicolumn{3}{|c|}{$\begin{array}{l}\text { Testing } \\
\text { Levers }\end{array}$} \\
\hline & & $\begin{array}{l}\text { Acceptance } \\
\text { Testing* }\end{array}$ & $\begin{array}{c}\text { Complia } \\
\text { nt } \\
\text { (Y/N/NA) }\end{array}$ & $\begin{array}{l}\text { Test } \\
\text { Date }\end{array}$ \\
\hline \multicolumn{5}{|l|}{ General Integrity } \\
\hline Uses system date correctly & R 1.1 & & & \\
\hline System date rollover & R 1.2 & & & \\
\hline \multicolumn{5}{|l|}{ Date Integrity } \\
\hline Uses date fields as expected & R 2.1 & & & \\
\hline Calculates leap year & $\mathbf{R} 2.2$ & & & \\
\hline Performs date math calculations & R 2.3 & & & \\
\hline Converts dates & R 2.4 & & & \\
\hline Compares dates (branching logic) & $\mathbf{R} 2.5$ & & & \\
\hline $\begin{array}{l}\text { Searches and indexes based on date } \\
\text { variables }\end{array}$ & R 2.6 & & & \\
\hline $\begin{array}{l}\text { Sorts and merges based on date } \\
\text { variables }\end{array}$ & $\mathbf{R} 2.7$ & & & \\
\hline
\end{tabular}

\begin{tabular}{|c|l|l|l|l|}
\hline Century Integrity (Explicit) & & & & \\
\hline $\begin{array}{l}\text { Correct use of tool kits or code } \\
\text { generators }\end{array}$ & $\mathbf{R 3 . 1}$ & & & \\
\hline Uses DBMS or layered product & R 3.2 & & & \\
\hline External interfaces & R 3.3 & & & \\
\hline Satisfies century compliance & R 3.4 & & & \\
\hline Century Integrity (Implicit) & & & & \\
\hline $\begin{array}{c}\text { Correct use of tool kits or code } \\
\text { generators }\end{array}$ & R 3.5 & & & \\
\hline Uses API interfaces correctly & R 3.6 & & & \\
\hline Correct use of user interface & R 3.7 & & & \\
\hline Satisfies century compliance & R 3.8 & & & \\
\hline
\end{tabular}




\section{ARAC YEAR 2000 PLAN}

\begin{tabular}{|l|l|l|l|}
\hline \multicolumn{5}{|c|}{ ARAC-3 VENDOR SOFTWARE TEST PLAN WORKSHEET } \\
\hline SYSTEM NAME: ARAC SYSTEM (MISSION ESSENTIAL SYSTEM) \\
\hline \multicolumn{3}{|c|}{ Primary Contact: Gary Berry Backup Contact: Ed Bush } \\
\hline Software: & Version(s): & Y2K status & ARAC Status \\
\hline Digital Unix & $4.0 \mathrm{~d}$ & & \\
\hline Sun Solaris & 2.5 .1 & & \\
\hline SGI IRIX & 2.6 & & \\
\hline IONA OrbixMT & 2.2 & & \\
\hline IONA OrbixWeb & 2.3 & & \\
\hline IONA OrbixOTM & & & \\
\hline ObjectDesign ObjectStore & 1.0 & & \\
\hline JDK & & & \\
\hline Swing & 1.1 .6 & & \\
\hline BONGO & 1.0 .1 & & \\
\hline ObjectSpace & 1.1 & & \\
\hline RogueWave Tools.h & 4.2 & & \\
\hline Rational ClearCase & & & \\
\hline Edinburgh Portable Compilers & 2.5 .1 .3 & & \\
Fortran 90 & & & \\
\hline $\begin{array}{l}\text { NRL/FNMOC } \\
\text { COAMPS/NORAPS }\end{array}$ & & & \\
\hline Unidata NetCDF & 2.4 .2 & & \\
\hline Unidata McIDAS & 3.4 & & \\
\hline IDL & 4.0 & & \\
\hline PV-Wave & 6.0 & & \\
\hline ssh & & & \\
\hline tcp wrappers & & & \\
\hline ftp wrappers (wu ftp) & & & \\
\hline SunNetManager & 5.2 & & \\
\hline NetWorker & & & \\
\hline Hierarchical Storage Operating & 7.0 & & \\
Firmware & & & \\
\hline & & & \\
\hline & & & \\
\hline
\end{tabular}




\section{ARAC YEAR 2000 PLAN}

\begin{tabular}{|c|c|c|c|c|}
\hline \multicolumn{2}{|c|}{ Baseline functionality established $(\mathrm{Y} / \mathrm{N} / \mathrm{NA})$} & \multirow{2}{*}{\multicolumn{3}{|c|}{$\begin{array}{l}\text { Coordination of special } \\
\text { requirements } \\
\text { prior to production (YN/NA) }\end{array}$}} \\
\hline \multicolumn{2}{|c|}{ Data recovery plans in place (Y/N/NA) $Y$} & & & \\
\hline \multicolumn{5}{|l|}{ Comments: } \\
\hline & \multicolumn{3}{|c|}{$\begin{array}{l}\text { Testing } \\
\text { Levels } \\
\end{array}$} \\
\hline Test Scenarios & $\begin{array}{l}\text { Rule } \\
\text { Ref. }\end{array}$ & $\begin{array}{c}\text { Acceptance } \\
\text { Testing* }\end{array}$ & $\begin{array}{c}\text { Complia } \\
\text { nt } \\
(\mathrm{Y} / \mathrm{N} / \mathrm{NA}) \\
\end{array}$ & $\begin{array}{l}\text { Test } \\
\text { Date }\end{array}$ \\
\hline \multicolumn{5}{|l|}{ General Integrity } \\
\hline Uses system date correctly & R 1.1 & & & \\
\hline System date rollover & R 1.2 & & & \\
\hline \multicolumn{5}{|l|}{ Date Integrity } \\
\hline Uses date fields as expected & R 2.1 & & & \\
\hline Calculates leap year & $\mathbf{R} 2.2$ & & & \\
\hline Performs date math calculations & R 2.3 & & & \\
\hline Converts dates & R 2.4 & & & \\
\hline Compares dates (branching logic) & \begin{tabular}{|l|} 
R 2.5 \\
\end{tabular} & & & \\
\hline $\begin{array}{l}\text { Searches and indexes based on date } \\
\text { variables }\end{array}$ & R 2.6 & & & \\
\hline $\begin{array}{l}\text { Sorts and merges based on date } \\
\text { variables }\end{array}$ & R 2.7 & & & \\
\hline
\end{tabular}

\begin{tabular}{|c|l|l|l|l|}
\hline Century Integrity (Explicit) & & & & \\
\hline $\begin{array}{l}\text { Correct use of tool kits or code } \\
\text { generators }\end{array}$ & R 3.1 & & & \\
\hline Uses DBMS or layered product & R 3.2 & & & \\
\hline External interfaces & R 3.3 & & & \\
\hline Satisfies century compliance & R 3.4 & & & \\
\hline Century Integrity (Implicit) & & & & \\
\hline $\begin{array}{l}\text { Correct use of tool kits or code } \\
\text { generators }\end{array}$ & R 3.5 & & & \\
\hline Uses API interfaces correctly & R 3.6 & & & \\
\hline Correct use of user interface & R 3.7 & & & \\
\hline Satisfies century compliance & R 3.8 & & & \\
\hline
\end{tabular}

ARAC-3 Vendor Software Worksheet Page 2 of 2 


\section{ARAC YEAR 2000 PLAN}

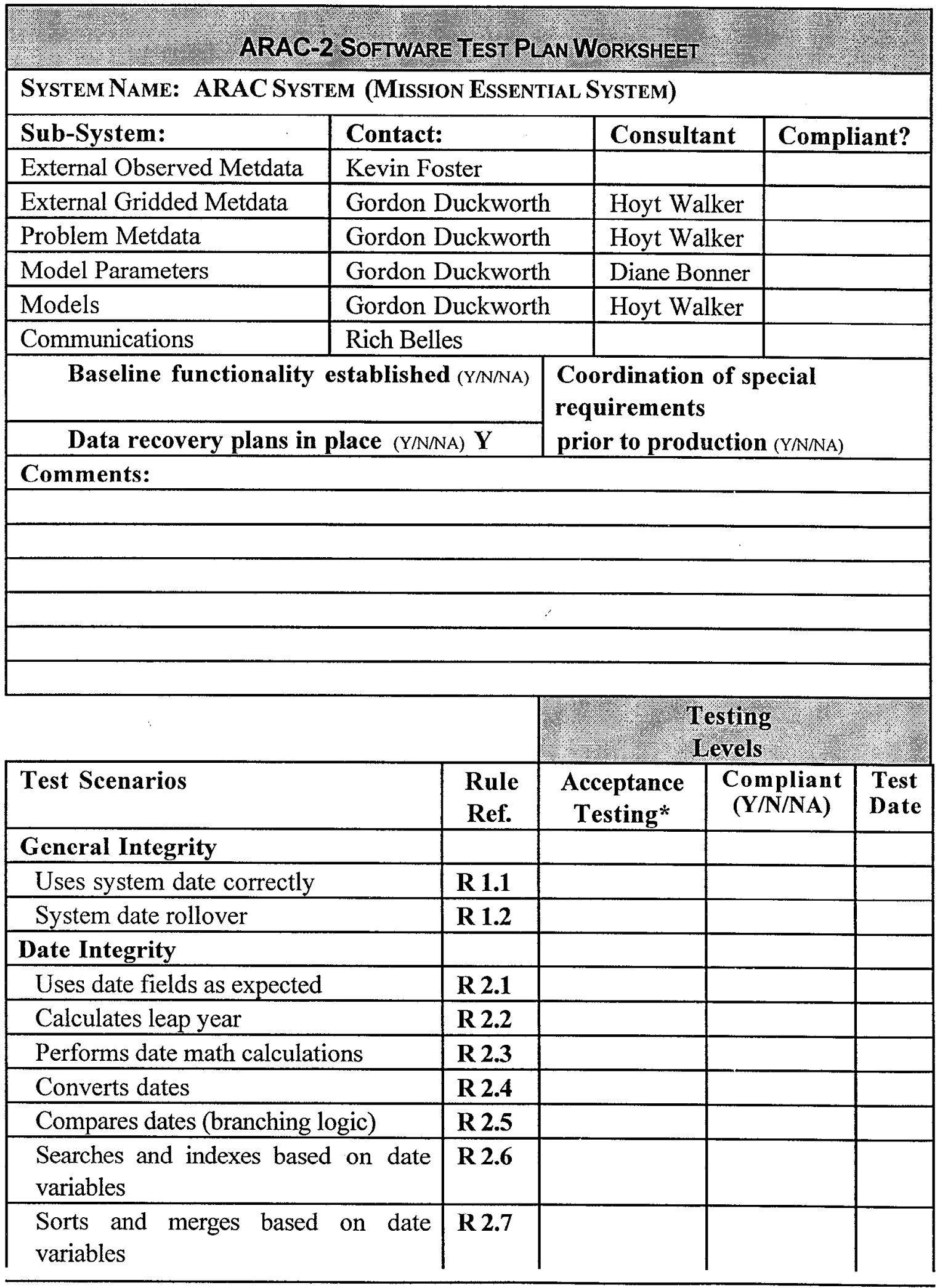




\begin{tabular}{|c|l|l|l|l|}
\hline Century Integrity (Explicit) & & & & \\
\hline $\begin{array}{l}\text { Corrcct usc of tool kits or codc } \\
\text { generators }\end{array}$ & R 3.1 & & & \\
\hline Uses DBMS or layered product & R 3.2 & & & \\
\hline External interfaces & R 3.3 & & & \\
\hline Satisfies century compliance & R 3.4 & & & \\
\hline Century Integrity (Implicit) & & & & \\
\hline $\begin{array}{l}\text { Correct use of tool kits or code } \\
\text { generators }\end{array}$ & R 3.5 & & & \\
\hline Uses API interfaces correctly & R 3.6 & & & \\
\hline Correct use of user interface & R 3.7 & & & \\
\hline Satisfies century compliance & R 3.8 & & & \\
\hline
\end{tabular}

ARAC-2 Software Worksheet Page 2 of 2 


\section{ARAC YEAR 2000 PLAN}

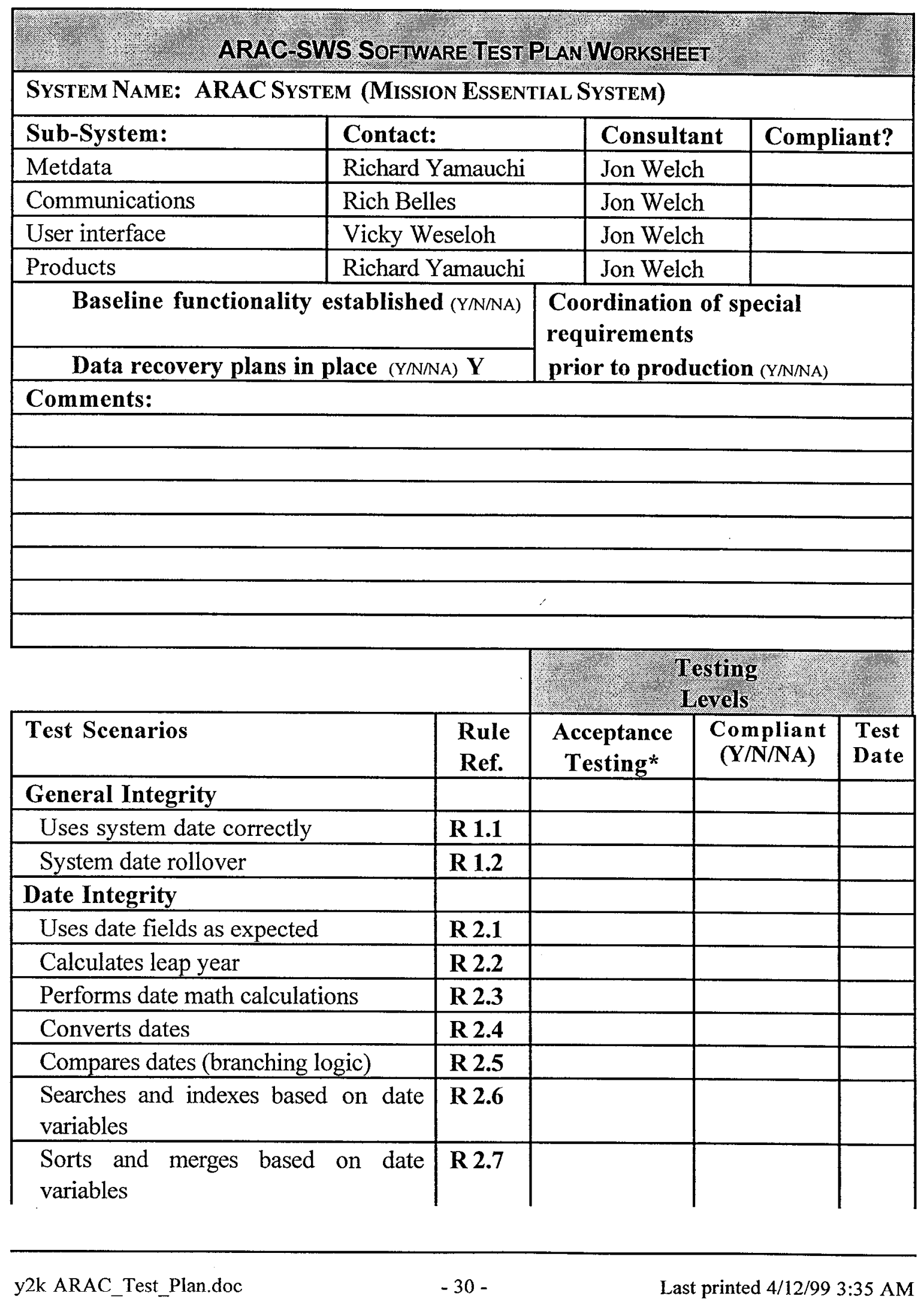


ARAC YEAR 2000 PLAN

\begin{tabular}{|c|l|l|l|l|}
\hline Century Integrity (Explicit) & & & & \\
\hline $\begin{array}{l}\text { Correct use of tool kits or code } \\
\text { generators }\end{array}$ & R 3.1 & & & \\
\hline Uses DBMS or layered product & R 3.2 & & & \\
\hline External interfaces & R 3.3 & & & \\
\hline Satisfies century compliance & R 3.4 & & & \\
\hline Century Integrity (Implicit) & & & & \\
\hline $\begin{array}{l}\text { Correct use of tool kits or code } \\
\text { generators }\end{array}$ & R 3.5 & & & \\
\hline Uses API interfaces correctly & R 3.6 & & & \\
\hline Correct use of user interface & R 3.7 & & & \\
\hline Satisfies century compliance & R 3.8 & & & \\
\hline
\end{tabular}

ARAC-2 Software Worksheet Page 2 of 2 
ARAC YEAR 2000 PLAN

\begin{tabular}{|l|l|l|l|l|}
\hline Century Integrity (Explicit) & & & & \\
\hline $\begin{array}{l}\text { Correct use of tool kits or code } \\
\text { generators }\end{array}$ & $\mathbf{R 3 . 1}$ & & & \\
\hline Uses DBMS or layered product & $\mathbf{R 3 . 2}$ & & & \\
\hline External interfaces & $\mathbf{R 3 . 3}$ & & & \\
\hline Satisfies century compliance & $\mathbf{R 3 . 4}$ & & & \\
\hline Century Integrity (Implicit) & & & & \\
\hline $\begin{array}{l}\text { Correct use of tool kits or code } \\
\text { generators }\end{array}$ & $\mathbf{R 3 . 5}$ & & & \\
\hline Uses API intcrfaces correctly & $\mathbf{R 3 . 6}$ & & & \\
\hline Correct use of user interface & $\mathbf{R 3 . 7}$ & & & \\
\hline Satisfies century compliance & $\mathbf{R 3 . 8}$ & & & \\
\hline
\end{tabular}

ARAC-3 Software Worksheet Page 2 of 2 


\section{ARAC YEAR 2000 PLAN}

ARAC Y2K Schedule:

\begin{tabular}{|c|c|}
\hline Tass & Completion Date \\
\hline ARAC-2 Models Integration Testing & - May 1996 \\
\hline ARAC-SWS Renovation & - March 1997 \\
\hline ARAC-SWS Unit \& Integration Testing & - May 1997 \\
\hline ARAC-SWS System Testing (with clocks set) & - June 1998 \\
\hline $\begin{array}{l}\text { ARAC-SWS Metdata Collection Integration Testing } \\
\text { (embedded Handar system) }\end{array}$ & - July 1998 \\
\hline $\begin{array}{l}\text { ARAC-SWS/Metdata Collection System Testing } \\
\text { (with clocks set) }\end{array}$ & - August 1998 \\
\hline ARAC-2 Renovation \& Unit Testing & - $\quad$ September 1,1998 \\
\hline ARAC-2 Integration \& System Testing & October 15,1998 \\
\hline ARAC-2 Third-party Packages Y2K Compliant & October 15,1998 \\
\hline ARAC-2 Beta Freeze (Acceptance Testing) & October 15,1998 \\
\hline ARAC-2 Production Update & November 1,1998 \\
\hline $\begin{array}{l}\text { ARAC-2 Green Room System Testing } \\
\text { (with clocks set) }\end{array}$ & December 1, 1998 \\
\hline $\begin{array}{l}\text { ARAC-2/SWS Green Room System Testing } \\
\text { (with clocks set) }\end{array}$ & January 1,1999 \\
\hline ARAC-3 Third-party Packages Y2K Compliant & January 1,1999 \\
\hline ARAC-2 Final Y2K Bela Freeze & January 15,1999 \\
\hline ARAC-2 Final Y2K Production Update & February 1,1999 \\
\hline $\begin{array}{l}\text { ARAC-3 Integration \& System Testing (with clocks } \\
\text { set) }\end{array}$ & February 1,1999 \\
\hline ARAC-3 Beta Freeze & February 1,1999 \\
\hline ARAC-3 Production Update & February 15,1999 \\
\hline Finalize ARAC Y2K Compliance Documentation & March 1, 1999 \\
\hline ARAC/AWFA Testing & TBA \\
\hline ARAC/FNMOC Testing & TBA \\
\hline ARAC/NCEP & TBA \\
\hline ARAC/ECN Testing & TBA \\
\hline ARAC/McIDAS & TBA \\
\hline
\end{tabular}

- - task completed

Note: An update to Solaris 2.6 is currently being evaluated. A number of issues must y2k ARAC_Test_Plan.doc 
considered before moving forward with this upgrade including the proper individual functioning and interworking of key third party packages on this operating system, the availability of appropriate replacement packages for some SWS printing capabilities, the maturity of the operating system itself and the status of the DOE Emergency Communications Network (ECN, managed by NN-60) with respect to this upgrade. Solaris 2.5.1 with the necessary $\mathrm{Y} 2 \mathrm{~K}$ patches and clocks reset appears to behave properly on all tests so far. Consequently, the migration to Solaris 2.6 is viewed primarily as one of general system evolution and not tightly coupled to the $\mathrm{Y} 2 \mathrm{~K}$ issue. Nevertheless, we do expect to be at Solaris 2.6 well bcfore December, 1999. 


\section{ARAC YEAR 2000 PLAN}

\section{Risk Assessment}

As mentioned in the ARAC risk statement earlier, some risk is inevitable due to the cost of a complete, independent certification of ARAC-2. Additional risk is incurred due to the practical impossibility of a true end-to-end system test. ARAC relies on meteorological data gathered from thousands of standard observing stations around the world and an endto-end test would need to incorporate all of these stations, the numerous national and international organizations involved in making the data available and all the supporting infrastructure (e.g., communications) that goes into providing a reliable data stream to programs such as ARAC. Over and above the inherent difficulty in orchestrating a full test of all these systems, the matter is further constrained by the fact that all the components of these systems have on-going, moment-to-moment operational needs that must be met and so they cannot be taken down for testing easily. Thus, certifying the compliance of the systems that provide meteorological data to ARAC is well beyond the scope of this plan (on the other hand, ARAC will participate, as resources permit, with testing activities at the key data providing institutions. For details of data vulnerability, see the following section.

Several overall strategies are incorporated into the ARAC Y2K Plan to minimize risk in a cost effective manner consistent,with the long term development of the program. First of all, the testing described in this plan is designed to ensure that both the ARAC-2 and ARAC-3 systems will function properly with respect to the critical dates assuming that some appropriate meteorological data is available to the system. The nature of these systems is such that the core functionality as well as the supporting infrastructure can be validated with confidence. In addition, this transitional period for ARAC between ARAC-2 and ARAC-3, while in many ways a problem, is used to advantage in this plan since these system will back each other up during the date demarcations. Since these systems generally have independent failure modes, this strategy minimizes risk with respect to ARAC as a whole.

The key source of risk is the receipt of meteorological data and, consequently, one important strategy is to maintain multiple data sources for each major type of mcteorological data. This is consistent with the design of both ARAC-2 and ARAC-3. ARAC-2 data sources supplemented by new data links developed in the course of completing ARAC-3 (such as NOAAPort, which provides satellite access to both observed and model generated meteorological data) provide some insulation from failures of individual data sources. Note that since pathways exist to move data to/from ARAC-2 from/to ARAC-3, there is synergy between these system with respect to reliable meteorological data. As long as one of the key data providers for each category of meteorological data is working during the date demarcation, ARAC should be able to

respond at essentially full capability (note that the various observed meteorological data 


\section{ARAC YEAR 2000 PLAN}

providers do not provide exactly the same set of observing stations so that the failure of a particular data source could somewhat reduce the quality of a specific ARAC product due to the absence of key data). See the next section for additional details regarding data vulnerability.

Risk also exists in the area of data delivery, which relies on network connections, modem connections and fax machines. As long as the telephone network remains largely intact, ARAC will be able to deliver product to its various customers, although failure of the DOE Emergency Communications Network would result in somewhat reduced service, primarily in the timeliness of product delivery. A complete collapse of the tclephonc system would essentially take ARAC off-line for certain emergency response situations. Another area of risk is date dependencies in ARAC's power distribution network. ARAC has generator and redundant UPS systems and so can function (as long as generator fuel as available) in the absence of the power grid. However, if an embedded system in the power distribution system was unidentified and so not tested, ARAC could be vulnerable to failure here. Reliance on factual information from various knowledgeable sources is necessary to reduce risk in this area.

In summary, risk due to problems in the ARAC systems and their local supporting infrastructure can be managed effectively. However, ARAC relies on a complex, interdependent network of data sources and communication pathways that are beyond the control of the program. See Contingency Plan section for further discussion. 


\section{ARAC YEAR 2000 PLAN}

\section{Data Vulnerability Assessment}

The following section provides some details of ARAC's sources of data and the vulnerability of the program to failure of these data sources. Each source of data is described in this context.

\section{AFWA observational metdata front end}

Observational meteorological data is a critical component of the ARAC system and Air Force Weather Agency (AFWA) has been the primary source of this data for over 20 years. ARAC-2 relies on a VMS MicroVAX 3200 that serves as a front end for AFWA communications to/from the Central System. Note that a backup machine is available although switchover is manual process. The communications are based on the X.25 protocol running over a $56 \mathrm{~Kb}$ leased line between ARAC and AFWA (note that old hardware in the ARAC-2 front end limits actual performance to $19.2 \mathrm{~Kb}$ ). ARAC currently receives only a small portion of the world on subscription and relies on a rerequest capability to cover other areas. The ARAC- 3 conncction to AFWA has not been defined yet but is expected to primarily rely on $\mathrm{ftp}$ interactions over Internet, intranet or via a leased line as in ARAC-2 but relying on Internet protocols. The ARAC-3/AFWA link will be in place before January 1,2000. ARAC is in discussions with AFWA on the nature of tests that would be appropriate to validate the connections between our systems. The AFWA data connection is the most important one with respect to ARAC's ability to respond at or near its full capability.

The communication between ARAC-2 and AFWA has some aspects that are difficult and expensive to test completely. This is particularly true with respect to the re-request capability. Vulnerability to probable weakness in testing in this area is being minimized by completing changes that will allow ARAC to receive global meteorological data from AFWA on subscription. When this update is complete the re-request capability will be relegated to a backup capability, i.e., it will only be used if AFWA subscription and the Alden metdata front-end (see below) do not provide the necessary data. A largely independent ARAC-3/AFWA connection and the likely acquisition of NOAAPort will place this potential vulnerability further into the background.

\section{Alden metdata front end}

Observational meteorological data, along with meteorological charts, are received from Alden, a commercial distributor of meteorological information, via a satellite link. The satellite dish is connected to ARAC-2 via a front-end that can also serve as the AFWA meteorological data front end. The same data stream is also routed to ARAC-3. U.S. meteorological data (Domestic Data Plus, DDP) and international meteorological data (International Data Service, IDS) are both received. This data source provides similar information as that provided by AFWA although it is generally somewhat less complete. Given a reliable connection to AFWA, ARAC is not extremely sensitive to Alden's 


\section{ARAC YEAR 2000 PLAN}

operational status. However, problems with the ARAC/AFWA link would raise this source to a much more critical level.

\section{Internet connection for receipt of FNMOC and NCEP grids}

ARAC receives global gridded meteorological data fields produced by the Navy's NOGAPS model at both 1.0 and 2.5 degree resolution from Fleet Numerical Meteorology and Oceanography Center (FNMOC) via the Internct. FNMOC pushes the files to ARAC using ftp. The files arrive initially in ARAC-3 and are transferred to ARAC-2. ARAC can call FNMOC to redeliver all or part of the data set for a watch if data was missed for any reason. The current connectivity between FNMOC and ARAC is via DREN and ESNET bridging at Moffett. Grids from models at the National Center for Environmental Prediction (NCEP) are pulled via ftp over the Internet. These grids are normally used only by ARAC- 3 .

Maintenance of at least one global gridded data source is critical to ARAC's ability to respond to a variety of situations. While this data is critical, the fact that these fields include forecast data does provide some latitude with respect to time. That is, ARAC normal receives analysis data (i.e., a sophisticated, physically-based interpolation of observed conditions to a grid) at a particular time along with forecast fields at 6 hourly intervals out to 72 hours. Such a data set is received every 12 hours and so a given forecast spans the next several data receipt times. While the accuracy of the forecasts degrade significantly over 72 hours, the loss of a single data set is not extremely critical.

\section{McIDAS metdata system}

ARAC receives various meteorological data from Unidata (part of the University Consortium for Atmospheric Research focused on providing access to atmospheric data, primarily for research purposes) in a specialized format over the Internet using custom protocols. These are used by the McIDAS (Man computer Interactive Data Access System) program primarily to support the ARAC weather briefings and general atmospheric analysis, particularly in the area of satellite images. These data are also used by the GEMPAK atmospheric data visualization program (also from Unidata) for model development use. The capabilities are not directly linked to the operational ARAC environment at this time. In cooperation with Unidata, ARAC has been designated as a backup data distribution node for the McIDAS data to a small number of universities in the area.

This data is not critical in the sense of the previously described data sources. However, their absence does limit the $\triangle \mathrm{RAC}$ assessment meteorologists ability to acquire a complete picture of the current state of the atmosphere in an area somewhat. On the other hand, equivalent capabilities are increasingly available via the Internet using a browser. Backup to Internet-based meteorological information is partly provided by the charts received via the Alden satellite system. 


\section{ARAC YEAR 2000 PLAN}

\section{SWS communications front end}

ARAC has about 40 sites that receive committed support from the project. This support includes a dedicated Sun workstation installed at the site that allows the sites to initiate an exercise or a response on the basis of information provided via a questionnaire interface and to receive the products generated by ARAC, along with various other processing and maintenance capabilities. In most cases installation of the operating system and all of the SWS software is handled by ARAC, as much as possible by logging into these systems remotely. Many of these SWS are installed with meteorological towers and metdata is collected and archived by the SWS as well as being available to ARAC directly over telephone lines. These systems are referred to as Site Workstation Systems (SWS). ARAC has a Site Support Team dedicated to dealing with these systems and their users. The majority of the SWS communicate with ARAC via dial-up modems that are part of the installed SWS using PPP as the basic protocol. ARAC receives these communications on one of two dedicated front ends with banks of modems. ARAC maintains two of these systems but switching to the backup system is a manual process. Equivalent capabilities are being developed for ARAC-3. Note that support for these SWS and access to the meteorological towers relies on a viable telephone system.

\section{SWS communications via ECN}

DOE NN-60 has developed an Emergency Communications Network (ECN) for use by DOE emergency response resources of which ARAC is one. ARAC communicates with SWS at most DOE facilities using this network. This network has two hubs, one in Washington, D.C. and the other at the Bechtel Nevada Remote Sensing Laboratory (RSL), that are connected with a T3 line and the various nodes are connected to one of the hubs using a T1 line. This intranet is connected to the Internet in Washington. Note that SWS support to ECN nodes is dependent on the viability of this network.

\section{Telephone communications}

In addition to the various data pathways described above, it is important to note that ARAC makes heavy use of voice and fax telephone communications during responses and exercises. For supported sites, this is used to supplement the information provided by the user using the SWS user interface, to describe special aspects of the products provided and to troubleshoot all manner of problems that can arise. For non-supported sites (i.e., those a locations that don't have an ARAC SWS), telephone communication takes on a more central role as the conduit most of the information transferred. For nonsupported sites, FAX delivery of products is typical. Thus, a functioning telephone system is key to an effective ARAC response. 


\section{ARAC YEAR 2000 PLAN}

\section{Contingency Plan}

While a variety of strategies have been described that lessen the vulnerability of ARAC to failure associated with date issues, the possibility of varying degrees of system failure has to be considered. While testing is expected to minimize the possibility of failures within the body of the ARAC system, failures could conceivably occur. As part of being ready for such eventualities, ARAC expects to have a small number of people with strong familiarity with the system at work for the most critical period who will monitor the status of data sources and system status. Failures of any type will be tracked by these people and, depending on their severity, will be resolved. As needed, other people will be called in to assist. The level of system administration support will be intermediate between the normal on-call procedures in effect in ARAC and the level of support provided during major responses and exercises. This will be supplemented by software development support. This approach will also apply to the possibility of a partial failure of both ARAC-2 and ARAC-3 which could necessitate a hybrid response assuming the failures in the systems could not be corrected rapidly. Thus both system administration and software development support will need to be knowlédgeable about both ARAC-2 and ARAC-3.

Assuming that the core system behaves properly the next general type of failure would be in the data sources. As implied in the previous discussion, ARAC can function at a reasonably complete level assuming at least one observational and one gridded meteorological data source remains viable. In the absence of observational data the models can rely exclusively on gridded data with a loss of quality in the resulting product that will vary greatly depending on the details of the situation. However, a credible product could generally be produced although smaller scale details might well be missed. The absence of gridded meteorological data would have a minor effect immediately after the date demarcation (assuming the last data set before the date change was received normally). However, continued unavailability would result in a steady decrease in the quality of ARAC's products in areas with sparse observational data and for large domains where the primary source of data is the gridded fields. Continued unavailability would also eventually curtail ARAC's in-house weather predictions. Failure of both the observational and gridded sources would mean that ARAC would have to rely exclusively on the last gridded meteorological data fields received before the date change. Thus, the quality of ARAC's ability to respond would be generally adequate (though less than optimal) for 24 hours after the failure of the data sources, less adequate through 48 hours and quite marginal through 72 hours. There are two key implications of this. One is that it is essential to receive the last set of gridded fields before the date change from both FNMOC and NCEP, and that the period from 24-48 hours is the time period during which ARAC can function to some degree without any data sources. Consequently all 
efforts will need to be made to reestablish any lost data links during the first day or two after the date change.

Non-meteorological data sources and data delivery rely on both telephone lines and DOE's ECN. ARAC should remain functional in the cvent of failure of one of these systems. Telephone communications can cover for ECN failure although scenario descriptions from ECN nodes would have to be acquired using voice over telephones lines and product delivery would have to be via fax. Failure of telephone communications would typically be more serious although the ECN would provide access to the DOE EOC, which would allow information exchange from that site and so permit ARAC to function, again at a reduced level. Failure of both the ECN and telephone communications would limit ARAC to responding to events reported on television or radio news channels and would require access to some emergency communications capability for product delivery and access of more specific scenario descriptions. No details of such emergency capabilities have been worked out at this time.

Assuming the ARAC's generator/UPS/PDU system does not contain any hidden Y2K flaws that would cause failure during the date transition, ARAC should be insulated against failures of the external power grid for as long as generator fuel is available. Note that reasonable redundancy is available in ARAC's power system so that some degree of failure of this system can be tolerated. Failure of half of the power distribution system should not result in loss of the operational system, which includes redundant machines and fail-over file systems arranged to have the essential components available with only half the normal power system working. Such a power failure could cause less critical elements (e.g., the tablet digitizer) of the system to be unavailable. Special circumstances that would raise the importance of such elements might require moving the capability to a new power source and reinitializing it. Thus, the need for heightened readiness on the part of the system support personnel. Complete failure of the power system could take ARAC off-line until it was fixed, thus it is essential that this system be examined for general robustness and $\mathrm{Y} 2 \mathrm{~K}$ compliance.

A complete ARAC backup system to be installed at AFWA is currently under discussion. While the exact nature of such a system and its status during the critical date transitions is not clear at this time, such a system could allow ARAC products to be provided even in the event of a complete failure of the ARAC system at LLNL. If such a system were to be installed and would be available for ARAC use in certain circumstances, then it would be incorporated into the ARAC Contingency Plan. 


\section{ARAC YEAR 2000 PLAN}

\section{Conclusion}

This test plan presents a framework and a comprehensive summary of testing methodologies and criteria for the ARAC year 2000 conversion effort. It presents the motivation and need behind testing. It also describes year 2000 compliance criteria, and outlines the testing procedures to be followed during the conversion effort. Testing guidelines and recommendations were also presented. These guidelines will provide structure for the review and testing of the system's year 2000 compliance.

\section{References}

A Framework for Testing Year 2000 Application Conversions. Compuware Corporation. $\mathrm{URL}=\mathrm{http}: / /$ www.year2000.com

Date-Compliance Checking: Objectives and Management. Institution of Electrical Engineers URL = http://www.iee.org.uk/2000risk/actseng.htm

DISC PD2000-1 A Definition of Year 2000 Conformity Requirements. DISC is a part of the British Standards Institution.

$\mathrm{URL}=\mathrm{http}: / /$ www.brainstorm.co.uk/disc/year2000/2000.html 


\section{Appendix 1, "Solution Techniques}

The following solution implementation techniques can be applied when modifying existing systems for date problems. These techniques are for information purposes only.

Expansion: Expand 2-digit years to 4-digit years.

Pros: The only true solution; simple.

Cons: More resource intensive; data conversion routines required.

Testing Requirements: Minimal.

Encoding: Stuffing 4-digit years into 2 physical bytes.

Pros: Conserves space.

Cons: Programs become more complex; requires extra processor time.

Testing Requirements: Need a thorough test of the compression and expansion routines.

Windowing: Keep 2-digit years but assign specific semantics for two different ranges. For example, years 50 through 99 represent 1950 through 1999, and years 00 through 49 represent 2000 through 2049.

Pros: Conserves space.

Cons: Programs become more complex; requires extra processor time; will not work for applications that need to keep dates in a range that's wider than 100 years.

Testing Requirements: Test limited to "windowing" range. 


\section{Appendix 2, "Additional Testing Considerations}

\section{Restarting the Computer}

Restarting or rebooting of host computer systems for correct date upon power up and reinitialization needs to be performed to ensure the changes made for $\mathrm{Y} 2 \mathrm{~K}$ compliance produce the desired results.

\section{Data Archiving}

If you have archiving capabilities, two separate areas need to be addressed. If your system requires access to existing archived data, tests must ensure that data is correctly interpreted for any $\mathrm{Y} 2 \mathrm{~K}$ considerations. Archiving process tests may need to be performed to ensure the archiving process produces compliant data. Both these options require additional testing of the given system during formal testing.

\section{Automated Test Tools}

Automated tools for testing certain aspects of a system are available for use during assessment, conversion, and testing phases. Available tools may not cover all the testing needs for a specific system. Most tools are geared to determining compliance of a known vendor provided environment, such as a PC or host computer system, or a database engine. Tools for testing site developed applications must be developed and tested by local resources. 
Department of Energy Lawrence Livermore

Laboratory
National

\section{Year 2000 Compliance Review}

Conducted at the Oakland Operations Site September 15 through September 18, 1998

Prepared by: Year 2000 Compliance Review Team

DRAFT

September 23, 1998 



\section{Table of Contents}

I. Executive Summary

II. Recommendations

III. Review Objectives

IV. Review Methodology

V. Review by System

VI. Appendices

Appendix A - Lawrence Livermore National Laboratory (LLNL) Year 2000 Mission-Essential System Status

Appendix B - Glossary of Year 2000 Terms

Appendix C - Detailed System Information 


\section{Executive Summary}

This summarizes the Oakland Operations Office organization's Year 2000 compliance status for their mission-essential systems.

This summary is followed by general recommendations for the five systems reviewed, ALARMS, ARAC, ARGUS, PAYROLL, and SCAT.

i A project plan was provided for four of the five systems. The information provided for ALARMS, was insufficient and did not constitute a project plan. One of the four plans provided, ARAC, was deemed incomplete, requiring additional Year 2000 plan narrative and detailed schedule information.

i A risk assessment was provided for four of the five systems. The ALARM system provided a risk assessment form, however, the form was not filled out.

i $\quad$ A data vulnerability (data exchange) assessment was provided for four of the five systems. The information provided for the ARAC system was deemed insufficient.

i $\quad$ A test plan was provided for three of the five systems. The ALARMS and ARAC systems plans were deemed incomplete, requiring additional detailed schedule information.

Although adequate test plans and test output were provided for ARGUS and SCAT, it was not evident that test plans for these systems were executed according to the test plan documents and checklists.

i $\quad$ Renovation was completed for three of the five systems. The documentation provided for the ALARMS and ARAC systems was not sufficient to assess completion of renovation.

i Validation was reported as completed for two of the five systems.

i Compliant implementation was reported for two of the five systems, ARGUS and SCAT, however, there was no documentation provided to support compliant implementation, e.g., self-certification, system owner acceptance, etc. It is our understanding that the site was advised by legal counsel not to sign any selfcertification document/form at this time.

i The status of the Year 2000 tracking data base was not consistent with the documentation provided for the ALARM, ARAC, and PAYROLL systems. It was recommended that the data base be updated to reflect the actual current status of these 
projects as being ongoing rather than complete, thereby establishing a new baseline for several checkpoints. The site accepted the recommendation and revised the data base. Hence, the review was based on, and this report reflects, this new data base (project) status.

i Although documentation was provided for each project, it appeared that the project files could have been more complete. It is good project management practice to review and update project files in an ongoing fashion, in order to maintain integrity and an audit readiness posture. 


\section{Recommendations}

The following recommendations are provided to minimize risk to the organization in achieving Year 2000 compliance. They should be evaluated and implemented as appropriatc for each system. These recommendations may not be applicable for those systems that have already indicated Year 2000 compliance.

i Year 2000 Project Plans for two of the five systems (ALARMS, and ARAC) should be enhanced to include additional information relative to their respective management and technical approaches, and schedules (start/completion dates for task activities, etc.). Additional Year 2000 planning guidance can be found on the General Accounting Office (GAO) website: http://www.gao.gov/. Choose the "Special Publications" section and then "Year 2000 Computing Crisis: An Assessment Guide," which is near the bottom of the list of special publications.

i The risk assessment for ALARMS should be completed to mitigate the occurrence of any adverse impacts on Year 2000 activities and elements.

i The data vulnerability assessment for ARAC should be reviewed and updated to include information such as specific interfaces exchanging data information and status of contacts with those sending/receiving organizations.

i Test plans for two of the five systems (ALARMS and ARAC) should be enhanced to include additional information such as the identification of modules to be tested, resources applied, test start/completion dates, date relationships, etc. After test plans are executed, the test and validation results should be retained in the project file until at least January 1, 2001.

i The project files for the ARGUS and SCAT systems should be updated to include documentation that supports the system being implemented as Year 2000 compliant. This could include a completed self-certification form, a statement of the system owner's acceptance of the compliant system, or similar documentation.

i . All systems that are infrastructure dependent, including those that have already declared Year 2000 compliancy, should be tested as soon as practical within a Year 2000 compliant infrastructure.

i $\quad$ Status information for the mission-essential systems should be kept up to date in the Headquarters Year 2000 Mission-Essential Detail Data Base System. 
i Any archival data should be considered and tested. This would be especially cvident for those areas that require prior year reviews and inquiries. 


\section{Review Objectives}

i Review the organization's Year 2000 plans for mission-essential systems to provide an independent assessment that Year 2000 activities are progressing toward meeting Year 2000 compliance.

i $\quad$ Validate the existence, completeness, and/or execution of:

- project and test plans,

- $\quad$ project deliverables,

- $\quad$ project documentation, and

- $\quad$ related factors, such as the project management approach and testing methodology, that have an impact on LLNL's ability to complete the Year 2000 compliance activities within the established Department target dates. 



\section{Review Methodology}

\section{Action}

1. Provide the organization with a review outline and methodology.

2. Conduct the review.

3. Brief the organization on preliminary

findings.

$\underline{\text { Results }}$

i $\quad$ Year 2000 compliance package from Woody Hall

(dated December 22, 1997) forwarded to all organizations.

i $\quad$ Organization notified of the pending review.

i $\quad$ Briefed the organization on the objectives and review activities.

i $\quad$ Conducted interviews with key project personnel. i Reviewed project records/files.

i Reviewed project work products/ documentation.

i $\quad$ Provided feedback on assessment findings and observations.

i $\quad$ Provided

recommendations on how to improve current work products/ documentation.

i $\quad$ Provided organization with draft report.

i Incorporated comments into final report. 


\section{Review by System}

During the compliance review kick-off meeting, the Lawrence Livermore National Laboratory staff provided a clear explanation and view regarding their Year 2000 Plan, approach, and direction.

The following provides discrete system-by-system information relative to the review. For an overall status of all systems, see Appendix A.

\section{i_ ALARMS - Advanced Livermore Alarm Recognition and Monitoring} System

- The information provided was insufficient, and did not contain the basic elements of a project plan, e.g., descriptive narrative, detailed schedule, technical approach, resource management, etc., specific to the ALARMS project.

- A risk assessment was provided, however, the form was blank and contained no data.

- A data vulnerability assessment was provided.

- $\quad$ A test plan was provided, however, it required additional detailed schedule information, e.g., specific tasks/activities, with planned start and completion dates, resources required, etc.

- A contingency plan is not required at this time.

- The documentation provided was insufficient to allow an assessment of the completion of renovation activities.

- Validation activities are reported as ongoing.

i__ ARAC - Atmospheric Release Advisory Capability

- A project plan was provided, however, additional information was needed in the area of descriptive narrative, and detailed schedule information.

- A risk assessment was provided.

- A data vulnerability assessment was provided, however, it should be updated to include information relative to specific interfaces exchanging data and status of contacts with those sending/receiving organizations.

- A test plan was provided, however, it required additional detailed schedule information, e.g., specific tasks/activities, with planned start and completion dates, resources required, etc.

- A contingency plan is not required at this time. 
- The documentation provided was insufficient to allow an assessment of the completion of renovation activities.

- Validation activities are reported as ongoing. 
i_ ARGUS - An access control and intrusion detection security system

- A project plan was provided.

- A risk assessment was provided.

- A data vulnerability assessment was provided.

- A test plan was provided.

- A contingency plan is not required since the system is reported to be compliant.

- $\quad$ Renovation and validation activities are complete. This system is reported to be compliant.

- Compliant implementation was reported, however, there was no documentation provided to support compliant implementation, e.g., selfcertification, system owner acceptance, etc.

\section{i PAYROLL - LLNL payroll system}

- A project plan was provided.

- A risk assessment was provided.

- A data vulnerability assessment was provided.

- A test plan was provided.

- A contingency plan is not required at this time, however, a contingency plan was provided.

- Renovation is reported to be completed.

- Validation activities are ongoing.

i_ SCAT - Secure Communication and Teleconference System

- A project plan was provided.

- $\quad$ A risk assessment was provided.

- A data vulnerability assessment was provided.

- $\quad$ A test plan was provided.

- A contingency plan is not required since the system is reported to be compliant.

Renovation and validation activities are complete. This system is reported to be compliant.

- Compliant implementation was reported, however, there was no documentation provided to support compliant implementation, e.g., selfcertification, system owner acceptance, etc. 
Appendix A

LAWRENCE LIVERMORE NATIONAL LABORATORY

(LLNL)

DOE Year 2000 Mission-Essential Systems Profile 


\begin{tabular}{|c|c|c|c|c|c|c|c|c|}
\hline Systems & $\begin{array}{l}\text { Y2K } \\
\text { Plan }\end{array}$ & $\begin{array}{c}\text { Risk } \\
\text { Assessment }\end{array}$ & $\begin{array}{c}\text { Data } \\
\text { Vulnerability } \\
\text { Assessment }\end{array}$ & $\begin{array}{c}{ }^{*} \text { Test } \\
\text { Plan } \\
(6 / 15 / 98)\end{array}$ & $\begin{array}{c}{ }^{*} \text { Contingency } \\
\text { Plan } \\
(3 / 15 / 99) \\
\text { If Applicable }\end{array}$ & $\begin{array}{c}\text { *Renovation } \\
(9 / 15 / 98)\end{array}$ & $\begin{array}{c}* \text { Validation } \\
(2 / 15 / 99)\end{array}$ & $\begin{array}{c}\text { *Compliant } \\
\text { Implementation } \\
(3 / 31 / 99)\end{array}$ \\
\hline ALARMS & 2 & 3 & $\mathrm{X}$ & 3 & & 3 & & \\
\hline ARAC & 3 & $X$ & 3 & 3 & & 3 & & \\
\hline ARGUS & $\mathrm{X}$ & $\mathrm{X}$ & $\mathrm{X}$ & $\mathrm{X}$ & & $\bar{X}$ & $\bar{X}$ & 2 \\
\hline PAYROLL & $X$ & $X$ & $X$ & $X$ & & $\mathrm{X}$ & & \\
\hline SCAT & $\mathrm{X}$ & $\mathrm{X}$ & $\mathrm{X}$ & $\mathrm{X}$ & & $X$ & $\mathrm{X}$ & 2 \\
\hline & & & & & & & & \\
\hline & & & & & & & & \\
\hline & & & & & & & & \\
\hline & & & & & & & & \\
\hline & & & & & & & & \\
\hline
\end{tabular}

\section{Completed.}

(1) Required, but not provided.

(2) Reported as completed, but not provided.

(3) Insufficient documentation provided.

Blank Not required, or not yet required.

* These items are due by DOE and OMB direction as of the dates indicated. Some items may already be completed.

Note: Compliant Implementation assumes testing within a Year 2000 compliant infrastructure will be performed when ready. $6 / 5 / 98$ 


\section{Appendix B}

\section{Glossary of Year 2000 Terms}

\section{Compliance}

Year 2000 compliant systems are those that have hardware, software, and firmware that shall be able to accurately process date data (including, but not limited to, calculating, comparing, and sequencing) from, into, and between the twentieth and twenty-first centuries, including leap-year calculations. In addition, systems must be able to accurately provide and receive data with external systems as required.

\section{Contingency Plan}

A management plan that identifies alternative strategies and solutions to be used to ensure business functions will not be interrupted if identified Year 2000 risk events occur.

\section{Data Vulnerability Assessment}

Involves the identification and related fixes, as appropriate of data exchanges (bridges, filters, interfaces) between two organizations outside of the home organization such as between federal agencies, states, counties, and private companies. This also includes data exchanges between dependent systems, e.g., accounting and payroll.

\section{Mission-Essential Systems}

Guidance was developed based on Title 36 of the Code of Federal Regulations, Chapter XII, Part 1236, Management of Vital Records and Office of Management and Budget Circular A-130, Management of Federal Information Resources. Besides these "legal" definitions, the following, simpler guidance was developed: Any system should be considered Year 2000 mission-essential, if that system's failure comes to the attention of the Secretary or Departmental senior programmatic official because a mission of the Department is not being accomplished.

\section{Project Plan}

A document for controlling/managing a project. A project plan defines the technical and managerial functions, activities, and tasks necessary to satisfy the requirements of the task assignment or project. Typically includes information relative to who, what, when, where, and how. Usually the level of detail for a Year 2000 mission-essential system project plan is commensurate with the scope of the modifications required.

\section{Risk Assessment}

Identifies and assesses the risk factors associated with Year 2000 non-compliance, and provides plans to mitigate and control these risks. 


\section{Test Plan}

The controlling document for verification and validation of operational integrity, efficiency, and effectiveness. Typically includes information relative to who, what, when, where, and how. A schedule of Year 2000 activities is generally included.

\section{Activity Schedule}

A graphic or written chart or representation that defines the project's milestones in sufficient detail, including the relationship of elements of work to each other and to achievement of the Year 2000 compliancy--the end product. The Year 2000 schedule information shows the relationship of all elements supporting the project's achievement of Year 2000 compliancy on schedule, provides a sound basis for Year 2000 costs, and assists in keeping the effort/project on schedule or provides early indicators of schedule problems.

\section{Year 2000 Phases:}

\section{Phase 1 - Awareness}

Define the Year 2000 problem and gain executive level support and sponsorship. Establish Year 2000 program team and develop an overall strategy. Ensure that everyone in the organization is fully aware of the issue.

\section{Phase 2 - Assessment}

Assess the Year 2000 impact on the enterprise. Identify core business areas and processes, inventory and analyze systems supporting the core business areas, and prioritize their conversion or replacement. Develop contingency plans to handle data exchange issues, lack of data, and bad data. Identify and secure the necessary resources.

\section{Phase 3 - Renovation}

Convert, replace, or eliminate selected platforms, applications, data bases, and utilities. Modify interfaces. 


\section{Phase 4 - Validation}

Test, verify, and validate converted or replaced platforms, applications, data bases, and utilities. Test the performance, functionality, and integration of converted or replaced platforms, applications, data bases, utilities, and interfaces in an operational environment.

\section{Phase 5 - Implementation}

Implement converted or replaced platforms, applications, data bases, utilities, and interfaces. Implement data exchange contingency plans, if necessary. 


\section{Appendix C}

\section{Detailed System Information}

Note: The Data Base Detail sheets were used as the baseline for the Review Analysis. These sheets were printed on Tuesday, September 15, 1998. 

Y2K End-to-End Test Strategy and Resource Plan

\begin{tabular}{|c|c|c|}
\hline & Y Y2K END-TO-END TE & TSTRATEGY AND RESOURCE PLAN \\
\hline Sys & in Name: Atmospheric Release Advisory Capability & 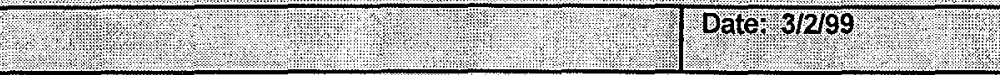 \\
\hline & 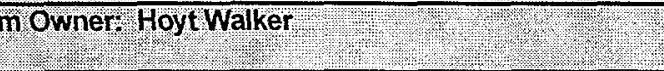 & 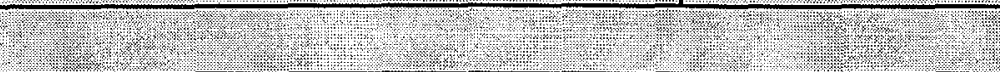 \\
\hline Org & Ization: Lawrence Livermore Nationäl Laboratory/E & th \& Environmental Sciences Directorate \\
\hline 11.0 & est Strategy (all items should be briefly addressed in & he space provided below - attach additional page(s) as necessary) \\
\hline 1.1 & $\begin{array}{l}\text { Provide a brief description of the core business } \\
\text { processes and activities to be supported by the systems } \\
\text { to be tested. }\end{array}$ & $\begin{array}{l}\text { The Atmospheric Release Advisory Capability (ARAC) provides estimates of the } \\
\text { dispersion of hazardous material in the atmosphere as an emergency response } \\
\text { capability. The service is provided to about } 40 \text { DOE and DOD sites as part of formal } \\
\text { support agreements. Supported sites run a system developed by ARAC, the Site } \\
\text { Workstation System (SWS), that runs on Sun workstations and allows customers to } \\
\text { submit descriptions of release scenarios and receive ARAC products in both } \\
\text { emergency response and exercise modes. Many supported sites also manage local } \\
\text { meteorological obsenvations using the SWS software. In addition, ARAC can } \\
\text { respond to events anywhere in the world as one of DOE's emergency response } \\
\text { assets. } \\
\text { ARAC's current operational system is referred to as ARAC-2. A complete } \\
\text { reengineering of the ARAC system is in progress with the initial operational fielding } \\
\text { of the new system (ARAC-3) scheduled for January } 1,2000 \text {. Since ARAC-3 is in } \\
\text { development it cannot be certified for compliance, so compliance activities are } \\
\text { focused on ARAC-2. }\end{array}$ \\
\hline 1.2 & $\begin{array}{l}\text { List the mission-critical systems, nonmission-critical } \\
\text { systems and supporting technology infrastructure to be } \\
\text { included in the end-to-end test. }\end{array}$ & $\begin{array}{l}\text { The ARAC-2 Central System is the primary system to be tested and includes a } \\
\text { number of mission-critical core subsystems. End-to-end testing of the Central } \\
\text { System includes the following critical subsystems: } \\
\text { modeling system } \\
\text { gridded metdata receiving system } \\
\text { gridded metdata processing system } \\
\text { observed meteorological data extraction system } \\
\text { geographic data system } \\
\text { model parameter generation system } \\
\text { visualization system } \\
\text { product generation system } \\
\text { product delivery system } \\
\text { communications system } \\
\text { The SWS is also part of the mission-critical core of ARAC and is included in the } \\
\text { end-to-end testing. SWS testing includes the meteorological data gathering system } \\
\text { that includes an embedded processor. } \\
\text { A nonmission-critical subsystem tested is the observed meteorological data } \\
\text { receiving system. This includes the ARAC software to receive observed } \\
\text { meteorological data from Air Force Weather Agency and the IDS and DDP satellite } \\
\text { feeds from Alden Electronics. }\end{array}$ \\
\hline
\end{tabular}




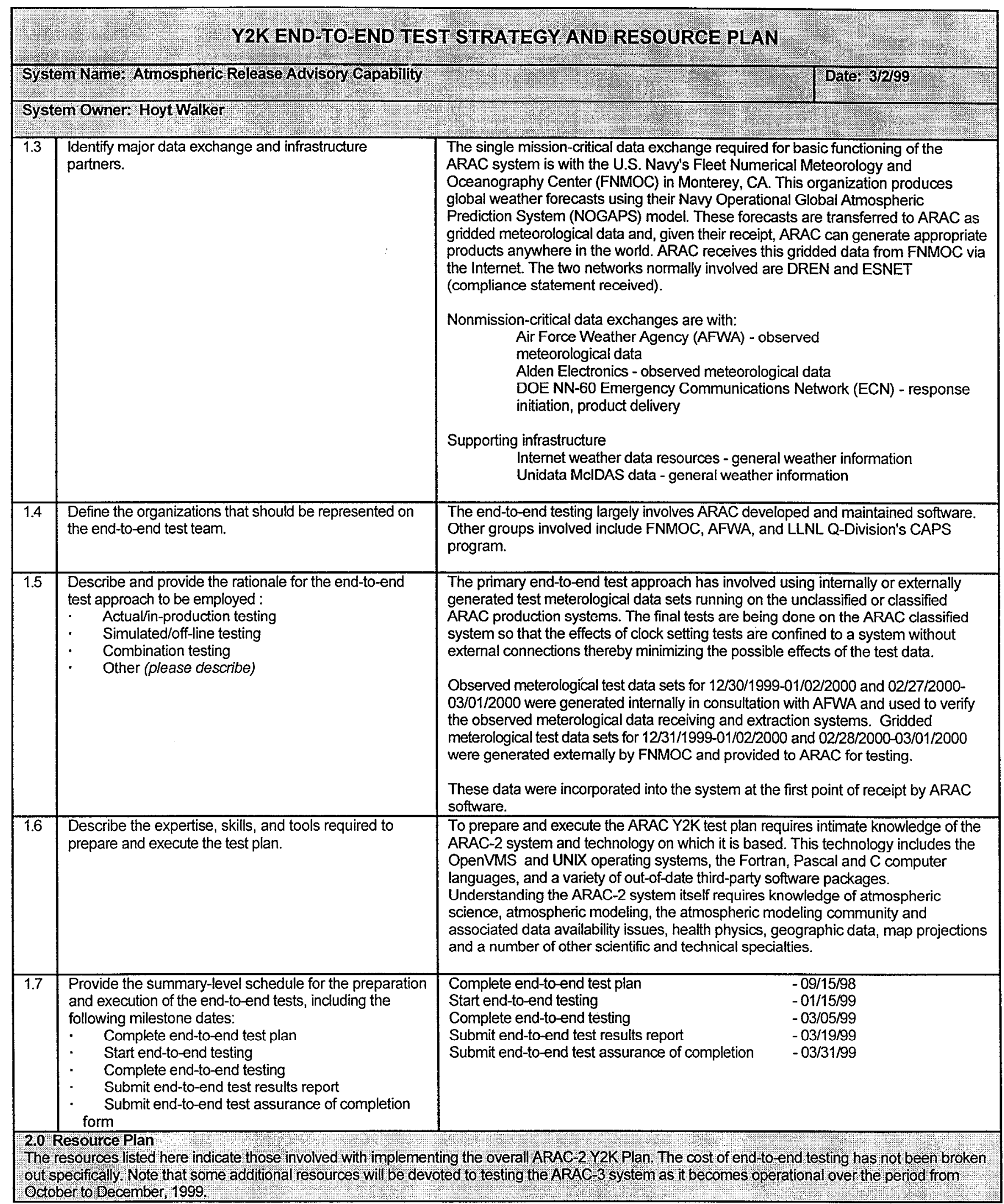




\begin{tabular}{|c|c|c|}
\hline & Y2K END-TO-ENDT & STRATEGYAND RESOURCEPLAN \\
\hline & m Name: Atmospheric Release Advisory Capabilit & 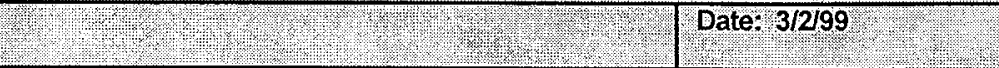 \\
\hline & Owner: Hoyt Walker & (1. \\
\hline 2.1 & $\begin{array}{l}\text { Provide summary-level resource estimates for the } \\
\text { preparation and execution of end-to-end test activities, } \\
\text { including: } \\
\text { - Federal and contractor staff (FTEs and dollars) } \\
\text { - Equipment (descriptions and dollars) } \\
\text { - Other direct costs (such as travel) } \\
\text { - Other resource requirements }\end{array}$ & $\begin{array}{l}\text { LLNL Staff - 1.6 FTEs, } \sim \$ 400 \mathrm{~K} \\
6 \text { people have made significant contributions to the ARAC-2 renovation } \\
\text { and testing effort with the body of the Central System work beginning in } \\
\text { August 1998. Another } 3 \text { people made significant contributions to the SWS } \\
\text { renovation and testing effort. } \\
\text { Licenses - } \$ 20 \mathrm{~K} \\
\text { A number of license upgrades were made to the ARAC-2 system } \\
\text { specifically to achieve Y2K-compliancy. } \\
\text { Equipment - \$O } \\
\text { Travel - } \$ 0 \text { (assuming no travel is required for IV\&V as is currently expected) } \\
\text { Other Staff - } 1 \text { FTE week }(\sim 5 \mathrm{~K}) \text { for reviewer }\end{array}$ \\
\hline 2.2 & Discuss resource constraints, if any. & $\begin{array}{l}\text { Given the focus of the program on both its on-going operational commitments and } \\
\text { the completion of ARAC-3, all people on the project have multiple roles and these } \\
\text { roles are tied to critical deadlines that are independent of the Y2K effort. This implies } \\
\text { that Y2K issues cannot be the sole focus of any person in the program and that all } \\
\text { Y2K efforts dilute the work in other critical areas. This effort is not explicitly funded } \\
\text { but is being handled as a maintenance effort out of existing funds. }\end{array}$ \\
\hline
\end{tabular}






\section{MEMORANDUM}

To:

ARAC Supported Sites

From:

James $S$. Ellis

Subject:

Systems and Software Year 2000 (Y2K) Issues

\section{ARAC Y2K compliance:}

In compliance with DOE orders, ARAC has prepared a detailed end-to-end testing plan in order to verify that all mission critical aspects of our ARAC capability will function fully on January 1st, 2000 (ARAC has been designated by DOE as a Mission Critical System).

This plan tests both internal and external systems and includes:

- Main operating system and networks

- System interfaces and architecture, including databases

- Computer models

- Remote site-workstation system operation

- Site-workstation collection of local meteorological data

- Regional and global observed and gridded meteorological data assimilation

- Communications links and nodes

ARAC has been conducting testing and verification following this plan since the summer of 1998, in order to meet Y2K compliance by March 31, 1999.

Following the plan ARAC has conducted multiple runs using a closed-system of the SiteWorkstation and the Central System software. The internal clocks for both of these isolated systems were changed; and a meteorological data set prepared by the Fleet Numerical Meteorological Operations Center (FNMOC) was used in the test.

The results of these tests have successfully demonstrated that all ARAC emergency response software will function appropriately into the year 2000 .

\section{Site-Workstation System:}

The SOLARIS 2.5 .1 operating system on the SUN UNIX machines is $Y 2 \mathrm{~K}$ compliant. The current ARAC software will function in the year 2000 , but has a cosmetic date display problem. This minor problem will be fixed with an upgrade package that will be shipped to all SiteWorkstation users by March 31, 1999.

Additionally, HANDAR has advised us that the tower meteorological data collection software is also $\mathrm{Y} 2 \mathrm{~K}$ compliant, which we have tested and verified.

\section{University of California}

\section{$\circlearrowleft$ Lawrence Livermore}




\section{Central System:}

With the successful isolated-system clock-setting test, we have completed our end-to-end testing and verified that all internal aspects of our emergency response system are $\mathrm{Y} 2 \mathrm{~K}$ compliant. Additionally, using the FNMOC data set in our isolated-system test, we have verified that at least one of our redundant meteorological data assimilation paths is also $\mathrm{Y} 2 \mathrm{~K}$ compliant. Systems verified to be functional in the year 2000 include:

- atmospheric simulation models

- model parameter creation

- model visualization

- product generation and delivery

- gridded meteorological data receiving and processing

- observed meteorological data extraction

- geographic data

- communications

In summary, we have evaluated not only the Site-Workstation and Central System software, but verified external communication links and third-party software to confirm our emergency response system is now, and will be functional on January 1st, 2000 and beyond.

\section{Documentation:}

We will soon be submitting to DOE for approval extensive, detailed technical documentation that includes:

- The testing plan

- Problems uncovered by the plan

- Solutions to the problems

- Results of tests of the problem fixes

- Results of all other tests

- Third-party written assurances of Y2K compliance as required

- Final closed-system verification results 



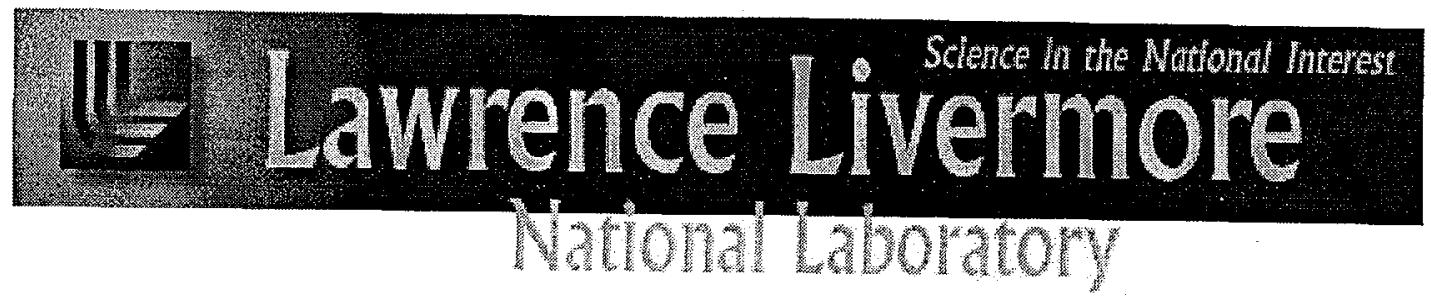

\section{ATMOSPHERIC RELEASE ADVISORY CAPABILITY}

\section{YEAR 2000 DOCUMENTATION: Plan, RENOVATION AND Test Results}




\section{ARAC Year 2000 Plan, Renovation and Tests}

\section{Foreword}

The ARAC has made a significant effort in detecting y ear 2000 (Y2K) problems, correcting these problems and verify ing $\mathrm{Y} 2 \mathrm{~K}$ compliance. For these efforts to be most useful, the entire process needs to be documented in some detail, both for ARAC's archives and to facilitate external reviews. This document is intended to cover all aspects of ARAC's Y2K effort including longterm program context, formal planning, summaries of compliance statements from hardware/software vendors, the various phases of testing, and test results.

In general, compliance methods used for determining Year 2000 compliance will vary bccause of sy stem or facility constraints. These constraints include varying levels of funding, resources, priority, system availability, and management premgative. In addition, a variety of system specific constraints will also influence the testing procss. While general guidelines provided give some indication of good practice concerning testing and test planning, the full range of formal tests has been adapted because of the constraints mentioned above.

Because full certification, i.e., externally performed testing of the current operational ARAC (ARAC-2) system and the next generation system (ARAC-3), would have been cost prohibitive, a measured response to the problem was necessary. This measured response included making changes to ARAC-2 in light of the experience base that exists with that sy stem, along with substantial but focused testing of this sy stem. Since a critical portions of both systems are vendor provided, reliance on vendor compliance certification and vendor compliance statements is important but was supplemented by in-house testing.

Since ARAC-3 will be in development, including critical date-dependent subsystems, until the beginning of FY 2000, compliance testing has focused on ARAC-2. Consequently, ARAC-2 is the primary focus of this document, although comments about ARAC-3 will be included where appropriate. The successful completion of the $\mathrm{Y} 2 \mathrm{~K}$ testing of the ARAC-2 system ensures the ARAC will be able to respond as a mission-critical sy stem. When the development of the initial ARAC-3 sy stem is completed, at the end of FY99, a three month period of intense testing of the new sy stem will begin, which will include $\mathrm{Y} 2 \mathrm{~K}$ tests, focused to producing an operationally stable sy stem by 1 January, 2000. 


\section{TABLE OF CONTENTS}

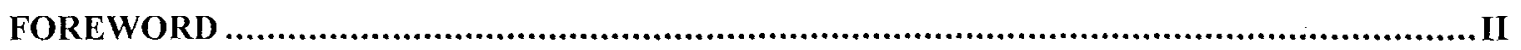

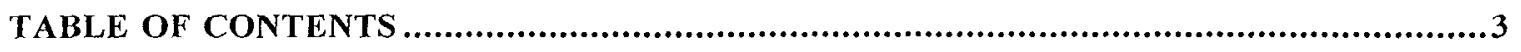

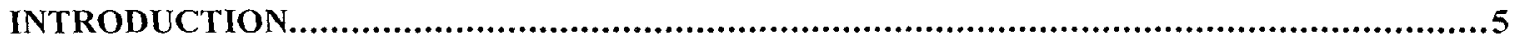

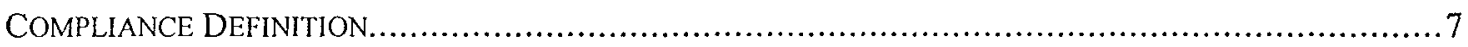

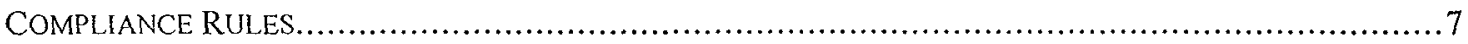

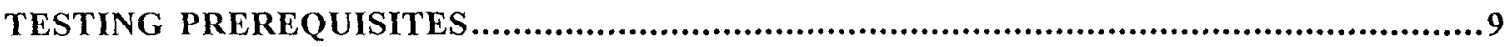

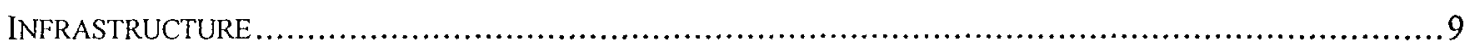

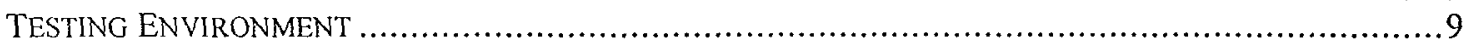

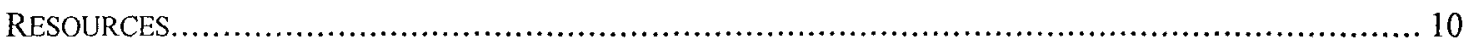

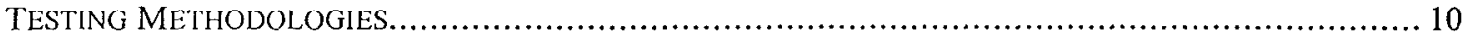

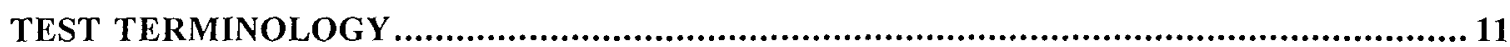

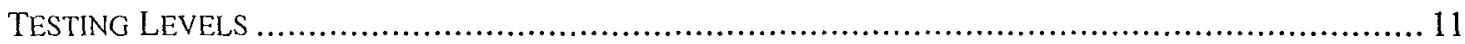

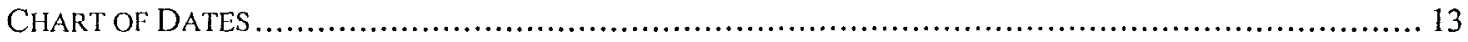

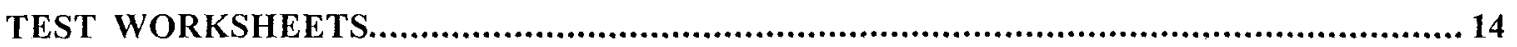

ARAC-2 VENDOR SOFTWARE TEST PLAN WORKSHEET .................................................... 15

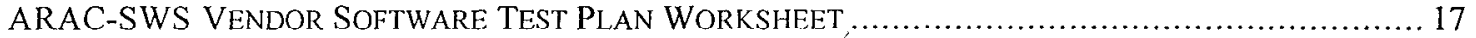

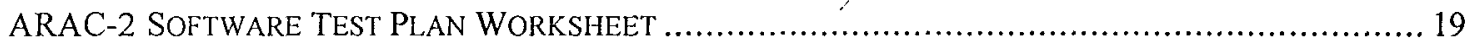

ARAC-SWS SOFTWARE TEST PLAN WORKSHEET ............................................................... 21

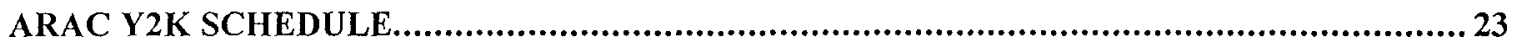

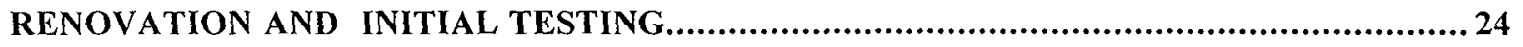

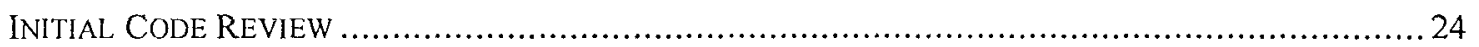

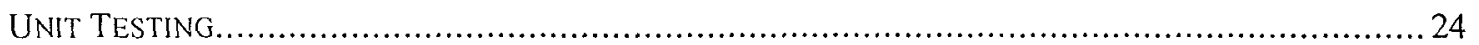

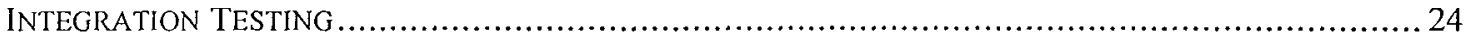

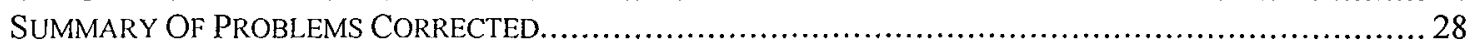

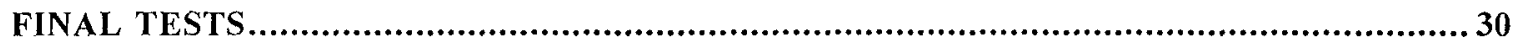

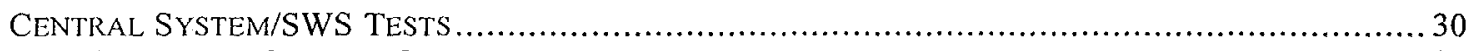

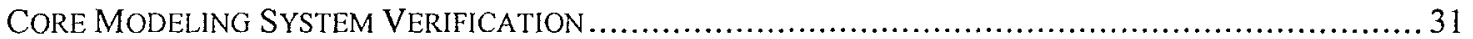

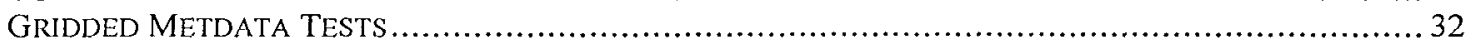

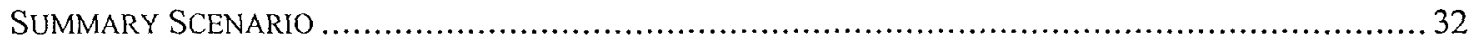

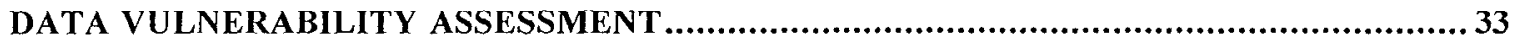

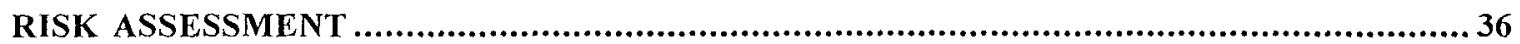

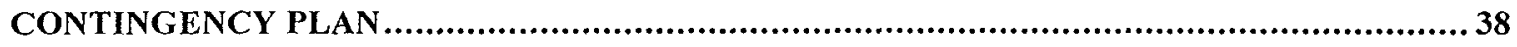


APPENDIX 1 - SWS METDATA OVERVIEW SCREEN...................................................41

APPENDIX 2 - SUMMARY OF OBSERVED METDATA TESTING.................................... 42

APPENDIX 3 - PRODUCTION SOFTWARE UPDATE MEMOS ........................................43

APPENDIX 4 - CENTRAL SYSTEM/SWS TEST PRODUCTS...............................................4 44

APPENDIX 5 - CORE MODELING SYSTEM TEST PRODUCTS......................................... 45

APPENDIX 6 - GRIDDED METDATA TEST PRODUCTS............................................... 46

APPENDIX 7 - SUMMARY SCENARIO PRODUCTS .............................................................4 47

APPENDIX 8 - SUMMARY OF PRIMARY SUPPORTING DOCUMENTATION .................... 48 


\section{ARAC Year 2000 Plan, Renovation and Tests}

\section{Introduction}

The Atmospheric Release Advisory Capability (ARAC) at Lawrence Livermore National Laboratory (LLNL) provides timely and credible estimates of the transport of hazardous material in the atmosphere as an emergency response resource to the Department of Energy and others. ARAC uses computer models, data acquisition, archiving and analysis systems along with highly trained personnel to provide this service. Given the reliance on computer technology inherent in the ARAC system, the $\mathrm{Y} 2 \mathrm{~K}$ issue is of significant concern to the program. This concern is highlighted by ARAC's designation as one of LLNL's and DOE's mission critical systems. To interpret the following document appropriately, some background regarding ARAC's current status is necessary and is provided in the next few paragraphs.

ARAC is in the process of rebuilding its entire system including the atmospheric models and all aspects of the system that supports the models. Development of the new system (referred to as ARAC-3 to distinguish it from the current operational system, ARAC-2) began in 1995 and was planned to be ready to supersede ARAC-2 during 1999. A variety of issues (funding deficits, loss of key personnel, etc.) have contributed to some extension of the expected delivery dates. ARAC-3 is being developed to avoid the $\mathrm{Y} 2 \mathrm{~K}$ problem (4-digit years are used in all situations), however, the likely delay in delivery of a stable, sufficiently complete, operational system until Jan. 1, 2000 implies that ARAC-2 must be updated to handle the Y2K problem.

As with many legacy systems, full update of ARAC-2 to verifiably handle the Y2K problem in all situations would likely be expensive. However, a careful evaluation of the situation has suggested that a relatively modest expenditure will be able to sufficiently verify the system to the point that ARAC can respond in a timely and credible way (though not necessarily optimal way in certain very unusual situations) independent of the status of the ARAC-3 development effort. However, a stable ARAC-3 system is also an important component of ARAC's overall response posture during this period of potential instability. Both of these systems should be viewed as backing each other up and ensuring that ARAC will be able to produce the best response possible to whatever situations develop at the time.

Given the transitional nature of the ARAC system during the next two years, planning at all levels must always be cognizant of the status of both ARAC-2 and ARAC-3. The current plan is to designate ARAC-3 as the primary system on January 1,2000. Development for this phase of the system is expected to be complete on October 15, 1999 and this will be followed by extensive testing to prepare the system for operational use. Development during the intervening period will include major reworkings of the heavily date-dependent subsystems for observed and gridded meteorological data processing. As a result, no useful end-to-end $\mathrm{Y} 2 \mathrm{~K}$ testing can begin until October. Thus, to both ensure ARAC's operational readiness through the critical period (as well as to meet DOE's March 31, 1999 requirement for mission-critical systems), ARAC-2 has

y2k ARAC_documentation DRAFT $\quad-5-\quad$ Last printed 5/17/99 12:47 PM




\section{ARAC YeAR 2000 Plan, Renovation AND TEsts}

been the focal point for Y2K testing and is the primary subject of this document. ARAC's Y2K efforts have focused on preparing ARAC-2 so that all primary ARAC requirements can be met with this system. The remainder of FY 1999 will focus on verifying that the ARAC-3 infrastructure (e.g., third-party software) is Y2K compliant and the testing of ARAC-3 during the first quarter of FY 2000 will include complete Y2K testing. In addition, a final round of testing of ARAC-2 will be associated with the last production update before January 1, 2000 (expected to occur in August-October, 1999) to ensure that no problems have crept into the ARAC-2 system as it has evolved (note that changes to ARAC-2 should be very minor).

The ovcrall ARAC testing strategy was constrained by funding and personnel requirements as well as ARAC's need to meet its on-going operational commitments. This implies that the Y2K effort was a balanced response not a maximal response. Consequently some degree of risk is involved. This risk is inevitable due to the cost of a complete external certification of ARAC-2, particularly regarding certain data-gathering functions. However, these risks are minimized by informed strategies regarding ARAC-2 capabilities that can appropriately focus on the heavily used portions of the system and place less effort on capabilities that are non-critical (e.g., capabilities that have rarely been used). Also, the fact that ARAC-3 will be a reasonably complete, operational system that can serve as important backup to ARAC-2 limits risk. For example, the ARAC-3 system will include a number of additional data paths that are distinct from those in ARAC-2 with at least partly independent failure modes. Given the links between these systems developed in the course of the development of ARAC-3, these system will back each other up in a variety of ways. Thus the program will accept something less than an ideal testing plan (e.g., foregoing a fully independent testing program) due to limitations in funding and the need to continue to progress as rapidly as possible. with the completion of ARAC-3 while maintaining the operational readiness of the ARAC-2 system.

The following sections include a restatement of the definition of Year 2000 (Y2K) compliance, a summary of testing infrastructure issues as the related to implementing the ARAC test plan, a review of the renovation process and completed test forms. In addition, the results of the testing will be described, beginning with unit testing, and building up to a set of end-to-end tests (with system clocks set) that demonstrate ARAC's Y2K compliance. Detailed discussion will focus on the end-to-end tests and summary results of these tests will be presented. References to further supporting documentation (e.g., Y2K-compliance statements from all vendors) will be included as appropriate. Note that the ARAC test plan relied on guidelines that are detailed in the "ARAC Year 2000 Guidelines and Test Plan" document that was reviewed by DOE in September, 1998.

In addition, updates of the Data Vulnerability Statement, Risk Assessment and preliminary Contingency Plan are included. Various Appendices provide some additional information about both the testing processing and some graphical results of the final tests. A summary of the primary supporting documentation is provided in the last Appendix. 


\section{ARAC Year 2000 Plan, Renovation and TEsts}

\section{Compliance Definition}

The following compliance definition is based on DISC PD2000-1, A Definition of Year 2000 Conformity Requirements, a document produced by the British Standards Institution.

Simply stated, Year 2000 compliance shall mean that neither performance nor functionality is affected by dates prior to, during, and after the year 2000. In particular the following rules must be satisfied:

- $\quad$ Rule 1 No value for current date will cause any interruption in operation. (General Integrity)

- $\quad$ Rule 2 Date-based functionality must behave consistently for dates prior to, during and after year 2000. (Date Integrity and Leap Year Integrity)

- $\quad$ Rule 3 In all interfaces and data storage, the century in any date must be specified either explicitly or by unambiguous algorithms or inference rules. (Century Integrity)

\section{Compliance Rules}

This section describes the compliance definition rules further to provide the reader and test planner a better understanding of each rule.

- $\quad$ Rule 1: No value for current date will cause any interruption in operation.

1.1: This rule is known as general integrity (see R 1.1 - Chart of Dates).

1.2: If this requirement is satisfied, roll-over between all significant time demarcations (e.g. days, months, years, and centuries) will be performed correctly.

1.3: Current date means today's date as known to the equipment or product.

- $\quad$ Rule 2: Date-based functionality must behave consistently for dates prior to, during and after year 2000.

2.1: This rule is sometimes known as date integrity.

2.2: This rule means that all equipment and products must calculate, manipulate and represent dates correctly for the purposes for which they were intended. For ARAC purposes, rule 2.2 will include Leap Year Integrity testing.

2.3: The meaning of functionality includes both processes and the results of 


\title{
araC Year 2000 Plan, Renovation and Tests
}

\author{
those processes.
}

2.4: If desired, a reference point for date values and calculations may be added by organizations; e.g. as defined by the Gregorian calendar.

2.5: No equipment or product shall use particular date values for special meanings; e.g. "99" to signify "no end value" or "end of file" or "00" to mean "not applicable" or "beginning of file".

Rule 3: In all interfaces and data storage, the century in any date must be specified either explicitly or by unambiguous algorithms or inference rules.

3.1: This rule is sometimes known as explicit/implicit century.

3.2: It covers two general approaches:

(a) Explicit representation of the year in dates: e.g. by using four digits or by including a century indicator. In this case, a reference may be inserted (e.g. 4-digit years as allowed by ISO standard 8601:1988) and it may be necessary to allow for exceptions where domain-specific standards (e.g. standards relating to Electronic Data Interchange) should have precedence.

(b) Implicit representation of the year in dates requires the use of inference rules: e.g. two-digit years with a value greater than 50 imply $19 \mathrm{xx}$, those with a valuc cqual to or less than 50 imply $20 \mathrm{xx}$. Rulcs for century inference as a whole must apply to all contexts in which the date is used, although different inference rules may apply to different date sets. The strategy of selecting an appropriate 100 year period for use by a system by the use of such inference rules is often referred to as windowing.

The ARAC-2 system relies on an implicit century approach (with the exception of the model parameter system, which uses a 4-digit year and so is explicit) with 2-digit years less than 50 being interpreted as $20 \mathrm{xx}$ and years greater than or equal to 50 being interpreted as 19xx. This covers the earliest field experiment data in ARAC's model evaluation database (1956) while extended 49+ years beyond the expected lifetime of the system. ARAC-3 uses 4-digit years throughout and so it is explicit. 


\section{ARAC YeAR 2000 Plan, Renovation And TEsts}

\section{Testing Prerequisites}

This section provides considerations that were made as part of developing and implementing the ARAC Y2K testing process. The comments here are specific to ARAC. For general comments on these issues see the "ARAC Year 2000 Guidelines and Test Plan" document.

\section{Infrastructure}

It was the responsibility of the Lead Administrator for Production Systems (Ed Bush) to verify the ARAC-2 infrastructure by contacting the vendors for all of the components of the system and to coordinate any required upgrades. It is the responsibility of the Lead Administrator for Development Systems (Gary Berry) to verify the ARAC-3 infrastructure by contacting the vendors for the components listed above regarding their Y2K status and arranging any required upgrades. It is also the responsibility of the Lead Administrators to ensure that compliant versions of all key third party components are installed on all ARAC operational and development systems as part of preparing for $\mathrm{Y} 2 \mathrm{~K}$ testing.

\section{Testing Environment}

The ARAC Program will utilize its current resources to provide the test environments for the $\mathrm{Y} 2 \mathrm{~K}$ effort. In addition, standard ARAC software quality assurance procedures will be followed as part of the testing infrastructure. The way time-dependent data is handled in the ARAC-2 systcm allowed significant portions of the testing to be completed in the Central System Beta environment without risk of compromising either the Beta or the Production environments. For example, much of the ARAC system software devoted to handling meteorological data is a function of reported measurement time of the data, but not of the current time. Since the ARAC system handles future meteorological data as an operational capability, synthetic datasets that span the critical time demarcations could be generated and entered into the Beta metdata archive. The software that extracts and utilizes this data was exercised and when the testing was complete the synthetic files could be removed thereby safely returning the system to a normal state. For testing requiring the setting of the system clocks, the ARAC and CAPSNET multi-user classified systems were used since these have carefully managed external connections, standard procedures for purging the data disks and a less formal requirement for $24 \mathrm{hr} /$ day availability. The ARAC Multi-User System was used for general testing of the system and the CAPSNET Multi-User System was used to exercise the Central System interactions with the CAPSNET Site Workstation System (SWS). Testing involving the CAPSNET systems was coordinated with the CAPS program. 


\section{ARAC Year 2000 Plan, Renovation AND Tests}

\section{Resources}

ARAC devoted a significant portion of several computer scientists and computer technicians to the testing and renovation effort. Fewer resources are expected to be needed for ARAC-3 testing. ARAC assessors, in particular the designated Beta testers played key roles in the more complete system tests in addition to their normal role in acceptance testing. A number of roles were assigned in implementing the ARAC-2 renovation and testing effort:

- Project Lead - Hoyt Walker (Systems Operations Team Leader)

- ARAC-2 software conversion - Gordon Duckworth, Richard Yamauchi, Vicky Weseloh

- Metdata decoding conversion and testing - Kevin Foster

- External software and system configuration - Ed Bush

- General system administration - Leon Richardson

- SWS system administration and testing - Jon Welch

- Handar system testing - Jon Welch

- Beta Testers - Fernando Aluzzi, Phil Vogt

The following roles have been tentatively assigned for the ARAC-3 effort:

- Project Lead - Hoyt Walker

- Metdata test strategy - Bob Shectman

- External software and system configuration - Gary Berry

- Beta Testers - Connee Foster, Brenda Pobanz

\section{Testing Methodologies}

Testing of the ARAC-2 system with respect to the $\mathrm{Y} 2 \mathrm{~K}$ problem primarily relied on two of the five testing methodologies described in the general comments on testing methodologies in the "ARAC Year 2000 Guidelines and Test Plan" document. Developers performed both unit tests and some integration tests. The results of these integration tests were evaluated by users of the system. Other integration testing was performed by users. Final tests were performed by users of the system. Note that reliance on an external, independent group to perform testing would have been much too costly given ARAC's funding. 


\section{ARAC Year 2000 Plan, Renovation and Tests}

\section{Testing Terminology}

This section reviews the terminology of testing levels as they were applied to the testing of the ARAC-2 system. In addition, a chart of significant dates is included.

\section{Testing Levels}

Unit testing: Individual routines that perform time calculations, particularly those that are changed as part of the ARAC-2 conversion effort were subjected to testing to verify the basic functioning of the routine. This testing was done by the responsible developer. Due to the nature of much of the ARAC software, the generation of hardcopy or screens appropriate for meeting unit testing was not always possible. In such cases, the software was run using debugging tools to verify functioning of the code sections.

Integration testing: Major sub-systems of the ARAC system, such as problem metdata extraction, were tested against synthesized data sets. This testing was done by the responsible developer.

System testing: The full ARAC system was exercised primarily by the designated Beta testers, supplemented with testing by other experienced users. A first round of testing was against synthesized data sets. A second round of testing involved setting system clocks along with the synthesized inputs that were consistent with the system clock settings. This round included tests of the SWS in exercises with the Central System using Totally Automated HandsOff Exercises (TAHOEs), as well as testing the Handar meteorological instrumentation. Tests included full system exercises that span the date demarcations, that started after the demarcation but use data from before the demarcation and other cases intended that stressed the system appropriately. The tests included both large and small time and space domains and consequently used both observational and gridded meteorological data. While any feasible set of tests cannot exercise all the code in the ARAC system, the tests were chosen to span the range of normal system usage experienced over that past several years

Acceptance testing: Once the system level testing was complete, a final Production Update was be performed with the requisite Beta freeze and acceptance testing procedures normally used as key components of the ARAC softwarc quality assurance process. These procedures emphasize testing by the users of the system who have the final say in pronouncing the system ready for operational use. 


\section{ARAC Year 2000 Plan, Renovation and Tests}

Interface testing: As resources permitted, ARAC worked with its primary external providers of meteorological data to arrange and perform tests with these various systems to verify, as much as possible, the functioning of both systems. The primary organization involved in the mission-critical core of ARAC-2 is Fleet Numerical Meteorology and Oceanography Center (FNMOC) in Monterey, CA, which is the primary provider of gridded meteorological data fields used in ARAC. By demonstrating the ability of ARAC to receive and process FNMOC gridded fields, the ability of ARAC to produce a credible response anywhere on earth is ensured. The gridded fields used in testing were provided by FNMOC. Additional interface testing focused on the receipt of observed meteorological data from the Air Force Weather Agency (AFWA) and Alden Electronics. These tests were based on data test sets generated by ARAC from original data received from these organizations in the normal course of business (in particular, the test data sets were generated from data received during the period from December 31, 1998 at 2200 UTC to January 1, 1999 at 0200 UTC). These data were altered to indicate that they covered the same time period one year later and resubmitted to the system at the point of receipt from external systems. In addition efforts will be made to organize tests of DOE's Emergency Communications Network (ECN). The completeness of these tests will be a function of resource availability both in ARAC and in ARAC's collaborating organizations. 


\section{ARAC Year 2000 Plan, Renovation and Tests}

\section{Chart of Dates}

There are a number of specific dates that were considered in the ARAC Y2K testing process that are described in the table below. For details on testing rules see the "ARAC Year 2000 Guidelines and Test Plan" document.

Chart of Dates:

\begin{tabular}{|c|c|}
\hline Stratas & Testing Recutromenis \\
\hline 1999 dates & $\begin{array}{l}\text { - Test once to ensure that } 1999 \text { dates are recognized when processing in } \\
2000\end{array}$ \\
\hline $9 / 9 / 99$ & $\begin{array}{l}\text { - Test date behavior; many programmers have used } 9999 \text { as end of file } \\
\text { indicator }\end{array}$ \\
\hline $12 / 31 / 99$ to $1 / 1 / 00$ & $\begin{array}{l}\text { - Transition to year } 2000 \\
\text { - Full test of all components }\end{array}$ \\
\hline $2 / 29 / 00$ & $\begin{array}{l}\text { - Leap Year - ensure } 2 / 29 \text { is recognized as a date } \\
\text { - Ensure calculations of number of days is correct }\end{array}$ \\
\hline $12 / 31 / 00$ to $1 / 1 / 01$ & $\begin{array}{l}\text { - Transition to year } 2001 \text { (not needed for ARAC-2, which should be out } \\
\text { of service by } 5 / 00 \text { ) }\end{array}$ \\
\hline
\end{tabular}




\section{Test Worksheets}

The following worksheets were used for coordinating the renovation and testing efforts. For clarification of each referenced testing criteria, refer to the section, Testing Rules, in the "ARAC Year 2000 Guidelines and Test Plan" document. 


\section{ARAC Year 2000 Plan, Renovation and Tests}

\begin{tabular}{|c|c|c|c|}
\hline SYSTEM NAME: ARAC SYSTEM & $\operatorname{SION} \mathrm{E}$ & iM) & \\
\hline Primary Contact: Ed B & Backup & ontact: Leon Richar & dson \\
\hline Software: & Version(s): & Y2K status & ARAC Status \\
\hline OpenVMS (VAX) & $\begin{array}{l}5.5-2 \\
6.2 \\
\end{array}$ & $\begin{array}{l}\text { compliant with } \\
\text { patches }\end{array}$ & $\begin{array}{l}\text { patches } \\
\text { installed }\end{array}$ \\
\hline OpenVMS (Alpha) & $7.1-1 \mathrm{H} 2$ & $\begin{array}{l}\text { compliant with } \\
\text { patches }\end{array}$ & $\begin{array}{l}\text { patches } \\
\text { installed }\end{array}$ \\
\hline Sun Solaris & 2.5 .1 & $\begin{array}{l}\text { compliant with } \\
\text { patches }\end{array}$ & $\begin{array}{l}\text { patches } \\
\text { installed }\end{array}$ \\
\hline UniData NetCDF & 2.4 .3 & unknown & works in tests \\
\hline Motif & $\begin{array}{l}1.2-3 \\
1.2-4\end{array}$ & compliant & installed \\
\hline B2 Systems SmartStar/Ideo & $7.2-4 / 1.7$ & compliant & installed \\
\hline Builder Xcessary & 3.5 & compliant & installed \\
\hline PV-Wave & 6.21 & compliant & installed \\
\hline Process Software MultiNet & 4.1 & compliant & installed \\
\hline $\begin{array}{l}\text { Hierarchical Storage Operating } \\
\text { Firmware }\end{array}$ & 3.5 & compliant & installed \\
\hline GrayMatter ScriptServer & $\begin{array}{l}5.1-1 \\
5.1-3 \\
\end{array}$ & compliant & installed \\
\hline Fortran (Vax) & 6.5 & compliant & installed \\
\hline Fortran (Alpha) & 7.1 & compliant & installed \\
\hline Pascal (Vax) & 5.6 & compliant & installed \\
\hline Pascal (Alpha) & & compliant & installed \\
\hline $\mathrm{C}(\operatorname{Vax})$ & 5.6 & compliant & installed \\
\hline C (Alpha) & 5.7 & compliant & installed \\
\hline CMS & 4.0 & compliant & installed \\
\hline LSE & 4.6 & compliant & installed \\
\hline PathWorks & 1.5 & compliant & installed \\
\hline DecServer & & & \\
\hline Raxco RaxMaster & 7.2 & compliant & installed \\
\hline Raxco UltraDisk & 2.1 & compliant & installed \\
\hline Baseline functionality estal & lished: Yes & $\begin{array}{l}\text { Coordination of } s \\
\text { requirements }\end{array}$ & pecial \\
\hline Data recovery plans in plac & Yes & prior to productio & n Yes \\
\hline
\end{tabular}




\section{ARAC Year 2000 Plan, Renovation and Tests}

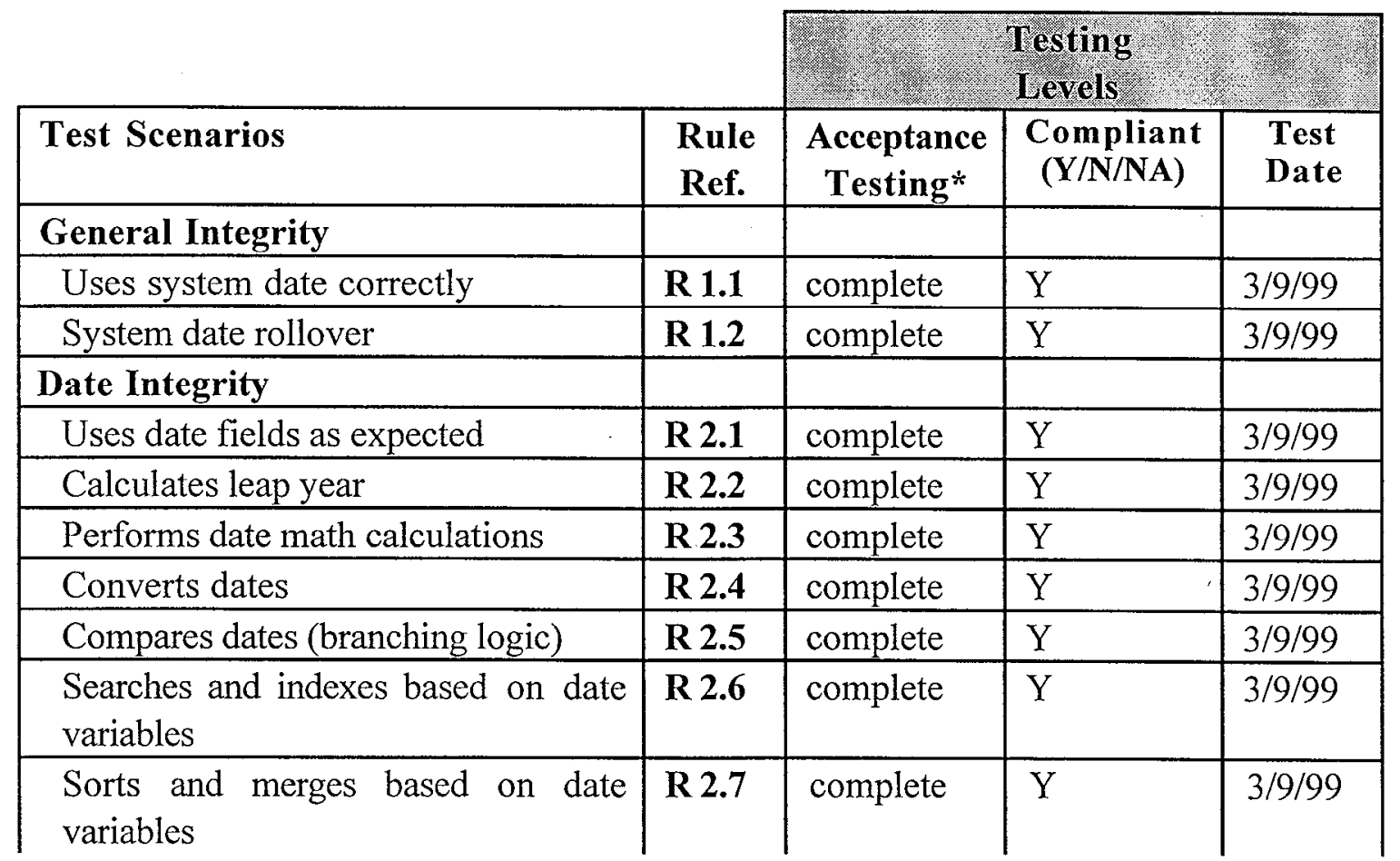

\begin{tabular}{|l|l|l|l|l|}
\hline Century Integrity (Explicit) & & & & \\
\hline $\begin{array}{l}\text { Correct use of tool kits or code } \\
\text { generators }\end{array}$ & $\mathbf{R 3 . 1}$ & complete & $\mathrm{Y}$ & $3 / 9 / 99$ \\
\hline Uses DBMS or layered product & $\mathbf{R 3 . 2}$ & complete & $\mathrm{Y}$ & $3 / 9 / 99$ \\
\hline External interfaces & $\mathbf{R 3 . 3}$ & complete & $\mathrm{Y}$ & $3 / 9 / 99$ \\
\hline Satisfies century compliance & $\mathbf{R 3 . 4}$ & complete & $\mathrm{Y}$ & $3 / 9 / 99$ \\
\hline Century Integrity (Implicit) & & & & \\
\hline $\begin{array}{l}\text { Correct use of tool kits or code } \\
\text { generators }\end{array}$ & $\mathbf{R 3 . 5}$ & complete & $\mathrm{Y}$ & $3 / 9 / 99$ \\
\hline Uses API interfaces correctly & $\mathbf{R 3 . 6}$ & complete & $\mathrm{Y}$ & $3 / 9 / 99$ \\
\hline Correct use of user interface & $\mathbf{R 3 . 7}$ & complete & $\mathrm{Y}$ & $3 / 9 / 99$ \\
\hline Satisfies century compliance & $\mathbf{R 3 . 8}$ & complete & $\mathrm{Y}$ & $3 / 9 / 99$ \\
\hline
\end{tabular}

ARAC-2 Vendor Software Worksheet Page 2 of 2 


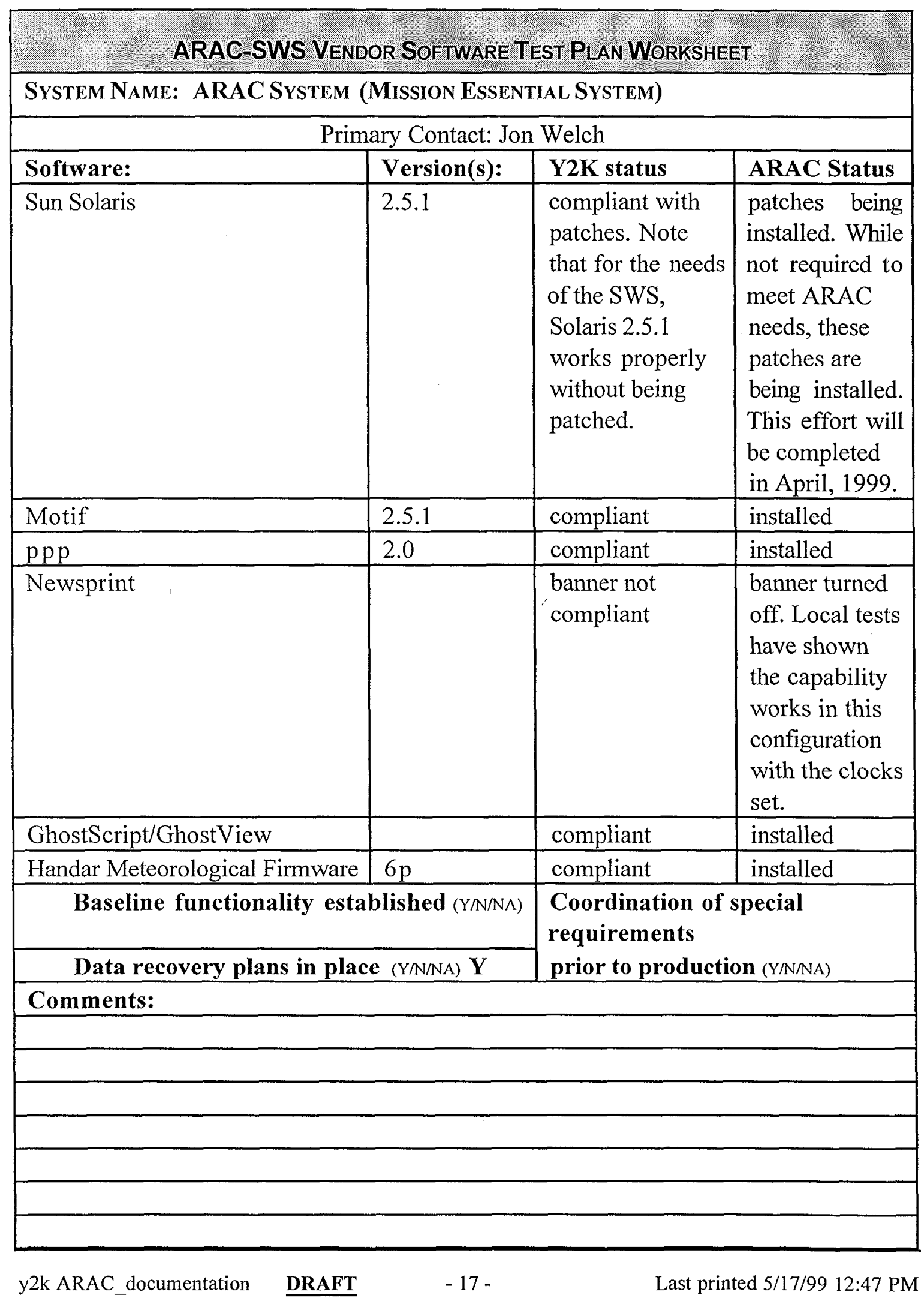


ARAC Year 2000 Plan, Renovation AND TEsts

\begin{tabular}{|c|c|c|c|c|}
\hline \multirow[b]{2}{*}{ Test Scenarios } & \multirow[b]{2}{*}{$\begin{array}{l}\text { Rule } \\
\text { Ref. }\end{array}$} & \multicolumn{3}{|c|}{$\begin{array}{l}\text { Testing } \\
\text { Levels }\end{array}$} \\
\hline & & $\begin{array}{c}\text { Acceptance } \\
\text { Testing* }\end{array}$ & $\begin{array}{l}\text { Compliant } \\
\text { (Y/N/NA) }\end{array}$ & $\begin{array}{l}\text { Test } \\
\text { Date }\end{array}$ \\
\hline \multicolumn{5}{|l|}{ General Integrity } \\
\hline Uses system date correctly & R 1.1 & complete & $\mathrm{Y}$ & $2 / 26 / 99$ \\
\hline System date rollover & R 1.2 & complete & Y & $2 / 26 / 99$ \\
\hline \multicolumn{5}{|l|}{ Date Integrity } \\
\hline Uses date fields as expected & R 2.1 & complete & $\mathrm{Y}$ & $2 / 26 / 99$ \\
\hline Calculates leap year & R 2.2 & complete & $\mathrm{Y}$ & $2 / 26 / 99$ \\
\hline Performs date math calculations & $\mathbf{R} 2.3$ & complete & $\mathrm{Y}$ & $2 / 26 / 99$ \\
\hline Converts dates & R 2.4 & complete & $\mathrm{Y}$ & 2/26/99 \\
\hline Compares dates (branching logic) & $\mathbf{R} 2.5$ & complete & $\mathrm{Y}$ & $2 / 26 / 99$ \\
\hline $\begin{array}{l}\text { Searches and indexes based on date } \\
\text { variables }\end{array}$ & $\mathbf{R} 2.6$ & complete & $\mathrm{Y}$ & $2 / 26 / 99$ \\
\hline $\begin{array}{l}\text { Sorts and merges based on date } \\
\text { variables }\end{array}$ & R 2.7 & complete & $\mathrm{Y}$ & $2 / 26 / 99$ \\
\hline
\end{tabular}

\begin{tabular}{|l|l|l|l|l|}
\hline Century Integrity (Explicit) & & & & \\
\hline $\begin{array}{l}\text { Correct use of tool kits or code } \\
\text { generators }\end{array}$ & $\mathbf{R 3 . 1}$ & complete & $\mathrm{Y}$ & $2 / 26 / 99$ \\
\hline Uses DBMS or layered product & $\mathbf{R 3 . 2}$ & complete & $\mathrm{Y}$ & $2 / 26 / 99$ \\
\hline External interfaces & $\mathbf{R 3 . 3}$ & complete & $\mathrm{Y}$ & $2 / 26 / 99$ \\
\hline Satisfies century compliance & $\mathbf{R 3 . 4}$ & complete & $\mathrm{Y}$ & $2 / 26 / 99$ \\
\hline Century Integrity (Implicit) & & & & \\
\hline $\begin{array}{l}\text { Correct use of tool kits or code } \\
\text { generators }\end{array}$ & $\mathbf{R 3 . 5}$ & complete & $\mathrm{Y}$ & $2 / 26 / 99$ \\
\hline Uses API interfaces correctly & $\mathbf{R 3 . 6}$ & complete & $\mathrm{Y}$ & $2 / 26 / 99$ \\
\hline Correct use of user interface & $\mathbf{R 3 . 7}$ & complete & $\mathrm{Y}$ & $2 / 26 / 99$ \\
\hline Satisties century compliance & $\mathbf{R 3 . 8}$ & complete & $\mathrm{Y}$ & $2 / 26 / 99$ \\
\hline
\end{tabular}

ARAC-SWS Vendor Software Worksheet Page 2 of 2 


\section{ARAC Year 2000 Plan, Renovation and Tests}

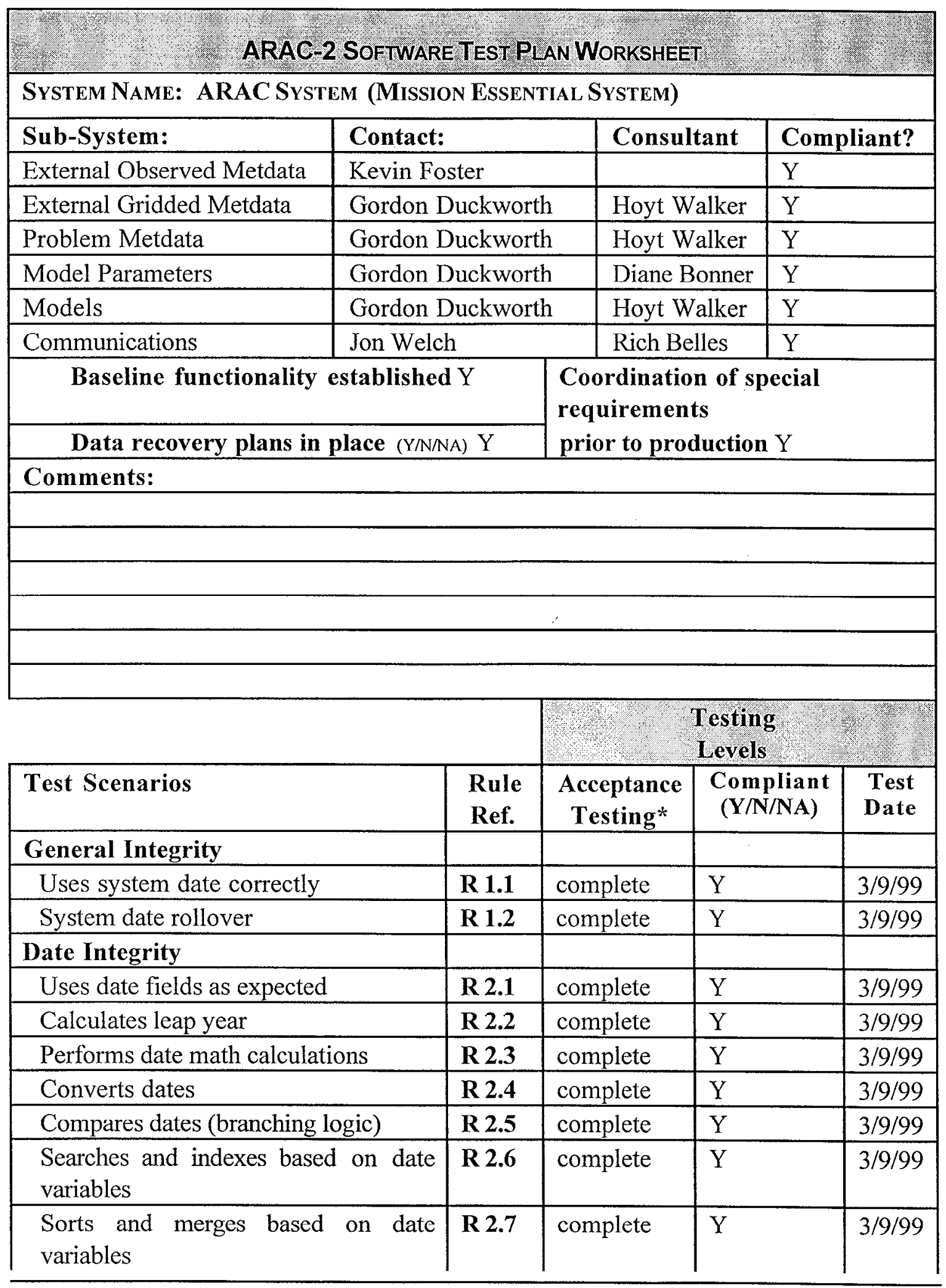


ARAC Year 2000 Plan, Renovation and Tests

\begin{tabular}{|l|l|l|l|l|}
\hline Century Integrity (Explicit) & & & & \\
\hline $\begin{array}{l}\text { Correct use of tool kits or code } \\
\text { generators }\end{array}$ & $\mathbf{R 3 . 1}$ & complete & $\mathrm{Y}$ & $3 / 9 / 99$ \\
\hline Uscs DBMS or laycrcd product & $\mathbf{R 3 . 2}$ & complete & $\mathrm{Y}$ & $3 / 9 / 99$ \\
\hline External interfaces & $\mathbf{R 3 . 3}$ & complete & $\mathrm{Y}$ & $3 / 9 / 99$ \\
\hline Satisfies century compliance & $\mathbf{R 3 . 4}$ & complete & $\mathrm{Y}$ & $3 / 9 / 99$ \\
\hline Century Integrity (Implicit) & & & & \\
\hline $\begin{array}{l}\text { Correct use of tool kits or code } \\
\text { generators }\end{array}$ & $\mathbf{R 3 . 5}$ & complete & $\mathrm{Y}$ & $3 / 9 / 99$ \\
\hline Uses API interfaces correctly & $\mathbf{R 3 . 6}$ & complete & $\mathrm{Y}$ & $3 / 9 / 99$ \\
\hline Correct use of user interface & $\mathbf{R 3 . 7}$ & complete & $\mathrm{Y}$ & $3 / 9 / 99$ \\
\hline Satisfies century compliance & $\mathbf{R 3 . 8}$ & complete & $\mathrm{Y}$ & $3 / 9 / 99$ \\
\hline
\end{tabular}

ARAC-2 Software Worksheet Page 2 of 2 
ARAC Year 2000 Plan, Renovation and Tests

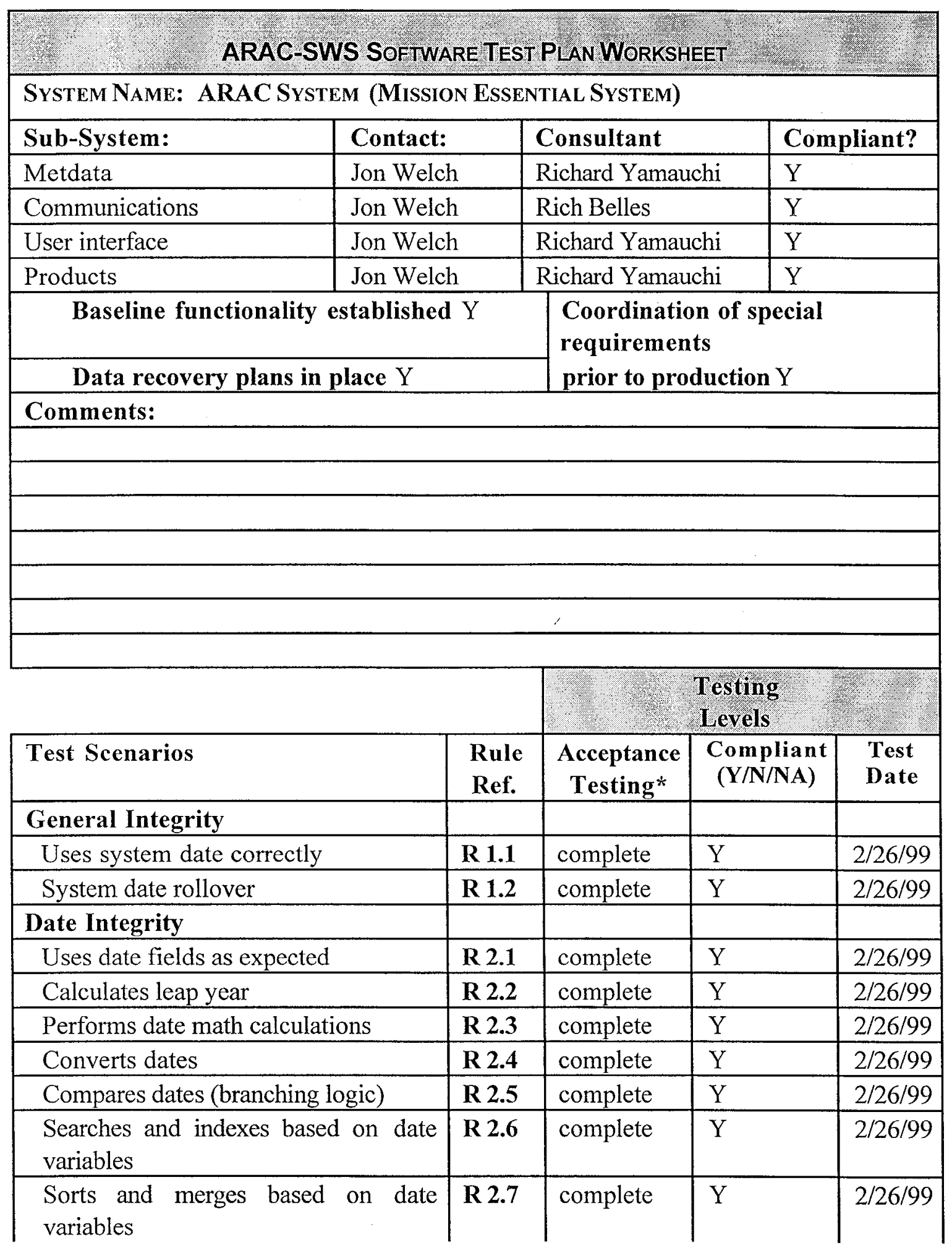


ARAC Year 2000 Plan, Renovation and Tests

\begin{tabular}{|l|l|l|l|l|}
\hline Century Integrity (Explicit) & & & & \\
\hline $\begin{array}{l}\text { Correct use of tool kits or code } \\
\text { generators }\end{array}$ & $\mathbf{R 3 . 1}$ & complete & $\mathrm{Y}$ & $2 / 26 / 99$ \\
\hline Uses DBMS or layered product & $\mathbf{R 3 . 2}$ & complete & $\mathrm{Y}$ & $2 / 26 / 99$ \\
\hline External interfaces & $\mathbf{R 3 . 3}$ & complete & $\mathrm{Y}$ & $2 / 26 / 99$ \\
\hline Satisfies century compliance & $\mathbf{R 3 . 4}$ & complete & $\mathrm{Y}$ & $2 / 26 / 99$ \\
\hline Century Integrity (Implicit) & & & & \\
\hline $\begin{array}{l}\text { Correct use of tool kits or code } \\
\text { generators }\end{array}$ & $\mathbf{R 3 . 5}$ & complete & $\mathrm{Y}$ & $2 / 26 / 99$ \\
\hline Uses API interfaces correctly & $\mathbf{R 3 . 6}$ & complete & $\mathrm{Y}$ & $2 / 26 / 99$ \\
\hline Correct use of user interface & $\mathbf{R 3 . 7}$ & complete & $\mathrm{Y}$ & $2 / 26 / 99$ \\
\hline Satisfies century compliance & $\mathbf{R 3 . 8}$ & complete & $\mathrm{Y}$ & $2 / 26 / 99$ \\
\hline
\end{tabular}

ARAC-2 Software Worksheet Page 2 of 2 


\section{ARAC Year 2000 Plan, Renovation and Tests}

ARAC Y2K Schedule:

\begin{tabular}{|c|c|}
\hline 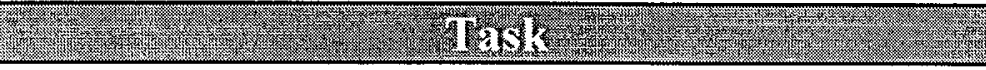 & Complotion Daro \\
\hline ARAC-2 Models Integration Testing & - $\quad$ May 1996 \\
\hline ARAC-SWS Renovation & - $\quad$ March 1997 \\
\hline ARAC-SWS Unit \& Integration Testing & - May 1997 \\
\hline ARAC-SWS System Testing (with clocks set) & - June 1998 \\
\hline $\begin{array}{l}\text { ARAC-SWS Metdata Collection Integration Testing } \\
\text { (embedded Handar system) }\end{array}$ & - July 1998 \\
\hline $\begin{array}{l}\text { ARAC-SWS/Metdata Collection System Testing } \\
\text { (with clocks set) }\end{array}$ & - $\quad$ August 1998 \\
\hline ARAC-2 Renovation \& Unit Testing & - September 1, 1998 \\
\hline ARAC-2 Integration \& System Testing & - October 15,1998 \\
\hline ARAC-2 Third-party Packages Y2K Compliant & - December 15,1998 \\
\hline ARAC-2 Beta Freeze (Acceptance Testing) & - December 1,1998 \\
\hline ARAC-2 Production Update & - December 15,1998 \\
\hline $\begin{array}{l}\text { ARAC-2 Green Room System Testing } \\
\text { (with clocks set) }\end{array}$ & - March 9,1999 \\
\hline $\begin{array}{l}\text { ARAC-2/SWS Green Room System Testing } \\
\text { (with clocks set) }\end{array}$ & - February 26, 1999 \\
\hline $\begin{array}{l}\text { ARAC-3 Third-party Packages Y2K Compliant (non- } \\
\text { mission critical) }\end{array}$ & October 1,1999 \\
\hline ARAC-2 Final Y2K Beta Freeze & - $\quad$ March 9, 1999 \\
\hline ARAC-2 Final Y2K Production Update & - $\quad$ March 22, 1999 \\
\hline $\begin{array}{l}\text { ARAC-3 Integration \& System Testing (with clocks set) } \\
\text { (non-mission critical) }\end{array}$ & October 31,1999 \\
\hline ARAC-3 Beta Freeze (non-mission critical) & November 1,1999 \\
\hline ARAC-3 Production Update (non-mission critical) & November 15,1999 \\
\hline Perform Independent Verification and Validation (IV\&V) & - April 1, 1999 \\
\hline Finalize IV\&V Documentation & April 15, 1999 \\
\hline Finalize ARAC Y2K Compliance Documentation & April 15, 1999 \\
\hline ARAC/FNMOC Testing & - February 26, 1999 \\
\hline ARAC/AFWA Testing (non-mission critical) & TBA \\
\hline ARAC/NCEP (non-mission critical) & TBA \\
\hline ARAC/ECN Testing (non-mission critical) & TBA \\
\hline ARAC/McIDAS (non-mission critical) & TBA \\
\hline
\end{tabular}

- - task completed 



\section{ARAC Year 2000 Plan, Renovation and Tests}

\section{Renovation and Initial Testing}

There were a number of major steps in the ARAC-2 renovation and testing process that merit some discussion. These steps were focused on identifying and correcting daterelated problems with software that has been developed by ARAC over the last 18 years. In addition, a summary of the problems discovered is provided.

\section{Initial Code Review}

To begin the renovation effort, code was reviewed in obvious data-dependent sections. The bulk of this initial effort was based on global searches through all sources files for patterns that had a reasonable probability of detecting time-dependent calculations (e.g., '9', '99', ' $\left.y y^{\prime}\right)$. These sections were reviewed and corrected when they did not handle the time calculations properly. As mentioned earlier, the various sub-systems in ARAC-2 differ in their time handling. Some, such as the model parameter generation system, were engineered with 4-digit years and were generally not identified as having problems. A number of other sub-systems did use 2-digit years. The cost of reengineering these systems with 4-digit years was deemed excessive, particularly given the need to perform schema migration on both active and archival databases in addition to the code changes necessary. Consequently, the windowing strategy was implemented. In all cases, the window boundaries were January 1, 1950 to December 31, 2049, i.e., years 50-99 are interpreted as 19xx while, years 00-49 are interpreted as 20xx. All date problems identified in this code review were corrected and the affected applications built in a testing environment.

\section{Unit Testing}

The first step in validating the changes identified in the initial code review was to test each routine that handled dates as an independent unit. Since most of the date calculations are done as part of a myriad other calculations and manipulations in relatively large codes, it was rarely sufficient to verify a unit just by running the program and examining the results. In all cases on the ARAC Central System, the programs were run using a debugging tool, and the details of the calculations evaluated for correctness. A similar strategy was used in renovating the Site Workstation System. On completion of this step, the expectation was that the majority of ARAC's software would perform correctly in all date situations within the 1950-2049 window.

\section{Integration testing}

A more complete evaluation of the system requires running sub-systems in increasingly realistic tests. The initial set of sub-systems tests focused on the core of the system after the receipt of observational meteorological data and its storage in ARAC-2's metdata archive. Programs were written that translate the dates associated with the data in this 


\section{ARAC Year 2000 Plan, Renovation And Tests}

archive thereby producing realistic data sets with tester controlled dates. For the bulk of the tests, simulated data sets were generated from the actual meteorological data received between 0000 UTC July 30, 1998 to 2300 UTC August 2, 1998. Simulated data sets were generated from this base data set for four periods:

1) UTC December 30, 1998 to 2300 UTC January 2, 1999 (the need for this data set will be discussed in the Core Modeling System Verification section of the FINAL TESTS Chapter)

2) UTC September 7, 1999 to 2300 UTC September 10, 1999

3) UTC December 30, 1999 to 2300 UTC January 2, 2000

4) UTC February 27, 2000 to 2300 UTC March 1, 2000

The files associated with these data sets (and for any data in the metdata archive) are organized in hourly files for surface and tower observations and in daily files for upper air observations. The file names include the date and time of the beginning of the interval for which data is stored. Consequently these files can be placed in the metdata archive and not interfere with normal functioning of the system. Thus, this level of testing could occur in parallel with the normal functioning of the system (note that these data sets need to be removed a few weeks before they would actually appear to be valid data to avoid mixing the simulated data with real data; note also that the ARAC-2 system handles future meteorological data to meet occasional operational needs so no special changes are required to allow basic testing (i.e., testing without setting the system clocks) to occur.

The tests began with a basic pass from metdata extraction, model parameter generation, model execution and production generation. This testing did identify a number of problems (see the following section). As these problems were fixed in the testing environment, a basic round of tests could be completed successfully. When the basic functioning of the system was validated at this level, the changes were installed in the Beta level of the ARAC-2 system. This set the stage for more complete tests where problems were initiated on the ARAC Site Workstation System (SWS) and the automated execution of the Central System (referred to as a Totally Automated HandsOff Exercise, TAHOE) was run to completion and products delivered back to the SWS. This demonstrated that the system could handle date changes in an end-to-end execution successfully. While no problems on the Central System were discovered at this stage, a cosmetic problem on the SWS was identified that resulted in an incorrect date being displayed on an ARAC product for valid times after January 1, 2000 (note that this problem has been fixed and will be fielded at all ARAC sites by mid-April, 1999). Other tests pointed out another date display problem on the SWS that affected the scrolling list for the selection of products to display. These errors did not seriously affect the functioning of the system but could have been confusing to an unprepared user. 


\section{ARAC Year 2000 Plan, Renovation And Tests}

This round of testing demonstrates the general ability of both individual sub-systems as well as the overall system to handle the various date changes of interest in the data being processed. Note that this round of testing does not eliminate the possibility of problems due to the current system time. The sub-systems tested using the simulated data sets above include:

- modeling system

- observed meteorological data extraction system

- model parameter generation system

- visualization system

- product generation system

- product delivery system

- communications system

Note the geographic data system was only lightly stressed in these tests since it is not date dependent and was expected to past the final tests without significant prior exercising.

Since the lifetime of the SWS was known to extend beyond the Y2K date change, the renovation of this system, including unit testing and integration testing was completed by May 1997. This early work did not include clock setting exercises or interaction with the Central System. Clock setting exercises for the SWS as an independent system were completed in June 1998. Testing of the SWS along with the Handar Metdata Collection System with clocks set was completed in July 1998 (see Appendix 1 for some ARAC products and a screen-capture from an SWS that demonstrate the proper functioning of this system through the $\mathrm{Y} 2 \mathrm{~K}$ date demarcation).

The sub-systems mentioned above, along with the SWS are considered the missioncritical core of the ARAC- 2 system and integration testing mentioned above demonstrated the readiness of these systems for final testing. Additional integration testing focused on the most important meteorological data sources for these systems (note that geographic data sources, while critical to the system, are time-independent, for ARAC-2 purposes, and have been stable in the system in recent months and are not expected to change for the remainder of ARAC-2's service life; thus, these data paths were not examined in these testing procedures). The mission-critical data for ARAC-2 is FNMOC 1.0 NOGAPS gridded fields. These data are pushed from FNMOC to ARAC via the Internet (the normal hops are via DREN and ESNET) where they are received and transferred to ARAC-2 system where they are translated from the compact WMO GRIB format used by FNMOC for data transfer into the format read by the ARAC-2 models, i.e., they were degribbed. To perform testing, test data sets for the $\mathrm{Y} 2 \mathrm{~K}$ date change along with leap year data sets were received from FNMOC. The data sets processed in the integration tests 


\section{ARAC Year 2000 Plan, Renovation and Tests}

were as follows:

1) a 72-hour forecast with data provided at 6-hour intervals based on an analysis at 1200

UTC, December 31, 1999.

2) a 72-hour forecast with data provided at 6-hour intervals based on an analysis at 0000

UTC, January 1, 2000.

3) a 72-hour forecast with data provided at 6-hour intervals based on an analysis at 1200

UTC, February 28, 2000.

4) a 72-hour forecast with data provided at 6-hour intervals based on an analysis at 0000

UTC, February 29, 2000.

Each of these data sets was degribbed successfully (after two related century processing problems were corrected). The forecasts based on 1200 UTC, December 31, 1999 and 0000 UTC, January 1, 2000 were used in the final tests. The 0000 UTC, January 1, 2000 forecast was also degribbed again with the system clocks sets as part of these final tests.

While the FNMOC gridded fields are viewed as the primary data source for ARAC-2, and therefore the mission-critical data source (since they provide global coverage and forecast capabilities), ARAC also relies heavily on the receipt of surface and upper air observations from both AFWA (the primary data source) and Alden Electronics (a satellite-based backup data source providing similar data). In this case, test data sets were generated by ARAC from original data received from these organizations in the normal course of business (in particular, the test data sets were generated from data received during the period from December 31, 1998 at 2200 UTC to January 1, 1999 at 0200 UTC). These data were altered to indicate that they cover the same time period one year later and resubmitted to the system at the point of receipt from external systems. Initial tests were run on the ARAC Central system. More complete tests were run on the ARAC Classified System with clocks sets. Y2K problems were discovered and corrected during this testing (see Appendix 2 for more detailed summary of the observed metdata renovation and testing effort).

Note that the testing of observational meteorological data did not focus on some aspects of requesting data. Until November, 1998, ARAC only received subscription data from AFWA for a small number of observing stations near ARAC's supported sites, i.e., those where SWS are installed. When data was required for other locations, ARAC would request the appropriate data from AFWA. AFWA would send the appropriate data back to ARAC. This mechanism has substantial time-related complexity and relies on communications with AFWA that are based on both archaic hardware and protocols. Consequently, any complete testing would have to include both systems; building parallel systems to support such testing would be slow (since old boards would need to fabricated) and expensive (configuring the protocols initially took six months and all the AFWA expertise in this area is no longer available). Thus, aspects of the request and re-

y2k ARAC documentation DRAFT $\quad-27-\quad$ Last printed 5/17/99 12:47 PM 


\section{ARAC Year 2000 Plan, Renovation AND TEsts}

request capabilities could not be cost-effectively tested. To minimize the possible effects on ARAC operations of this weakness in lesting, ARAC implemented a capability to receive a new data format from AFWA, which allowed AFWA to deliver global observational meteorological data by subscription. That is, ARAC can and does receive all this data all the time, thus minimizing the needed for requesting and re-requesting the data. The new capability and delivery policy was implemented in November, 1998, thereby insulating ARAC operations from any failures of the request metdata capability (note that this change also decoupled ARAC from AFWA's System 1, which was scheduled to go out of service in 1999).

Completion of this phase of testing prepared the system for the final tests described in the next chapter.

\section{Summary of Problems Corrected}

Renovation of the Central System required numerous changes. About 50 routines used by about 50 programs were updated (see Appendix 3 for the relevant parts of the two Production Software Update memos that list the Y2K changes installed in the production system). In addition, a number of DCL command files had to be updated to list filenames that included dates correctly. While a variety of problems were uncovered and corrected in the overall process, few summary comments can be made.

- Most ARAC software relies on the VMS operating system to do time calculations. Once the operating system was certified as $\mathrm{Y} 2 \mathrm{~K}$ compliant, the primary remaining issue was the conversion routines used to translate from the various formats used in the ARAC software to the VMS format and back again. Several changes had to be made to these conversion routines so they would handle $\mathrm{Y} 2 \mathrm{~K}$ and leap year date calculations correctly.

- Several routines that validated time-related fields in user interfaces had to be updated to perform correctly.

- Several routines that performed time calculations and comparisons had to be updated.

- Numerous routines and scripts that sorted filenames with dates or database records with date fields had to be corrected.

- A GRIB convention that counts years from $1 . .100$ had to be accounted for in two places, one being a 2 character field in a format.

While the various operating system and third-party software upgrades took substantial time to acquire and install, they did not, in general, cause any problems. There were two exceptions.

1) The VMS C compiler on the system for most of the renovation effort had at least one 


\section{ARAC YEAR 2000 PLAN, RENOVATION AND TESTS}

time utility that was not $\mathrm{Y} 2 \mathrm{~K}$ compliant. Software was written to account for this limitation to allow renovation to proceed. Note that a Y2K-compliant version of the VMS C compiler was installed late in the renovation effort.

2) A user interface package used heavily in the ARAC-2 system (SmartStar) required a full version upgrade to become $\mathrm{Y} 2 \mathrm{~K}$ compliant. This introduced a number of problems that took some time to fix. In particular, all forms that required transfer vectors, which are necessary when user-written code is attached to a form, had to undergo a special process to run with the new version. It took some time and consulting with the vendor to determine the problem and establish the correct processing steps to correct it. In addition, the new version display a case-sensitivity between field names and their references in routine arguments which was not true in earlier versions and several forms had to be modified to conform to the new constraints. These problems delayed fielding of the bulk of the $\mathrm{Y} 2 \mathrm{~K}$ changes by about four weeks.

No record was kept of the changes made to the SWS during the initial renovation effort. A single problem in date manipulation was discovered during the later phases of testing that affected the display of products and how they were listed in a selection list. This problem was corrected and the fix was being fielded as of March 31, 1999 (note that this problem did not break the SWS but could have been confusing to the unprepared user). 


\section{ARAC Year 2000 Plan, Renovation and Tests}

\section{Final Tests}

While the earlier rounds of unit and integration testing provided increasingly strong evidence of the ARAC's ability to function properly with respect to dates, a round of final tests was necessary to complete the demonstration of ARAC's Y2K compliance. These tests were generally done with clocks set on either the ARAC or CAPS Classified Systems and were intended, in total, to complete the certification process.

Several questions were intended to be answered by the final round of testing. These were:

- Does the ARAC system, in combination with the SWS, run correctly independent of the data, problem and system times?

- Do the ARAC models perform in the same way independent of the data, problem and system times?

- Can the primary data source be processed correctly independent of the data, problem and system times?

- Can the ARAC respond to a realistic situation independent of the data, problem and system times?

These questions were answered by the following series of tests.

\section{Central System/SWS Tests}

A good test of the functioning of the overall ARAC system is the ability to run a Totally Automated Hands-Off Exercise (TAHOE). A TAHOE exercises to varying degrees all the main components of the core ARAC system in combination with the SWS. In a TAHOE, a user on the SWS fills in a set of information that describes a release situation. This information is sent to the Central System via the communications system. The geographic data system is used to access pre-defined data sets for the location of interest and meteorological data is collected for the test scenario. Model parameters are generated on the basis of all the information and the models are executed. On the basis of the model calculations, products are generated and shipped back to the SWS via the communications system where the user can view them. Thus, a TAHOE is a good end-to-end test of the ARAC system. TAHOEs normally run for 2 hours of simulation time on the basis of the best meteorological data available at the start of the problem.

Six TAHOEs were run as part of the final test suite:

1) A TAHOE was run with both the problem and system times set to January 1,2000 .

2) A TAHOE was initiated with the problem and system times set to just before the date change from December 31, 1999 to January 1, 2000.

3) Another TAHOE was run like the first test but with a slightly different system clock setting (still before the date change) so that different processing steps were occurring when the system clock rolled over. 


\section{ARAC YeAR 2000 Plan, RenOVATION AND TEsts}

4) A TAHOE was initiated with problem and system times just before the date change from Hebruary 28 to February 29, 2000

5) A TAHOE was run with both the problem and system times set to February 29, 2000.

6) A TAIIOE was initiated with problem and systcm times just before the date change from February 29 to March 1, 2000

These tests worked properly (see Appendix 4 for sample ARAC products from these tests).

\section{Core Modeling System Verification}

To demonstrate that core modeling system was not only functioning but was giving correct results a somewhat more complex problem was run against the original observation metdata test set with the original times, i.e., July 30-August 2, 1998 and the same problem was run with the same data but with the dates indicated as December 30 , 1999 to January 2, 2000. The goal was to achieve an exact match between the original and the comparison runs. These runs were performed on the ARAC Classified system with the system clocks set appropriately.

The fictitious problem scenario involved a release from LLNL that lasted for 24 hours beginning 12 hours before the relevant date change. The problem was run for 36 hours, i.e., for 12 hours after the release ended. Elevation data and geographic base map data were generated (thereby exercising the geographic data system more completely). The selected grid was a $50 \mathrm{~km}$ dispersion modeling grid with a $1050 \mathrm{~m}$ grid depth. After the grid was built, a problem station library was created and problem metdata was built for a 36 hour period. The windfield codes and the dispersion model were run against this data set and products generated. In all cases, the model parameters were generated by the system and the core models were run on the OpenVMS Alpha systems (which allowed the extracted metdata to compared easily).

The initial execution of this problem did not produce an exact match. Investigation showed that this was due to different mixing layer heights being generated for the dispersion model by the model parameters system. Further investigation revealed that the default algorithm for determining this parameter is based on day/night considerations so the difference was due to the problem times being in summer and winter. To work around this problem another data set was generated for the period from December 30, 1998 to January 2, 1999 starting with the same original data. A run was made with this data for a release beginning at 1200 UTC, December 31, 1998 and compared with the original data with the mixing layer heights edited to match the winter case. This produced an exact match and was not convolved with any $\mathrm{Y} 2 \mathrm{~K}$ date issues. The run was now compared to the same scenario beginning at 1200 UTC, December 31, 1999. Now an exact match was 


\section{ARAC YeAR 2000 Plan, Renovation AND TEsts}

produced. The matching was tested both by examining the contours in the products generated (which is an extremely strong test given the nature of the dispersion model used) as well as by differencing log files with the various arrays printed out (see Appendix 5 for matching ARAC products from these tests).

Note that the core modeling system was also tested against a September 9 data set using the same scenario, although clocks were not set. This was a quick check against possible use of 9999 as a end-of-data or end-of-file flag, although such mechanisms for manage data are not used in ARAC-2.

\section{Gridded Metdata Tests}

To test the receipt of gridded metdata, the GRIB files provided by FNMOC for the forecast beginning at 0000 UTC, January 1, 2000 were transferred to the ARAC Classified System and the system clocks were set to early on January 1, 2000. The GRIB files were degribbed and converted into the form used by the ARAC models. Geographic data for the west coast of United States was generated and $c$ (see Appendix 6 for an ARAC Product from the clock set test).

\section{Summary Scenarios}

To provide a realistic exercise of the ARAC system, a plausible scenario was generated (based on a suggestion by ARAC'S IV\&V reviewer) and the models run in a manner similar to what might happen during a real response. The scenario was based on the assumption the Ukrainian reactors do not become Y2K compliant by January 1, 2000 . Thus, a 0001 Ukraine local time, a reactor at Chernobyl melts down (the timeline here is not particularly realistic) and begins to release material. ARAC was notified of this release thirty minutes before the $\mathrm{Y} 2 \mathrm{~K}$ date change (based on UTC time) and two model runs were performed. One run was on a $500 \mathrm{~km}$ grid and the material was modeled for 36 hours. For this first run, observational meteorological data was used. The other run was on a $3700 \mathrm{~km}$ grid and the release was also modeled for 5 days. In this case, gridded meteorological data was used, specifically the NOGAPS 1.0 degree data. System clocks were set appropriately. These tests were also successful (See Appendix 7 for ARAC products from these two tests). 


\section{ARAC Year 2000 Plan, Renovation And Tests}

\section{Data Vulnerability Assessment}

The following section provides some details of ARAC's sources of data and the vulnerability of the program to failure of these data sources. Each source of data is described in this context. 


\section{ARAC YeAR 2000 Plan, Renovation AND TEsts}

\section{AFWA observational metdata front end}

Observational meteorological data is a key component of the ARAC system and Air Force Weather Agency (AFWA) has been the primary source of this data for over 20 years. ARAC-2 relies on a VMS MicroVAX 3200 that serves as a front end for AFWA communications to/from the Central System. Note that a backup machine is available although switchover is a manual process. The communications are based on the X.25 protocol running over a $56 \mathrm{~Kb}$ leased line between ARAC and AFWA (note that old hardware in the ARAC-2 front end limits actual performance to $19.2 \mathrm{~Kb}$ ). ARAC receives observed metdata for the entire world on subscription and only rarely relies on a re-request capability to handle missing data. The $\Lambda \mathrm{R} \Lambda \mathrm{C}-3$ connection to AFWA has not been defined yet but is expected to primarily rely on ftp interactions over Internet, intranet or via a leased line as in ARAC-2, but relying on Internet protocols.

The communication between ARAC-2 and AFWA has some aspects that are difficult and expensive to test completely. This is particularly true with respect to the re-request capability. Vulnerability to probable weakness in testing in this area had been minimized by completing changes that allowed ARAC to receive global meteorological data from AFWA on subscription. The re-request capability has been relegated to a backup capability, i.e., it will only be used if AFWA subscription and the Alden metdata frontend (see below) do not provide the necessary data. A largely independent ARAC3/AFWA connection will place this potential vulnerability further into the background.

\section{Alden metdata front end}

Observational meteorological data, along with meteorological charts, are received from Alden, a commercial distributor of meteorological information, via a satellite link. The satellite dish is connected to ARAC-2 via a front-end computer that can also serve as the AFWA meteorological data front end. The same data stream is also routed to ARAC-3. U.S. meteorological data (Domestic Data Plus, DDP) and international meteorological data (International Data Servicc, IDS) are both reccived. This data source provides similar information as that provided by AFWA although it is generally somewhat less complete. By having a reliable connection to AFWA, ARAC is not extremely sensitive to Alden's operational status. However, problems with the ARAC/AFWA link would raise this source to a much more significant level.

\section{Internet connection for receipt of FNMOC and NCEP grids}

ARAC receives global gridded meteorological data fields produced by the Navy's NOGAPS model at 1.0 degree resolution in both latitude and longitude from Fleet Numerical Meteorology and Oceanography Center (FNMOC) via the Internet. FNMOC pushes the files to ARAC using ftp. The files arrive initially on ARAC-3 compute servers and are transferred to ARAC-2. ARAC can call FNMOC to re-deliver all or part of the data from a NOGAPS models run if data was missed for any reason. The current connectivity between FNMOC and ARAC is via DREN and ESNET bridging at Moffett. Grids from models at the National Center for Environmental 


\section{ARAC Year 2000 Plan, RenOVATION AND TEsts}

Prediction (NCEP) are pulled via ftp over the Internet. The NCEP grids are normally used only by ARAC-3.

Maintenance of at least one global gridded data source is critical to ARAC's ability to respond to a variety of situations. While this data is mission-critical, the fact that these fields include forecast data does provide some latitude with respect to time. That is, ARAC normally receives analysis data (i.e., a sophisticated, physically-based interpolation of observed conditions to a grid) at a particular time along with forecast fields at 6 hourly intervals out to 72 hours. Such a data set is received every 12 hours and so a given forecast spans the next several data receipt times. While the accuracy of the forecasts degrade significantly over 72 hours, the loss of a single data set is not extremely significant.

\section{Internet connection for delivery of special $\Lambda \mathbf{R A C}$ products}

ARAC delivers its products to the DOE emergency response community using a different format, which facilitates the use of ARAC products in ARC/Info and ARC/View systems, via a password-protected FTP account. This is currently the standard way of distributing products to all participants in many multi-agency exercises so that this data path, while very simple and only used occasionally, is used in highly visible situations and so is of great importance. This data transfer is partly automated. The ECN (see below) provides a backup connection for the Internet since it also provides network connectivity.

ARAC products can also be distributed to any customer/agency, including the DOF, community, as e-mail enclosures.

\section{McIDAS metdata system}

ARAC receives various meteorological data from Unidata (part of the University Consortium for Atmospheric Research focused on providing access to atmospheric data, primarily for research purposes) in a specialized format over the Internet using custom protocols. These are used by the McIDAS (Man computer Interactive Data Access System) program primarily to support the ARAC weather briefings and general atmospheric analysis, particularly in the area of satellite images. The capabilities are not directly linked to the operational ARAC environment at this time. In cooperation with Unidata, ARAC has been designated as a backup data distribution node for the McIDAS data to a small number of universities in the area.

This data is not critical in the sense of the previously described data sources. However, their absence does limit the ARAC assessment meteorologists ability to acquire a complete picture of the current state of the atmosphere in an area somewhat. On the other hand, equivalent capabilities are available via the Internet using a browser. Backup to Internet-based meteorological information is partly provided by the charts received via the Alden satellite system. 


\section{ARAC Year 2000 Plan, Renovation AND TEsts}

\section{SWS communications front end}

ARAC has about 40 sites that receive committed, on-line support from the project. This support includes a dedicated Sun workstation installed at the site that allows the sites to initiate an exercise or a response on the basis of information provided via a questionnaire interface and to receive the products generated by ARAC, along with various other processing and maintenance capabilities. In most cases installation of the operating system and all of the SWS software is handled by ARAC, as much as possible by logging into these systems remotely. Many of these SWS are installed with meteorological towers and metdata is collected and archived by the SWS as well as being available to ARAC directly over telephone lines. These systems are referred to as Site Workstation Systems (SWS). ARAC has a Site Support Team dedicated to dealing with these systems and their users. The majority of the SWS communicate with ARAC via dial-up modems that are part of the installed SWS using PPP as the basic protocol. ARAC receives these communications on one of two dedicated front ends with banks of modems. ARAC maintains two of these systems but switching to the backup system is a manual process. Equivalent capabilities are being developed for ARAC-3. Note that support for these SWS and access to the meteorological towers relies on a viable telephone system.

\section{SWS communications via ECN}

DOE NN-60 has developed an Emergency Communications Network (ECN) for use by DOF emergency response resources of which ARAC is one. ARAC communicates with SWS at most DOE facilities using this network. This network has two hubs, one in Washington, D.C. and the other at the Bechtel Nevada Remote Sensing Laboratory (RSL), that are connected with a T3 line; the various nodes are connected to one of the hubs using a T1 line. This intranet is connected to the Internet in Washington, DC. Note that SWS support to ECN nodes is dependent on the viability of this network.

As mentioned above the ECN can also be used to delivery ARC/Info-style products to RSL as an alternative to the Internet.

\section{Telephone communications}

In addition to the various data pathways described above, it is important to note that ARAC makes heavy use of voice and fax telephone communications during responses and exercises. For supported sites, this is used to supplement the information provided by the uscr using the SWS user interface, to describe special aspects of the products provided and to troubleshoot all manner of problems that can arise. For non-supported sites (i.e., those a locations that don't have an ARAC SWS), telephone communication takes on a more central role as the conduit most of the information transferred. For nonsupported sites, FAX delivery of products is typical. Thus, a functioning telephone system is key to an effective ARAC response.

y2k ARAC_documentation $\underline{\text { DRAFT }} \quad-36-\quad$ Last printed 5/17/99 12:47 PM




\section{ARAC Year 2000 Plan, Renovation and Tests}

\section{Risk Assessment}

As mentioned previously, some risk is inevitable due to the cost of a complete, independent certification of ARAC-2. More importantly, risk is incurred due to the practical impossibility of a true end-to-end system test with all data providers. ARAC relies on meteorological data gathered from thousands of standard observing stations around the world and an end-to-end test would need to incorporate all of these stations, the numerous national and international organizations involved in making the data available and all the supporting infrastructure (e.g., communications) that goes into providing a reliable data stream to programs such as $\Lambda \mathrm{RAC}$. Over and above the inherent difficulty in orchestrating a full test of all these systems, the matter is further constrained by the fact that all the components of these systems have on-going, moment-to-moment operational needs that must be met and so they cannot be taken down for testing easily. Thus, certifying the compliance of the systems that provide meteorological data to ARAC is well beyond the scope of this plan (on the other hand, ARAC will participate, as resources permit, with testing activities at the key data-providing institutions described in the previous section).

Several overall strategies are incorporated into the ARAC Y2K Plan to minimize risk in a cost effective manner consistent with the long term development of the program. First of all, the testing described in this plan is designed to ensure that both the ARAC-2 and ARAC-3 systems will function properly with respect to the critical dates assuming that some appropriate meteorological data is available to the system. The nature of these systems is such that the core functionality as well as the supporting infrastructure can be validated with confidence. In addition, this transitional period for ARAC between ARAC-2 and ARAC-3, while in many ways a problem, is used to advantage in this plan since these system will back each other up during the date demarcations. Since these systems generally have independent failure modes, this strategy minimizes risk with respect to $A R A C$ as a whole.

The key source of risk is the receipt of meteorological data and, consequently, one important strategy is to maintain multiple data sources for each major type of meteorological data. This is consistent with the design of both ARAC-2 and ARAC-3. ARAC-2 data sources supplemented by new data links developed in the course of completing ARAC-3 provide some insulation from failures of individual data sources. Note that since pathways exist to move data to/from ARAC-2 from/to ARAC-3, there is synergy between these system with respect to reliable meteorological data. As long as one of the key data providers for each category of meteorological data is working during the date demarcation, ARAC should be able to respond at essentially full capability (note that the various observed meteorological data providers do not provide exactly the same set of observing stations so that the failure of a particular data source could somewhat 


\section{ARAC YeAR 2000 Plan, Renovation AND TESts}

reduce the quality of a specific ARAC product due to the absence of key data). See the previous section for additional details regarding data vulnerability.

Risk also exists in the area of data delivery, which relies on network connections, modem connections and fax machines. As long as the telephone network remains largely intact, ARAC will be able to deliver product to its various customers, although failure of the DOE Emergency Communications Network would result in somewhat reduced service, primarily in the timeliness of product delivery. A complete collapse of the telephone system would essentially take ARAC off-line for certain emergency response situations. Another area of risk is date dependencies in ARAC's power distribution network. ARAC has generator and redundant UPS systems and so can function (as long as generator fuel is available) in the absence of the power grid. However, if an embedded system in ARAC's power distribution system was unidentified and so not tested, ARAC could be vulnerable to failure here. Reliance on factual information from various knowledgeable sources is necessary to reduce risk in this area.

In summary, risk due to problems in the ARAC systems and their local supporting infrastructure can be managed effectively. However, ARAC relies on a complex, interdependent network of data sources and communication pathways that are beyond the control of the program. See Contingency Plan section for further discussion. 


\section{ARAC Year 2000 Plan, RenOVATION AND TEsts}

\section{Contingency Plan}

While a variety of strategies have been described that lessen the vulnerability of ARAC to failure associated with date issues, the possibility of varying degrees of system failure has to be considered. While testing is expected to minimize the possibility of failures within the body of the ARAC system, failures could conceivably occur. As part of being ready for such eventualities, ARAC expects to have a small number of people with strong familiarity with the system at work for the most critical period who will monitor the status of data sources and system status. Failures of any type will be tracked by these people and, depending on their severity, will be resolved. As needed, other people will be called in to assist. The level of system administration support will be intermediate between the normal on-call procedures in effect in ARAC and the level of support provided during major responses and exercises. This will be supplemented by software development support. This approach will also apply to the possibility of a partial failure of both ARAC-2 and ARAC-3 which could necessitate a hybrid response assuming the failures in the systems could not be corrected rapidly. Thus both system administration and software development support will need to be knowledgeable about both ARAC-2 and ARAC-3.

Assuming that the core system behaves properly the next general type of failure would be in the data sources. As implied in the previous discussion, ARAC can function at a reasonably complete level assuming at least one observational and one gridded meteorological data source remains viable. In the absence of observational data the models can rely exclusively on gridded data with a potential loss of quality in the resulting product that will vary greatly depending on the details of the situation. A credible product could generally be produced although smaller scale details might be missed in some cases (note that in regions where there are little or no observational data, there will not generally be any loss of quality). The absence of gridded meteorological data would have a minor effect immediately after the date demarcation (assuming the last data set before the date change was received normally). However, continued unavailability would result in a steady decrease in the quality of ARAC's products in areas with sparse observational data and for large domains where the primary source of data is the gridded fields. Continued unavailability would also eventually curtail the use of ARAC's in-house weather prediction models. Failure of both the observational and gridded sources would mean that ARAC would have to rely exclusively on the last gridded meteorological data fields received before the date change. Thus, the quality of ARAC's ability to respond would be generally adequate (though less than optimal) for 24 hours after the failure of the data sources, less adequate through 48 hours and quite marginal through 72 hours. There are two key implications of this. One is that it is essential to receive the last set of gridded fields before the date change from both FNMOC and NCEP, and that the period

y2k ARAC_documentation DRAFT $\quad$ - 39 L $\quad$ Last printed 5/17/99 12:47 PM




\section{ARAC Year 2000 Plan, Renovation AND Tests}

from 24-48 hours is the time period during which ARAC can function to some degree without any additional data sources. Consequently all efforts will need to be made to reestablish any lost data links during the first day or two after the date change. If data links to FNMOC cannot be established, the proximity of this organization, which is in Monterey, CA, to ARAC would allow the data to be acquired by courier. With proper coordination (e.g., meeting someone from FNMOC at a halfway point), the delay receiving the data could be as little as 150 minutes.

Non-meteorological data sources and data delivery rely on both telephone lines and DOE's ECN. ARAC should remain functional in the event of failure of one of these systems. Telephone communications can cover for ECN failure although scenario descriptions from $\mathrm{ECN}$ nodes would have to be acquired using voice over telephones lines and product delivery would have to be via fax or e-mail enclosures via the Internet. Failure of telephone communications would typically be more serious although the ECN would provide access to the DOE EOC, which would allow information exchange from that site and so permit $\triangle \mathrm{RAC}$ to function, again at a reduced level. Failure of both the ECN and telephone communications would limit ARAC to responding to events reported on television or radio news channels and would require access to some emergency communications capability for product delivery and access of more specific scenario descriptions. Access to such capabilities could involve ARAC personnel hand-carrying products to a remote facility. No details of such emergency capabilities have been worked out at this time.

Assuming the ARAC's generator/UPS/PDU system does not contain any hidden Y2K flaws that would cause failure during the date transition, ARAC should be insulated against failures of the external power grid for as long as generator fuel is available. Note that reasonable redundancy is available in ARAC's power system so that some degree of failure of this system can be tolerated. Failure of half of ARAC's power distribution system should not result in loss of the operational system, which includes redundant machines and fail-over file systems arranged to have the essential components available with only half the normal power system working. Such a power failure could cause less critical elements (e.g., the tablet digitizer) of the system to be unavailable. Special circumstances that would raise the importance of such elements might require moving the capability to a new power source and reinitializing it. Thus, there will be a need for heightened readiness on the part of the system support personnel. Complete failure of the power system could take ARAC off-line until it was fixed, thus it is essential that this system be examined for general robustness and $\mathrm{Y} 2 \mathrm{~K}$ compliance. 


\section{Conclusion}

The ARAC Year 2000 implementation and testing has demonstrated that ARAC is Y2Kcompliant (see IV\&V documentation). ARAC-2 will be able to produce timely and credible products over the period. ARAC-3 will also be Y2K-compliant and will be the primary response system in the Year 2000 and beyond. 


\section{ARAC Year 2000 Plan, Renovation and Tests}

\section{Appendix 1 - SWS Metdata Overview Screen}

Several important aspects of the SWS are displayed in the following screen-capture. In the upper right is the SWS Session Manager, which is the main dialog for user interactions with the SWS. Note the Message Log, which contains messages with Year 2000 dates. In the upper right are clocks with local and UTC time in the Year 2000 (the particular system used to generate this display has been running with its clock set one year ahead of the current time for some months). Bclow the clocks is the ARAC Plots selection list showing Year 2000 dates. The highlighted plot is displayed in the lower right. Note the valid times that straddle the beginning of the Year 2000. In the lower left is a display of the tower metdata extending through the beginning of the Year 2000. 



\section{3...}

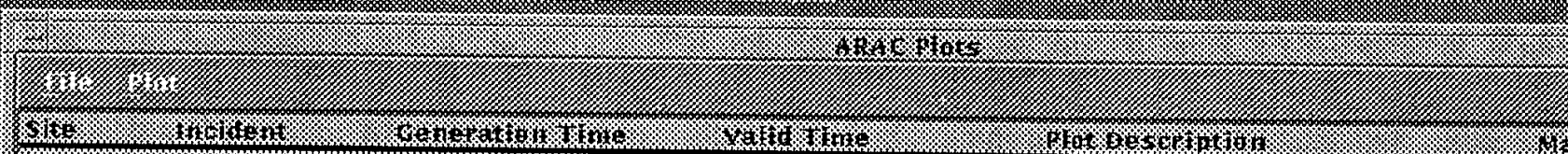
$\beta_{3}$ H
:

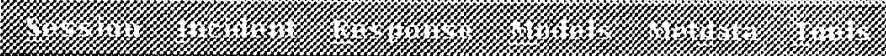

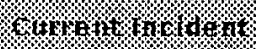

10.1.

1,

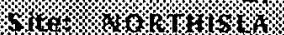

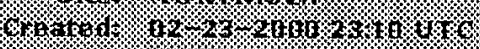

\section{.}

2.1.

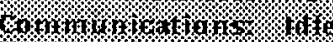

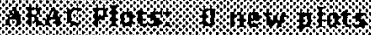

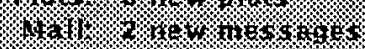

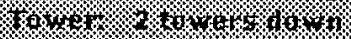

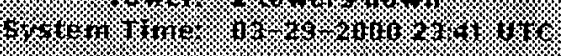

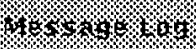

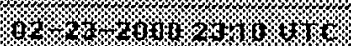

2.1.

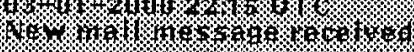

6.10\%,

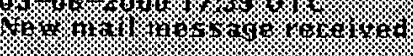

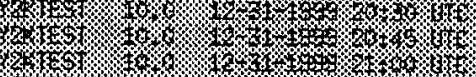

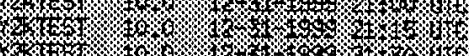

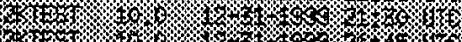

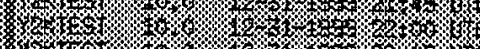

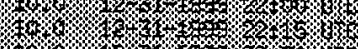

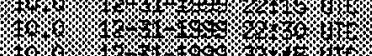

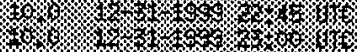

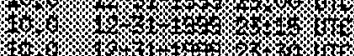

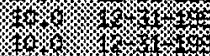

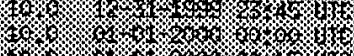

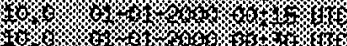

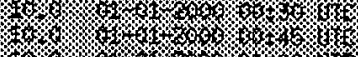

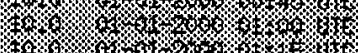

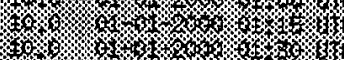

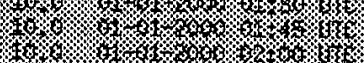

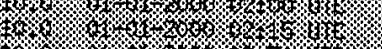

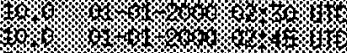

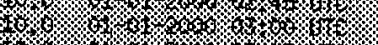

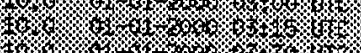

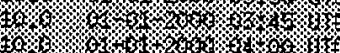

0.6.

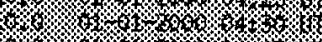

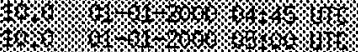

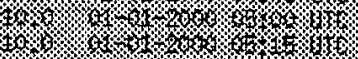

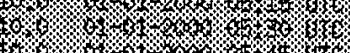

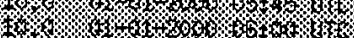

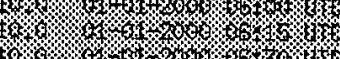

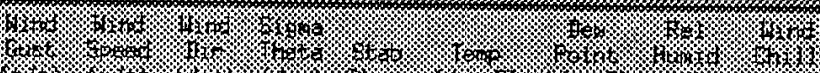

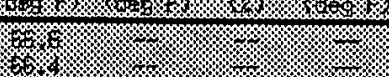

x

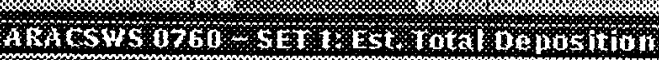

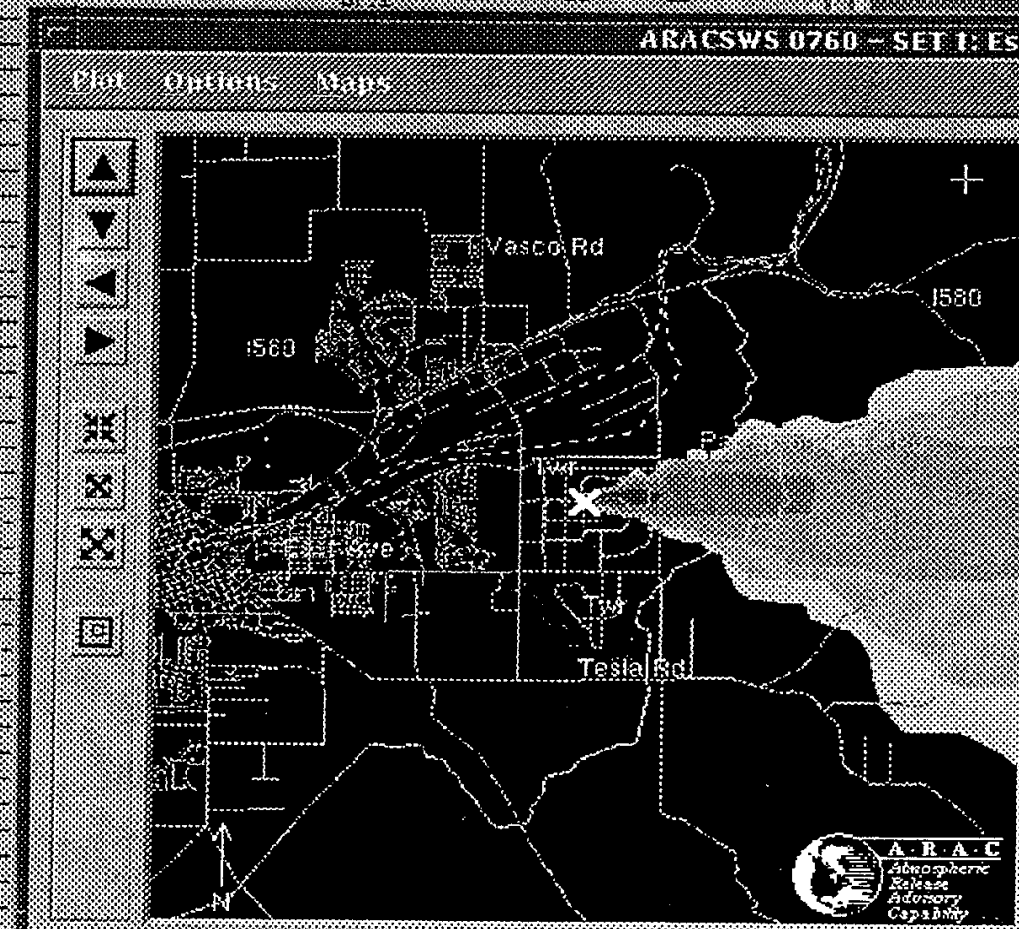

Contours: (Level and Area Covered)

$>1.000 \mathrm{E}+02 \mathrm{uCi} / \mathrm{m2}$

$0.195 q \mathrm{~km}$

$>1.000 \mathrm{E}+01 \mathrm{uci} / \mathrm{m} 2$

$1.76 \mathrm{sq} \mathrm{km}$

$>1.000 \mathrm{E}+00 \mathrm{uCi} / \mathrm{m} 2$

$13.46 \mathrm{sq} \mathrm{km}$

$>1.000 \mathrm{E}-01 \mathrm{uCi} / \mathrm{m} 2$

$62.26 \mathrm{sq} \mathrm{km}$

$>1.000 \mathrm{E}-02 \mathrm{uCi} / \mathrm{m} 2$

$105.17 \mathrm{sq} \mathrm{km}$

ARAC Computer Simulation Notes

Generation time:

Contour type

Yahid torm:

Material:

Source
Location (Lat,Long):

Location $(X, Y)$ :

Remarks
01-29-1999 04:36 UTC

Total Deposition at $0.0 \mathrm{~m}$ aboy e terrain

12-31-1999 23:05 uTC

Pu-239

$377^{\circ} 41^{\prime} 23^{\prime \prime N}, 121^{\circ} 42^{\prime} 27^{\prime \prime} \mathrm{W}$

$613.957,4172.174$ 


\section{ARAC YEAR 2000 PLAN, RENOVATION AND TESTS}

\section{Appendix 2 - Summary of Observed Metdata Testing}

The ARAC System users meteorological observations collected from a variety of sources. These observations arrive in raw code forms as defined by the World Meteorological Organization Manual on Codes (WMO Publication No. 306). Processes running on the Primary VAX system decode and reformat these raw data into out meteorological data archive format. METAR, SYNOP, TEMP and PILOT raw observation formats are of primary interest.

To test $\mathrm{Y} 2 \mathrm{~K}$ compliance of these decoder/reformat processes, the International Data Service (IDS, from Alden Electronics), Domestic Data Plus (DDP, also from Alden Electronics) and Air Force Weather Agency (AFWA) raw format data streams were logged over the December 31, 1998 to January 1, 1999 time period. The resulting formatted data archive files were also saved. The raw data logs were then used to test decoder/reformat process performance on a VAXStation with its system clock set to various times on and around the December 31, 1999 to January 1, 2000 crossover period. Any indications of the observation year in the raw data were altered from 1998 to 1999 and from 1999 to 2000 (years only appear in the headers of AFWA responses to ARACgenerated requests). The resulting reformatted data files were compared with the data decoded during the original data collection. No Y2K-related differences were found between the reformatted data created during the 1998-1999 period and the same data generated with the system time set for the 1999-2000 period. 


\section{ARAC Year 2000 Plan, Renovation And TEsts}

\section{Appendix 3 - Production Software Update Memos}

The following documents are lists of the changes made to the ARAC Production system to implement the Y2K-compliant software. Two production updates were required with the volume of changes coming with the first update. The Production Software Update Memos are a normal part of ARAC's software quality assurance process. 


\section{Year 2000 Compliance Fixes:}

Updated several time related routines. The following table shows the updated routines and the program(s) which use(s) the routine:

\begin{tabular}{|c|c|c|}
\hline Category & Routine & Programs using the routine(s): \\
\hline \multirow[t]{11}{*}{ AEROS } & $\begin{array}{l}\text { Convert_dst_to_absolute } \\
\text { Convert_obs_date_time_to_binary }\end{array}$ & $\begin{array}{l}\text { CREATE_PROBLEM_METDATA } \\
\text { HANDSOFF_MAKEPMF } \\
\text { MONITOR } \\
\text { REQUESTMT } \\
\text { PRINT_PROBLEM_METDATA } \\
\text { WAIT_FOR_METDATA }\end{array}$ \\
\hline & $\begin{array}{l}\text { Leapyear } \\
\text { Validate_observation_date_time }\end{array}$ & $\begin{array}{l}\text { BLDREQ } \\
\text { DISPLAY_GRIDS_STATUS } \\
\text { EDITPMF } \\
\text { SHOW_DEC_MET } \\
\text { UPRDSP } \\
\text { VALFORSIT } \\
\text { VALFORSUP }\end{array}$ \\
\hline & Find_next_Timed_request & NEXTREQ. \\
\hline & Separate_ARQ_message & DECGWCREQ \\
\hline & $\begin{array}{l}\text { Display_tower_decoded_metdata } \\
\text { Sort_upr_by_station }\end{array}$ & $\overline{\text { SHOW_DEC_MET }}$ \\
\hline & $\begin{array}{l}\text { Age_metdata_request_log_record } \\
\text { Convert_obs_date_time_to_absdt }\end{array}$ & REQUESTMT \\
\hline & $\begin{array}{l}\text { Change_stop_time_current } \\
\text { System_times } \\
\text { Increment_time_by_interval }\end{array}$ & $\begin{array}{l}\text { BATBLDREQ } \\
\text { DISPAT }\end{array}$ \\
\hline & Compare_with_current_time & $\begin{array}{l}\text { BLDREQ } \\
\text { DISPLAY_GRIDS_STATUS } \\
\text { EDITPMF } \\
\text { SHOW_DEC_MET } \\
\text { UPRDSP }\end{array}$ \\
\hline & $\begin{array}{l}\text { Get_new_forecast_filename } \\
\text { validate_observation_date }\end{array}$ & DECGWCREQ \\
\hline & Read_gwc & READ_GWC \\
\hline & $\begin{array}{l}\text { Check_regmet_fields_on_exit_kar } \\
\text { Ss_validate_stop_date_time } \\
\text { Get_regmet_user_input }\end{array}$ & CREATE_REGMET_PARAMETERS \\
\hline MODPARAMS & $\begin{array}{l}\text { Convert_dst_to_absolute } \\
\text { Convert_obs_date_time_to_binary }\end{array}$ & $\begin{array}{l}\text { CREATE_HANDSOFF_PARAMETERS } \\
\text { CREATE_REGMET_PARAMETERS } \\
\text { EDIT_REGMET_PARAMETERS } \\
\text { HANDSOFF_REGMET_PARAMS }\end{array}$ \\
\hline
\end{tabular}




\begin{tabular}{|c|c|c|}
\hline SWSCOMM & $\begin{array}{l}\text { Current_date_string } \\
\text { Message_logger } \\
\text { Operator_message }\end{array}$ & $\begin{array}{l}\text { CS_FILE_SERVER } \\
\text { CS_MSGRECEIVER } \\
\text { CS_MSGSENDER } \\
\text { CS_NODESENDER }\end{array}$ \\
\hline $\begin{array}{l}\text { Command } \\
\text { Files }\end{array}$ & $\begin{array}{l}\text { Added a new VMS command file: } \\
\text { Find_latest_file.com }\end{array}$ & $\begin{array}{l}\text { EDIT_METDATA-RAW_GWC.COM } \\
\text { EDIT_METDATA-RAW_SITE.COM } \\
\text { EDIT_METDATA-RAW_GWC.COM } \\
\text { EDIT_METDATA-RAW_SITE.COM } \\
\text { EDIT_METDATA-RAW_GWC.COM } \\
\text { EDIT_METDATA-RAW_SITE.COM }\end{array}$ \\
\hline GRAPH & $\begin{array}{l}\text { Load_file_names } \\
\text { (Sorts graphics files by dates) }\end{array}$ & PRODUCT_VIEW(SHOGRAMOD) \\
\hline QUEST & \multirow[t]{7}{*}{$\begin{array}{l}\text { Calendar } \\
\text { Convertdate }\end{array}$} & QUEST \\
\hline CSDEV & & $\begin{array}{l}\text { DISBARB } \\
\text { HANDSOFF } \\
\text { METSELECT } \\
\text { SAMPLER }\end{array}$ \\
\hline GEOG & & $\begin{array}{l}\text { CREGEOG } \\
\text { CREPRJ } \\
\text { DISPLAYMAP }\end{array}$ \\
\hline GRAPH & & $\begin{array}{l}\text { CREATEMAPLIST } \\
\text { PERSPEC }\end{array}$ \\
\hline MODEV & & MODEVL \\
\hline MODPROD & & $\begin{array}{l}\text { SITEPLOT } \\
\text { SWSAUTOSENDPROD }\end{array}$ \\
\hline TOPO & & CRETOPO \\
\hline \multirow[t]{3}{*}{ MODELS } & Read_gridgen_data & MEDIC \\
\hline & Bubble_sort & ADPIC \\
\hline & Bubble_sort (sorting of conc* files) & PLCNT/TIMEHIS \\
\hline
\end{tabular}




\section{Production Software Update}

March 22, 1999

(Production Software Update briefing at 9:00 am, March 22, 1999)

\section{METDATA}

- Decoders:

Several changes related to $\mathrm{Y} 2 \mathrm{~K}$ issues were implemented on both the unclassified system and in the green room on the ARAC Classified system.

- NOGAPS10:

Changes were made in the degribbing software to allow it to handle Y2K FNMOC data. In their numbering scheme, years are numbered 1-100, not 0-99, so it was necessary for the codes to allow 3 digit years.

\section{SHOTER}

- Sorting of PARTPOS* files:

Y2K related fix implemented allowing correct sorting across the millenium change. 


\section{ARAC Year 2000 Plan, Renovation AND TESTS}

\section{Appendix 4 - Central System/SWS Test Products}

1) Peak air concentration product from a TAHOE initiated with the problem and system times on January 1, 2000.

2) Averaged air concentration product from a TAHOE initiated with the problem and system times on January 1, 2000.

3) Peak air concentration product from a TAHOE initiated with the problem and system times just before the date change from December 31, 1999 to January 1, 2000 so the system was working on the problem through the data change.

4) Peak air concentration product from a TAHOE initiated with the problem and system times just before the date change from February 28 to February 29, 2000

5) Peak air concentration product from a TAHOE initiated with both the problem and system times set to February 29, 2000.

6) Peak air concentration product from a TAHOE initiated with the problem and system times just before the date change from February 29 to March 1, 2000 


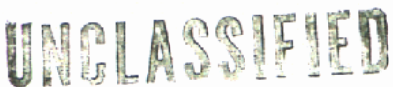

Peak Air Concentration

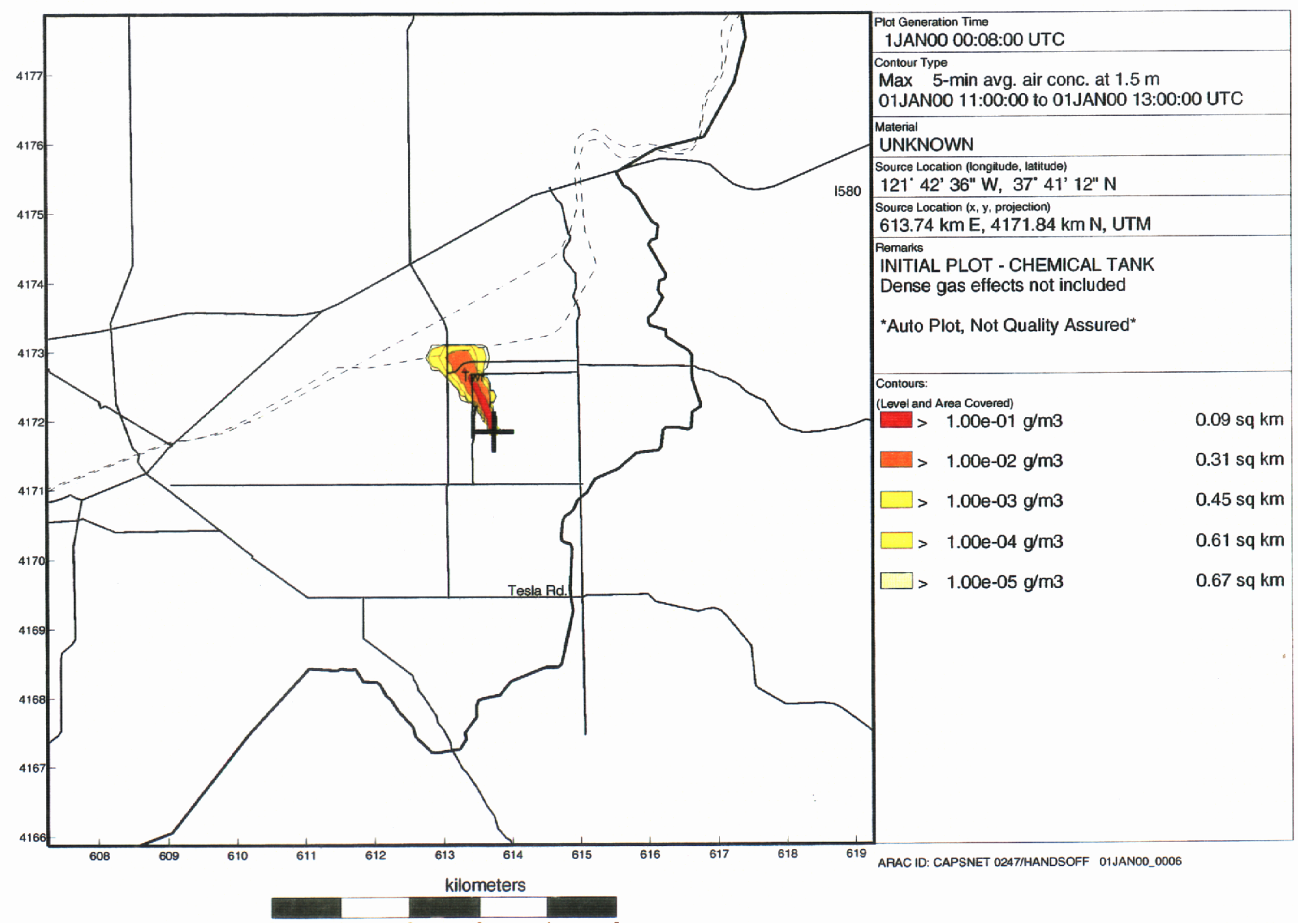

ARAC Computer Simulation Notes

ot Generation Time

nc. at $1.5 \mathrm{~m}$

UNKNOWN

Source Location $(x, y$, projection

$613.74 \mathrm{~km} \mathrm{E}, 4171.84 \mathrm{~km} \mathrm{~N}$, UTM

INITIAL PLOT - CHEMICAL TANK

Dense gas effects not included

*Auto Plot, Not Quality Assured"

W $1.00 \mathrm{e}-02 \mathrm{~g} / \mathrm{m3}$

$0.31 \mathrm{sq} \mathrm{km}$

$0.45 \mathrm{sq} \mathrm{km}$

$1 \mathrm{sq} \mathrm{km}$

$67 \mathrm{sq} \mathrm{km}$ 



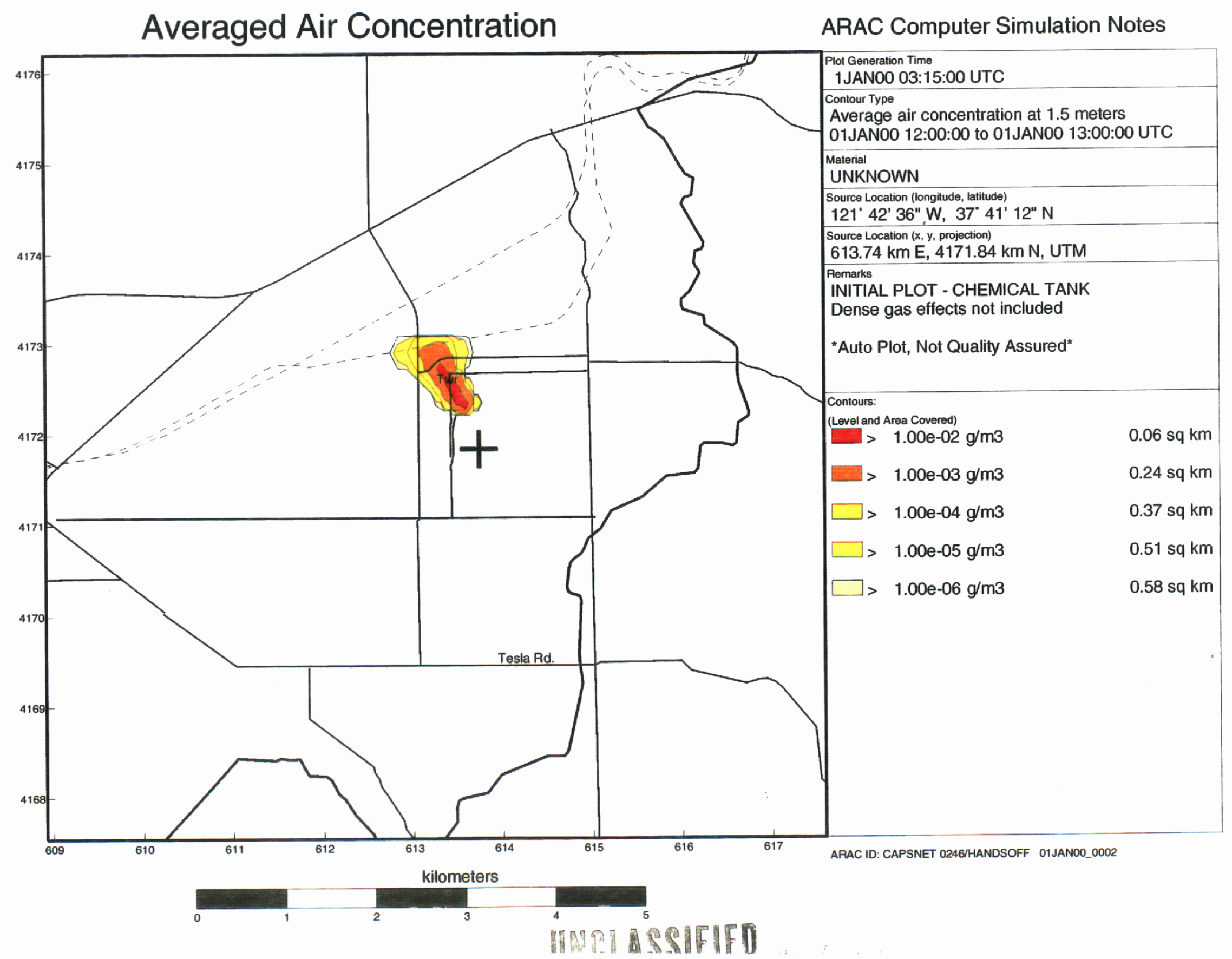





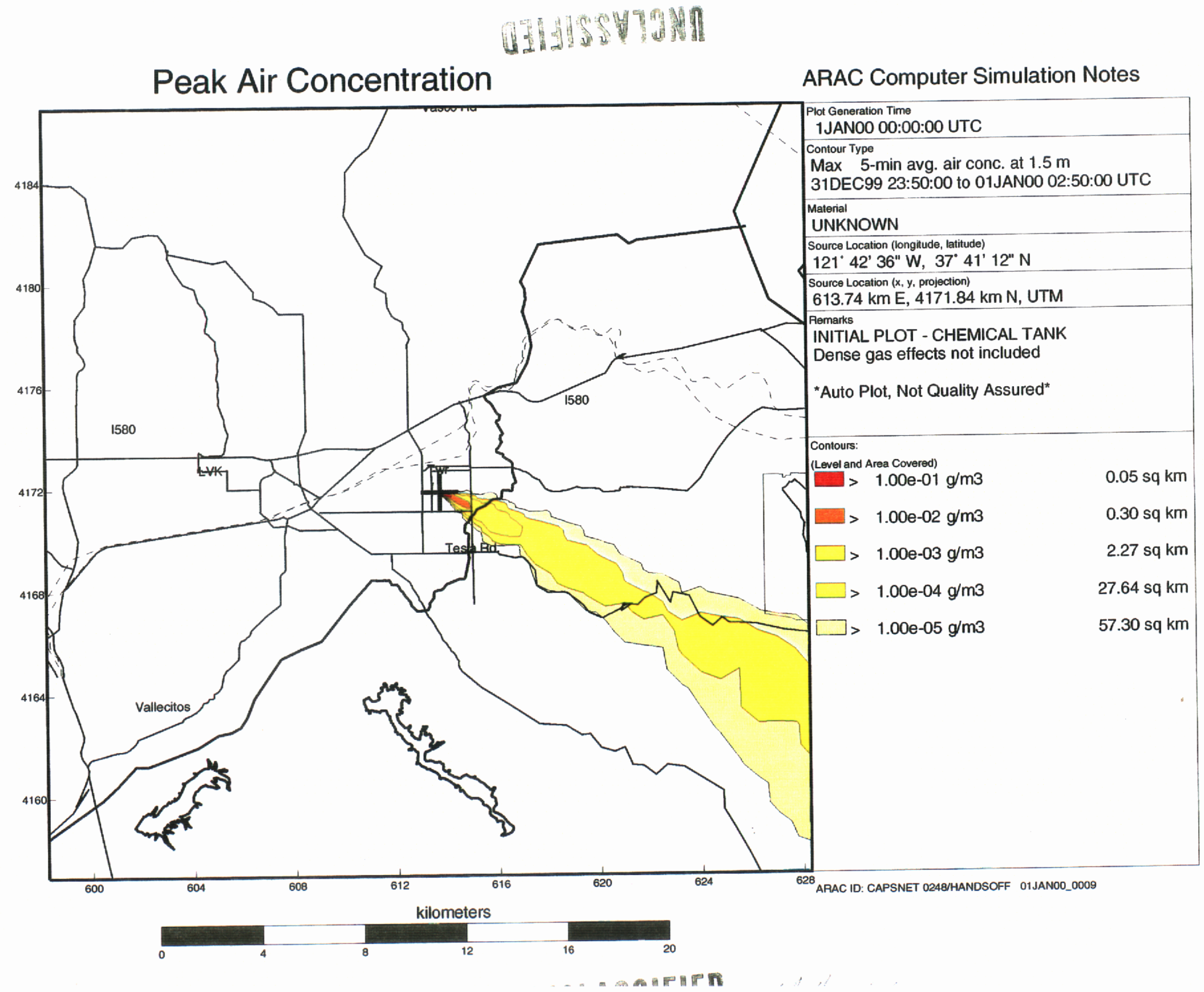





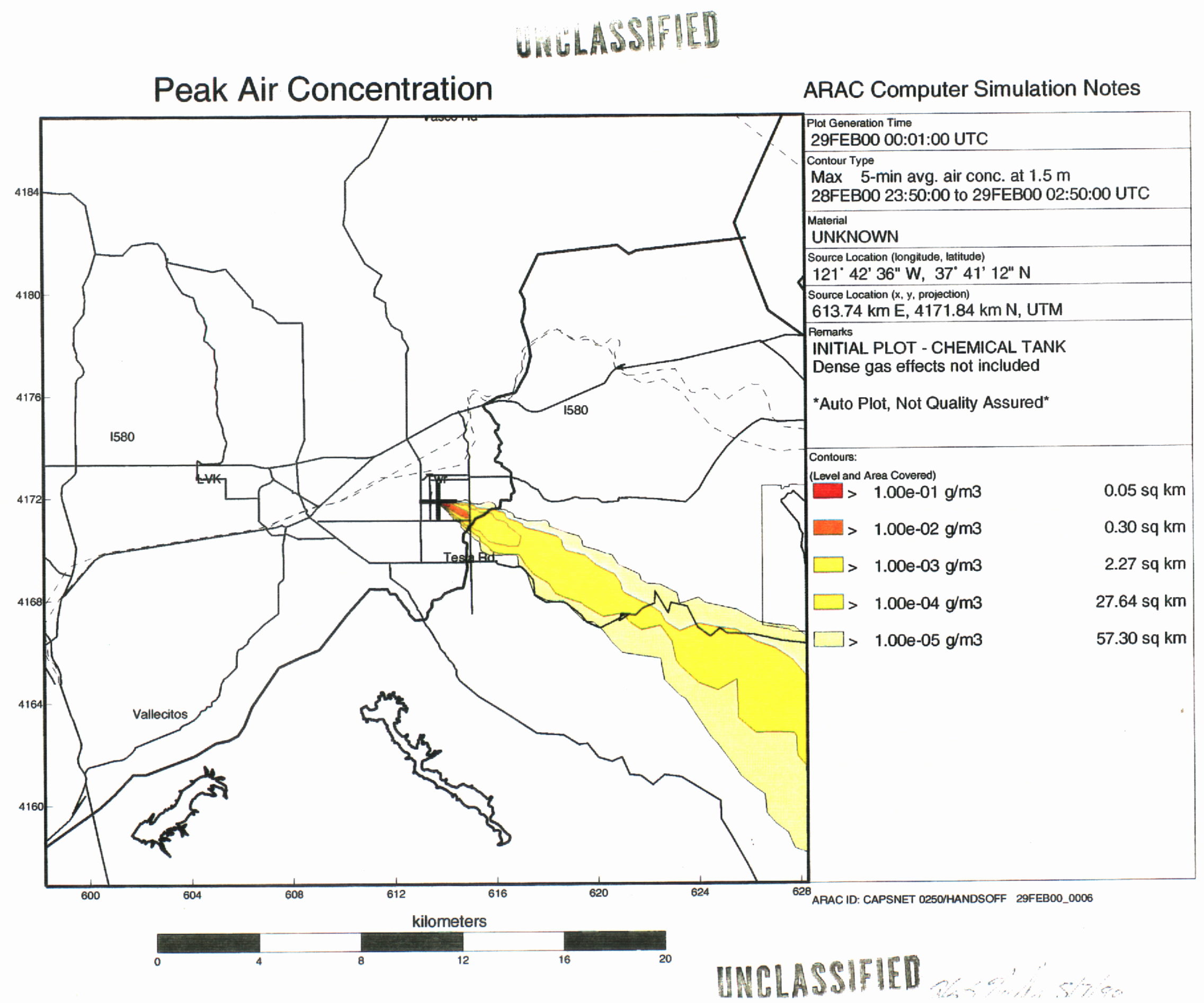





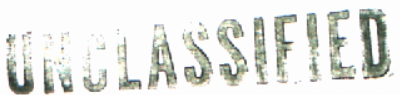

Peak Air Concentration

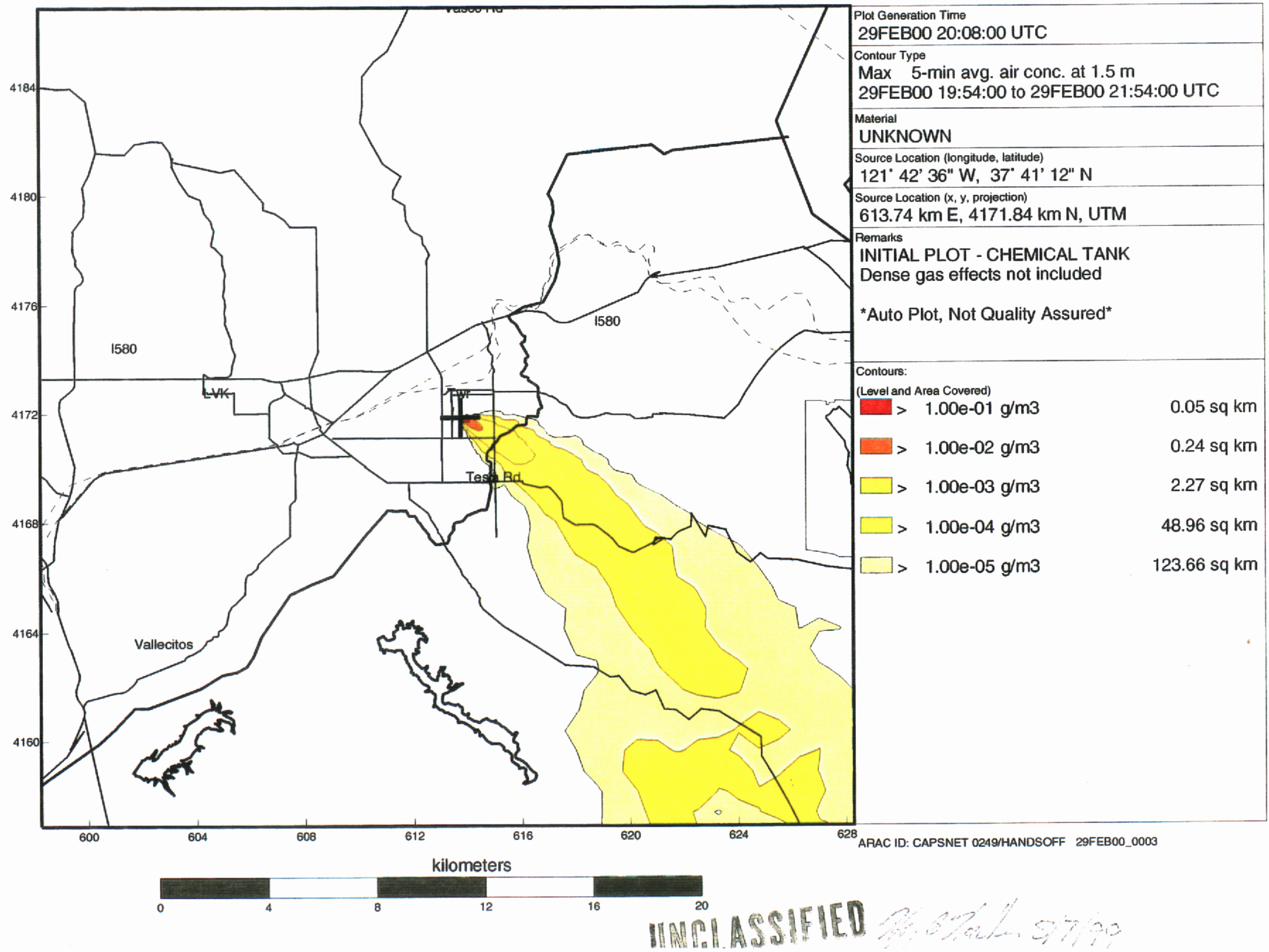





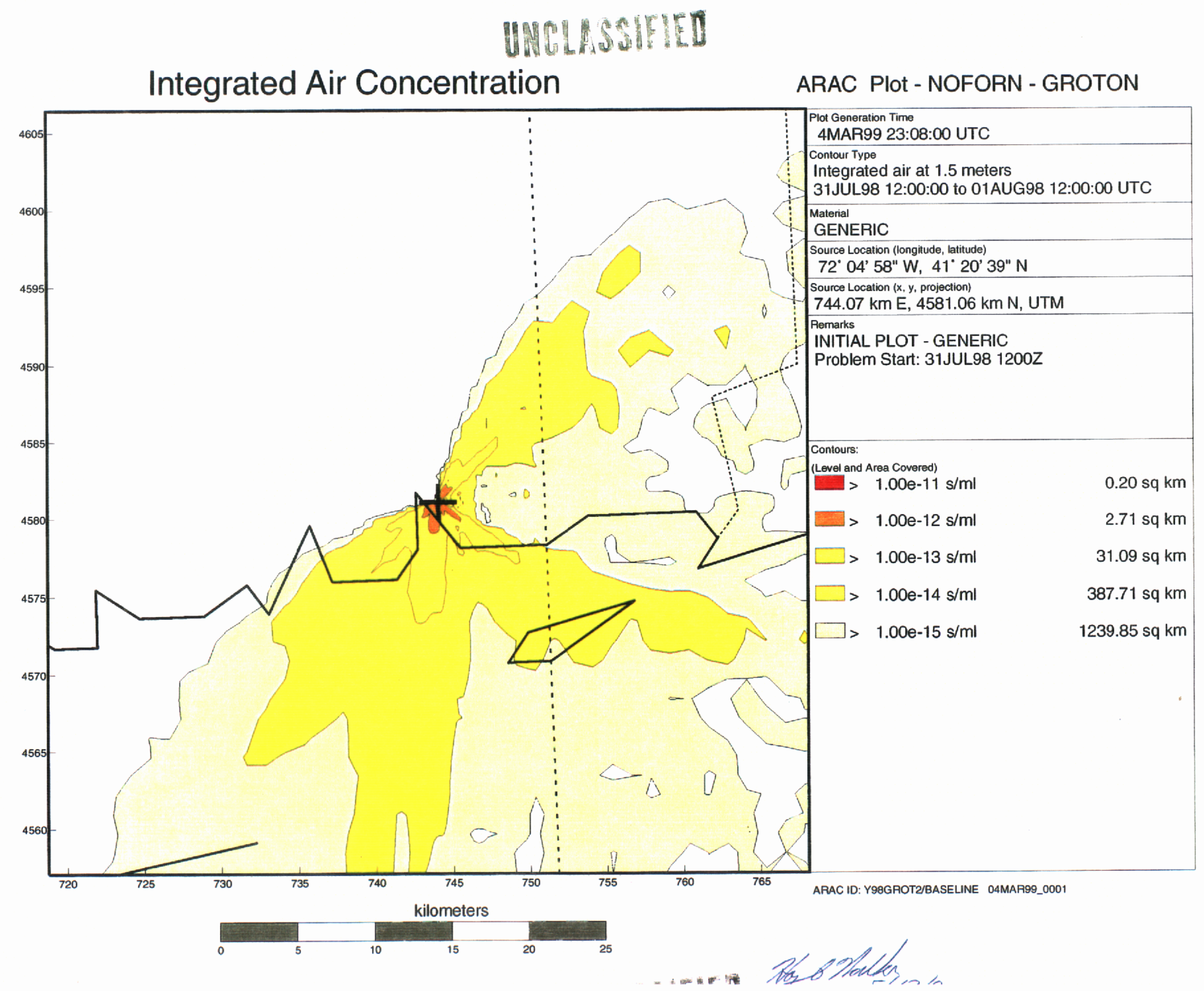





\section{ARAC YeAR 2000 Plan, Renovation AND TEsts}

\section{Appendix 5 - Core Modeling System Test Products}

1) Baseline case - integrated air concentration product from a 36 hour problem from 1200UTC July 31, 1998 to 0000UTC August 2, 1998 using actual surface, tower and upper air meteorological observations for the same period.

2) Adjusted baseline case - integrated air concentration product from a 36 hour problem from 1200UTC December 31, 1998 to 0000UTC January 2, 1999 using simulated surface, tower and upper air meteorological observations for this period derived from the observations used in the baseline case. Note that this adjustment involved no $\mathrm{Y} 2 \mathrm{~K}$ issues and that the results match exactly.

3) Test case - integrated air concentration product from a 36 hour problem from 1200UTC December 31, 1999 to 0000UTC January 2, 2000 using simulated surface, tower and upper air meteorological observations for this period derived from the observations used in the baseline case. Note that the system clocks were set after 0000UTC January, 12000 and that the results match exactly. 



\section{UMCLRSBIETD}

Integrated Air Concentration

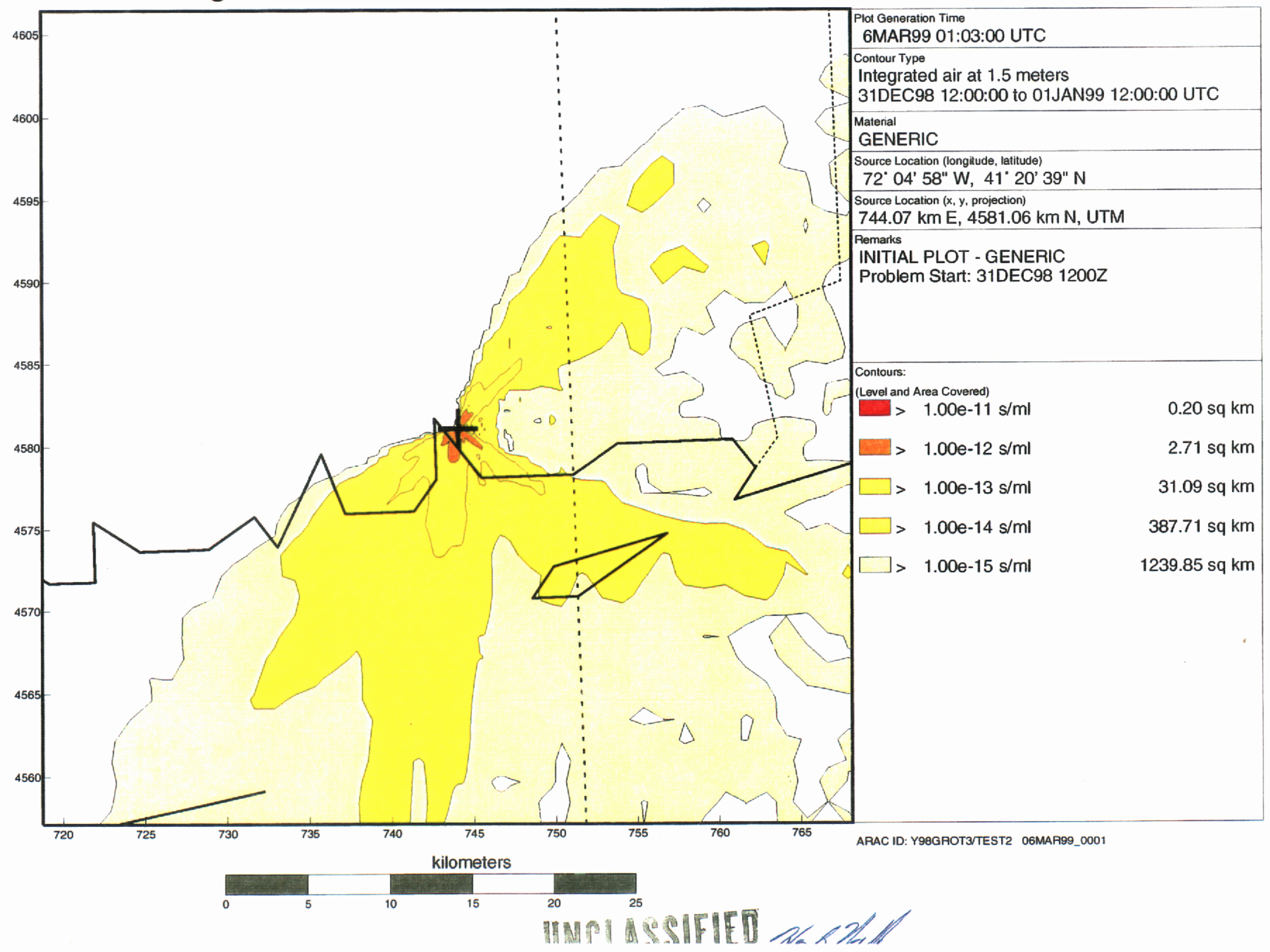

ARAC Plot - NOFORN - GROTON

01:03:00 UTC

Materia

Problem Start: 31DEC98 1200Z

$>1.00 \mathrm{e}-11 \mathrm{~s} / \mathrm{m}$

$.20 \mathrm{sq} \mathrm{km}$

$87.71 \mathrm{sq} \mathrm{km}$

1239.85 sq km 



\section{UNRLASTHED}

Integrated Air Concentration

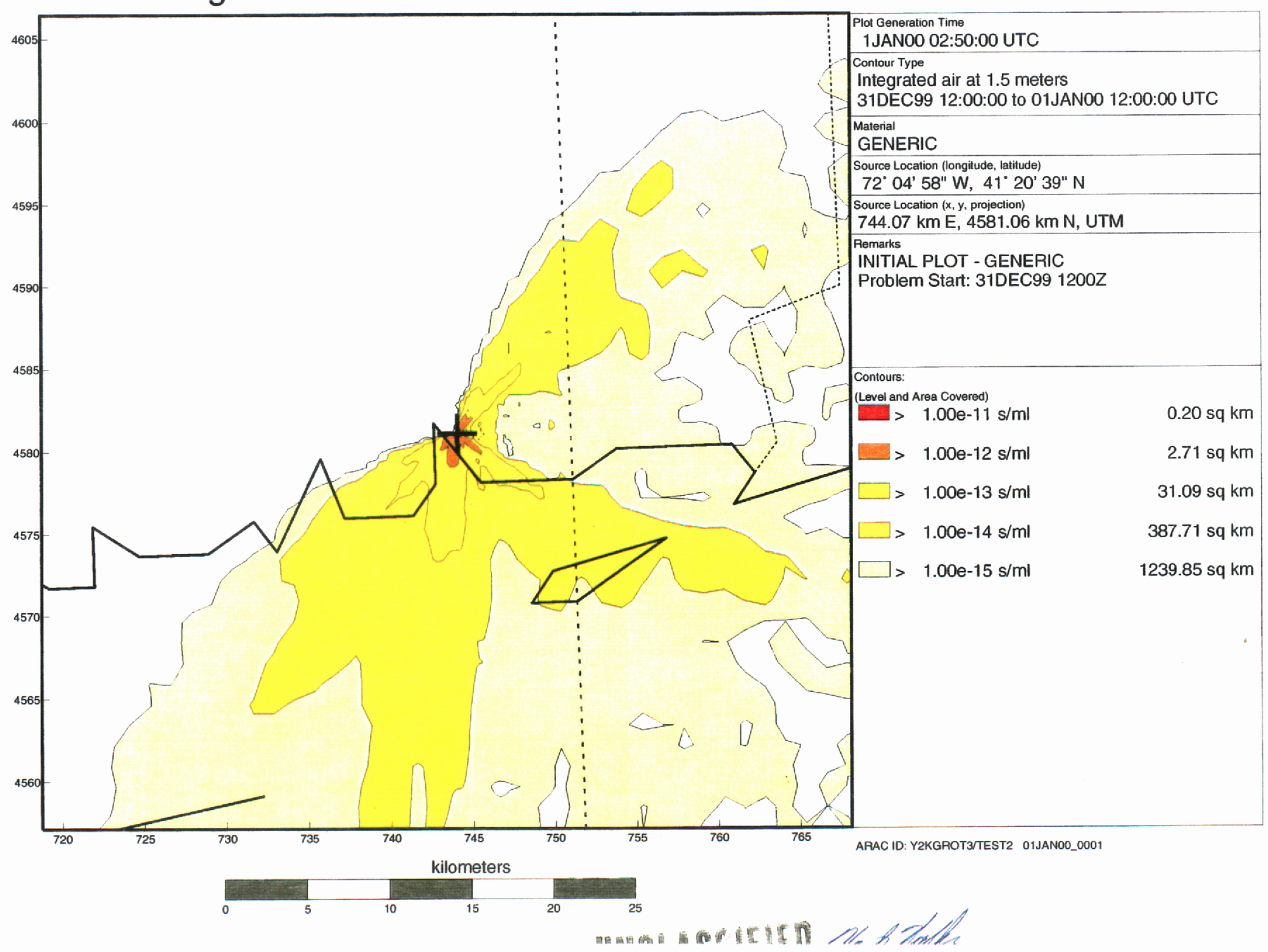





\section{UNRLASTHED}

Integrated Air Concentration

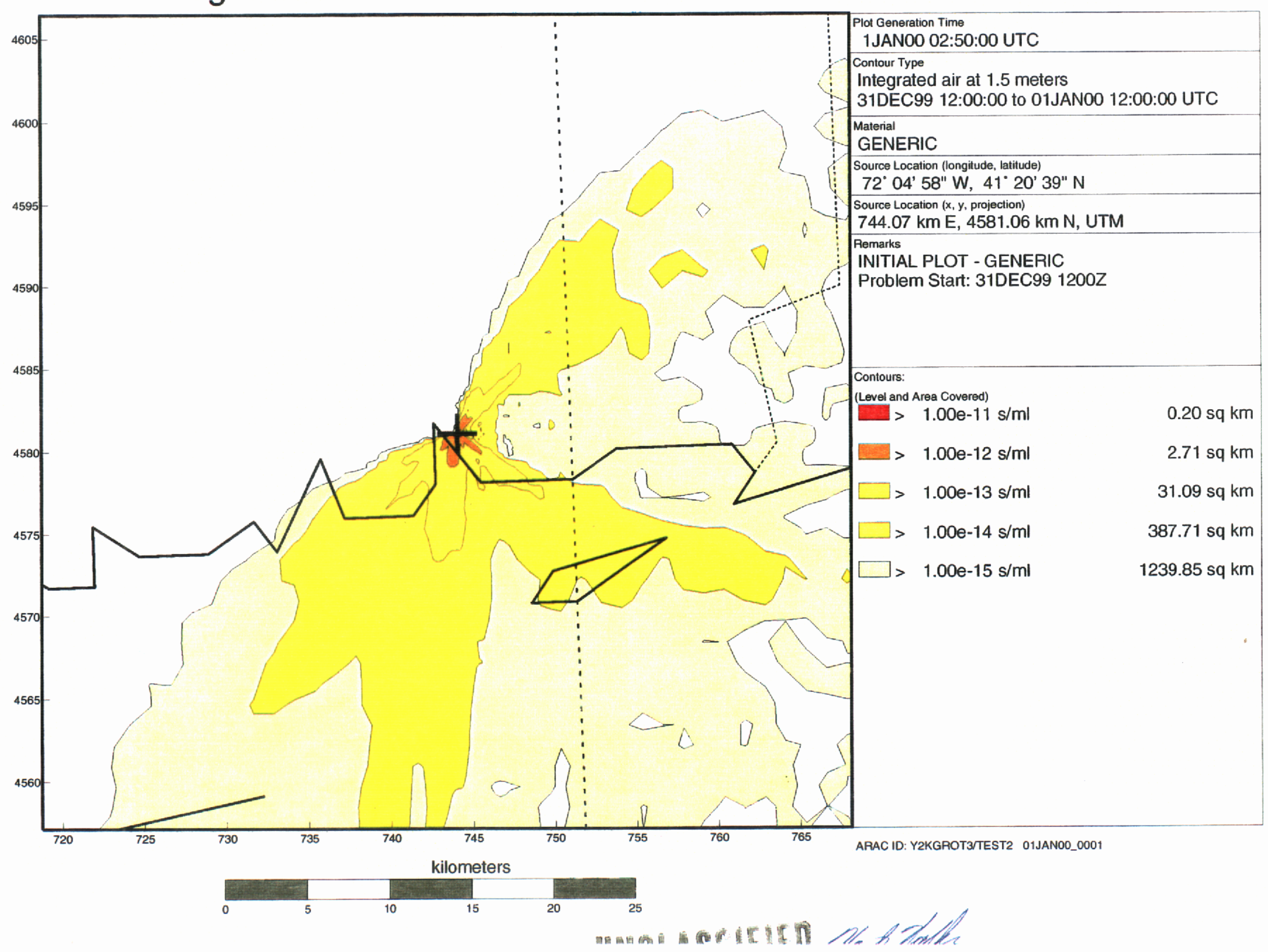



ARAC Year 2000 Plan, Renovation and Tests

Appendix 6 - Gridded Metdata Test Products

Total deposition product from gridded metdata test. 



\section{UWCLASIIIED}

Estimated Total Deposition

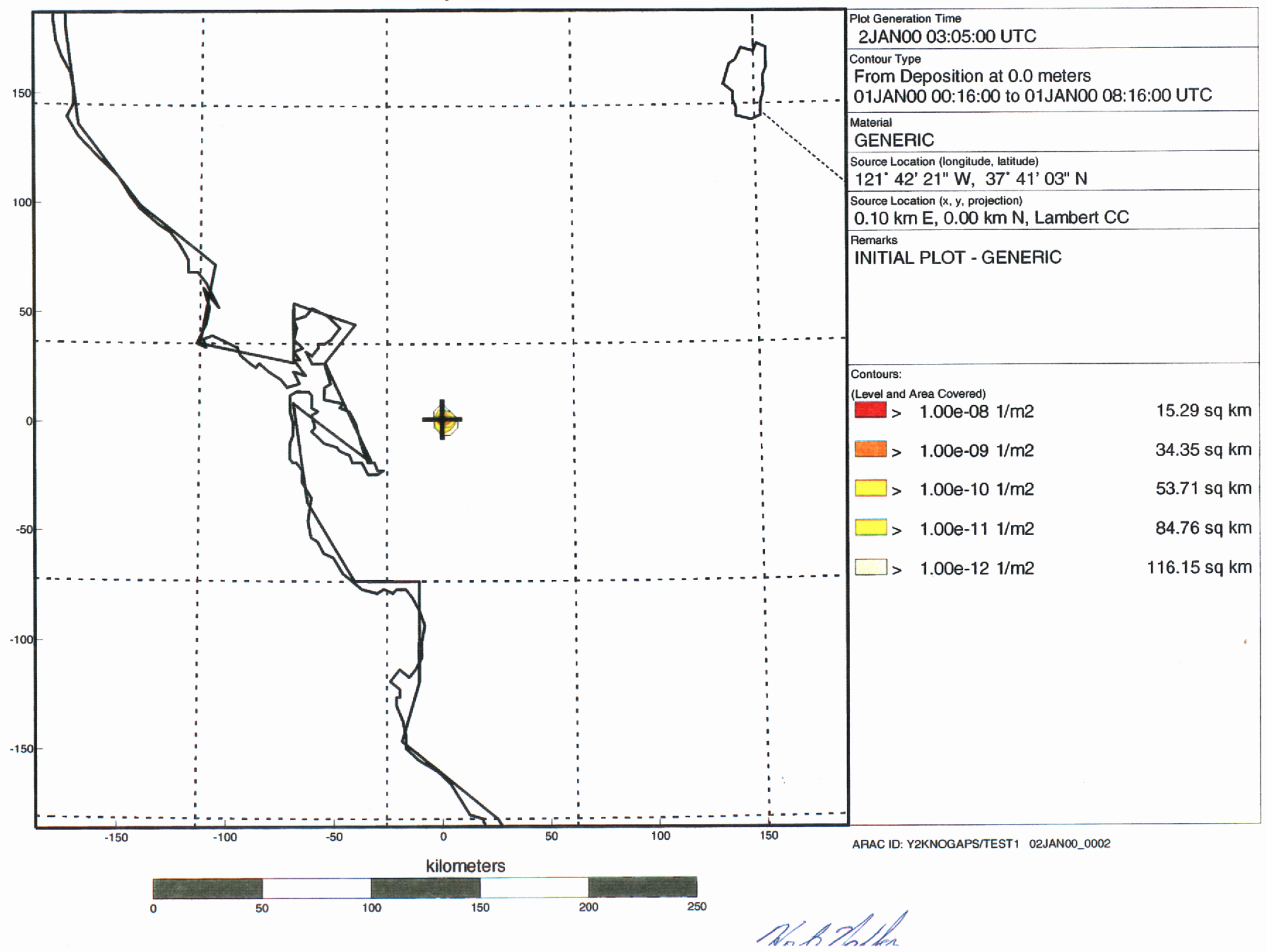





\section{ARAC Yeaf 2000 Plan, Renovation and Tests}

\section{Appendix 7 - Summary Scenario Test}

1) Regional case - Total deposition product at 24 hours for a hypothetical Chernobyl release at 0001 local time in Chernobyl on a $500 \mathrm{~km}$ domain using simulated surface and upper air meteorological observations for this period.

2) Long range case - Total deposition product at 5 days for a hypothetical Chernobyl release at 0001 local time in Chernobyl on a $3700 \mathrm{~km}$ domain using gridded meteorological data for this period. 



\section{UMCLASSYTEL}

Set 1: Total Deposition

Y2K TEST - CHERNOBYL OBS METDATA

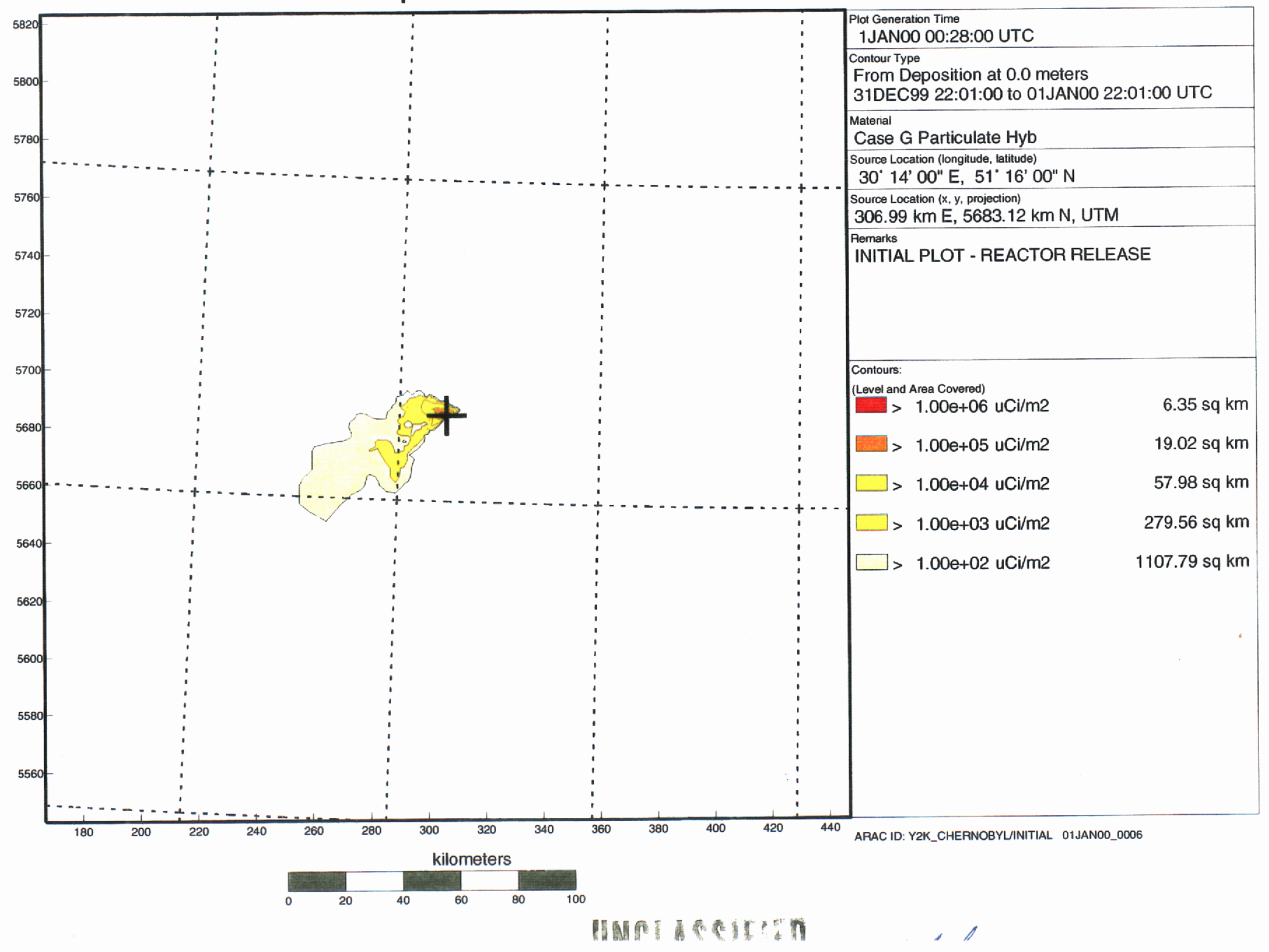





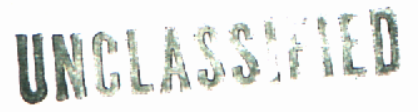

Set 1: 50 Year CEDE from Inhalation

Y2K TEST - CHERNOBYL GRIDDED DATA

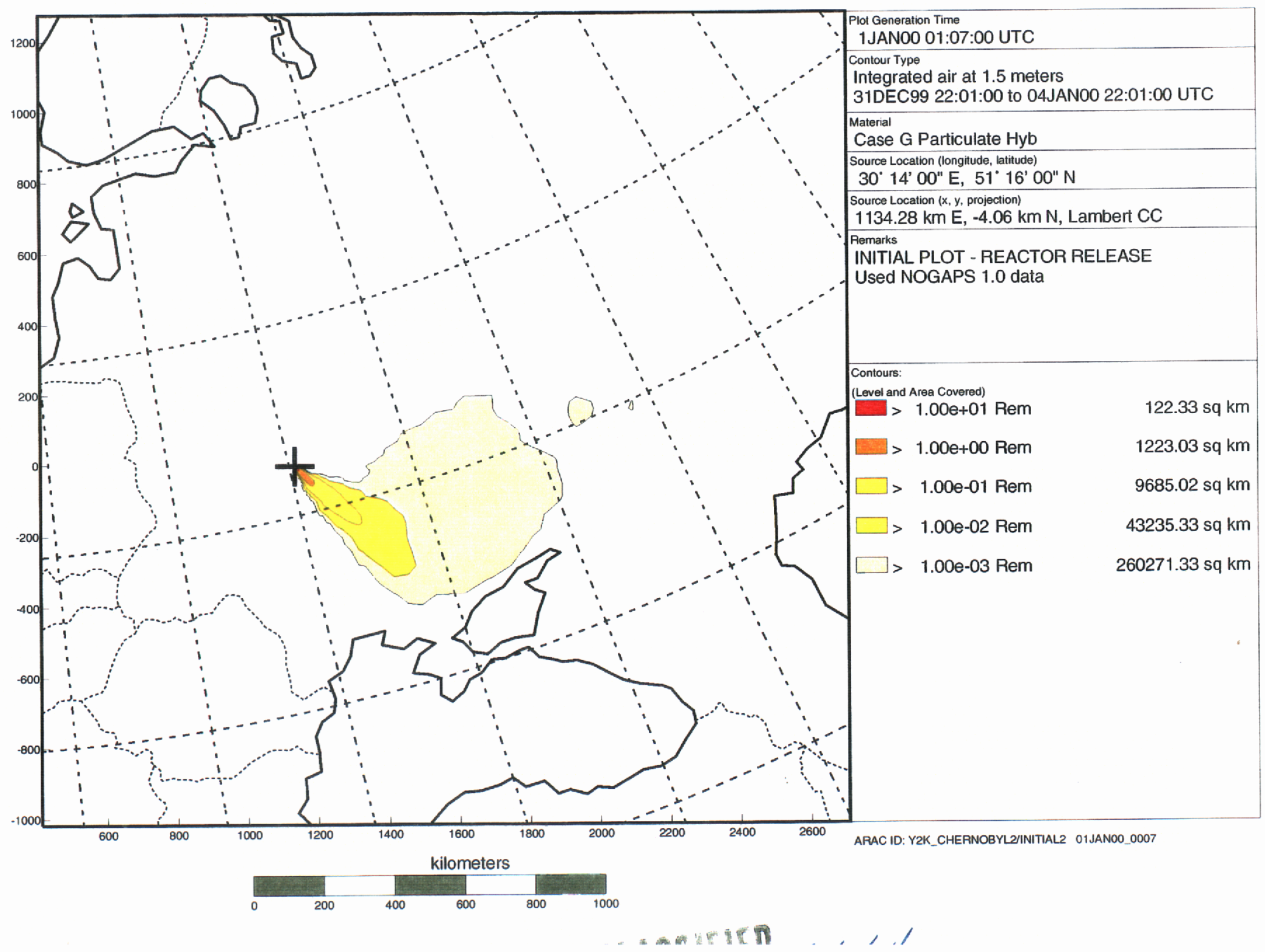





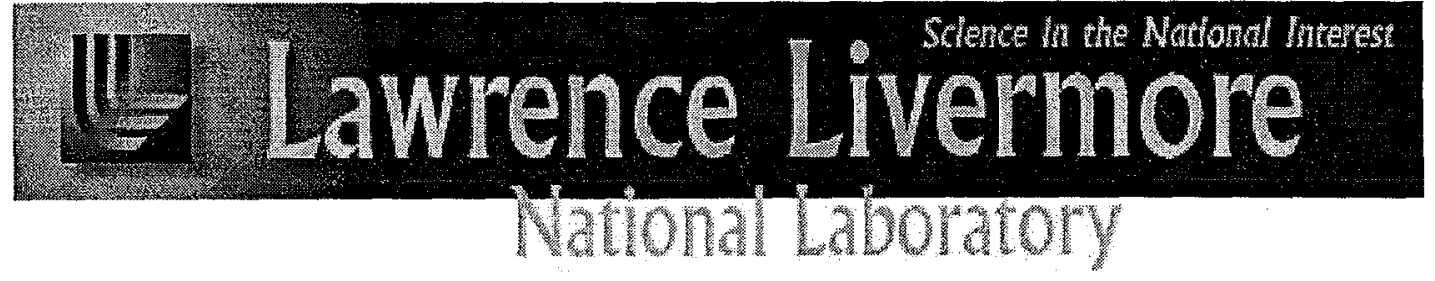

\section{ATMOSPHERIC RELEASE ADVISORY CAPABILITY}

\section{YEAR 2000 DOCUMENTATION: Contingency Plan}




\section{ARAC Year 2000 Contingency Plan}

\section{Foreword}

The ARAC has made a significant effort in detecting y ear 2000 (Y2K) problems, correcting these problems and verify ing $\mathrm{Y} 2 \mathrm{~K}$ compliance. However, this effort is not sufficient to guarantee full functioning of the ARAC sy stem during the relevant date transitions for two reasons. One is that, given the complexity of the this system, no implementable testing suite can verify all possible paths through the system and so the possibility of failure of the ARAC software cannot be excluded. The other reason is that it is not possible to conduct a complete end-to-end test of all direct and indirect data sources that could potentially be of interest to ARAC (e.g, ARAC relies on weather observing stations around the globe and so a complete test would have to include all these stations and all the communication paths and procssing steps between these stations and ARAC). Because the performance of all components of the ARAC sy stem cannot be absolutely guaranteed, a final step in ensuring Year 2000 readiness is to give careful thought to possible failure modes in the system, its data sources and product delivery mechanisms, and to develop alternative strategies for handling these problem areas. This document is a summary of this thinking, which includes specific preparations when these are appropriate in increasing the readiness of ARAC to fulfill its mission over the critical time periods.

This document was prepared using the LLNL Controller's Organization Pay roll Sy stem Year 2000 Contingency Plan as a guideline which was provided by Ted Michels, the LLNL Y2K coordinator. Comments about this document should be referred to:

\section{Hoyt Walker}

Year2000 Project TeamLead

Phone: (925) 422-1840

Internet: walker7@llnl.gov or Kevin Foster

Systems Operations TeamLcad

Phone: (925) 422-1864

Internet: kfoster@llnl.gov 


\section{ARAC Year 2000 Contingency PLAN}

\section{TABLE OF CONTENTS}

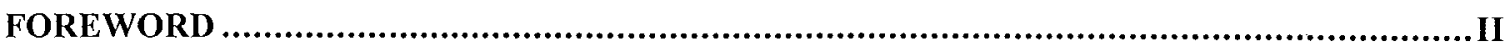

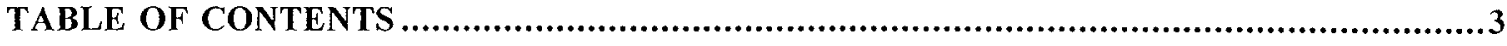

SCOPE

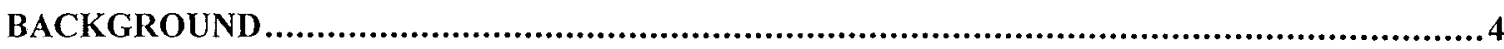

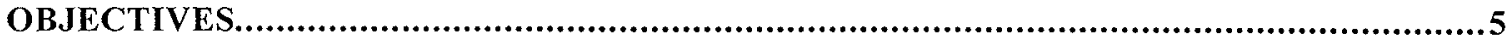

SYSTEM DESCRIPTION

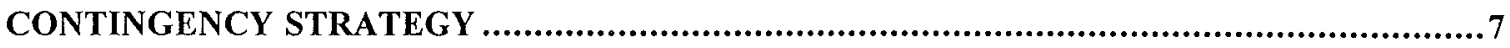

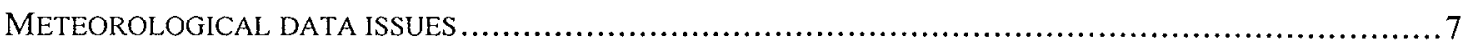

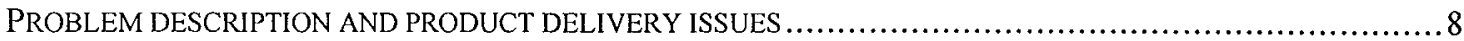

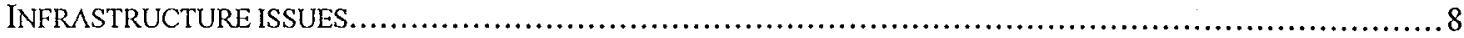

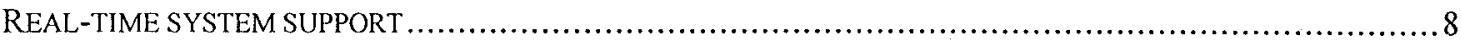

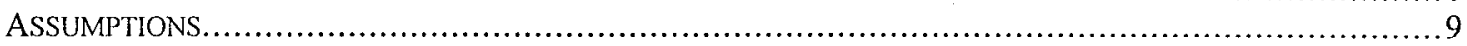

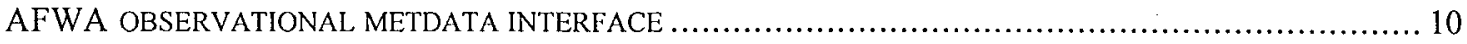

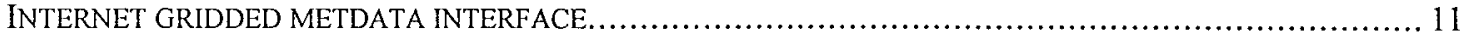

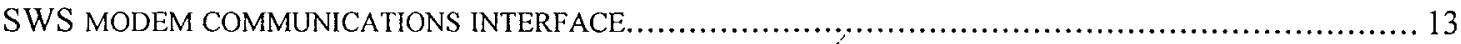

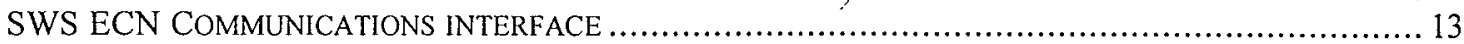

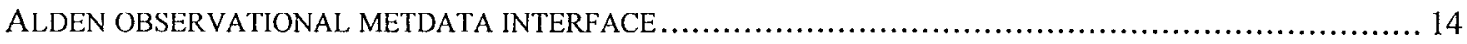

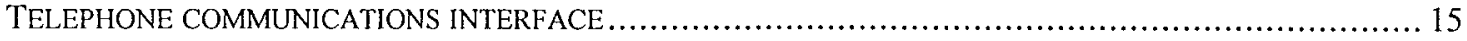

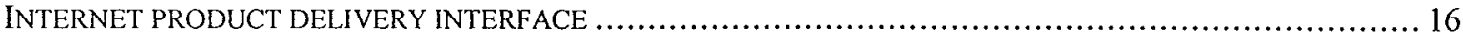

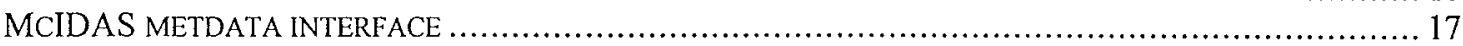

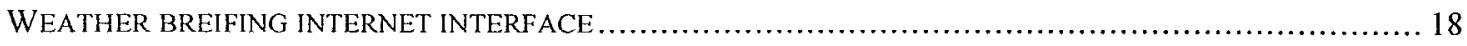

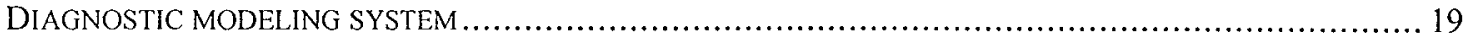

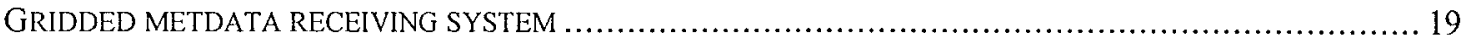

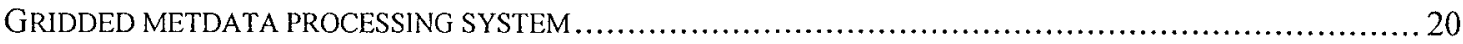

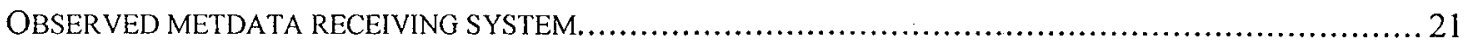

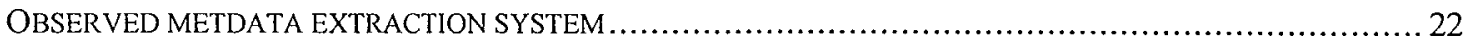

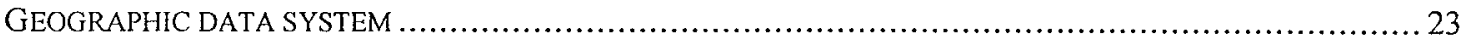

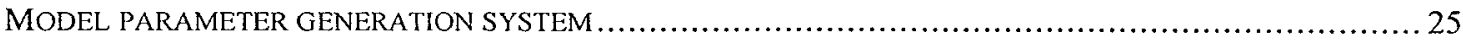

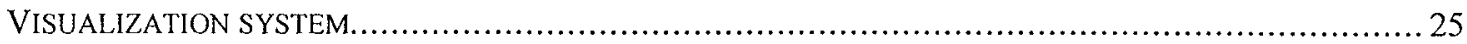

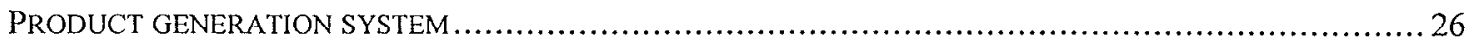

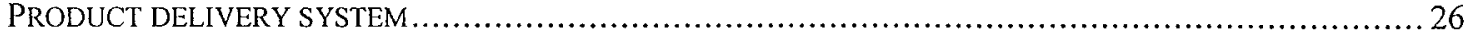

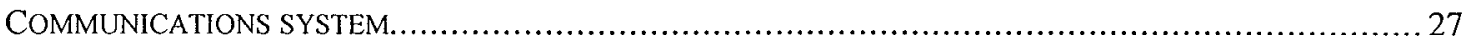

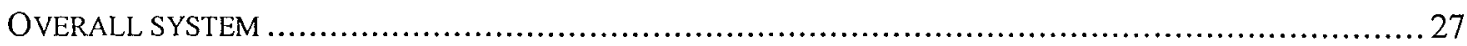

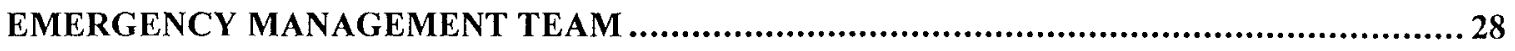

SUMMARY OF CONTINGENCY PLAN REQUIREMENTS AND PROCEDURES.................. 29

y2k ARAC_contingency DRAFT $\quad-3-\quad$ Last printed 5/17/99 2:23 PM 


\section{ARAC Year 2000 Contingency Plan}

\section{Scope}

The scope of the ARAC Year 2000 Contingency Plan is to ensure that for all foreseeable failure modes in the ARAC system clearly defined plans have been developed to ensure that ARAC will meet its operational commitments after the beginning of the new century. Based on end-to-end testing performed, which was reviewed as part of the IV\&V process, ARAC should work properly during the date transition. However, while testing has demonstrated proper functioning of the system in a wide range of circumstances, failures are possible both in the data sources on which ARAC relies and within the system itself. This contingency plan will cover the possible failure modes in the system and its data sources, providing strategies for continuing service in case of these failure modes. It will also attempt to enumerate and describe the sensitivity of ARAC's performance on infrastructure support that is beyond the control of ARAC. It is hoped that this will be of assistance to LLNL and other organizations in prioritizing their efforts in these areas.

\section{Background}

The Atmospheric Release Advisory Capability (ARAC) at Lawrence Livermore National Laboratory (LLNL) provides timely and credible estimates of the transport of hazardous material in the atmosphere as an emergency response resource to the Department of Energy and others. ARAC uses computer models, data acquisition, archiving and analysis systems along with highly trained personnel to provide this service. Given the reliance on computer technology inherent in the ARAC system, the Y2K issue is of significant concern to the program. This concern is highlighted by ARAC's designation as one of LLNL's and DOE's mission critical systems. To interpret the following document appropriately, some background regarding ARAC's current status is necessary and is provided in the next few paragraphs.

ARAC is in the process of rebuilding its entire system including the atmospheric models and all aspects of the system that supports the models. Development of the new system (referred to as ARAC-3 to distinguish it from the current operational system, ARAC-2) began in 1995 and was planned to be ready to supersede ARAC-2 during 1999. A variety of issues (funding deficits, loss of key personnel, etc.) have contributed to some extension of the expected delivery dates. ARAC-3 is being developed to avoid the Y2K problem (4digit years are used in all situations), however, the likely delay in delivery of a stable, sufficiently complete, operational system until Jan. 1, 2000 implies that ARAC-2 must be updated to handle the Y2K problem.

As with many legacy systems, full update of ARAC-2 to verifiably handle the $\mathrm{Y} 2 \mathrm{~K}$ problem in all situations would likely be expensive. However, a careful evaluation of the situation has suggested that a relatively modest expenditure will be able to sufficiently verify the system to the point that ARAC can respond in a timely and credible way 


\section{ARAC Year 2000 Contingency Plan}

(though not necessarily optimal way in certain very unusual situations) independent of the status of the ARAC-3 development effort. However, a stable ARAC-3 system is also an important component of ARAC's overall response posture during this period of potential instability. Both of these systems should be viewed as backing each other up and ensuring that ARAC will be able to produce the best response possible to whatever situations develop at the time.

Given the transitional nature of the ARAC system during the next two years, planning at all levels must always be cognizant of the status of both ARAC-2 and ARAC-3. The current expectation is that ARAC-3 will be designated as the primary system on January 1,2000 . Development for this phase of the system is expected to be complete on October 15, 1999 and this will be followed by extensive testing to prepare the system for operational use. Development during the intervening period will include major reworkings of the heavily date-dependent subsystems for observed and gridded meteorological data processing. As a result, no useful end-to-end $\mathrm{Y} 2 \mathrm{~K}$ testing can begin until October. Thus, to both ensure ARAC's operational readiness through the critical period (as well as to meet DOE's March 31, 1999 requirement for mission-critical systems), ARAC-2 has been the focal point for $\mathrm{Y} 2 \mathrm{~K}$ testing and is the primary subject of this document. ARAC's Y2K efforts have focused on preparing ARAC-2 so that all primary ARAC requirements can be met with this system. The remainder of FY 1999 will focus on verifying that the ARAC-3 infrastructure (e.g., third-party software) is Y2K compliant and the testing of ARAC-3 during the first quarter of FY 2000 will include complete Y2K testing. In addition, a final round of testing of ARAC-2 will be associated with the last production update before January 1, 2000 (expected to occur in August-October, 1999) to ensure that no problems have crept into the ARAC-2 system as it has evolved (note that changes to ARAC-2 should be very minor).

\section{Objectives}

The intent of this document is to provide a summary of the strategies that will be used to deal with various situations that could arise as a result of the Year 2000 date transition. More specifically, this document will include, at an appropriate level of detail:

the components of the ARAC system

- Identify the possible failure modes of these components

- Specify the steps that will be taken to continuing functioning in the event of failure

- Identify all preparations that should be made prior to the date transition to facilitate recovery from failure

- Identify the infrastructure support required to ensure the successful functioning of ARAC 


\section{ARAC Year 2000 Contingency Plan}

\section{System Description}

The ARAC-2 system is a complex, unique system that incorporates about 1.5 million lines of in-house developed software built on top of many third-party packages. Consequently, there are myriad potential failure modes. Discussion of these will be organized on the basis of external connections and of the basis of the key subsystems that make up the ARAC Central System. The data paths external to ARAC are, in rough order in terms of their importance to the mission-critical core of ARAC:

- Internet connections for gridded metdata

- SWS telephone communications

- SWS ECN communications

- AFWA observational metdata

- Alden observational metdata

- Telephone communications

- Internet connections for product delivery

- McIDAS metdata

- Internet connections for weather briefings

These data paths are discussed in some detail in the ARAC Year 2000 Documentation: Plan, Implementation and Test Results document in the Data Vulnerability Assessment section. The key subsystems of the ARAC Central System are:

- diagnostic modeling system

- gridded metdata receiving system

- gridded metdata processing system

- observed metdata extraction system

- geographic data system

- model parameter generation system

- visualization system

- product generation system

- product delivery system

- communications system

The Site Workstation System (SWS) is part of the mission-critical core of ARAC. While the observational metdata receiving system is not designated as part of the core of ARAC, it is very important and will be considered in this document. 


\section{ARAC Year 2000 Contingency Plan}

\section{Contingency Strategy}

The ARAC Y2K Team has attempted to consider the full range of possible problems that could occur and identified contingencies for dealing with these problems. Before beginning a comprehensive list of problems and strategies (at an appropriate level of detail) some general discussion of various areas is necessary.

\section{Meteorological data issues}

Assuming that the core system behaves properly, ARAC can function at a reasonably complete level assuming at least one observational and one gridded meteorological data source remains viable. The observed meteorological data sources are AFWA, Alden Electronics and, for ARAC supported sites, local observations from meteorological observing towers managed by ARAC. In the absence of observational data, the models can rely exclusively on gridded data with a potential loss of quality in the resulting product that will vary greatly depending on the details of the situation. A credible product could generally be produced although smaller scale details might be missed in some cases (note that in regions where there are little or no observational data, there will not generally be any loss of quality). The absence of gridded meteorological data would have a minor effect immediately after the date demarcation (assuming the last data set before the date change was received normally). However, continued unavailability would result in a steady decrease in the quality of ARAC's products in areas with sparse observational data and for large domains where the primary source of data is the gridded fields. Continued unavailability would also eventually curtail the use of ARAC's in-house weather prediction models. Failure of both the observational and gridded sources would mean that ARAC would have to rely exclusively on the last gridded meteorological data fields received before the date change. Thus, the quality of ARAC's ability to respond would be generally adequate (though less than optimal) for 24 hours after the failure of the data sources, less adequate through 48 hours and quite marginal through 72 hours. There are two key implications of this. One is that it is essential to receive the last set of gridded fields before the date change from both FNMOC and NCEP, and that the period from 24-48 hours is the time period during which ARAC can function to some degree without any additional data sources. Consequently all efforts will need to be made to reestablish any lost data links during the first day or two after the date change. If data links to FNMOC cannot be established, the proximity of this organization, which is in Monterey, CA, to ARAC would allow the data to be acquired by courier. With proper coordination (c.g., mecting somcone from FNMOC at a halfway point), the delay receiving the data could be as little as 150 minutes. 


\section{ARAC Year 2000 Contingency Plan}

\section{Problem description and product delivery issues}

Non-meteorological data sources and data delivery rely on both telephone lines and DOE's ECN. ARAC should remain functional in the event of failure of one of these systems. Telephone communications can cover for ECN failure although scenario descriptions from ECN nodes would have to be acquired using voice over telephones lines and product delivery would have to be via fax or e-mail enclosures via the Internet. Failure of telephone communications would typically be more serious although the ECN would provide access to the DOE EOC, which would allow information exchange from that site and so permit ARAC to function, again at a reduced level. Failure of both the ECN and telephone communications would limit ARAC to responding to events reported on television or radio news channels and would require access to some emergency communications capability for product delivery and access of more specific scenario descriptions. Access to such capabilities could involve ARAC personnel hand-carrying products to a remote facility. No details of such emergency capabilities have been worked out at this time.

\section{Infrastructure issues}

Assuming the ARAC's generator/UPS/PDU system docs not contain any hidden Y2K flaws that would cause failure during the date transition, ARAC should be insulated against failures of the external power grid for as long as generator fuel is available. Note that reasonable redundancy is available in ARAC's power system so that some degree of failure of this system can be tolerated. Failure of half of ARAC's power distribution system should not result in loss of the operational system, which includes redundant machines and fail-over file systems arranged to have the essential components available with only half the normal power system working. Such a power failure could cause less critical elements (e.g., the tablet digitizer) of the system to be unavailable. Special circumstances that would raise the importance of such elements might require moving the capability to a new power source and reinitializing it. Thus, there will be a need for heightened readiness on the part of the system support personnel. Complete failure of the power system could take ARAC off-line until it was fixed, thus it is essential that this system be examined for gencral robustness and $\mathrm{Y} 2 \mathrm{~K}$ compliance.

\section{Real-time system support}

Given the possibility of failure of data paths or of system components, however unlikely, ARAC expects to have a small number of people with strong familiarity with the system at work for the most critical period. These people will monitor the status of data sources and the general system status. Failures of any type will be tracked by these people and, depending on their severity, will be resolved. As needed, other people will be called in to assist. The level of system administration support will be intermediate between the normal on-call procedures in effect in ARAC and the level of support 


\section{ARAC YEAR 2000 CONTINGENCY PLAN}

provided during major responses and exercises. This will be supplemented by software development support. This approach will also apply to the possibility of a partial failure of both ARAC-2 and ARAC-3 which could necessitate a hybrid response assuming the failures in these two systems could not be corrected rapidly. Thus both system administration and software development support will need to be knowledgeable about both ARAC-2 and ARAC-3.

\section{Assumptions}

The ARAC Year 2000 implementation and testing has demonstrated that ARAC is Y2Kcompliant (see IV\&V documentation). ARAC-2 will be able to produce timely and credible products over the period. ARAC-3 will also be $\mathrm{Y} 2 \mathrm{~K}$-compliant and will be the primary response system in the Year 2000 and beyond. The contingencies listed below are focused on ARAC-2 but a number of the strategies rely on the fact the ARAC-3 will be an operational system starting on January 1,2000 and so could be incorporated into a hybrid system to meet operational needs in certain failure scenarios. The basic integrity of the local hardware and power system is assumed. Note that most of the contingencies noted below are part of ARAC's normal operational procedures. 
ARAC YeAR 2000 Contingency Plan

\begin{tabular}{|c|c|c|}
\hline \multicolumn{3}{|c|}{ ARAC Contingency Plan Sumimary } \\
\hline \multicolumn{3}{|c|}{ AFWA Observational Metdata Interface } \\
\hline Application/Interface & Scenario & \begin{tabular}{|l|} 
Contingencies \\
\end{tabular} \\
\hline AFWA met system & $\begin{array}{l}\text { complete failure of ArWA } \\
\text { met systems on which } \\
\text { ARAC relies }\end{array}$ & $\begin{array}{l}\text { 1) utilize NOAA/Alden } \\
\text { satellite link for observational } \\
\text { data along with tower } \\
\text { observations for supported } \\
\text { sites. } \\
\text { Preparation required: none, } \\
\text { built into current system } \\
\text { 2) if Alden also down, key in } \\
\text { observations available on } \\
\text { Internet } \\
\text { or } \\
\text { list global observation data } \\
\text { available from NWS via the } \\
\text { Internet which is } \\
\text { automatically gathered by } \\
\text { ARAC-3 and enter to } \\
\text { ARAC-2. For long down } \\
\text { times, the ARAC-3 to } \\
\text { ARAC-2 data transfer would } \\
\text { be automated. }\end{array}$ \\
\hline $\begin{array}{l}\text { AFWA/ARAC } \\
\text { communications system }\end{array}$ & $\begin{array}{l}\text { failure of 56Kb leased line } \\
\text { between AFWA and ARAC }\end{array}$ & $\begin{array}{l}\text { 1) work with AFWA, Tinker } \\
\text { and AT\&T on reestablishing } \\
\text { communications. } \\
\text { 2) During downtime follow } \\
\text { contingencies for AFWA met } \\
\text { system }\end{array}$ \\
\hline
\end{tabular}




\section{ARAC Year 2000 Contingency Plan}

\begin{tabular}{|c|c|c|}
\hline \multicolumn{3}{|c|}{ Internet Gridded Metdata Interface } \\
\hline Application/Interface & Scenario & Contingencies \\
\hline $\begin{array}{l}\text { FNMOC NOGAPS } \\
\text { model }\end{array}$ & $\begin{array}{l}\text { failure of the model or the } \\
\text { model support system in } \\
\text { Monterey }\end{array}$ & $\begin{array}{l}\text { Use AVN grids available on } \\
\text { the Internet } \\
\text { or } \\
\text { Use Eta grids available on the } \\
\text { Internet in the U.S. } \\
\text { or } \\
\text { Use most recent previously } \\
\text { received forecast grids from } \\
\text { NOGAPS, AVN or Eta as } \\
\text { appropriate, out to } 72 \text { hours. }\end{array}$ \\
\hline NOGAPS data receipt & $\begin{array}{l}\text { failure of Internet data } \\
\text { transfer }\end{array}$ & $\begin{array}{l}\text { for down times of }<36-48 \\
\text { hours follow contingencies } \\
\text { for FNMOC NOGAPS } \\
\text { model problems. } \\
\text { for longer down times, begin } \\
\text { courier transfer of } \\
\text { appropriate media between } \\
\text { FNMOC and ARAC. } \\
\text { Action Item: make } \\
\text { arrangements with FNMOC } \\
\text { for manual data transfer } \\
\text { including specification of } \\
\text { media, and personnel in both } \\
\text { organizations who would be } \\
\text { available for this procedure. }\end{array}$ \\
\hline AVN model/data receipt & $\begin{array}{l}\text { failure of model at NCEP or } \\
\text { in Internet data transfer }\end{array}$ & $\begin{array}{l}\text { This data source is a backup } \\
\text { to the primary NOGAPS } \\
\text { data. In the absence of other } \\
\text { problems, AVN failure is not } \\
\text { a critical problem but it does } \\
\text { increase the vulnerability to } \\
\text { failure of the NOGAPS data } \\
\text { path. }\end{array}$ \\
\hline
\end{tabular}




\begin{tabular}{|l|l|l|}
\hline Eta model/ data receipt & $\begin{array}{l}\text { failure of model at NCEP or } \\
\text { in Internet data transfer }\end{array}$ & $\begin{array}{l}\text { This data source is a backup } \\
\text { to the primary NOGAPS } \\
\text { data. In the absence of other } \\
\text { problems, Eta failure is not a } \\
\text { critical problem but it does } \\
\text { increase the vulnerability to } \\
\text { failure of the NOGAPS data } \\
\text { path. }\end{array}$ \\
\hline
\end{tabular}




\section{ARAC YeAR 2000 Contingency PLAN}

\begin{tabular}{|c|c|c|}
\hline \multicolumn{3}{|c|}{$\begin{array}{c}\text { ARAC CONTINGENCY PLAN SUMMARY } \\
\text { SWS Modem Communications Interface } \\
\end{array}$} \\
\hline Application/Interface & & Contingencies \\
\hline $\begin{array}{l}\text { Questionnaire } \\
\text { information }\end{array}$ & communications failure & $\begin{array}{l}\text { take questionnaire } \\
\text { information over the } \\
\text { telephone. }\end{array}$ \\
\hline ARAC products & communications failure & $\begin{array}{c}\text { send products via FAX } \\
\text { or } \\
\text { e-mail enclosure. }\end{array}$ \\
\hline $\begin{array}{l}\text { local meteorological } \\
\text { observations }\end{array}$ & communications failure & $\begin{array}{l}\text { acquire observations via } \\
\text { telephone connection to } \\
\text { Handar box. }\end{array}$ \\
\hline
\end{tabular}

\begin{tabular}{|l|l|l|}
\hline \multicolumn{3}{|c|}{ ARAC CONTINGENCY PLAN SUMMARY } \\
\hline \multicolumn{2}{|c|}{ SWS ECN Communications Interface } \\
\hline $\begin{array}{l}\text { Application/Interface } \\
\text { Questionnaire } \\
\text { information }\end{array}$ & Scenario & Contingencies \\
\hline ARAC products & network failure & $\begin{array}{l}\text { take questionnaire } \\
\text { information over the } \\
\text { telephone. }\end{array}$ \\
\hline & $\begin{array}{l}\text { send products via FAX } \\
\text { e-mail enclosure over } \\
\text { Internet. or } \\
\text { have RSL use dial-up number } \\
\text { to connect to ARAC using a } \\
\text { password to pickup } \\
\text { ARC/View- compatible files }\end{array}$ \\
\hline
\end{tabular}




\section{ARAC Year 2000 Contingency PLAN}

\begin{tabular}{|c|c|c|}
\hline \multicolumn{3}{|c|}{ ARAC CONTINGENCY PLAN SUMMARY } \\
\hline \multicolumn{3}{|c|}{ Alden Observational Metdata Interface } \\
\hline Application/Interface & Scenario & Contingencies \\
\hline Alden metdata system & $\begin{array}{l}\text { failure of NWS metdata } \\
\text { system } \\
\text { or } \\
\text { failure of satellite } \\
\text { communications }\end{array}$ & $\begin{array}{l}\text { Alden observed metdata is a } \\
\text { backup to AFWA metdata. In } \\
\text { the absence of other } \\
\text { problems, Alden failure is not } \\
\text { a critical problem but it does } \\
\text { increase the vulnerability to } \\
\text { failure of the AFWA data } \\
\text { path as well as decreasing the } \\
\text { availability of gencral met } \\
\text { information. } \\
\text { if required, list global } \\
\text { observation data available } \\
\text { from NWS via the Internet } \\
\text { which is automatically } \\
\text { gathered by ARAC-3 and } \\
\text { enter to ARAC-2. For long } \\
\text { down times, the ARAC-3 to } \\
\text { ARAC-2 data transfer would } \\
\text { automated. }\end{array}$ \\
\hline
\end{tabular}


ARAC YeAR 2000 Contingency Plan

\begin{tabular}{|c|c|c|}
\hline \multicolumn{3}{|c|}{ 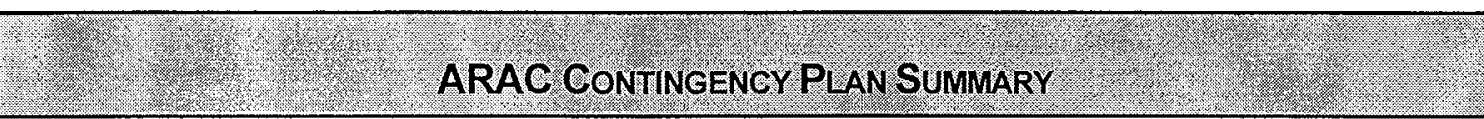 } \\
\hline \multicolumn{3}{|c|}{ Telephone Communications Interface } \\
\hline Application/Interface & Scenario & Contingencies \\
\hline telephone system & $\begin{array}{l}\text { degradation of phone line } \\
\text { quality (but voice } \\
\text { communications still work) }\end{array}$ & $\begin{array}{l}\text { e-mail and enclosures over } \\
\text { Internet. } \\
\text { have RSL use dial-up number } \\
\text { to connect to ARAC using a } \\
\text { password to drop-off and } \\
\text { pickup appropriate files }\end{array}$ \\
\hline telephone system & $\begin{array}{l}\text { failure of the phone system } \\
\text { so that both data and voice } \\
\text { are unavailable }\end{array}$ & \begin{tabular}{l} 
use Internet based \\
communications to handle all \\
incoming and outgoing \\
information \\
\multicolumn{1}{c}{ or } \\
use courier to and from \\
emergency communications \\
center. \\
Action item: contact regional \\
emergency response groups \\
to determine where such \\
communication centers would \\
be located, how to contact \\
them and have arrangements \\
in place to use such centers if \\
necessary.
\end{tabular} \\
\hline
\end{tabular}


ARAC YeAR 2000 Contingency Plan

\begin{tabular}{|l|l|l|}
\hline \multicolumn{2}{|c|}{ ARAC CONTINGENCY PLAN SUMmaRY } \\
\hline \multicolumn{3}{|c|}{ Internet Product Delivery Interface } \\
\hline Application/Interface & Scenario & Contingencies \\
\hline Product Delivery & $\begin{array}{l}\text { failure or saturation of the } \\
\text { Internet }\end{array}$ & $\begin{array}{l}\text { This interface is a backup to } \\
\text { the normal product delivery } \\
\text { mechanisms, although its use } \\
\text { (in the form of product } \\
\text { delivery as e-mail enclosures } \\
\text { is increasing. Thus, in the } \\
\text { absence of other problems, } \\
\text { failure is not a critical } \\
\text { problem given current } \\
\text { procedures, but it may } \\
\text { become more critical by } \\
\text { January 1, 2000. }\end{array}$ \\
\hline
\end{tabular}


ARAC YeAR 2000 Contingency PLAN

\begin{tabular}{|l|l|l|}
\hline & ARAC CONTINGENCY PLAN SUMmaRr \\
\hline \multicolumn{3}{|l|}{ McIDAS Metdata Interface } \\
\hline Application/Interface & Scenario & Contingencies \\
\hline McIDAS & $\begin{array}{l}\text { failure of the McIDAS } \\
\text { system }\end{array}$ & $\begin{array}{l}\text { This data source is used for } \\
\text { weather briefings and is not } \\
\text { critical for operations. } \\
\text { However, its absence would } \\
\text { limit operational } \\
\text { meteorologists ability to } \\
\text { interpret the overall weather } \\
\text { situations in responses and so } \\
\text { would be of concern. Some } \\
\text { equivalent information is } \\
\text { available ovcr the Internet and } \\
\text { provides a backup to this } \\
\text { system. Note that McIDAS } \\
\text { data is received over the } \\
\text { Internet. } \\
\text { The Difax charts received } \\
\text { from Alden Electronics via } \\
\text { satellite and printed out as an } \\
\text { operational procedure would } \\
\text { also be available as backup. }\end{array}$ \\
\hline
\end{tabular}


ARAC YeAR 2000 Contingency PLAN

\begin{tabular}{|l|l|l|}
\hline \multicolumn{2}{|c|}{ ARAC CONINGENCY PLAN SUmMARY } \\
\hline \multicolumn{3}{|c|}{ Weather Briefing Internet Interface } \\
\hline Application/Interface & Scenario & Contingencies \\
\hline Internet Weather sites & $\begin{array}{l}\text { failure or saturation of the } \\
\text { Internet }\end{array}$ & $\begin{array}{l}\text { Weather information is } \\
\text { available from numerous Web } \\
\text { sites and so its use is not } \\
\text { particularly vulnerable to any } \\
\text { particular site being down. } \\
\text { lhis information backs up } \\
\text { and extends the McIDAS } \\
\text { information and so its failure, } \\
\text { in the absence of other } \\
\text { problems is not critical in and } \\
\text { of itself. However, failure of } \\
\text { the Internet does carry } \\
\text { implications as described } \\
\text { above. } \\
\text { The Difax charts received } \\
\text { from Alden Electronics via } \\
\text { satellite and printed out as an } \\
\text { operational procedure would } \\
\text { also be available as backup. }\end{array}$ \\
\hline
\end{tabular}




\begin{tabular}{|l|l|l|}
\hline \multicolumn{3}{|c|}{ ARAC CONTINGENCY PLAN SUMMARY } \\
\hline \multicolumn{3}{|c|}{ Diagnostic Modeling System } \\
\hline Application/Interface & Scenario & Contingencies \\
\hline $\begin{array}{l}\text { TOPOG/MEDIC/MAT } \\
\text { HEW/ADPIC }\end{array}$ & failure of model programs & $\begin{array}{l}\text { begin debugging efforts } \\
\text { and } \\
\text { run parallel ARAC-3 } \\
\text { simulation } \\
\text { (GridGen,ADAPT,LODI) }\end{array}$ \\
\hline
\end{tabular}

\begin{tabular}{|c|c|c|}
\hline \multicolumn{3}{|c|}{ Gridded Metdata Receiving System } \\
\hline Application/Interface & Scenario & Contingencies \\
\hline NOGAPS scripts & failure of scripts & $\begin{array}{l}\text { if data incomplete or } \\
\text { incorrect then follow normal } \\
\text { re-request procedures } \\
\text { or } \\
\text { begin debugging processing } \\
\text { scripts } \\
\text { or } \\
\text { follow contingency plan for } \\
\text { failure of gridded metdata } \\
\text { interface as appropriate. }\end{array}$ \\
\hline
\end{tabular}


ARAC Year 2000 Contingency Plan

\begin{tabular}{|l|l|l|}
\hline \multicolumn{3}{|c|}{ ARAC CONTINGENCY PLAN SUMmaRY } \\
\hline \multicolumn{3}{|c|}{ Gridded Metdata Processing System } \\
\hline Application/Interface & Scenario & Contingencies \\
\hline DEGRIB_NOGAPS10 & failure of degribbing program & $\begin{array}{l}\text { check for complete receipt of } \\
\text { NOGAPS grids } \\
\text { if data complete and correct, } \\
\text { begin debugging efforts } \\
\text { and }\end{array}$ \\
$\begin{array}{l}\text { extract ARAC-3 format } \\
\text { subsets of NOGAPS grids } \\
\text { and make available to ARAC- } \\
\text { 2 via cross-mounted disks. }\end{array}$ \\
\hline
\end{tabular}




\section{ARAC Year 2000 Contingency Plan}

\begin{tabular}{|c|c|c|}
\hline 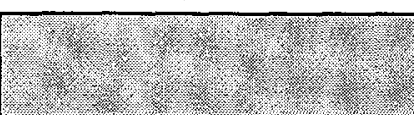 & VAC CONTINGENCY PLAI & IARY \\
\hline \multicolumn{3}{|c|}{ Observed Metdata Receiving System } \\
\hline Application/Interface & Scenario & Contingencies \\
\hline READGWC/decoders & failure of metdata ingest & $\begin{array}{l}\text { review keyed raw file for } \\
\text { possible format problems and } \\
\text { indications of } \\
\text { communications problems or } \\
\text { failures at AFWA and NWS } \\
\text { and } \\
\text { beginning other efforts to } \\
\text { isolate and resolve the } \\
\text { problem and } \\
\text { perform an ARAC-3 } \\
\text { observed metdata extraction } \\
\text { for the same area and edit the } \\
\text { ASCII version of this metdata } \\
\text { into the ARAC-2 system (if } \\
\text { this failure is on-going this } \\
\text { process should be automated) } \\
\text { gather metdata from available } \\
\text { sources (e.g., listings of the } \\
\text { metdata archive, the Internet) } \\
\text { and enter into problem } \\
\text { metdata archive or edit } \\
\text { OBSER.MET file as } \\
\text { appropriate. }\end{array}$ \\
\hline
\end{tabular}


ARAC Year 2000 Contingency Plan

\begin{tabular}{|c|c|c|}
\hline \multicolumn{3}{|c|}{ Observed Metdata Extraction System } \\
\hline Application/Interface & Scenario & Contingencies \\
\hline Crcate Problem Metdata & failure of metdata extraction & $\begin{array}{l}\text { begin debugging efforts } \\
\quad \text { and } \\
\text { perform an ARAC-3 } \\
\text { observed metdata extraction } \\
\text { for the same area and edit the } \\
\text { ASCII version of this metdata } \\
\text { into the ARAC-2 system (if } \\
\text { this failure is on-going this } \\
\text { process should be automated) } \\
\quad \text { or } \\
\text { gather metdata from available } \\
\text { sources (e.g., listings of the } \\
\text { metdata archive, the Internet) } \\
\text { and enter into problem } \\
\text { metdata archive or edit } \\
\text { OBSERV.MET file as } \\
\text { appropriate. }\end{array}$ \\
\hline
\end{tabular}




\section{ARAC YeAR 2000 Contingency PLAN}

\begin{tabular}{|c|c|c|}
\hline 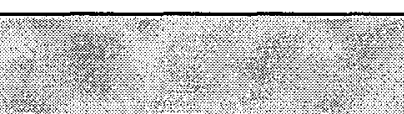 & RAC CONTINGENEY PLAN S & ARY \\
\hline & Geographic Data Syst & \\
\hline Application/Interface & Scenario & Contingencies \\
\hline projection system & failure of projection system & $\begin{array}{l}\text { review projection information } \\
\text { for consistency. If this does } \\
\text { not resolve the problem, then } \\
\text { begin debugging efforts } \\
\quad \text { and } \\
\text { being parallel ARAC-3 } \\
\text { response. }\end{array}$ \\
\hline base map system & failure of basemap system & $\begin{array}{l}\text { review base map information } \\
\text { for consistency. If this does } \\
\text { not resolve the problem, then } \\
\text { begin debugging efforts } \\
\quad \text { and } \\
\text { build ARAC-3 base map and } \\
\text { export to ARAC-2 } \\
\quad \text { or } \\
\text { begin parallel ARAC-3 } \\
\text { response or } \\
\text { use previously generated base } \\
\text { maps of applicable } \\
\quad \text { or } \\
\text { gcncratc products without a } \\
\text { base map and provide extra } \\
\text { textual or telephone guidance } \\
\text { to customers to interpret } \\
\text { product without a } \\
\text { map. }\end{array}$ \\
\hline elevation system & failure of elevation system & $\begin{array}{l}\text { review elevation information } \\
\text { for consistency. If this does } \\
\text { not resolve the problem, then } \\
\text { begin debugging efforts } \\
\quad \text { and } \\
\text { build ARAC-3 elevations and } \\
\text { export to ARAC-2 }\end{array}$ \\
\hline
\end{tabular}




\begin{tabular}{|l|l|l|}
\hline & \begin{tabular}{l}
\multicolumn{1}{c|}{ or } \\
begin parallel ARAC-3 \\
response \\
or \\
enter elevations directly into \\
TOPOG from topographic \\
map.
\end{tabular} \\
$\begin{array}{l}\text { or } \\
\text { run TOPOG with flat } \\
\text { topography, this is } \\
\text { particularly useful in areas of } \\
\text { little terrain relief. }\end{array}$ \\
\hline
\end{tabular}




\section{ARAC Year 2000 Contingency Plan}

\begin{tabular}{|l|l|l|}
\hline \multicolumn{3}{|c|}{ ARAC CONTINGENCY PLAN SUMmaRY } \\
\hline \multicolumn{3}{|c|}{ Model Parameter Generation System } \\
\hline Application/Interface & Scenario & Contingencies \\
\hline model parameter system & $\begin{array}{l}\text { failure of model parameter } \\
\text { system }\end{array}$ & $\begin{array}{l}\text { review inputs for } \\
\text { consistency. If this does not } \\
\text { resolve the problem, then } \\
\text { begin debugging efforts } \\
\text { and }\end{array}$ \\
$\begin{array}{l}\text { enter model parameters } \\
\text { directly into namelist files } \\
\text { or } \\
\text { begin parallel ARAC-3 } \\
\text { response }\end{array}$ \\
\hline
\end{tabular}

\begin{tabular}{|c|c|c|}
\hline 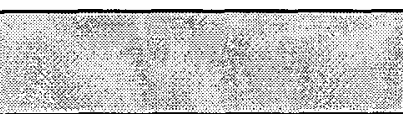 & \multicolumn{2}{|c|}{ ARAC Contingency Plan SUMMARY } \\
\hline \multicolumn{3}{|c|}{ Visualization System } \\
\hline Application/Interface & Scenario & Contingencies \\
\hline GKS graphics & GKS graphics failure & use PV-Wave graphics \\
\hline PV-Wave graphics & PV-Wave graphics failure & $\begin{array}{l}\text { begin debugging Wave } \\
\text { configuration and scripts } \\
\quad \text { and } \\
\text { review model output and } \\
\text { products as much as possible } \\
\text { via text and Xlib graphical } \\
\text { tools. }\end{array}$ \\
\hline
\end{tabular}


ARAC Year 2000 Contingency Plan

\begin{tabular}{|l|l|l|}
\hline \multicolumn{3}{|l|}{ ARAC Contingency Plan Sumimary } \\
\hline \multicolumn{3}{|c|}{ Product Generation System } \\
\hline Application/Interface & Scenario & Contingencies \\
\hline PLCNT & PLCNT failure & $\begin{array}{l}\text { review inputs for } \\
\text { consistency. If this does not } \\
\text { resolve the problem, then } \\
\text { begin debugging efforts } \\
\text { and } \\
\text { begin parallel ARAC-3 } \\
\text { response }\end{array}$ \\
\hline
\end{tabular}

\begin{tabular}{|c|c|c|}
\hline \multicolumn{3}{|c|}{ Product Delivery System } \\
\hline Application/Interface & Scenario & Contingencies \\
\hline SitePlot & SitePlot failure & $\begin{array}{l}\text { review inputs for } \\
\text { consistency. If this does not } \\
\text { resolve the problem, then } \\
\text { begin debugging efforts } \\
\quad \text { and } \\
\text { begin parallel ARAC-3 } \\
\text { response }\end{array}$ \\
\hline
\end{tabular}




\section{ARAC YeAR 2000 Contingency PLAN}

\begin{tabular}{|l|l|l|}
\hline \multicolumn{3}{|c|}{ ARAC CONTINGENCY PLAN SUMmARY } \\
\hline \multicolumn{3}{|c|}{ Communications System } \\
\hline Application/Interface & Scenario & Contingencies \\
\hline Communications & $\begin{array}{l}\text { failurc of cither Ccntral } \\
\text { System communications, } \\
\text { SWS communications or } \\
\text { both. }\end{array}$ & $\begin{array}{l}\text { review routing tables for } \\
\text { obvious problems. If this } \\
\text { does not resolve the problem, } \\
\text { then begin debugging efforts } \\
\text { and } \\
\text { deliver either automated or } \\
\text { manual FAX plots of ARAC } \\
\text { products. }\end{array}$ \\
& $\begin{array}{l}\text { or } \\
\text { if failure is on Central System } \\
\text { end, begin parallel ARAC-3 } \\
\text { response and deliver products } \\
\text { using ARAC-3 } \\
\text { communications }\end{array}$ \\
\hline
\end{tabular}

\begin{tabular}{|l|l|l|}
\hline \multicolumn{3}{|c|}{ ARAC CONTINGENCY PLAN SUMmARY } \\
\hline \multicolumn{3}{|c|}{ Overall System } \\
\hline Application/Interface & Scenario & Contingencies \\
\hline ARAC-2 & ARAC-2 failure & $\begin{array}{l}\text { review problem and decide if } \\
\text { a pure ARAC-3 response or a } \\
\text { hybrid ARAC-2/ARAC-3 } \\
\text { response is appropriate. For } \\
\text { on-going hybrid responses, } \\
\text { automate as appropriate. }\end{array}$ \\
\hline
\end{tabular}




\section{ARAC Year 2000 Contingency Plan}

\section{Emergency Management Team}

The roles in responding to problems in either the ARAC- 2 or and ARAC- 3 system are similar to the roles filled in normal ARAC operations.

- Y2K Project Lead - Hoyt Walker

- Systems Operations Team Leader - Kevin Foster

- ARAC-2 software maintenance - Gordon Duckworth, Richard Yamauchi

- SWS software maintenance - Richard Yamauchi

- Metdata receipt and dccoding - Kevin Foster

- General ARAC-2 consulting - Diane Bonner

- Operational Systems Administration Lead - Ed Bush

- Network administration - Fric Davis

- General system administration - Leon Richardson

- On-call technicians - Leon Richardson, Tony Hoang, Mark Shakespeare, Eric Davis

- General system administration - Leon Richardson

- Acceptance Testers - Fernando Aluzzi (Central System), Phil Vogt (SWS)

The following roles have been assigned for the ARAC-3 effort:

- ARAC-3 Project Lead - Denise Sumikawa

- Metdata interfaces - Bob Shectman

- ARAC-3 systems integration - Bob Shectman, John Gash, Bryan Lawver

- ARAC-3 software development - Diane Bonner, Kathleen Fischer, Ernie Arnold, Robert Mariano, Jessica Mauvais, Jim Trasher, Joe Warzecha, Chris Webster David Bentz, Kevin Foster

- ARAC-3 model development - Gayle Sugiyama (ADAPT), John Nasstrom (LODI), John Pace (COAMPS), Hoyt Walker (GridGen)

- Development Systems Administration Lead - Gary Berry

- Supporting technicians - Tony Hoang, Mark Shakespeare, Eric Davis, Rhonda Fletcher

- Beta Testers - Connee Foster, Brenda Pobanz 


\section{Summary of Contingency Plan Requirements and Procedures}

ARAC is an operational emergency response system and, as such, must deal with the possibility of internal and external system failures in the course of normal operations. Thus, procedures are in place for deal with failures in any part of the system and the operations staff is trained to implement these procedures as the need arises. Consequently, this contingency plan is primarily a summary of how problems in the various data paths and subsystems are or would be handled in normal operations with a particular focus on $\mathrm{Y} 2 \mathrm{~K}$ issues. Thus, the cost of implementing this plan is minimal, testing of ARAC's response to certain failure modes (e.g., problems with the connection between ARAC and AFWA) is on-going due to the vagaries of communications systems, and the procedures for invoking and operating the contingency plan are in place and working. The same can be said for returning to normal operations. Note that since this plan is focused on ARAC-2, it will cease to apply when ARAC-2 goes out of service in the third quarter of FY00. As a consequence of the above, the cost of the contingency plan is minimal ( $\sim 1.5$ FTE-months) and mainly includes writing the plan, completing the action items indicated in the tables and summarizing any lessons learned in a postcontingency report if necessary. The main staffing issues would occur as part of the more extreme scenarios where courier communications would be necessary. ARAC staff would be able to handle this load in emergency mode, which can support 24 hour operations for 2-3 weeks. The program is not staffed to maintain this level of effort beyond 2-3 weeks and would have to rely on assistance from other resources in the Atmospheric Sciences Division or from the Laboratory at large. 